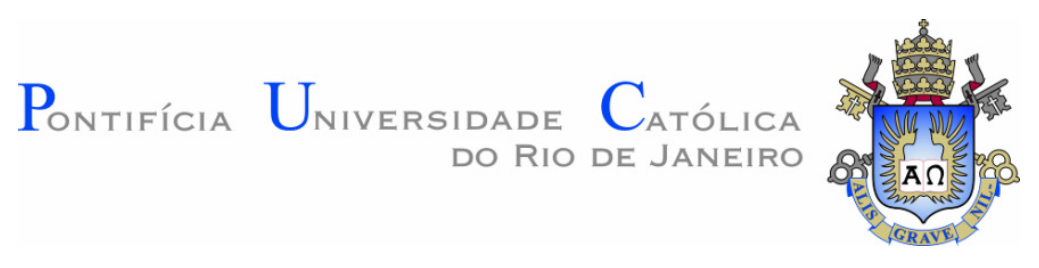

José Angel Florián Gutiérrez

Escoamento de gotas de óleo através de micro capilares

Dissertação de Mestrado

Dissertação apresentada como requisito parcial para obtenção do título de Mestre pelo Programa de PósGraduação em Engenharia Mecânica da PUC - Rio.

Orientador: Prof. Márcio da Silveira Carvalho

Rio de Janeiro, Abril de 2013 
José Angel Florián Gutiérrez

\section{Escoamento de gotas de óleo através de micro capilares}

Dissertação apresentada como requisito parcial para obtenção do grau de Mestre pelo Programa de PósGraduação em Engenharia Mecânica do Centro Técnico Científico da PUC-Rio. Aprovada pela Comissão Examinadora abaixo assinada.

Prof. Márcio da Silveira Carvalho

Orientador

Departamento de Engenharia Mecânica - PUC - Rio

Prof. Luis Fernando Alzuguir Azevedo

Departamento de Engenharia Mecânica - PUC - Rio

Prof. Francisco Ricardo da Cunha

Universidade de Brasília

Prof. José Eugenio Leal

Coordenador Setorial do Centro Técnico Científico - PUC - Rio 
Todos os direitos reservados. É proibida a reprodução total ou parcial do trabalho sem autorização da universidade, do autor e do orientador.

\section{José Angel Florián Gutiérrez}

Graduou-se em Engenharia Mecânica na Universidad Nacional de Trujillo - UNT (Trujillo, Peru) em 2003.

Ficha Catalográfica

Gutiérrez, José Angel Florián

Escoamento de gotas de óleo através de micro capilares / José Angel Florián Gutiérrez; orientador: Márcio da Silveira Carvalho. -2013.

170 f. : il. (color.) ; $30 \mathrm{~cm}$

Dissertação (mestrado) - Pontifícia Universidade Católica do Rio de Janeiro, Departamento de Engenharia Mecânica, 2013.

Inclui bibliografia.

1. Engenharia Mecânica - Teses. 2. Gota de óleo. 3. Emulsão. 4. Capilaridade. 5. Micro-PIV. I. Carvalho, Márcio da Silveira. II. Pontifícia Universidade Católica do Rio de Janeiro. Departamento de Engenharia Mecânica. III. Título. 
Dedico este trabalho a Deus, aos meus pais Angel e Adriana, minha irmã Sara, aos pequenos Mimi, Claudio e Manchitas. 


\section{Agradecimentos}

Agradeço a Deus por me proteger e ter a melhor família.

À minha família, pelo suporte, carinho, amor e formação, e em especial a minha mãe que é o melhor presente que eu ganhei da vida.

Ao meu orientador, professor Márcio da Silveira Carvalho, o fato de me ter dado a oportunidade de realizar este trabalho. Agradeço-lhe a confiança demonstrada, pela orientação e conhecimentos repassados durante todo o desenvolvimento do trabalho nos últimos dois anos.

Aos profissionais do grupo de trabalho do professor Márcio da Silveira Carvalho, ao Felicle e à Ranena, pela ajuda nas inúmeras dificuldades em que enfrentei.

Aos meus colegas e amigos da PUC, pela amizade e apoio em cada momento, em especial ao Jordane, Bruno, Leo e Jerry, pelos seus conselhos e ensinamentos durante minha permanência no Brasil.

À Banca examinadora, pelas observações contribuídas ao presente trabalho.

Ao departamento de Engenharia Mecânica da Pontifícia Universidade Católica do Rio de Janeiro, que me proporcionou a oportunidade de cursar Pós-graduação, por se constituir na minha casa de estudos e valorizar minha formação profissional.

À PUC - Rio, pela bolsa de isenção do curso. Às instituições CAPES e FAPERJ, pelo auxílio financeiro concedido durante o mestrado. 


\section{Resumo}

Gutiérrez, José Angel Florián; Carvalho, Márcio da Silveira. Escoamento de gotas de óleo através de micro capilares. Rio de Janeiro, 2013. 170p. Dissertação de Mestrado - Departamento de Engenharia Mecânica, Pontifícia Universidade Católica do Rio de Janeiro.

Estudos recentes mostram que a injeção de emulsões óleo-água pode levar a uma melhor varredura do reservatório e reduzir consideravelmente a saturação residual de óleo em processos de recuperação avançada. Estes efeitos estão diretamente ligados ao comportamento do escoamento de gotas de óleos suspensas em água através das gargantas de poros. Desta forma, a otimização do processo de injeção e da formulação da emulsão com o objetivo de aumentar o volume de óleo recuperado requer por um melhor entendimento do escoamento na escala de poros. Este trabalho apresenta um estudo do escoamento de gotas de óleos suspensa em água através de micro canais de seção reta constante e através de uma garganta, que são usados como modelos do espaço poroso. O campo de velocidade da fase contínua e a velocidade da gota de óleo foi determinado através da técnica de velocimetria por imagem de partículas em escala micrométrica $(\mu$ PIV) para diferentes tamanhos de gotas e geometria do capilar e garganta. Os resultados obtidos mostram a variação do padrão do escoamento devido a presença da gotas de óleo e fornecem importantes informações de como gotas de óleo mudam a mobilidade do fluido injetado quando o mesmo escoa através de poros com gargantas menores do que tamanho das gotas.

\section{Palavras-chave}

Gota de óleo; emulsão; capilaridade; micro-PIV. 


\section{Abstract}

Gutiérrez, José Angel Florián; Carvalho, Márcio da Silveira (Advisor). Flow of oil drops through micro capillaries. Rio de Janeiro, 2013. 170p. MSc. Dissertation - Departamento de Engenharia Mecânica, Pontifícia Universidade Católica do Rio de Janeiro.

Recent studies show that oil-water emulsion injection may lead to a better reservoir sweep and reduce residual oil saturation in enhanced oil recovery processes. These effects are directly linked to the flow behavior of oil drops suspended in water through the pore throats of a porous material. Therefore, the optimization of the injection process and of the emulsion properties with the goal to increase the volume of oil displaced requires a better understanding of the emulsion flow in the pore scale. This work presents an analysis of the flow of oil drops suspended in water through micro channels with constant cross-section area and with a throat, that are used as a model for the pore scale. The velocity field of the continuous phase and the drop velocity are obtained using the micro particle image velocimetry techniques ( $\mu$-PIV) for different drop sizes and micro channel geometries. The results show the changes in the flow pattern due to the presence of oil drops and yield important information on how oil drops reduce the mobility of the injected liquid when it flows through pore throats smaller than the drop size.

\section{Keywords}

Oil drop; emulsion; capillarity; micro PIV. 


\section{Sumário}

1. Introdução 25

1.1. Motivação 28

1.2. Revisão bibliográfica $\quad 29$

1.3. Objetivos da dissertação 33

1.4. Estrutura da dissertação 34

2. Fundamentos Teóricos 35

2.1. Escoamento de emulsões através de micro capilares 35

2.1.1. Tensão interfacial e superficial 35

2.1.2. Número de capilaridade 36

2.1.3. Fluxo em miro canais 36

2.1.4. Mobilidade de um fluido no escoamento através de micro capilares 36

3. Experimento 41

3.1. Introdução 41

3.2. Fundamentos do micro velocimetria por imagem de partículas (MPIV) 41

3.2.1. Principio de Funcionamento $\mu \mathrm{PIV}$

3.2.2. Partículas 44

3.2.3. Concentração de Partículas 45

3.2.4. Iluminação no sistema $\mu \mathrm{PIV} \quad 46$

3.2.5. Profundidade de Campo 48

3.2.6. Processamento de Imagens 49

3.2.6.1. Etapa de Pré-processamento 49

3.2.6.2. Etapa de Processamento 51

3.2.6.2.1. Técnica de Correlação Cruzada 52

3.2.6.2.2. Interpolação de sub-pixels $\quad 54$

3.2.6.3. Etapa de Pós-processamento 56

3.2.6.3.1. Validação dos dados 56 
3.2.6.3.2. Substituição dos dados incorretos

3.3. Medição do campo de velocidade do escoamento monofásico

3.3.1. Bancada experimental

3.3.1.2. Sistema $\mu$ PIV

61

3.3.2. Fluido de Trabalho 69

3.3.2.1. Preparação da fase 70

3.3.2.2. Caracterização da fase 70

3.3.3. Procedimento experimental 71

3.4. Medição do campo de velocidade do escoamento bifásico óleo-água $\quad 77$

3.4.1. Bancada experimental $\quad 77$

3.4.1.1. Sistema de injeção 78

3.4.1.2. Sistema de visualização na formação da gota 80

3.4.1.3. Sistema $\mu$ PIV 82

3.4.2. Fluido de Trabalho 82

3.4.2.1. Preparação da fase 83

3.4.2.2. Caracterização da fase $\quad 84$

3.4.3. Procedimento experimental 85

3.5. Limitações e dificuldades encontradas nos processos experimentais $\quad 88$

4. Resultados 90

4.1. Medição do campo de velocidade do escoamento monofásico $\quad 91$

4.1.1. Medição do campo de velocidade do escomento monofásico no micro canal de seção reta constante $\quad 91$

4.1.2 Medição do campo de velocidade do escoamento monofásico no micro canal com garganta $\quad 98$

4.2. Medição do campo de velocidade do escoamento bifásico $\begin{array}{ll}\text { óleo-água } & 108\end{array}$

4.2.1. Medição do campo de velocidade do escoamento bifásico óleo-água no micro canal de seção reta constante 109

4.2.2. Mediçaõ do campo de velocidade do escoamento bifásico óleo-água no micro canal com garganta 
5. Conclusões e Sugestões

5.1. Conclusões

5.2. Sugestões

6. Referências bibliográficas 


\section{Lista de figuras}

Figura 1.1: Participação na matriz energética mundial nos 2010, e o cenário de novas políticas em 2035. Fonte EIA (2012)

Figura 1.2: Esquema de um processo de recuperação secundaria de óleo ediante a injeção de um fluido

Figura 1.3: Sistema de injeção de água. a) Deslocamento ideal do óleo tipo pistão. b) Deslocamento real do óleo com geração de fingers

Figura 1.4: a) Representação esquemática do mecanismo de bloqueio mediante a injeção de emulsões. b) Modelo físico através de um micro capilar com garganta 28

Figura 2.1: a) Escoamento sem gota. b) Escoamento com uma gota 37

Figura 2.2: Gota parada em um micro canal reto 38

Figura 2.3: Gota escoando em um micro canal reto 39

Figura 2.4: Gota escoando em um micro canal com garganta 40

Figura 3.1: Sincronização do laser com a câmera CCD 43

Figura 3.2: Representação esquemática de um sistema $\mu$-PIV 44

Figura 3.3: a) Iluminação no sistema PIV. b) Iluminação no sistema H-PIV 47

Figura 3.4: a) Modo espalhada. b) Modo fluorescência 48

Figura 3.5: Profundidade do campo no sistema $\mu$-PIV 49

Figura 3.6: a) Imagens sem pré-processamento. b) Processo de substração de fundo das imagens. c) Imagens com préprocessamento

Figura 3.7: Janelas de interrogação base e de busca para correlação cruzada

Figura 3.8: Correlação cruzada de um par de imagens

Figura 3.9: Correlação cruzada de vários campos instantâneos "Média Amostral" 
Figura 3.10: a) Deslocamento sub-pixel na direção x. b) Deslocamento sub-pixel na direção y. c) Ajuste gaussiano em 2D 55

Figura 3.11: a) Matriz de vetores

Figura 3.12: a) Mapa com vetores incorretos. b) Mapa sem vetores incorretos. c) Mapa com vetores substituídos

Figura 3.13: Esquema da bancada experimental do sistema $\mu$-PIV para a injeção da fase contínua e a medição do campo de velocidade do escoamento

Figura 3.14: Montagem do sistema de injeção da fase contínua no sistema $\mu$-PIV

Figura 3.15: a) Micro capilar. b) Conector linear com tubos e selo.

c) Seção transversal da montagem. d) Seção transversal dos canais. e) Vista da Junção T. f) Micro-capilar montado.

g) Geometria e dimensões da garganta

Figura 3.16: Bomba de seringa Cole-parmer ${ }^{\circledR}$ Mod. 78-0200C

Figura 3.17: a) Seringa Hamilton Gastight $1 \mathrm{ml}$. b) Conexões entre a seringa e o micro capilar

Figura 3.18: Microscópio de fluorescência Olympus ${ }^{\circledR}$-Mod. IX71S1F-3 62

Figura 3.19: a) Cubo de filtro. b) Objetiva Olympus ${ }^{\circledR} 10 x / 0,30$

Figura 3.20: a) Luz de iluminação emitida pelo laser. b) Luz refletida pelas partículas. c) Luz emitida pelas partículas fluorescentes

Figura 3.21: Câmera CCD Powerview ${ }^{\mathrm{TM}}$ de 1.4MP Sensicam Mod. 630066

Figura 3.22: a) Fonte de energia. b) Cabeça do laser. c) Controles do laser

Figura 3.23: Valores configurados de Q-Switch delay no programa Insight $3 G^{\mathrm{TM}}$

Figura 3.24: Sincronizador LaserPulse-Modelo 610034

Figura 3.25: a) Janela principal do programa Insight $3 G^{T M}$. b) Aba "Exp. Tree". c) Aba "Capture". d) Aba "Processing" 68

Figura 3.26: Micro-esferas de poliestireno Fluoro-Max ${ }^{\mathrm{TM}}$ 69

Figura 3.27: Picos de fluorescência de absorção e emissão das 
partículas

Figura 3.28: Bomba de vácuo Quimis Mod. Q355D2 e o filtro com malha $0,45 \mu \mathrm{m}$

Figura 3.29: Micro capilar utilizado, apresentando a entrada e saída do escoamento monofásico e a região de observação

Figura 3.30: Desenvolvimento do perfil de velocidade na região de entrada de um escoamento em um duto circular

Figura 3.31: Montagem do micro capilar

Figura 3.32: a) Eixo do microscópio. b) Régua vertical na base do microscópio. c) Régua horizontal na base do microscópio. d) A centralização do microcanal reto no programa Insight $3 G^{\mathrm{TM}}$. e) A centralização do microcanal com uma garganta no programa Insight $3 \mathrm{G}^{\mathrm{TM}}$

Figura 3.33: Posição do plano focal do escoamento para a captura das imagens

Figura 3.34: Ajuste macrométrico e micrométrico do microscópio 75

Figura 3.35: Calibração no sistema $\mu$-PIV 75

Figura 3.36: a) Tamanho das partículas em pixels. b) Imagem do microcanal reto. c) Imagem dividida em janelas de interrogação de 32×32

Figura 3.37: Esquema da bancada experimental para a visualização da quebra da gota, e a medição do campo de velocidade

Figura 3.38: Montagem do sistema de injeção no sistema de visualização, da quebra da gota

Figura 3.39: Montagem do sistema de injeção da fase contínua e a fase dispersa no sistema $\mu$-PIV

Figura 3.40: Bombas de seringa Cole-Parmer ${ }^{\circledR}$ Mod. 78-0100C e Mod. 78-0200C

Figura 3.41: a) Seringas Hamilton Gastight $0.10 \mathrm{ml}$. b) Conexões entre as seringas e o micro capilar

Figura 3.42: Microscópio ótico invertido Carl Zeiss 40MAT 81

Figura 3.43: Câmera PixeLink PL-A662 81

Figura 3.44: Software AxioVision 4.7 
Figura 3.45: Balança Quimis Mod. Q-500L210C e o surfactante Sódio Dodecil Sulfato $\mathrm{C}_{12} \mathrm{H}_{25} \mathrm{NaSO}_{4}$

Figura 3.46: Agitador magnético Corning Mod. PC-420D

Figura 3.47: Micro capilar utilizado, apresentando a entrada e saída do escoamento bifásico, a região de formação da gota de óleo e as regiões avaliadas no escoamento

Figura 3.48: a) Formação da gota pequena na junção microfluídica T.

b) Formação da gota média na junção microfluídica $T$

86

Figura 4.1: Resumo dos experimentos realizados 90

Figura 4.2: Máscara do micro canal de seção reta constante 92

Figura 4.3: Campos de vetores de velocidade produzido do processamento de 1, 5, 10, 20 e 100 pares de imagens, realizado no software Insight $3 \mathrm{G}^{\mathrm{TM}}$, através do micro canal de seção reta constante

Figura 4.4: Comparação do perfil parabólico e experimental para diferentes pares de imagens através do micro canal de seção reta constante

Figura 4.5: Campo de velocidade do escoamento monofásico de 100 pares de imagens, realizado no software "Tecplot ${ }^{{ }^{\natural}}$, através do microcanal de seção reta constante

Figura 4.6: Campo de velocidade do escoamento monofásico mostrando $50 \%$ dos perfis de velocidade, através do micro canal de seção reta constante

Figura 4.7: Comparação do perfil parabólico e experimental média, mínima e máxima através do micro canal de seção reta constante

Figura 4.8: Máscara do micro canal com garganta do primeiro micro capilar

Figura 4.9: Máscara do micro canal com garganta do segundo micro capilar

Figura 4.10: Campo de vetores de velocidade produzidos do processamento de 100 pares de imagens, realizado no software Insight $3 G^{\mathrm{TM}}$, através do primeiro micro canal com 
garganta

Figura 4.11: Campo de vetores de velocidade produzido do processamento de 100 pares de imagens, realizado no software Insight $3 \mathrm{G}^{\mathrm{TM}}$, através do segundo micro canal com garganta

Figura 4.12: Campo de velocidade do escoamento monofásico de 100 pares de imagens, realizado no software Tecplot $^{\circledR}$, através do primeiro micro canal com garganta

Figura 4.13: Campo de velocidade do escoamento monofásico mostrando $50 \%$ dos perfis de velocidade, através do primeiro micro canal com garganta 102

Figura 4.14: Campo de velocidade do escoamento monofásico de 100 pares de imagens, realizado no software Tecplot ${ }^{\circledR}$, através do segundo micro canal com garganta 102

Figura 4.15: Campo de velocidade do escoamento monofásico mostrando $50 \%$ dos perfis de velocidade, através do segundo micro canal com garganta

Figura 4.16: Região convergente e divergente na garganta do primeiro micro canal

Figura 4.17: Variação da velocidade média do escoamento através da garganta

Figura 4.18: Campo de vetor de velocidade produzido de 10 pares de imagens sobrepostas realizada por Wereley em 2002

Figura 4.19: Região convergente e divergente na garganta do segundo micro canal

Figura 4.20: Comparação dos perfis parabólicos e experimentais na entrada e na saída do primeiro micro canal com garganta 107

Figura 4.21: Comparação dos perfis parabólicos e experimentais na entrada e na saída do segundo micro canal com garganta 108

Figura 4.22: a) Posição da gota pequena $(\alpha=1,4)$ no micro canal de seção reta constante. b) Máscara da gota pequena no micro canal de seção reta constante

Figura 4.23: a) Posição da gota média $(\alpha=1,5)$ no micro canal de seção 
reta constante. b) Máscara da gota média no micro canal de seção reta constante

Figura 4.24: Campos de vetores de velocidade produzidos do processamento de 50 pares de imagens por separado ao redor da gota pequena, através do micro canal de seção reta constante

Figura 4.25: Campo de vetores de velocidade produzido no processamento de 100 pares de imagens ao redor da gota pequena, através do micro canal de seção reta constante 112

Figura 4.26: Campos de vetores de velocidade produzidos do processamento de 50 pares de imagens por separado ao redor da gota média, através do micro canal de seção reta constante

Figura 4.27: Campo de vetores de velocidade produzido do processamento de 100 pares de imagens ao redor da gota média, através do micro canal de seção reta constante

Figura 4.28: Campos de velocidade do escoamento bifásico de 50 pares de imagens por separado ao redor da gota pequena $(\alpha=1,4)$, através do micro canal de seção reta constante

Figura 4.29: Campo de velocidade de escoamento bifásico de 100 pares de imagens ao redor da gota pequena $(\alpha=1,4)$, através do micro canal de seção reta constante

Figura 4.30: Campos de velocidade do escoamento bifásico de 50 pares de imagens por separado ao redor da gota média $(\alpha=1,5)$, através do micro canal de seção reta constante

Figura 4.31: Campo de velocidade do escoamento bifásico de 100 pares de imagens ao redor da gota média $(\alpha=1,5)$, através do micro canal de seção reta constante

Figura 4.32: Comparação dos perfis parabólicos e experimentais na entrada e na saída do micro canal de seção reta constante, no escoamento bifásico de 100 pares de imagens ao redor da gota pequena $(\alpha=1,4)$ 
Figura 4.33: Comparação dos perfis parabólicos e experimentais na entrada e na saída do micro canal de seção reta constante, no escoamento bifásico de 100 pares de imagens ao redor da gota média $(\alpha=1,5)$

Figura 4.34: Variação da velocidade na linha de simetria ao longo do comprimento do micro canal de seção reta constante, no escoamento bifásico de 100 pares de imagens ao redor da gota pequena $(\alpha=1,4)$

Figura 4.35: Variação da velocidade na linha de simetria ao longo do comprimento do micro canal de seção reta constante no escoamento bifásico de 100 pares de imagens ao redor da gota média $(\alpha=1,5)$

Figura 4.36: Campo de velocidade do escoamento bifásico de 100 pares de imagens, na interface óleo-água à montante da gota pequena $(\alpha=1,4)$, através do micro canal de seção reta constante

Figura 4.37: Campo de velocidade do escoamento bifásico de 100 pares de imagens, na interface óleo-água à montante da gota média ( $\alpha=1,5)$, através do micro canal de seção reta constante

Figura 4.38: Campo de velocidade do escoamento bifásico dos 100 pares de imagens relativo à gota pequena $(\alpha=1,4)$, através do micro canal de seção reta constante

Figura 4.39: Campo de velocidade do escoamento bifásico de 100 pares de imagens relativo à gota média $(\alpha=1,5)$, através do micro canal de seção reta constante

Figura 4.40: Região do lado esquerdo e direito do campo de velocidade relativo à gota pequena $(\alpha=1,4)$, através do micro canal de seção reta constante

Figura 4.41: Região do lado esquerdo e direito do campo de velocidade relativo à gota média $(\alpha=1,5)$, através do micro canal de seção reta constante

Figura 4.42: Campo de velocidade de uma gota pequena e grande 
realizada numericamente por Martinez \& Udell em 1989

Figura 4.43: Linhas de corrente do campo de velocidade do escoamento bifásico dos 100 pares de imagens relativo à gota pequena $(\alpha=1,4)$

Figura 4.44: Região de linhas de corrente do lado esquerdo e direito do campo de velocidade do escoamento bifásico dos 100 pares de imagens relativo à gota pequena $(\alpha=1,4)$

Figura 4.45: Linhas de corrente do campo de velocidade do escoamento bifásico dos 100 pares de imagens relativo à gota média $(\alpha=1,5)$

Figura 4.46: Região de linhas de corrente do lado esquerdo e direito do campo de velocidade do escoamento bifásico dos 100 pares de imagens relativo à gota média $(\alpha=1,5)$

Figura 4.47: a) Primeira posição da gota pequena ( $\alpha=1,4)$ no primeiro micro canal com garganta. b) Máscara da primeira posição da gota pequena no primeiro micro canal com garganta

Figura 4.48: Segunda posição da gota pequena $(\alpha=1,4)$ no primeiro micro canal com garganta. b) Máscara da segunda posição da gota pequena no primeiro micro canal com garganta

Figura 4.49: Terceira posição da gota pequena $(\alpha=1,4)$ no primeiro micro canal com garganta. b) Máscara da terceira posição da gota pequena no primeiro micro canal com garganta

Fgura 4.50: Campo de vetores de velocidade produzido do processamento dos 50 pares de imagens, ao redor da primeira posição da gota pequena, através do micro canal com garganta do primeiro micro capilar

Figura 4.51: Campo de vetores de velocidade produzido do processamento dos 50 pares de imagens, ao redor da segunda posição da gota pequena, através do micro canal com garganta do primeiro micro capilar

Figura 4.52: Campo de vetores de velocidade produzido do processamento dos 50 pares de imagens, ao redor da terceira posição da gota pequena, através do micro canal 
com garganta do primeiro micro capilar

Figura 4.53: Campo de velocidade do escoamento bifásico dos 50 pares de imagens ao redor da primeira posição da gota pequena, através do micro canal com garganta do primeiro micro capilar

Figura 4.54: Campo de velocidade do escoamento bifásico dos 50 pares de imagens ao redor da segunda posição da gota pequena, através do micro canal com garganta do primeiro micro capilar

Figura 4.55: Campo de velocidade do escoamento bifásico dos 50 pares de imagens ao redor da terceira posição da gota pequena, através do micro canal com garganta do primeiro micro capilar

Figura 4.56: Comparação dos perfis parabólicos e experimentais na entrada do micro canal com garganta do primeiro micro capilar, nas 3 posições da gota pequena

Figura 4.57: Comparação dos perfis parabólicos e experimentais na saída do micro canal com garganta do primeiro micro capilar, nas 3 posições da gota pequena

Figura 4.58: Variação da velocidade na linha de simetria do micro canal com garganta do primeiro micro capilar, ao redor da primeira posição da gota pequena

Figura 4.59: Variação da velocidade na linha de simetria do micro canal com garganta do primeiro micro capilar, ao redor da segunda posição da gota pequena

Figura 4.60: Variação da velocidade na linha de simetria do micro canal com garganta do primeiro micro capilar, ao redor da terceira posição da gota pequena

Figura 4.61: Campo de velocidade do escoamento bifásico dos 50 pares de imagens, na interface óleo-água à montante da primeira posição da gota pequena, através do micro canal com garganta do primeiro micro capilar

Figura 4.62: Campo de velocidade do escoamento bifásico dos 50 
pares de imagens, na interface óleo-água à montante da segunda posição da gota pequena, através do micro canal com garganta do primeiro micro capilar

Figura 4.63: Campo de velocidade do escoamento bifásico dos 50 pares de imagens, na interface óleo-água à montante da terceira posição da gota pequena, através do micro canal com garganta do primeiro micro capilar

Figura 4.64: a) Primeira posição da gota pequena $(\alpha=1,4)$ no segundo micro canal com garganta. b) Máscara da primeira posição da gota pequena no segundo micro capilar com garganta 147

Figura 4.65: a) Segunda posição da gota pequena $(\alpha=1,4)$ no segundo micro canal com garganta. b) Máscara da segunda posição da gota pequena no segundo micro canal com garganta

Figura 4.66: a) Terceira posição da gota pequena $(\alpha=1,4)$ no segundo micro canal com garganta. b) Máscara da terceira posição da gota pequena no segundo micro canal com garganta 148

Figura 4.67: a) Quarta posição da gota pequena $(\alpha=1,4)$ no segundo micro canal com garganta. b) Máscara na quarta posição da gota pequena no segundo micro canal com garganta

Figura 4.68: Campo de vetores de velocidade do processamento dos 50 pares de imagens, ao redor da primeira posição da gota pequena, através do micro canal com garganta do segundo micro capilar

Figura 4.69: Campo de vetores de velocidade do processamento dos 50 pares de imagens, ao redor da segunda posição da gota pequena, através do micro canal com garganta do segundo micro capilar

Figura 4.70: Campo de vetores de velocidade do processamento dos 50 pares de imagens, ao redor da quarta posição da gota pequena, através do micro canal com garganta do segundo micro capilar

Figura 4.71: Campo de velocidade do escoamento bifásico dos 50 pares de imagens ao redor da primeira posição da gota 
pequena, através do micro canal com garganta do segundo micro capilar

Figura 4.72: Campo de velocidade do escoamento bifásico dos 50 pares de imagens ao redor da segunda posição da gota pequena, através do micro canal com garganta do segundo micro capilar

Figura 4.73: Campo de velocidade do escoamento bifásico dos 50 pares de imagens ao redor da terceira posição da gota pequena, através do micro canal com garganta do segundo micro capilar

Figura 4.74: Campo de velocidade do escoamento bifásico dos 50 pares de imagens ao redor da quarta posição da gota pequena, através do micro canal com garganta do segundo micro capilar

Figura 4.75: Comparação dos perfis parabólicos e experimentais na entrada do micro canal com garganta do segundo micro capilar, em 3 posições da gota pequena

Figura 4.76: Comparação dos perfis parabólicos e experimentais na saída do micro canal com garganta do segundo micro capilar, em 3 posições da gota pequena

Figura 4.77: Variação da velocidade na linha de simetria do micro canal com garganta do segundo micro capilar, ao redor da primeira posição da gota pequena

Figura 4.78: Variação da velocidade na linha de simetria do micro canal com garganta do segundo micro capilar, ao redor da segunda posição da gota pequena

Figura 4.79: Variação da velocidade na linha de simetria do micro canal com garganta do segundo micro capilar, ao redor da quarta posição da gota pequena

Figura 4.80: Campo de velocidade do escoamento bifásico dos 50 pares de imagens, na interface óleo-água à montante da primeira posição da gota pequena, através do micro canal com garganta do segundo micro capilar 
Figura 4.81: Campo de velocidade do escoamento bifásico dos 50 pares de imagens, na interface óleo-água à montante da segunda posição da gota pequena, através do micro canal com garganta do segundo micro capilar

Figura 4.82: Campo de velocidade do escoamento bifásico dos 50 pares de imagens, na interface óleo-água à montante da quarta posição da gota pequena, através do micro canal com garganta do segundo micro capilar 


\section{Lista de tabelas}

Tabela 3.1: Valores de SRN para diferentes concentrações e profundidades no canal

Tabela 3.2: Valores selecionados de Energy e Q-Switch delay laser $\quad 66$

Tabela 3.3: Propriedade da fase contínua a $23^{\circ} \mathrm{C} \quad 70$

Tabela 3.4: Propriedade da fase contínua e dispersa a $23^{\circ} \mathrm{C}$

Tabela 4.1: Valores de velocidades dos perfis de entrada e de saída do escoamento, através do primeiro micro canal com garganta

Tabela 4.2: Valores de velocidades dos perfis de entrada e de saída do escoamento, através do segundo micro canal com garganta

Tabela 4.3: Valores de velocidades experimentais dos perfis de entrada e saída do escoamento ao redor da gota pequena $(\alpha=1,4)$, através do micro canal de seção reta constante

Tabela 4.4: Valores de velocidades experimentais dos perfis de entrada e saída do escoamento ao redor da gota média $(\alpha=1,5)$, através do micro canal de seção reta constante

Tabela 4.5: Valores de velocidade da gota pequena $(\alpha=1,4)$, através do micro canal de seção reta constante

Tabela 4.6: Valores de velocidade da gota pequena $(\alpha=1,5)$, através do micro canal de seção reta constante

Tabela 4.7: Valores de velocidades experimentais dos perfis de entrada e saída do escoamento, ao redor das 3 posições da gota pequena, através do micro canal com garganta do primeiro micro capilar

Tabela 4.8: Valores de velocidade da gota pequena, para cada posição, através do micro canal com garganta do primeiro micro capilar 
Tabela 4.9: Valores de velocidades experimentais dos perfis de entrada e saída do escoamento, ao redor das 4 posições de gota pequena, através do micro canal com garganta no segundo micro capilar 


\section{Introdução}

Hoje, o petróleo representa a principal fonte energética do planeta, com uma participação de aproximadamente $32,4 \%$ na matriz energética mundial, de acordo com o relatório de 2012 da International Energy - EIA. A Agência Internacional da Energia (EIA) projetou que até o ano 2035 o consumo de óleo vai aumentar de 4120 Mtoe (Million tonnes of oil equivalent) para 4647 Mtoe, como é apresentado na figura (1.1).
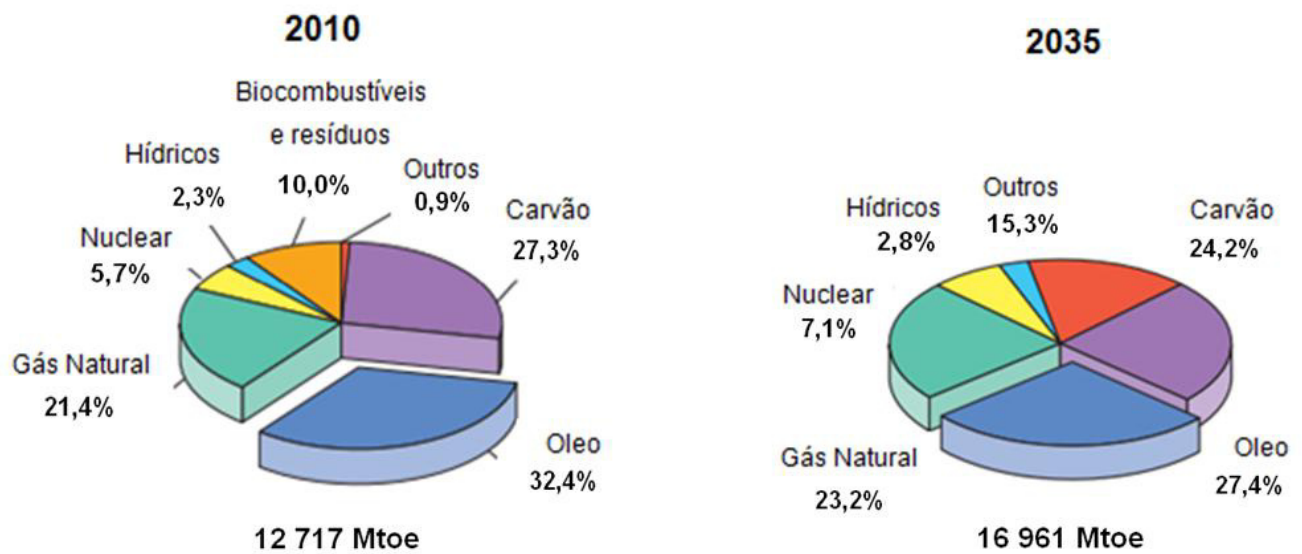

Figura 1.1: Participação na matriz energética mundial nos 2010, e o cenário de novas políticas em 2035. Fonte: EIA (2012) [1].

Devido a este cenário, considera-se que grandes esforços estarão dirigidos a incrementar a eficiência dos campos petrolíferos já descobertos e ao desenvolvimento de novas tecnologias e técnicas de extração com o objetivo de aumentar a recuperação do óleo do reservatório. Uma dessas técnicas é a chamada recuperação secundaria [2], que é utilizada para manter ou aumentar a pressão do reservatório, e deslocar o óleo em direção aos poços produtores, incrementando assim a produtividade dos poços.

O processo de recuperação secundaria consiste na injeção de um fluido dentro do reservatório através dos poços injetores, e é responsável pelo deslocamento do óleo até os poços produtores. A figura (1.2) apresenta um 
esquema deste método, onde o fluido 1 representa o fluido injetado e o fluido 20 óleo que se deseja extrair do meio poroso.

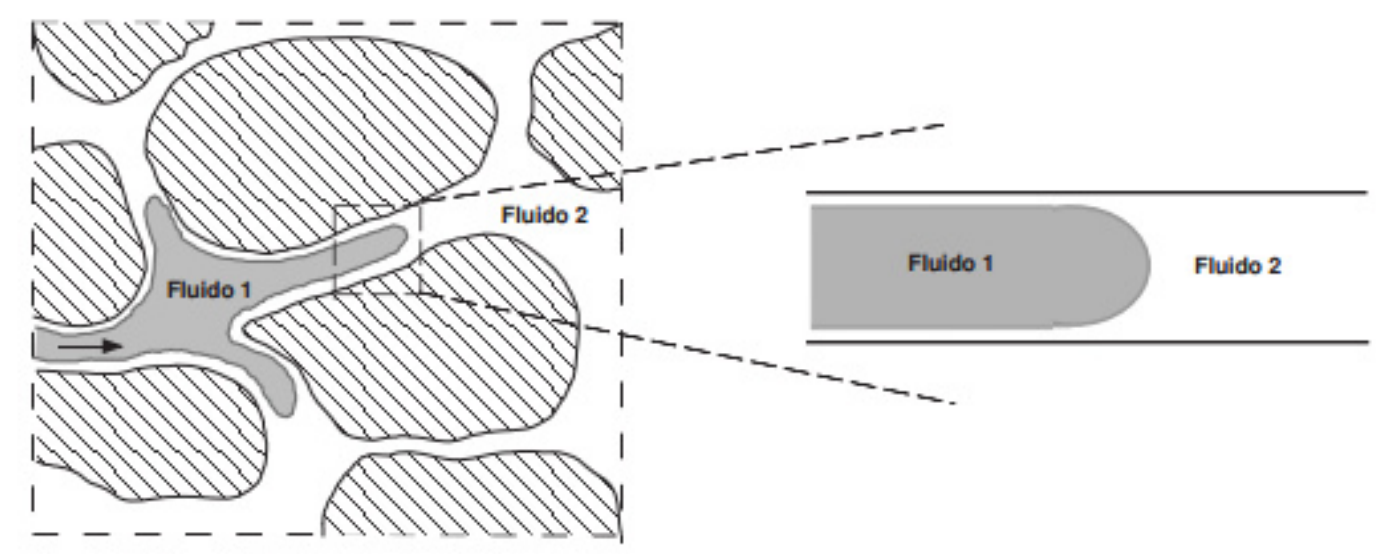

Figura 1.2: Esquema de um processo de recuperação secundaria de óleo mediante a injeção de um fluido [3].

O método de recuperação secundaria mais utilizado é a injeção de água. Primeiro foi utilizada no campo de Bradford Estados Unidos, no inicio do século. No Brasil, o primeiro campo que utilizou esse processo foi o de Dom João na Bahia, em 1953. O comportamento ideal no reservatório seria um deslocamento tipo pistão, como representado na figura (1.3a). Neste caso, a frente de avanço da água é uniforme, no entanto, devido a diversos fatores, a frente de avanço da água é não-uniforme, com o aparecimento de configurações denominadas "fingers" [4]. Grandes áreas do reservatório não são atingidas pela água, reduzindo o volume de óleo que é produzido. Este fenômeno é representado esquematicamente na figura (1.3b). A formação de frentes de deslocamentos não uniformes está associada a uma desfavorável razão de mobilidade entre o óleo e água, causada pela diferença de viscosidades entre elas. 
a)

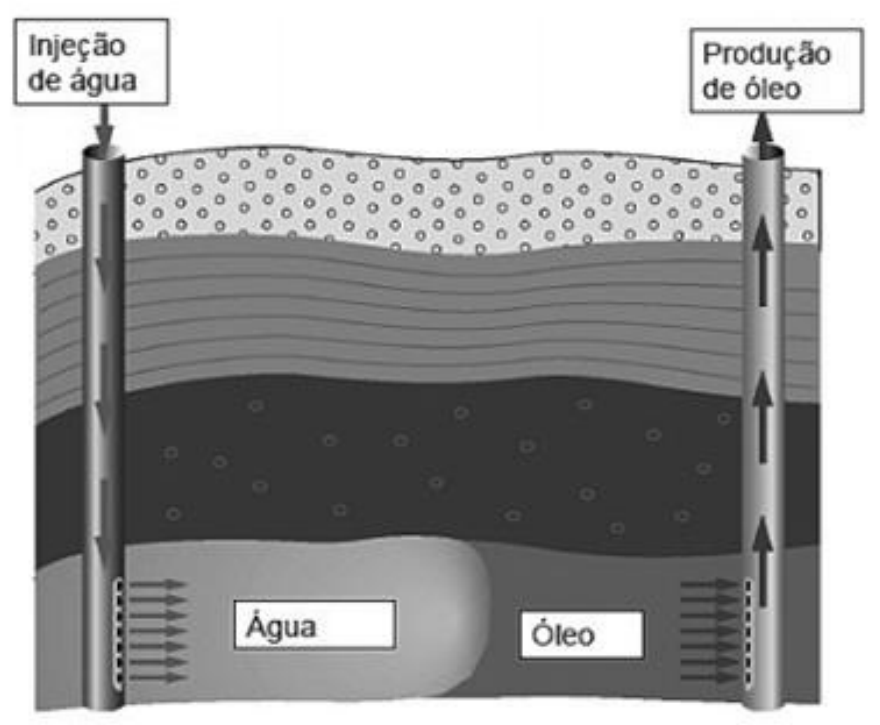

b) Injẹçăo

Produçāo

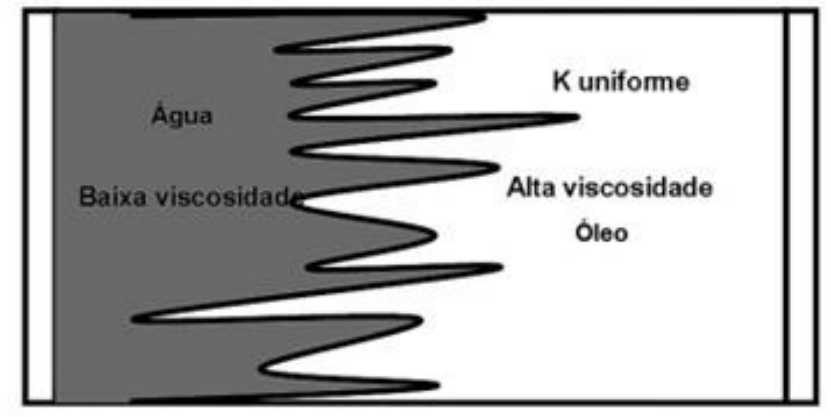

Figura 1.3: Sistema de injeção de água. a) Deslocamento ideal do óleo tipo pistão. b) Deslocamento real do óleo com geração de fingers [5].

Existem outros métodos de recuperação secundaria, como por exemplo, a injeção de polímeros que podem ser utilizados como agentes de controle da mobilidade, para conseguir frentes de deslocamentos mais uniformes. Porém, a principal desvantagem são os custos elevados das substancias químicas envolvidas neste método e a interação entre as moléculas poliméricas e a rocha do reservatório. Diferentes métodos químicos foram desenvolvidos tanto para melhorar a varredura do reservatório (levando a formação de frentes de deslocamentos uniformes) como melhorar a eficiência do deslocamento na escala de poros (redução da saturação residual de óleo). Dentre estes métodos a injeção de emulsões aparenta ser uma opção interessante no processo de recuperação secundária, devido a seus baixos custos de produção comparados 
com a injeção de polímeros e a sua eficiência tanto em melhorar a varredura do reservatório com a diminuição da saturação residual de óleo [6].

Esta técnica não totalmente desenvolvida consiste em injetar emulsões com a capacidade de bloquear os poros já varridos por injeção de água. A figura (1.4a) apresenta um esquema do processo de bloqueio de poros pelas gotas de óleo e a redistribuição do fluxo da fase aquosa. O comportamento macroscópico do escoamento de emulsões em meios porosos é uma função direita do escoamento na escala de poros. O espaço poroso pode ser representado por um conjunto de tubos com gargantas, conforme mostrado na figura (1.4b).

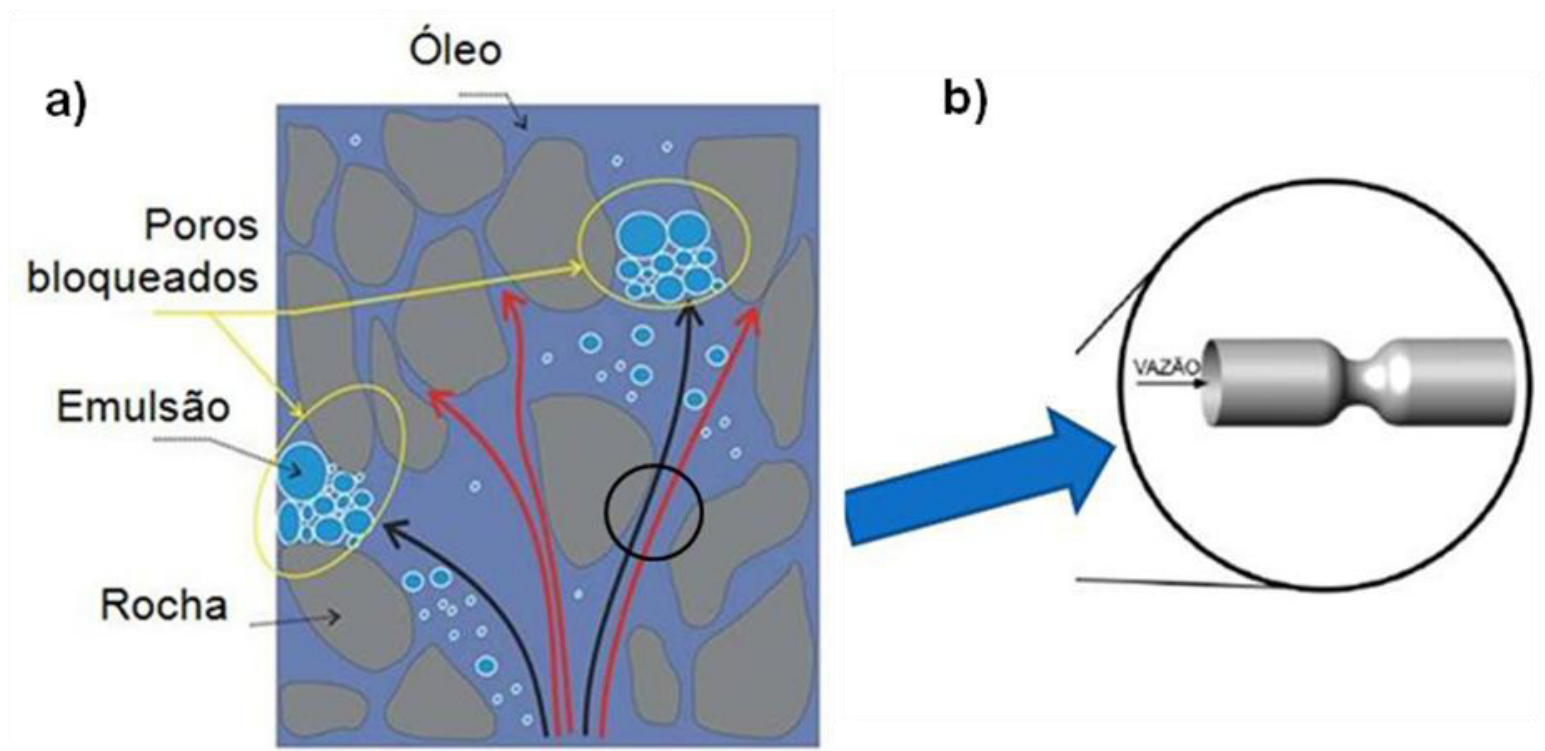

Figura 1.4: a) Representação esquemática do mecanismo de bloqueio mediante a injeção de emulsões. b) Modelo físico através de um micro capilar com garganta.

\section{1.}

\section{Motivação}

Testes de campo [7] já mostraram que a injeção de emulsões leva a um aumento da recuperação de óleo. Os mecanismos que levaram a este escoamento não eram perfeitamente compreendidos. Estudos recentes mostram que a injeção de emulsões óleo-água atua tanto na escala de poros como na escala macroscópica levando a um aumento do fator de recuperação de óleo [6]. 
Para a otimização deste processo, é fundamental um perfeito entendimento de como emulsões escoam em meios porosos, particularmente como emulsões escoam através das gargantas dos poros.

Diversos trabalhos na literatura apresentam estudos do escoamento de gotas de um fluido suspensas em outros fluidos através de capilares de seção reta constante. Poucos estudos foram realizados com capilares com garganta. A maior parte destes estudos é focada na relação vazão-diferença de pressão em função das condições do escoamento. Detalhes do campo de velocidade ao redor das gotas são descritos apenas através de soluções numéricas.

Este trabalho foca no estudo detalhado no escoamento de gotas de óleo suspensas em uma fase aquosa através de um capilar com seção reta constante e de um capilar com garganta. Uma revisão bibliográfica do assunto e os objetivos específicos são discutidos a seguir.

\section{2. \\ Revisão bibliográfica}

Nesta seção são citados os trabalhos realizados sobre o escoamento de gotas de um fluido suspensas em outro, através de capilares de diferentes geometrias; e os estudos realizados com a técnica do sistema micro-PIV, aplicado a diferentes áreas de estudos.

Ho \& Leal (1975) [25] estudaram experimentalmente o movimento progressivo de gotas neutralmente flutuantes através de um tubo circular. $O$ diâmetro das gotas era comparável ao diâmetro do tubo. A bancada utilizada consistiu de um tubo de vidro horizontal de $120 \mathrm{~cm}$ de comprimento e $1 \mathrm{~cm}$ de diâmetro interior. Duas tomadas de pressão foram posicionadas ao longo do tubo de vidro, uma válvula para gerar uma diferença de pressão entre as duas tomadas, e um transdutor diferencial de pressão para tomar as leituras de pressão. As gotas foram injetadas manualmente ao sistema usando uma seringa micrométrica, e o fluido em suspensão foi bombeado a uma taxa de fluxo constante mediante uma bomba de seringa. Eles reportaram as linhas de corrente do fluxo para diferentes razões de viscosidade, razões de fluxo total e tamanhos de gotas.

Em 1983, Olbricht e Leal [26] estudaram experimentalmente o movimento progressivo de gotas neutralmente flutuantes e não flutuantes, através de um tubo circular que possuía um diâmetro que varia sinusoidalmente com a posição 
axial (convergente-divergente). Olbricht modificou a bancada experimental utilizada por Ho \& Leal em 1975. O tubo horizontal de vidro foi dividido em duas partes com dimensões diferentes, e apresentou variações nos seus diâmetros (convergente-divergente). Foi avaliado o efeito das gotas suspensas no escoamento, mediante as leituras de pressão adicional, para diferentes relações de viscosidades, fluxo volumétrico e tamanho de gotas.

Henrik, em 1989, estudou o movimento progressivo de bolhas não viscosas e gotas viscosas escoando em tubos capilares, através do método de elementos finitos-Galerkin [27]. A influência da tensão interfacial foi incluída nesta análise. Foram determinados os perfis de velocidade dentro como fora da gota e da bolha, a qual apresentou informações importantes de como o fluxo recircula tanto na parte dianteira como a parte traseira das gotas. Além disso, proporcionou uma estimativa da influência da viscosidade na espessura do filme da fase contínua.

Martinez \& Udell em 1990 [28] estudaram numericamente o movimento progressivo de gotas neutralmente flutuantes e deformáveis escoando em um tubo circular, através de uma simulação numérica usando o método de integral de contorno. Os fluidos analisados foram considerados imiscíveis, incompressíveis e a taxa de fluxo constante. A relação de viscosidade entre a gota e o fluido em suspensão foi arbitraria, e os raios da gota variaram desde 0,5 até 1,15 vezes o raio do tubo. Foram examinados os efeitos do número de capilaridade, relação de viscosidade, e o tamanho das gotas sobre a deformação, a velocidade da gota e a perda de pressão adicional. Os valores calculados de perda de pressão adicional e velocidade da gota tiveram uma boa concordância com os dados experimentais de Ho \& Leal (1975) para gotas de tamanhos comparáveis com o raio do tubo.

Tsay \& Miksis, em 1994, [29] estudaram a deformação e ruptura de uma gota à medida que percorria através de um capilar circular reto e com garganta, devido a um gradiente de pressão imposto. Foi utilizado um método numérico para avaliar o efeito dos parâmetros físicos (o raio efetivo da gota, a relação de viscosidade e o número de capilaridade) sobre a dinâmica da gota, sob as suposições de ser um fluxo progressivo, e as gotas com um movimento com simetria axial e neutralmente flutuante.

Santiago, Wereley, Meinhart, Beebe \& Adrian, em 1998, [9] desenvolveram uma técnica chamada velocimetria por imagem de partículas em escala micrométrica " $\mu$-PIV", para investigar o campo de fluxo em um dispositivo microfluídico. A iluminação do experimento foi proporcionada por uma lâmpada 
de mercúrio acoplada a um microscópio epi-fluorescente, e as partículas foram visualizadas através de uma câmera CCD intensificada. A técnica $\mu$-PIV foi aplicada por primeira vez, para medir o campo de velocidade do escoamento através de uma célula Hele-Shaw, e foi capaz de proporcionar medições de campos de velocidades com distâncias entre vetores de 3,45 $\mu \mathrm{m}$ usando uma resolução espacial de 6,9 × 6,9 × 1,5 $\mu^{3}$. Além disso, para o processamento foi utilizada a técnica "clássica" através de uma só imagem, e depois foi melhorada com a técnica "ensemble-average" através de 8 imagens.

Em 1999, Meinhart, Wereley \& Santiago [30] utilizaram a técnica de microPIV para medir o campo de velocidade do escoamento de água deionizada, através de um micro canal de vidro de seção retangular de $30 \mu \mathrm{m} \times 300 \mu \mathrm{m} \times 25$ $\mathrm{mm}$. As imagens obtidas foram analisadas perto e longe da parede utilizando uma resolução espacial de 13,6 x 0,9 $\mu \mathrm{m}^{2}$ e 13,6 x 4,4 $\mu \mathrm{m}^{2}$ respectivamente, ambos os casos foram escolhidos 20 campos de velocidades instantâneos. $O$ sistema foi composto de um microscópio epi-fluorescênte, uma câmera CCD com resolução espacial de 1300 x 1030 pixels, e dois lasers tipo Nd.YAG. Desta maneira foi melhorado o sistema de iluminação nas partículas e a frequência na captura das imagens.

Meinhart e Zhang, em 2000, [31] mediram campos de vetor de velocidade instantâneos na cabeça de impressão a jato de tinta, utilizando o sistema microPIV. Esta técnica foi composta de partículas fluorescentes de $700 \mathrm{~nm}$ diâmetro, um laser Nd:YAG do tipo pulso que foi usado para iluminar as partículas traçadoras de diâmetro $0,7 \mu \mathrm{m}$, um microscópio epi-fluorescente e uma câmera CCD. Os campos vetoriais foram obtidos com resoluções espaciais de 5-10 $\mu \mathrm{m}$, e o tempo de atraso entre as duas imagens foram de 2-5 $\mu \mathrm{s}$, dependendo das características de velocidade do fluxo. A velocidades máximas alcançadas no fluido no bocal foi de 8 m/s, correspondendo um numero de Reynolds de 500 .

Em 2002, Wereley \& Gui [9] demonstraram a vantagem de utilizar novas técnicas de registro e algoritmos avançados de processamento de imagens no sistema micro-PIV. Eles estudaram a passagem do escoamento de água deionizada através de um micro-bocal com uma restrição de $28 \mu \mathrm{m}$. O sistema $\mu$-PIV foi composto de um microscópio epi-fluorescente, um laser Nd:YAG, uma câmera CCD e as partículas fluorescentes de poliestireno de $700 \mathrm{~nm}$ de diâmetro. A resolução obtida foi $10,9 \times 5,4 \mu \mathrm{m}$ a uma vazão de $4 \mathrm{ml} / \mathrm{h}$, correspondendo um numero de Reynolds de 22.

Em 2003, Okuda, Sugii \& Okamoto [32] investigaram as propriedades reológicas do fluxo do sangue em vivo e em vidro ("in vitro") através da técnica 
micro-PIV. O experimento foi realizado em um microtubo redondo de diâmetro $100 \mu \mathrm{m}$ escoando sangue com partículas fluorescentes de 0,5 $\mu \mathrm{m}$ de diâmetro no seu interior. Além disso, o sistema consistiu de um microscópio de fluorescência, um laser de duplo pulso YAG e uma câmera CCD. Distribuições de velocidades com resoluções espaciais de 5,9 x 0,73 $\mathrm{mm}$ foram obtidas perto da região da parede. Os resultados mostraram características típicas de um fluido não newtoniano.

Shinohara, Sugii \& Aota, em 2004, [33] desenvolveram uma técnica de micro-PIV de alta velocidade para medir fenômenos transientes em um dispositivo microfluídico. Os fluidos utilizados (óleo e água) foram injetados em contra-fluxo formando duas camadas separadas, e os microcanais utilizados foram de $100 \mu \mathrm{m}$ de largura e $25 \mu \mathrm{m}$ de profundidade (perfil-semi-circular). $\mathrm{O}$ sistema consistiu de um microscópio epi-fluorescente, um laser CW e uma câmera de alta velocidade CMOS com resolução espacial de $512 \times 512$ pixels e 2000 frame/s. Foram determinados perfis de velocidade na fase da água onde foram semeadas as partículas fluorescentes, e os vórtices ao redor da interface óleo-água, com uma resolução espacial de 2,2 x 2,2 $\mu \mathrm{m}$.

Steijn, Kreutzer e Kleijn, em 2007, [34] apresentaram medições transientes do campo de fluxo, durante a formação de bolhas em uma Junção $T$ de um dispositivo microfluídico utilizando a técnica $\mu$-PIV. A imagem tridimensional do campo de velocidade na fase contínua foi construída a partir do campo de velocidade bidimensional para quatro profundidades diferentes. O fluxo de gás (ar) e o liquido (etanol) foram injetados através de dois canais diferentes, encontrando-se na junção $T$ formando a bolha de ar. O gás foi fornecido desde um recipiente a pressão e o liquido foi injetado através de uma seringa acionada por uma bomba. A seção da junção T é um quadrado de $800 \mu \mathrm{m}$ x $800 \mu \mathrm{m}$. Além disso, o sistema $\mu$-PIV foi composto de um microscópio invertido, um laser de dupla cabeça Nd:YAG, uma câmera CCD de alta velocidade e partículas fluorescentes que foram semeadas na fase contínua. As velocidades na junção $T$ foram medidas com uma resolução espacial de $20 \times 20 \times 100 \mu \mathrm{m}^{3}$.

Em 2009 Lac \& Sherwood [35] estudaram numericamente o comportamento hidrodinâmico de uma gota escoando através de um capilar circular com baixo numero de Reynolds, utilizando o método integral de contorno. A medição relativa entre as forças viscosas e capilares foram obtidos a partir de três parâmetros independentes: o tamanho relativo entre a gota não deformada e o raio do capilar, a relação de viscosidade e o número de capilaridade. Foi investigada também, como a presença de uma gota causa uma 
mudança na diferença de pressão entre os extremos do capilar em um fluxo constante.

A pesar do grande número de estudos de escoamentos de gotas (e bolhas) através de micro canais, vários aspectos do escoamento ainda não foram explorados. A maior parte dos estudos foi realizada em capilares de seção reta constante com diâmetro geralmente maior do que $1 \mathrm{~mm}$. As análises de escoamento através de uma garganta são bastante raras. Por outro lado, como descrito neste capítulo, a técnica de $\mu$-PIV tem sido desenvolvida ao longo do tempo de forma a permitir medida de campos de velocidades na escala micrométrica.

Neste trabalho, a técnica de $\mu$-PIV é utilizada para estudar o escoamento de gotas de óleos suspensas em uma fase aquosa através de um capilar de seção reta constante (escoamento em regime permanente) e com garganta (escoamento em regime transiente, periódico), para um melhor entendimento do escoamento na escala de poros. Forneceram informações importantes, como a presença de gotas de óleo muda a mobilidade do fluido quando o mesmo escoa através de poros com gargantas menores do que tamanho das gotas.

\section{3. \\ Objetivos da dissertação}

O objetivo específico deste trabalho foi determinar o efeito da geometria do capilar e garganta e do tamanho da gota no campo de velocidade do escoamento de uma emulsão em uma escala micrométrica.

O campo de velocidade foi obtido experimentalmente através da técnica de velocimetria por imagem de partículas em escala micrométrica $(\mu \mathrm{m})$. Esta técnica permitiu a determinação do campo de velocidade da fase contínua na região próxima à gota e a velocidade da gota. Estes resultados podem ser utilizados para validar modelos numéricos sendo desenvolvidos no grupo. 


\section{4 .}

\section{Estrutura da dissertação}

Esta dissertação foi dividida em cinco capítulos:

Capitulo №1 "Introdução": Nesta seção é apresentada a motivação, a justificativa e os objetivos da dissertação.

Capitulo N² "Fundamentos Teóricos": É apresentada uma breve descrição do mecanismo de bloqueio do escoamento na escala de poros, e a técnica de medição $\mu$-PIV. Além disso, apresenta-se uma revisão bibliográfica dos estudos realizados na área de escoamento na escala de poros junto com o desenvolvimento da técnica $\mu$-PIV na medição do campo de velocidade em escoamentos microscópicos.

Capitulo №3 "Experimento": Este capítulo apresenta uma descrição detalhada dos dispositivos e procedimentos experimentais utilizados no estudo, neccesários para obter os resultados.

Capitulo N4 "Resultados": São apresentados os resultados dos campos de velocidade de um escoamento monofásico (água) e bifásico (gota de óleo suspensa em água), através de 2 micro capilares com garganta.

Capitulo $N^{\circ} 5$ "Conclusões e sugestões": São citadas as conclusões de forma resumida e objetiva, assim como recomendações para trabalhos futuros. 


\section{2 \\ Fundamentos Teóricos}

\section{1. Escoamento de emulsões através de micro capilares}

O comportamento macroscópico do escoamento de emulsões em um meio poroso é uma função direta das características do escoamento bifásico na escala de poros. Este depende de diversos fatores, como a distribuição de tamanho de gotas e de poros, a velocidade do escoamento, a estabilidade da emulsão, e a razão de viscosidades entre as duas fases. Desta maneira, os mecanismos que alteram o escoamento podem ser estudados na escala microscópica através de dispositivos microfluídicos. O estudo na escala de poros possibilita a análise detalhada do escoamento durante o avanço da emulsão. As gotas atravessam poros de diferentes formas e tamanhos, e a diferentes velocidades, causando variações na relação vazão-gradiente de pressão. Citaremos a seguir algumas definições relacionadas com este processo.

\subsection{1.}

\section{Tensão interfacial e superficial}

A tensão interfacial $\sigma_{\text {int }}$ possui a dimensão de força por unidade de comprimento ou energia por área, e atua tangencialmente à superfície de contacto entre dois fluidos imiscíveis. Quando a superfície de contacto se dá na interface entre um líquido e um gás, o fenômeno e as propriedades que aparecem são denominadas superficiais. Quando se refere ao contacto na interface entre dois líquidos imiscíveis, o fenômeno é denominado interfacial. A tensão interfacial entre dois líquidos $\sigma_{\text {int }}$ pode ser aproximada pela diferença das tensões superficiais $\sigma_{\text {supi }}$ das fases [8]:

$$
\sigma_{\text {int }}=\sigma_{\text {sup1 }}-\sigma_{\text {sup2 }}
$$




\subsection{2.}

\section{Número de Capilaridade}

O número de capilaridade Ca representa a razão das forças viscosas e as forças capilares que atuam em uma interface entre um liquido e um gás ou entre dois líquidos imiscíveis. É definido pela seguinte relação:

$$
\mathrm{Ca}=\frac{\mu_{\mathrm{c}} \mathrm{V}_{\mathrm{m}}}{\sigma_{\text {int }}}
$$

em que $\mu_{c}$ é a viscosidade do líquido, $V_{m}$ é uma velocidade característica do escoamento e $\sigma_{\text {int }}$ é a tensão interfacial entre as duas fases. Quando Ca>>1, as forças ou tensões viscosas dominam sobre as forças capilares, e quando $\mathrm{Ca}<<1$, as forças capilares dominam sobre as forças ou tensões viscosas.

\subsection{3.}

\section{Fluxo em micro canais}

O escoamento de fluidos em dispositivos microfluídicos é caracterizado tipicamente por apresentar baixos números de Reynolds [9], que representa a razão entre forças inerciais e forças viscosas, e é definida como:

$$
\operatorname{Re}=\frac{\rho_{\mathrm{c}} \mathrm{V}_{\mathrm{m}} \mathrm{D}}{\mu_{\mathrm{c}}}
$$

em que $\rho_{c}$ é a densidade do fluido, $V_{m}$ é uma velocidade característica, $\mu_{c}$ é a viscosidade do fluido, e $D$ é um comprimento característico do escoamento. Como a dimensão dos escoamentos em microcanais é muito pequena ( $D \sim 10^{-4}$ $m), R e<<1$, as forças viscosas têm uma maior influência que as forças inerciais.

\subsection{4.}

\section{Mobilidade de um fluido no Escoamento através de micro capilares}

A mobilidade de um fluido $G$ no escoamento através de um micro canal é definida como a razão entre a vazão $\mathrm{q}$ e a diferença de pressão $\Delta \mathrm{P}$ entre as extremidades do canal: 
$\mathrm{q}=\mathrm{G} \Delta \mathrm{P}$

O efeito de gotas de óleo dispersas em uma fase aquosa no escoamento pode ser caracterizado por uma mudança na mobilidade do fluido.

É importante notar que na escala micrométrica a mobilidade de uma emulsão pode ser diferente da mobilidade da fase contínua mesmo que a viscosidade da emulsão seja bem próxima da viscosidade da fase contínua. $\mathrm{Na}$ escala micrométrica, o tamanho de gotas da fase dispersa é da mesma ordem de grandeza das dimensões do canal. Desta forma, a emulsão não pode ser tratada como uma fase única, caracterizada pela sua viscosidade. A análise deve ser feita como a de um escoamento bifásico.

Gotas de óleo dispersas em uma fase contínua podem levar a uma diminuição da mobilidade do fluido por dois mecanismos: viscoso e capilar.

O mecanismo viscoso aparece quando um fluido de baixa viscosidade (fase contínua), figura (2.1a) é substituído por outro fluido de maior viscosidade (fase dispersa), figura (2.1b), produzindo um incremento na queda de pressão $\Delta \mathrm{P}$ do escoamento:

$$
\left(\Delta \mathrm{P}=\mathrm{P}_{\mathrm{A}}-\mathrm{P}_{\mathrm{B}}\right)_{\text {Sem gota }}<\left(\Delta \mathrm{P}=\mathrm{P}_{\mathrm{A}}-\mathrm{P}_{\mathrm{B}}\right)_{\text {Com gota }}
$$

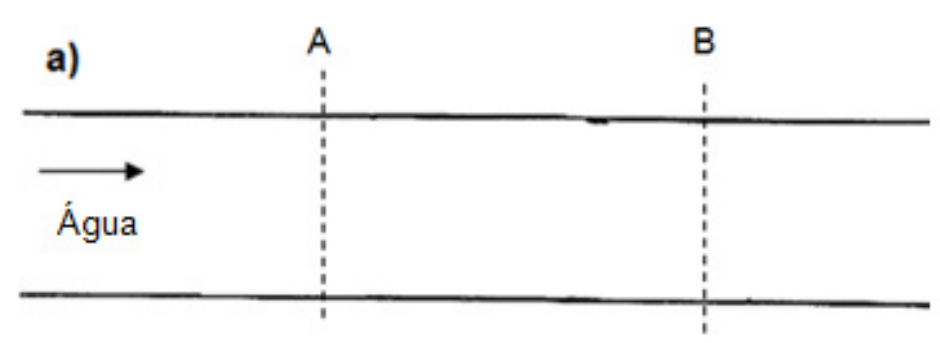

b)

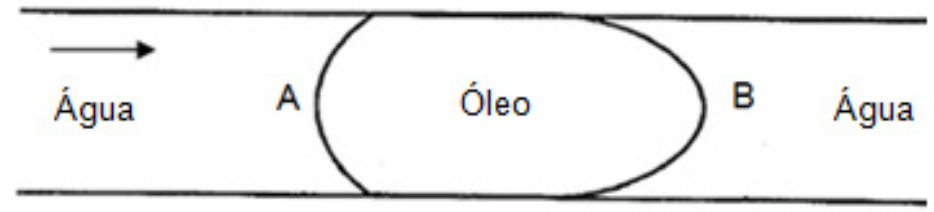

Figura 2.1: a) Escoamento sem gota. b) Escoamento com uma gota [10]. 
O mecanismo capilar acontece quando aparece uma mudança na curvatura da gota da fase dispersa, ou seja, uma deformação da gota, resultando no aumento da queda de pressão no escoamento de duas fases (bifásico).

A figura (2.2) ilustrada uma gota (óleo) da fase dispersa em condição estática, a diferença de pressão entre os pontos $A$ e $B$ do escoamento é dada pela seguinte equação (2.6):

$$
\Delta \mathrm{P}=\mathrm{P}_{\mathrm{A}}-\mathrm{P}_{\mathrm{B}}=\mathrm{P}_{\mathrm{CB}}-\mathrm{P}_{\mathrm{CA}},
$$

em que $P_{A}$ e $P_{B}$ são as pressões na fase contínua (água) nos pontos $A$ e $B$, e $P_{C A}$ e $P_{C B}$ são as pressões capilares nas interfaces $A$ e $B$ respectivamente. Como os ângulos de contacto $\theta$, os raios do micro canal $R$ e as tensões interfaciais $\sigma_{\text {int }}$ são os mesmos nos dois pontos $A$ e $B$, então as pressões capilares são iguais também, e iguais a:

$$
\mathrm{P}_{\mathrm{CA}}=\mathrm{P}_{\mathrm{CB}}=\frac{2 \sigma_{\mathrm{int}} \cos \theta}{\mathrm{R}}
$$

Agora substituindo a equação (2.7) na equação (2.6) obtemos uma diferença de pressão igual a zero, ou seja, a gota da fase dispersa ficará imóvel, submetida à mesma pressão nos pontos $\mathrm{A}$ e $\mathrm{B}$, dada pela equação (2.8):

$$
\Delta \mathrm{P}=\mathrm{P}_{\mathrm{A}}-\mathrm{P}_{\mathrm{B}}=\mathrm{P}_{\mathrm{CB}}-\mathrm{P}_{\mathrm{CA}}=0
$$

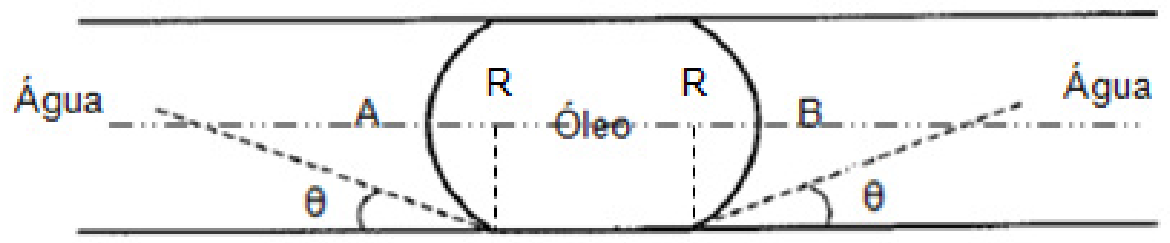

Figura 2.2: Gota parada em um micro canal reto [10].

No caso que uma gota da fase dispersa escoa através de um micro canal de seção reta constante, um gradiente de pressão externa aparecerá no escoamento, modificando o raio de curvatura da gota e o ângulo de contacto. $\mathrm{Na}$ 
figura (2.3) o raio de curvatura em $A$ é maior que em $B\left(\theta_{A}>\theta_{B}\right)$, e consequentemente a pressão capilar é menor em $A\left(P_{C A}<P_{C B}\right)$. As equações (2.9) e (2.10) descrevem as pressões capilares nas duas interfaces.

$$
\begin{aligned}
& \mathrm{P}_{\mathrm{CA}}=\frac{2 \sigma_{\text {int }} \cos \theta_{\mathrm{A}}}{\mathrm{R}}=\frac{2 \sigma_{\text {int }}}{\mathrm{R}_{\mathrm{A}}} \\
& \mathrm{P}_{\mathrm{CB}}=\frac{2 \sigma_{\text {int }} \cos \theta_{\mathrm{B}}}{\mathrm{R}}=\frac{2 \sigma_{\text {int }}}{\mathrm{R}_{\mathrm{B}}}
\end{aligned}
$$

Agora substituindo as equações (2.9) e (2.10) em (2.6) obtemos uma diferença de pressão diferente de zero, dada pela equação (2.11). Quando maior é o gradiente de pressão entre os pontos $A$ e $B$, maior é a deformação da gota ( $\theta_{\mathrm{A}}$ aumenta e $\theta_{\mathrm{B}}$ diminui).

$$
\Delta \mathrm{P}=\mathrm{P}_{\mathrm{A}}-\mathrm{P}_{\mathrm{B}}=\mathrm{P}_{\mathrm{CB}}-\mathrm{P}_{\mathrm{CA}}=\frac{2 \sigma_{\text {int }}}{\mathrm{R}_{\mathrm{B}}}-\frac{2 \sigma_{\text {int }}}{\mathrm{R}_{\mathrm{A}}}
$$

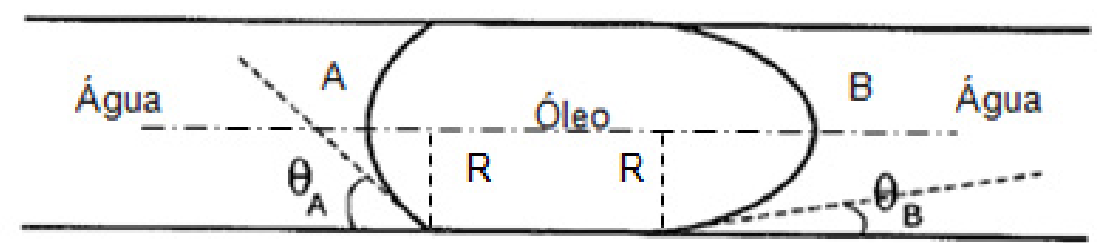

Figura 2.3: Gota escoando em um micro canal reto [10].

No caso que a gota da fase dispersa escoa através de um micro canal com garganta, figura (2.4), uma queda de pressão adicional aparecerá no escoamento, devido a uma redução do raio da curvatura na frente da gota $R_{g}$. Como decorrência, a pressão capilar em $B$ é maior que em $A$, e é descrita pela equação (2.12).

$$
\Delta \mathrm{P}=\mathrm{P}_{\mathrm{A}}-\mathrm{P}_{\mathrm{B}}=\mathrm{P}_{\mathrm{CB}}-\mathrm{P}_{\mathrm{CA}}=\frac{2 \sigma_{\text {int }} \cos \theta_{\mathrm{B}}}{\mathrm{R}_{\mathrm{g}}}-\frac{2 \sigma_{\text {int }} \cos \theta_{\mathrm{A}}}{\mathrm{R}}
$$




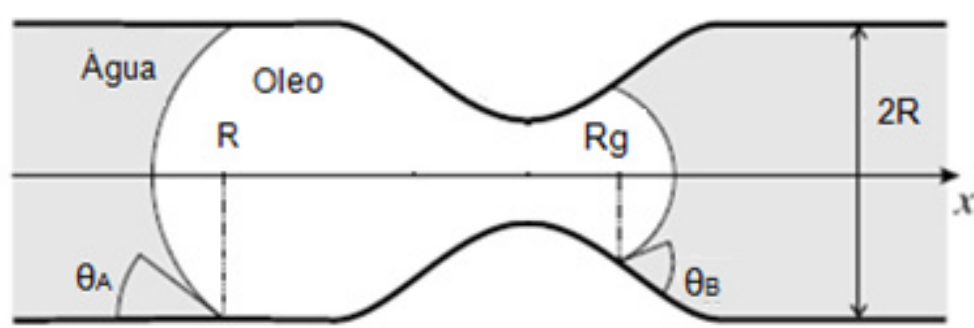

Figura 2.4: Gota escoando em um micro canal com garganta. 


\section{3 \\ Experimento}

\section{1.}

Introdução

Este capítulo apresenta uma descrição detalhada dos dispositivos e procedimentos experimentais utilizados no estudo. Os estudos foram realizados no Laboratório de Microhidrodinâmica e Escoamento em Meios Porosos do DEM da PUC-Rio.

Foram realizados experimentos de escoamento monofásico (água) e bifásico (gota de óleo suspensa em água) através de um micro canal de seção reta constante e de um micro canal com uma garganta.

A medição do campo de velocidade do escoamento monofásico através do canal com seção reta constante, no qual o perfil de velocidade é conhecido, foi realizado para verificar o erro obtido nas medições.

As dificuladades encontradas durante a realização dos experimentos são discutidas na parte final do capítulo.

\section{2.}

\section{Fundamentos do micro velocimetria por imagem de partículas ( $\mu \mathrm{PIV}$ )}

Existem várias técnicas experimentais para determinar campos de velocidade, essenciais para caracterizar os mais diferentes tipos de escoamento, como por exemplo, a técnica Velocimetria laser, Velocimetria por imagem de partículas, Micro velocimetria por imagem de partículas, entre outras.

A técnica $\mu$-PIV é uma extensão do sistema PIV. As principais diferenças entre estas duas técnicas é que as dimensões do escoamento de interesse no sistema $\mu$-PIV é muito menor, normalmente através de dispositivos microfluídicos bidimensionais.

O campo emergente da microfluídica vai encontrando novas aplicações, aumentando assim a necessidade de realizar medições precisas de parâmetros de fluxo na escala microscópica. O sistema $\mu$-PIV é viável para a medição de campos de velocidades nesta escala, incorporando novas técnicas de óptica. 
Segundo Wereley [9] existem três fatores que distinguem o sistema $\mu$-PIV do PIV. Primeiro, as partículas traçadoras são pequenas em comparação com o comprimento de onda de iluminação, exigindo a aplicação de imagem por fluorescência em micro-PIV. Segundo, devido ao tamanho pequeno da partícula, o movimento browniano pode se tornar uma fonte significativa de erro aleatório na medição do deslocamento das partículas entre imagens. Terceiro, em PIV o escoamento é iluminado em um plano gerado pela luz do laser. Ao contrário, em micro-PIV todo o volume do escoamento de interesse é iluminado.

\subsection{1. \\ Principio de Funcionamento $\mu$ PIV}

Em $\mu$-PIV a velocidade do fluido é determinada a partir do deslocamento das partículas traçadoras. As partículas traçadoras são consideradas como ideal quando elas exatamente seguem o movimento do fluido, não alteram o fluxo ou as propriedades do fluido e não interagem entre si. A velocidade é medida indiretamente, como o deslocamento $\Delta \mathrm{x}$ das partículas traçadoras em um intervalo de tempo finito $\Delta \mathrm{t}$ :

$$
\mathrm{U}=\frac{\Delta \mathrm{x}}{\Delta \mathrm{t}}
$$

em que $U$ é a velocidade da partícula traçadora. Para partículas traçadoras ideais, a velocidade traçadora $U$ é igual à velocidade local do fluido. No entanto, em uma situação prática o conceito de tracadoras ideais só pode ser aproximado. Além disso, a equação (3.1) implica que o campo de deslocamento só fornece informações sobre a velocidade média ao longo da trajetória em um tempo $\Delta \mathrm{t}$.

O sistema típico $\mu$-PIV consiste de uma fonte de luz pulsada, usualmente um laser, que é sincronizado com uma câmera CCD que registra duas imagens sucessivas em uma unidade de tempo. A sincronização é realizada através de um sincronizador, na qual o primeiro pulso do laser é definido ao final da primeira exposição da câmera (Frame A) e o segundo pulso é definido em um tempo arbitrário na segunda exposição da câmera (Frame B). Desta forma o intervalo de tempo $\Delta \mathrm{t}$ é independente da frequência da câmera, mas definido pelo 
intervalo de tempo entre os dois pulsos do laser sincronizado. Para escoamentos com velocidades altas, o segundo pulso laser é posicionado estrategicamente ao inicio da segunda exposição da câmera, esta técnica é conhecida como "frame straddling", como mostrado esquematicamente na figura (3.1).

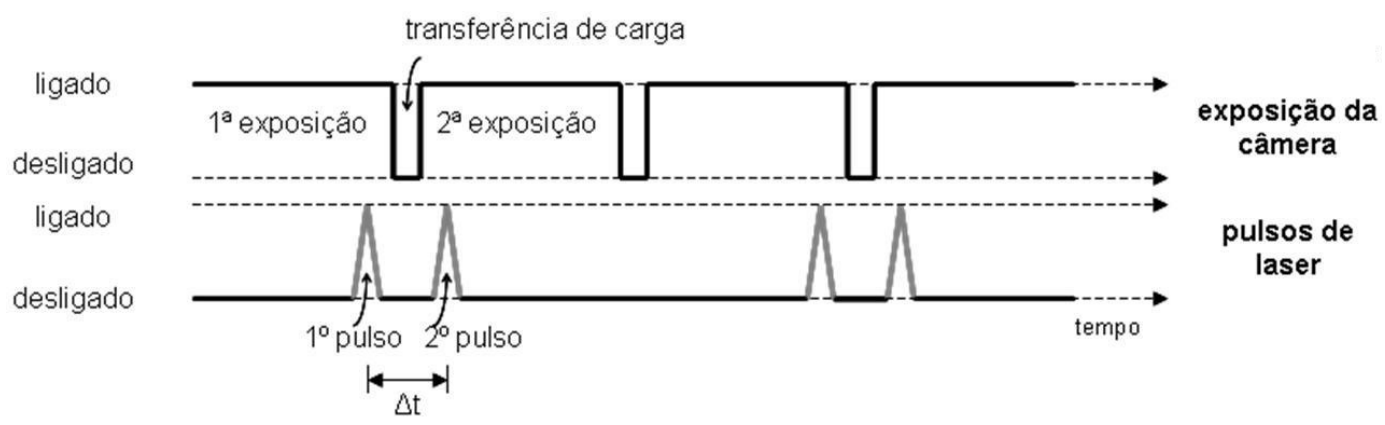

Figura 3.1: Sincronização do laser com a câmera CCD.

O feixe do laser é expandido de uma forma adequada por meio de um feixe de expansão ou óptica apropriada, e geralmente é levado ao microscópio através de uma fibra óptica. Em seguida, o feixe de luz ingressa no microscópio através de uma abertura em direção ao espelho dicróico. O espelho dicróico funciona como um filtro passa alta para certo comprimento de onda $\lambda_{\text {passo }}$, ou seja, valores maiores ao $\lambda_{\text {passo }}$ serão transmitidos, e valores menores ao $\lambda_{\text {passo }}$ serão refletidos em um ângulo de $90^{\circ}$. Geralmente o comprimento de onda do laser $\lambda_{\text {laser }}$ é menor que o $\lambda_{\text {passo, }}$, portanto, o feixe do laser será refletido pelo espelho dicróico e logo transmitido através da objetiva do microscópio, até atingir as partículas fluorescentes que se encontram dispersas em um fluido dentro de um dispositivo microfluídico.

Finalmente, a luz de fluorescência emitida pelas partículas e a luz refletida pelas superfícies do dispositivo microfluídico passam através da objetiva do microscópio, para atingir novamente o espelho dicróico. O comprimento de onda da luz refletida $\lambda_{\text {laser }}$ é menor que o comprimento de onda do filtro $\lambda_{\text {passo, }}$, por tanto, esta luz (ruído) é refletida pelo espelho dicróico. Entretanto o comprimento de onda da luz de fluorescência emitida pelas partículas $\lambda_{\text {emitida }}$ é maior que o

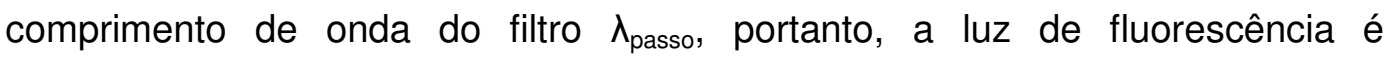
transmitida pelo filtro e é gravada na câmera CCD. Uma ilustração esquemática de um sistema $\mu$-PIV típico é mostrada na figura (3.2). 


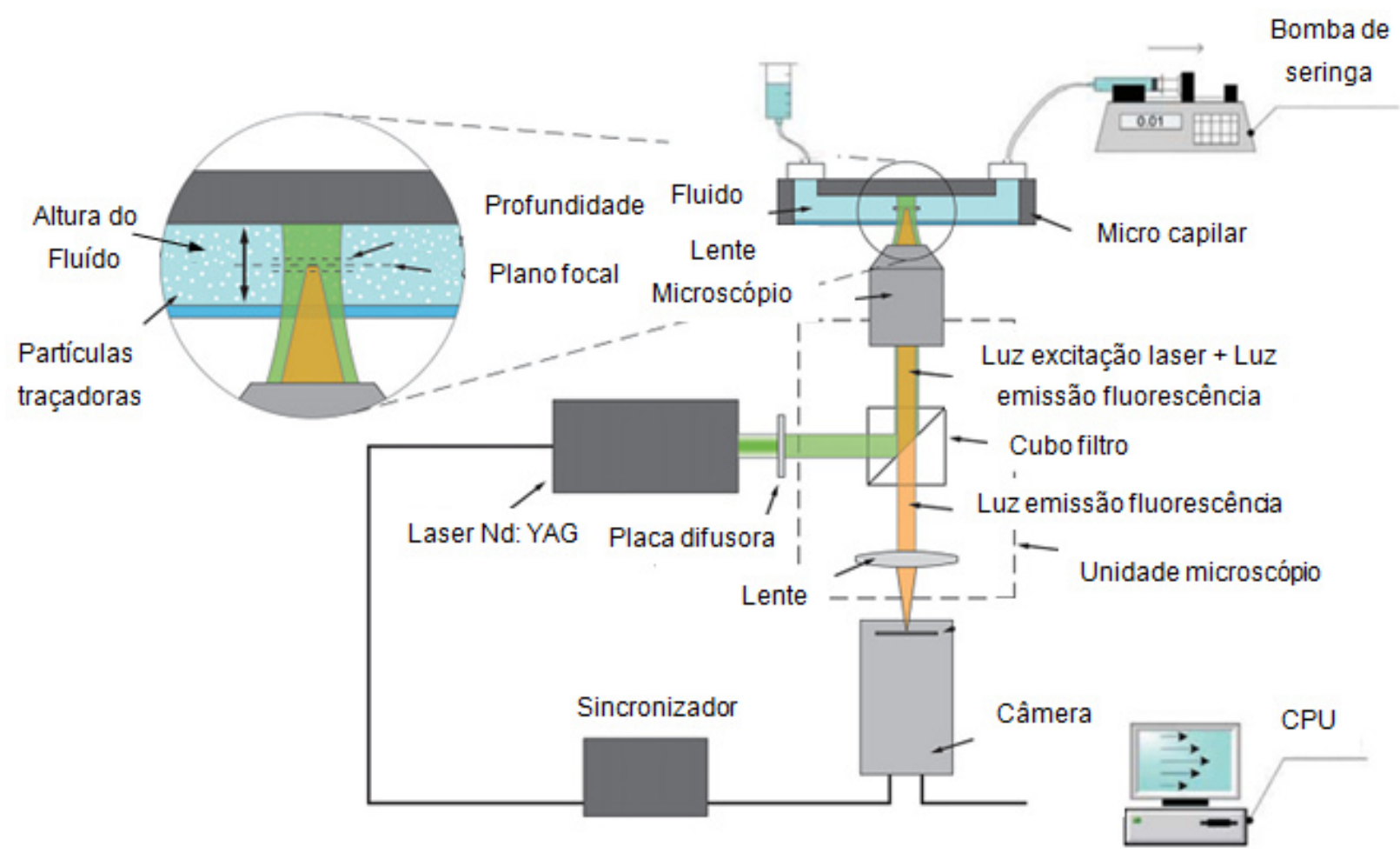

Figura 3.2: Representação esquemática de um sistema $\mu$-PIV [11].

\subsection{2. \\ Partículas}

Em micro-PIV, o tamanho das partículas semeadas deve ser suficientemente pequeno para poder seguir fielmente o escoamento, sem interromper o campo de escoamento, e por outro lado suficientemente grandes para serem visualizadas e atenuar os efeitos do movimento browniano, a fim de evitar erros aleatórios no deslocamento das partículas [9].

O movimento browniano é um fator importante quando se trata de partículas de tamanho da ordem de $1 \mu \mathrm{m}$ ou menores. $\mathrm{O}$ erro relativo devido ao movimento browniano das partículas $\varepsilon_{B}$ pode ser reduzido utilizando a maior quantidade de imagens ou partículas nas janelas de interrogação mediante a seguinte expressão: $\varepsilon_{B} / N^{1 / 2}$, em que $N$ é o número total de partículas na média, ou seja, o número de partículas nas janelas de interrogação multiplicada pelo número de imagens instantâneas que foram utilizadas na média amostral [10]. 


\subsection{3.}

\section{Concentração de Partículas}

A escolha das partículas para um experimento micro-PIV requer várias considerações.

As partículas devem acompanhar fielmente o movimento do fluido, sem exercer influência sobre ele. Devido a esta razão, as partículas utilizadas devem ter uma densidade próxima à densidade do fluido, para evitar os efeitos gravitacionais (sedimentação ou flutuação). O número adimensional de Stokes Stk caracteriza o comportamento das partículas suspensas no escoamento e é definida como:

$$
\mathrm{Stk}=\frac{\tau \times \mathrm{U}_{0}}{\mathrm{~d}_{\mathrm{C}}},
$$

em que $U_{o}$ é a velocidade do fluido longe do obstáculo ou corrente livre, $\tau$ é o tempo de relaxação da partícula e $d_{c}$ é a dimensão característica do obstáculo, para Stk $<<1$ as partículas seguiram as linhas de corrente do fluido.

A concentração de partículas é feita para obedecer à equação de difusão da partícula (difusão de massa), definido pelo número adimensional Peclet Pe.

$$
\mathrm{Pe}=\frac{\mathrm{U} \times \mathrm{L}}{\mathrm{D}_{0}},
$$

em que $U$ é a velocidade da partícula, $L$ é o comprimento característico e Do é o coeficiente de difusão de massa. No presente trabalho, o fluido utilizado foi água com surfactante, e as partículas foram de poliestireno com uma densidade de $1,05 \mathrm{~g} / \mathrm{cm}^{3}$ [12].

A propriedade de fluorescência das partículas é importante para obter uma boa intensidade de luz emitida pelas partículas nas imagens. O comprimento de onda de excitação do corante fluorescente dentro das partículas deve se aproximar ao comprimento de onda do laser utilizado para iluminar o escoamento, a fim de garantir uma elevada intensidade de fluorescência das partículas.

As partículas localizadas fora do plano focal geram ruído no fundo da imagem, reduzindo assim a relação sinal/ruído (SNR) nas imagens. Meinhart [13] identificou dois parâmetros que podem influenciar na SNR, a concentração de 
partículas no fluido e a profundidade da seção avaliada do dispositivo microfluídico; também demonstrou que reduzindo a profundidade do canal avaliado ou a concentração de partículas pode se obtiver um maior SNR, como apresentado na tabela (3.1).

\begin{tabular}{|c|c|c|c|c|}
\hline \multirow{2}{*}{$\begin{array}{c}\text { Teste - seção de } \\
\text { profundidade }(\boldsymbol{\mu m})\end{array}$} & \multicolumn{4}{|c|}{ Concentração de partículas por volume (\%) } \\
\cline { 2 - 5 } & $\mathbf{0 , 0 1}$ & $\mathbf{0 , 0 2}$ & $\mathbf{0 , 0 4}$ & $\mathbf{0 , 0 8}$ \\
\hline $\mathbf{2 5}$ & 2,2 & 2,1 & 2,0 & 1,9 \\
\hline $\mathbf{5 0}$ & 1,9 & 1,7 & 1,4 & 1,2 \\
\hline $\mathbf{1 2 5}$ & 1,5 & 1,4 & 1,2 & 1,1 \\
\hline $\mathbf{1 7 0}$ & 1,3 & 1,2 & 1,1 & 1,0 \\
\hline
\end{tabular}

Tabela 3.1: Valores de SNR para diferentes concentrações e profundidades no canal [13].

Geralmente, as dimensões geométricas do dispositivo microfluídico já estão pré-definidas, então, só o parâmetro de concentração de partículas pode ser ajustado. Uma boa escolha deve ser realizada a fim de obter imagens de qualidade, para sua a posterior análise de correlação. Uma baixa concentração de partículas pode levar a uma resolução espacial ruim. A fim de evitar a perda de resolução espacial são utilizadas janelas de interrogação especial ou técnicas de processamento aplicadas no sistema micro-PIV.

\subsection{4.}

\section{Iluminação no Sistema $\mu$ PIV}

A principal diferença entre o sistema $\mu$-PIV e o sistema PIV convencional é a iluminação do escoamento em estudo. No sistema PIV, as partículas traçadoras são iluminadas no escoamento através de um plano fino de luz do laser, sendo a profundidade do campo, determinada pela espessura do plano de luz, como apresentado esquematicamente na figura (3.3a).

Para os estudos a uma escala micro é impossível produzir planos de luz de espessuras de 1-10 $\mu \mathrm{m}$ [14]. Devido a esta limitação, no sistema $\mu$-PIV é necessário iluminar todo o volume de interesse no escoamento, figura (3.3b). No plano de interesse os valores $\Delta x$ e $\Delta y$ representam o tamanho de pixels na 
matriz, e $\Delta z$ a profundidade do plano focal determinada pelas características focal da objetiva do microscópio [15]. As partículas não localizadas dentro desta profundidade do plano focal podem influir no processamento do sinal, proporcionando ruído indesejável, que deve ser minimizada através de um tratamento estatístico sobre os dados experimentais.

a)

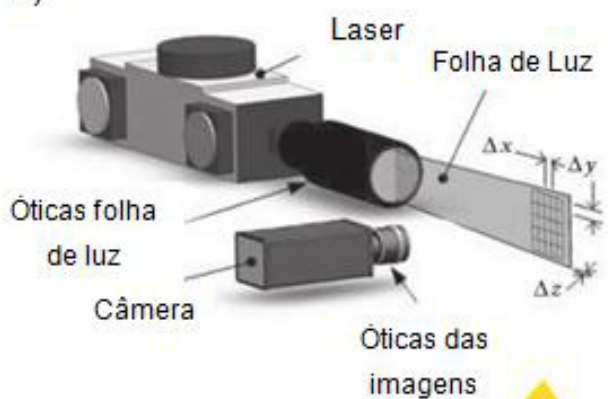

imagens

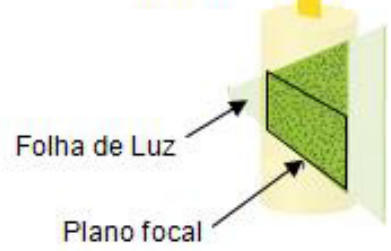

b)
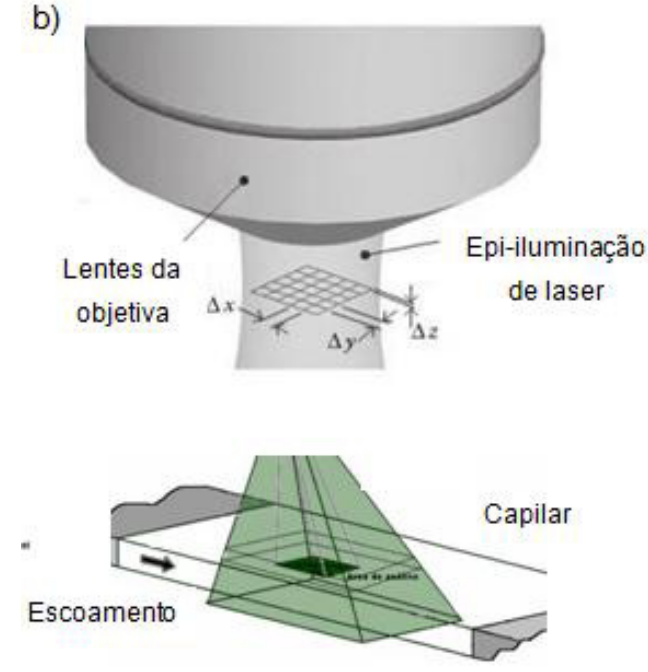

Figura 3.3: a) Iluminação no sistema PIV. b) lluminação no sistema $\mu$-PIV. [16]

O volume de iluminação pode ser aplicado através de duas configurações diferentes: lluminação por fluorescência "Fluorescente mode" e iluminação espalhada "Scattered mode", como é apresentado na figura (3.4). Nos experimentos, a iluminação por fluorescência foi utilizada devido às propriedades fluorescentes das partículas. A câmera produz imagens de campo escuro e as partículas apareceram brilhantes no fundo. A iluminação espalhada é uma luz refletida (ruído), portanto não é adequado no sistema $\mu$-PIV. 

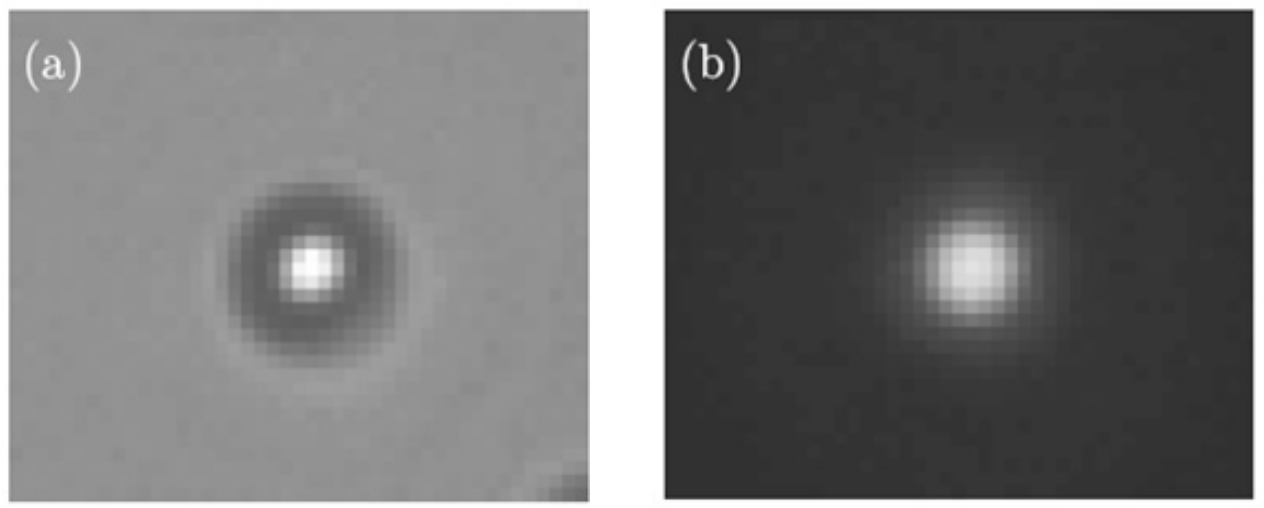

Figura 3.4: a) Modo espalhada. b) Modo fluorescência [17].

\subsection{5. \\ Profundidade de Campo}

A profundidade de um volume de luz que ilumina um escoamento pode ser definida como, duas vezes a distância a partir do centro do plano focal até uma posição onde as partículas na imagem ainda aparecem focadas, ou seja, com uma intensidade suficiente que possa contribuir significativamente à medição da velocidade. Valores menores a 10\% da intensidade máxima das partículas focadas não terão influência significativa sobre o campo de velocidade, ademais deve se considerar o diâmetro da partícula $d_{p}$, devido aos efeitos de difração e a geometria da óptica [13]. A profundidade $\delta_{Z m}$ pode ser estimada pela equação (3.4), onde o primeiro termo é devido ao efeito da difração, o segundo termo à geometria da óptica e o terceiro termo ao tamanho da partícula, $n$ é o índice refração do fluido entre o dispositivo microfluídico e as lentes da objetiva, $\lambda_{0}$ é o comprimento de onda da luz emitida, "NA" é a abertura numérica das lentes da objetiva, e " $\theta$ " é o semi-ângulo do cone da luz coletada.

$$
\delta \mathrm{z}_{\mathrm{m}}=\frac{3 \mathrm{n} \lambda_{\mathrm{o}}}{(\mathrm{NA})^{2}}+\frac{2.16 \mathrm{~d}_{\mathrm{p}}}{\tan \theta}+\mathrm{d}_{\mathrm{p}}
$$

A luz proveniente da lente da objetiva ilumina o volume da seção em estudo, a qual é definida pelo cone de iluminação. Todas as partículas no cone de iluminação emitem luz, porém apenas as partículas dentro da profundidade $\delta_{Z m}$ são suficientemente focadas e contribuem para função de correlação entre 
imagens consecutivas. As demais partículas iluminadas fora da profundidade do plano focal contribuem para o sinal do ruído no fundo da imagem.

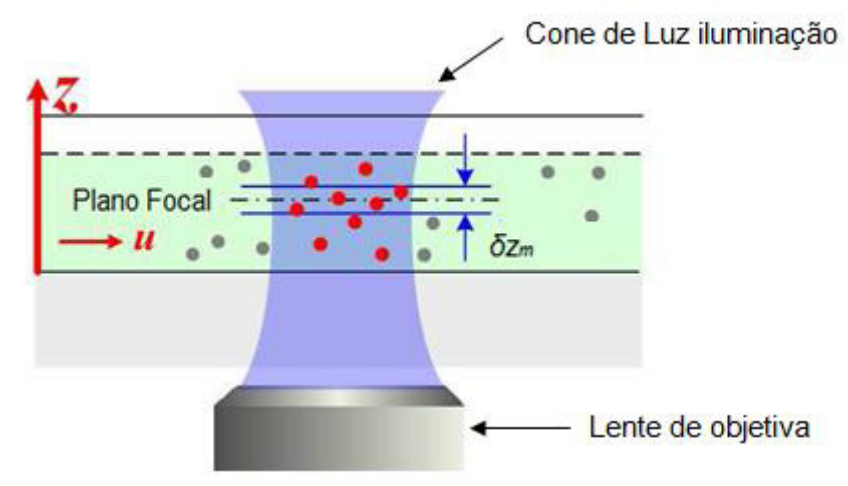

Figura 3.5: Profundidade do campo no sistema $\mu$-PIV.

\subsection{6. \\ Processamento de Imagens}

\subsubsection{1. \\ Etapa de Pré-processamento}

O propósito desta etapa é melhorar a aparência das imagens capturadas e aumentar a relação sinal/ruído, detectando e eliminando as partículas fixas, paredes e manchas produzidas pela reflexão das partículas localizadas fora do plano focal, que contribuem para o ruído de fundo. Existem várias técnicas de pré-processamento disponíveis, como por exemplo, "filtros passa-baixa e passaalta", "gerador de imagem" que cria uma única imagem a partir de várias imagens usando as intensidades mínimas, médias e máximas dos pixels, "image calculator" que realiza operações aritméticas entre duas imagens, etc.

No presente trabalho, uma imagem de fundo de intensidade média foi criada a partir das imagens originais usando o operador "Gerador de imagem", depois essa intensidade de fundo foi removida de cada imagen original através do operador "Calculator-Substração", os ambos operadores fornecidos no software $\mathrm{TSI}^{\boxplus}$. A figura (3.6a) apresenta $\mathrm{n}$ imagens originais que contém partículas e ruído de fundo. Na figura (3.6b) é gerada uma imagem do mesmo tamanho, e cada valor do seu pixel é calculada, a partir do pixel de intensidade mínimo localizado na mesma posição na sequência de imagens originais. A 
figura (3.6c) apresenta as imagens depois do processo de subtração do fundo das imagens originais, ou seja, a subtração das intensidades dos pixels das imagens originais com respeito à intensidade dos pixels da imagem de intensidade mínima.
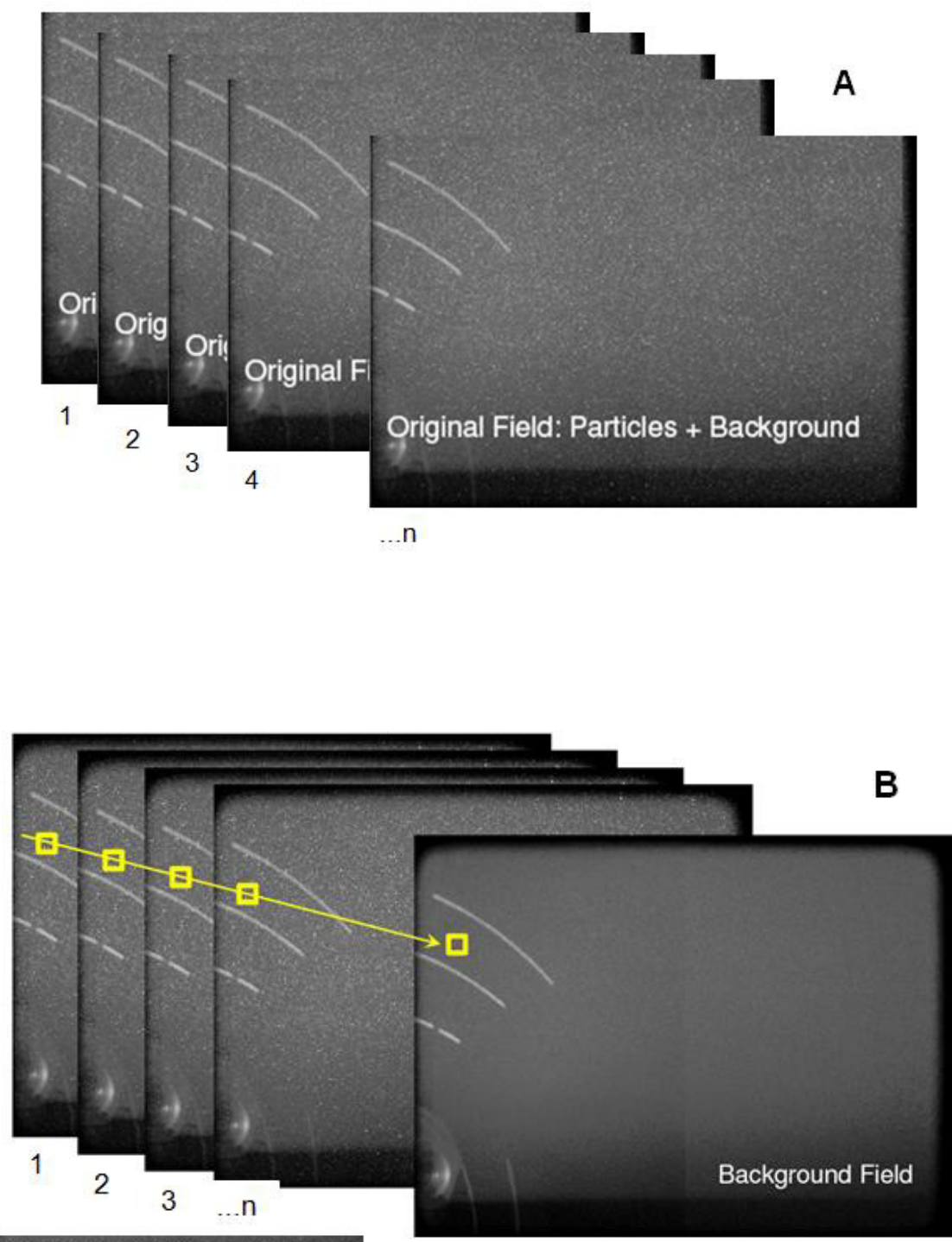

Original Field: Particles + Background 


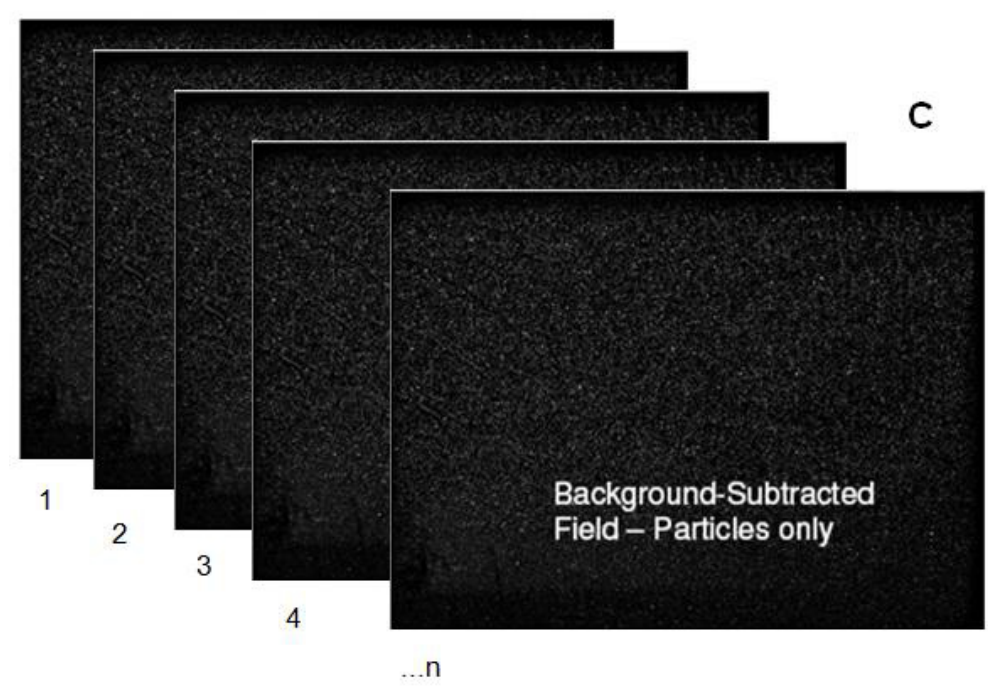

Figura 3.6: a) Imagens sem pré-processamento. b) Processo de subtração de fundo das imagens. c) Imagens com pré-processamento. [18].

\subsubsection{2. Etapa de Processamento}

A técnica PIV foi desenvolvida na década dos 80 por Adrian [19], e os primeiros estudos realizados com a técnica $\mu$-PIV foram iniciados por Santiago em 1998 [9]. Ambas as técnicas são baseadas na determinação da velocidade de um fluido em uma área de observação, através da quantificação da distância percorrida pelas partículas em um dado intervalo de tempo.

O deslocamento bidimensional das partículas é determinado através de um par de imagens consecutivas (Frame A e Frame B), separados por um intervalo de tempo $\Delta t$. Um par de imagens pode conter centenas ou milhares de partículas, devido a isto, as imagens são divididas em subáreas chamadas de janelas de interrogação ou spots. A área onde desejamos determinar a velocidade é selecionada na primeira imagem (Frame A) chamada "Janela base", e é correlacionada com sua correspondente na segunda imagem (Frame B) chamada "janela de busca". As janelas de busca e de base devem ser iguais, e a escolha da dimensão de cada janela depende do escoamento, como apresentado esquematicamente na figura (3.7). 

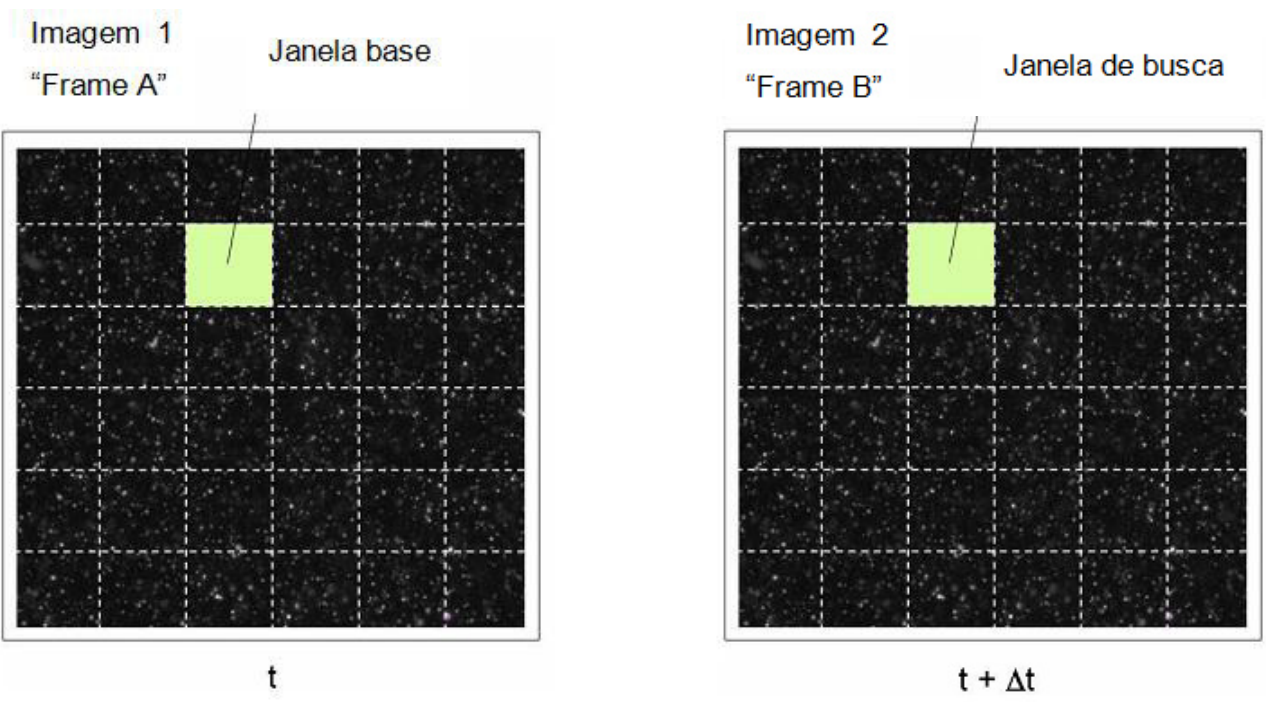

Figura 3.7: Janelas de interrogação base e de busca para correlação cruzada.

\subsubsection{1. \\ Técnica de Correlação Cruzada}

A correlação cruzada consiste em efetuar a correlação entre as janelas de interrogação de duas imagens consecutivas do sistema $\mu$-PIV, correspondentes a dois pulsos laser. Como a técnica de correlação cruzada, as imagens são divididas em subáreas pequenas chamadas janelas de interrogação como foi dito anteriormente, 0 que permite calcular 0 vetor de deslocamento correspondente a cada par de janelas usando técnicas estatísticas de correlação. Teoricamente, todas as partículas dentro desta janela devem se deslocar de maneira homogênea (mesma direção, magnitude e sentido). No entanto, a seleção do tamanho da janela deve possuir cerca de uma dezena de partículas para se obtiver uma boa correlação. O algoritmo fundamental de correlação cruzada utiliza só um par de imagens [20], como é apresentado na figura (3.8). 


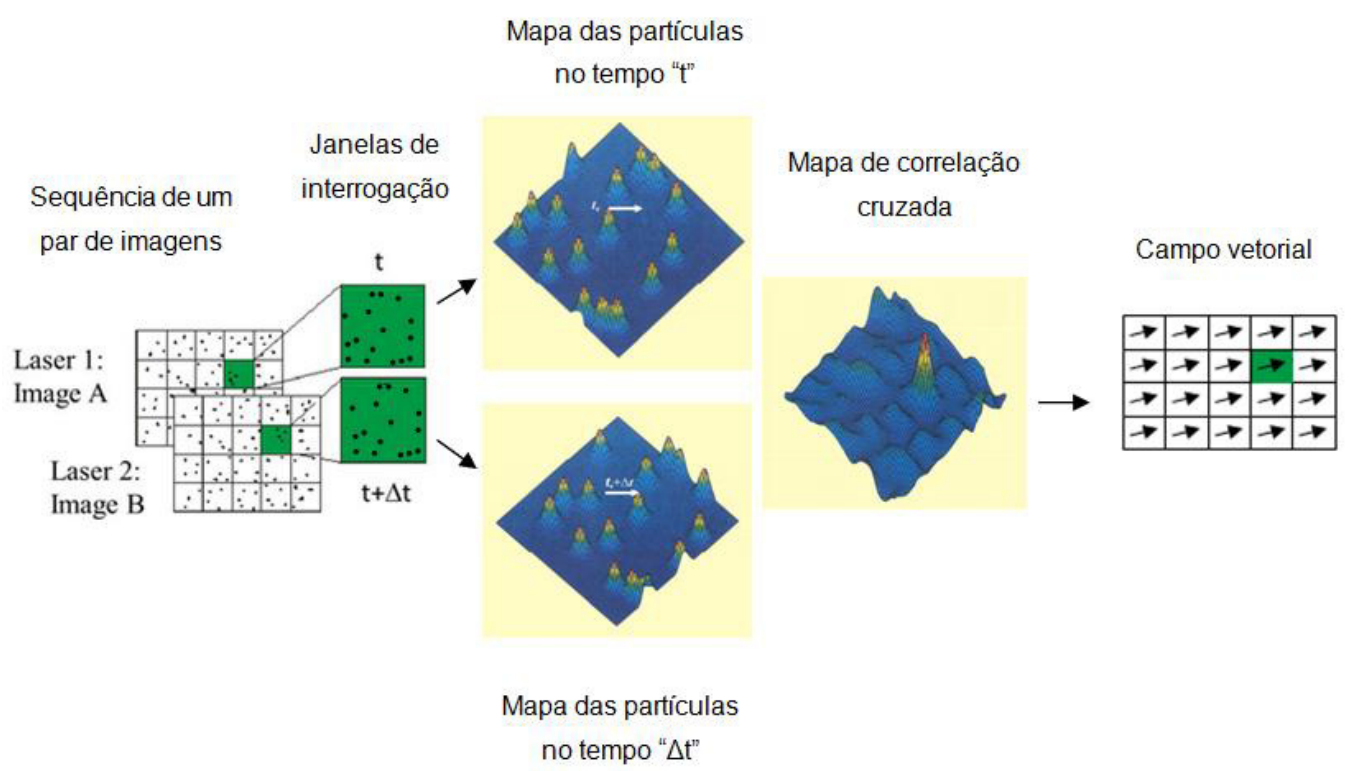

Figura 3.8: Correlação cruzada de um par de imagens [20].

A localização do pico maior no mapa de correlação cruzada dá a medida do deslocamento das partículas contidas na janela de interrogação analisada. A janela base é selecionada da imagem $N^{\circ} 1$ e a janela de busca obtida da imagem $N^{\circ} 2$. A janela base da imagem $N^{\circ} 1$ é sobreposta em cada posição dentro da janela de busca da imagem $\mathrm{N}^{\circ} 2$, com resolução de 1 pixel. A nova posição da janela base apresenta o maior coeficiente de correlação R. O deslocamento médio das partículas é a distância entre a posição da janela de busca e a nova posição da janela base onde ocorre o pico mais alto da correlação cruzada, ou seja, o maior valor do coeficiente $R$.

Para melhorar a relação sinal/ruído em escoamentos em regime permanente é utilizado o algoritmo de correlação média, denominada também média amostral (ensemble average), que determina o vetor mapa baseado na correlação média de vários pares de imagens que possam ser usados. A localização do pico maior pode ser calculada usando a função de correlação [21]. Esta técnica de correlação não tem nenhum limite com o número de imagens aplicadas no procedimento da média, porque a operação é executada nas funções de correlação e não sobre as imagens das partículas propriamente dita. Na realidade, o maior número de imagens contribui para a melhora dos valores de vetor de velocidade média. Este método é representando esquematicamente na figura (3.9). 


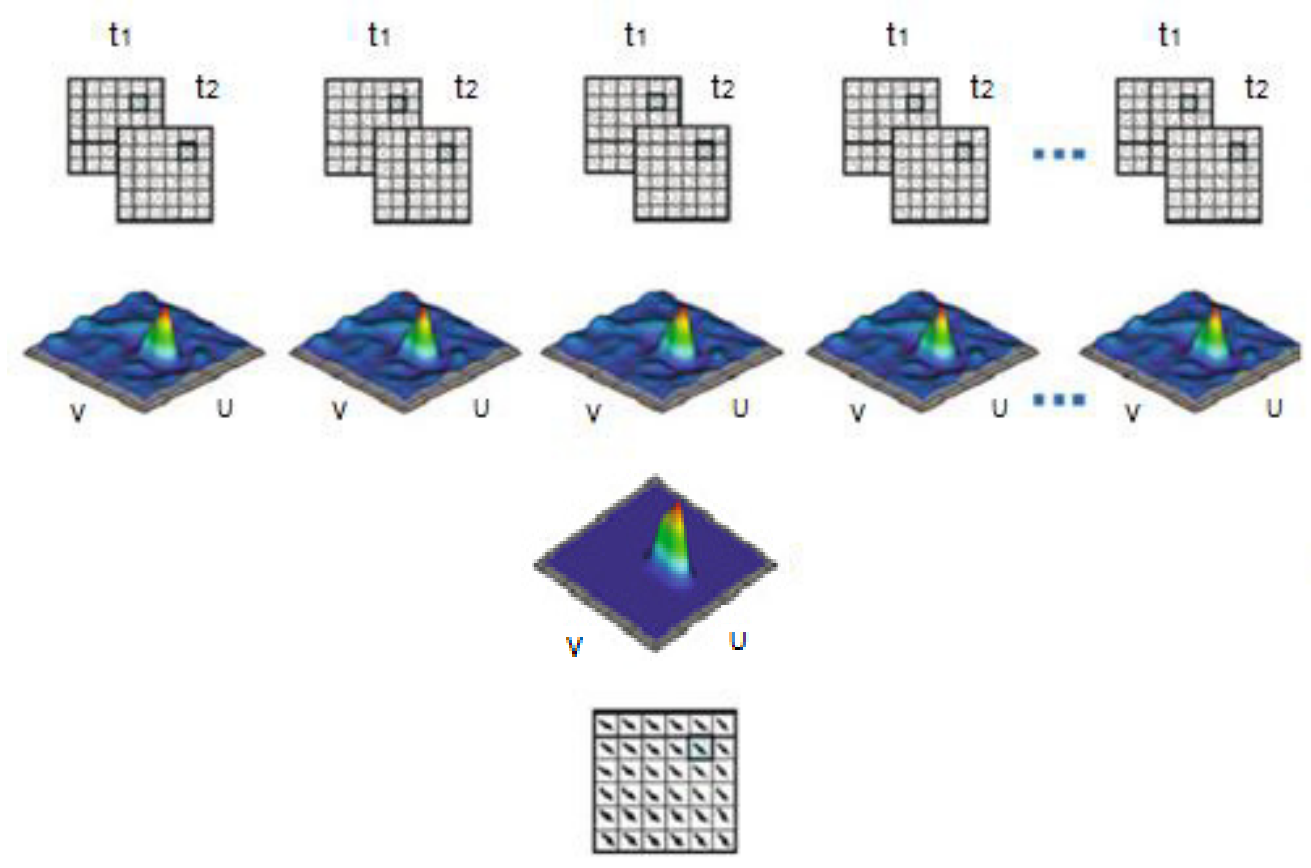

Sequência de pares de imagens

Mapas de correlação cruzada instantâneos

Mapa de correlação média

Campo vetorial tempo médio

Figura 3.9: Correlação cruzada de vários campos instantâneos "Média Amostral" [22].

\subsubsection{2. Interpolação de sub-pixels}

Como todas as magnitudes utilizadas no software de análise das imagens são variáveis discretas, na correlação de mapa, o vetor deslocamento determinado possui valores inteiros (pixels), com uma incerteza de +-1/2 pixel, para as duas componentes $\mathrm{x}$ e y. Em geral, tais valores não correspondem à localização exata do pico de correlação, senão valores inteiros mais próximos aos de interesse. A posição do pico de correlação é medida com melhor precisão usando interpolações sub-pixels.

Existem vários métodos para determinar o deslocamento das partículas em sub-pixels, como por exemplo, o ajuste bi-linear, parabólico e Gaussiano. No presente trabalho, o ajuste "Gaussiano" foi utilizado e localiza o pico de correlação com resolução sub-pixel ajustando uma curva gaussiana no pixel mais alto $(R)$ e nos quatro vizinhos adjacentes, figura (3.10c). Foram feitos dois ajustes de três-pontos, um na direção $X$, com $R$ e o pixel adjacente à direita $e$ esquerda, figura (3.10a); e outro na direção $Y$, com $R$ e o pixel adjacente acima $e$ abaixo, figura (3.10b). Este procedimento pode determinar deslocamento com 
resolução de até 1/20 pixel. As equações (3.5) e (3.6) determinam a posição nas duas direções do pico a nível sub-pixel.

$$
\begin{aligned}
& \mathrm{x}_{0}=\mathrm{i}+\frac{\ln \mathrm{R}_{(\mathrm{x}-1, \mathrm{y})}-\ln \mathrm{R}_{(\mathrm{x}+1, \mathrm{y})}}{2 \ln \mathrm{R}_{(\mathrm{x}-1, \mathrm{y})}-4 \ln \mathrm{R}_{(\mathrm{x}, \mathrm{y})}+2 \ln \mathrm{R}_{(\mathrm{x}+1, \mathrm{y})}}, \\
& \mathrm{y}_{0}=\mathrm{j}+\frac{\ln \mathrm{R}_{(\mathrm{x}, \mathrm{y}-1)}-\ln \mathrm{R}_{(\mathrm{x}, \mathrm{y}+1)}}{2 \ln \mathrm{R}_{(\mathrm{x}, \mathrm{y}-1)}-4 \ln \mathrm{R}_{(\mathrm{x}, \mathrm{y})}+2 \ln \mathrm{R}_{(\mathrm{x}, \mathrm{y}+1)}} .
\end{aligned}
$$

em que, $x_{0}$ e $y_{0}$ são os deslocamentos totais em cada direção, as variáveis i e j correspondem aos valores de deslocamento inteiro na direção $x$ e $y$, e R representa os valores de intensidade dos pixels vizinhos.
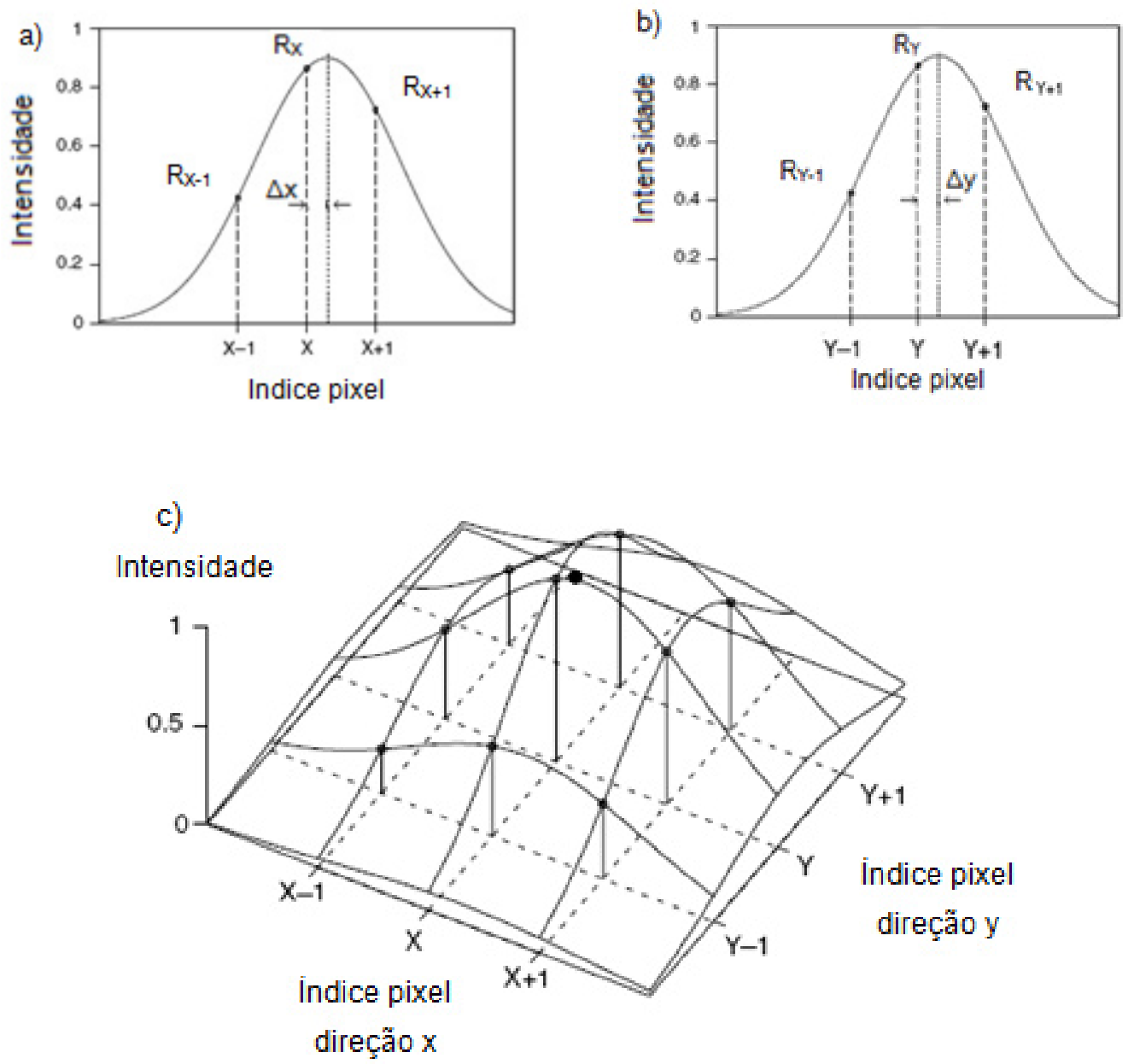

Figura 3.10: a) Deslocamento sub-pixel na direção x. b) Deslocamento sub-pixel na direção y. c) Ajuste gaussiano em 2-D. 


\subsubsection{3.}

\section{Etapa de Pós-processamento}

Uma vez obtidos os dados da etapa de processamento, algoritmos especiais devem ser utilizados para detectar, eliminar e substituir os vetores incorretos do campo de velocidade. A etapa é conhecida como pósprocessamento e é dividida em duas etapas:

\subsubsection{1.}

\section{Validação dos dados}

Os métodos mais comuns de validação usados são: Media global, Media local, Mediana local e Histograma global [23] [24]. A técnica de validação vetor mediana local foi empregada, a qual utiliza a mediana de todos os seus vetores de vizinhança de cada vetor para calcular um vetor de referência para validação. $\mathrm{Na}$ figura (3.11) é apresentada uma matriz que representa o mapa de vetores de um vetor $\mathrm{V}(\mathrm{i}, \mathrm{j})$ com a sua vizinhança (ao redor do vetor). Se a diferença entre um vetor em magnitude e direção com respeito aos seus vizinhos é maior que um limite determinado, então o vetor é considerado incorreto e é eliminado. Depois da avaliação das imagens, pode-se distinguir com uma simples observação o número de vetores incorretos.

\subsubsection{2. \\ Substituição dos dados incorretos}

Depois da validação é necessário substituir com novos vetores todos os espaços dos vetores incorretos que foram eliminados.

A técnica vetor condição foi empregada, que utiliza a média dos vetores de vizinhança ao redor do buraco para preenchê-los. O limite utilizado pode ser definido como uma porcentagem da diferença entre um vetor e o desvio padrão dos seus vizinhos. Na figura (3.12) é mostrado um mapa típico de vetores antes e depois da validação e substituição. 


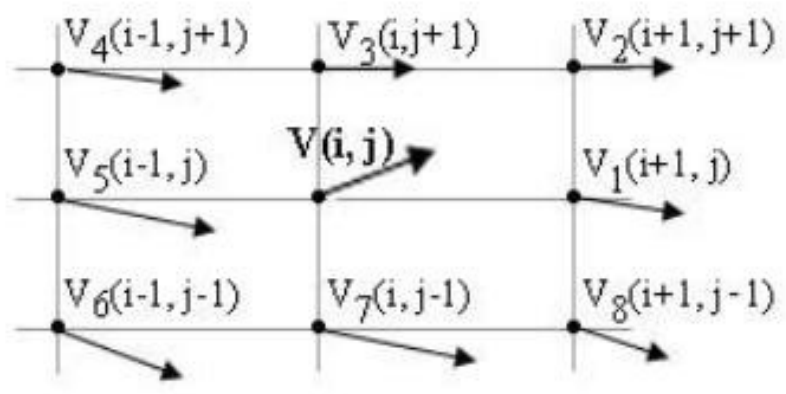

Figura 3.11: Matriz de vetores.

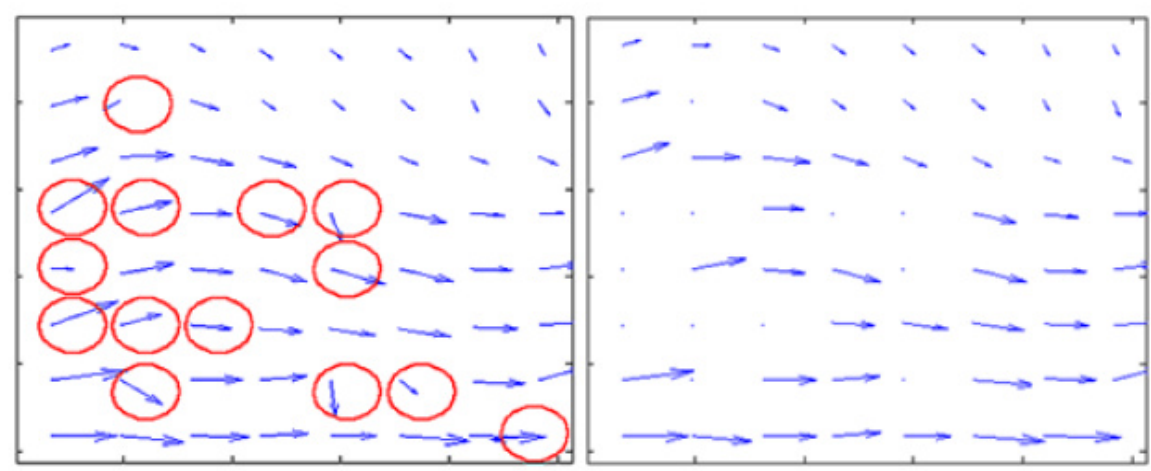

(a)

(b)

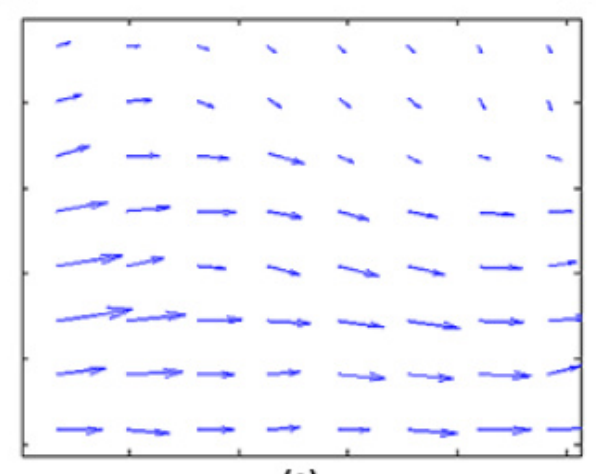

(c)

Figura 3.12: a) Mapa com vetores incorretos. b) Mapa sem vetores incorretos. c) Mapa com vetores substituídos. 


\section{3.}

Medição do Campo de Velocidade do Escoamento Monofásico

\subsection{1.}

\section{Bancada Experimental}

A bancada experimental utilizada é composta de dois principais sistemas:

- Sistema de Injeção.

- Sistema $\mu$-PIV (micro-velocimetria por imagem de partículas).

A figura (3.13) apresenta um esquema simples do experimento, indicando os equipamentos que foram utilizados.

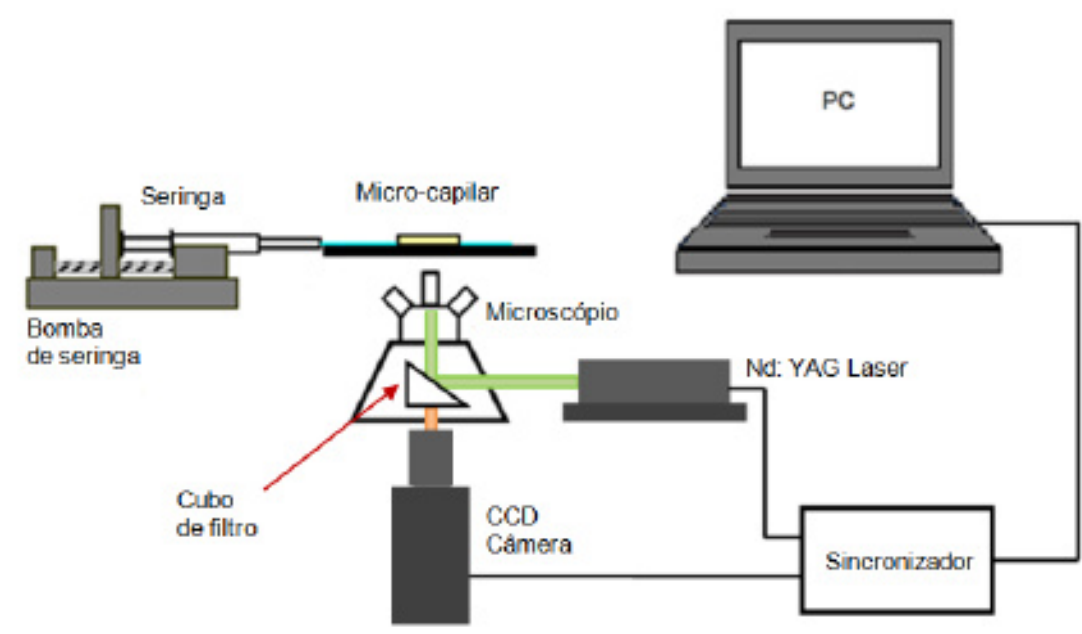

Figura 3.13: Esquema da bancada experimental do sistema $\mu$-PIV para a injeção da fase contínua e a medição do campo de velocidade do escoamento [36].

\subsubsection{1.}

\section{Sistema de Injeção}

O sistema de injeção é composto do dispositivo microfluídico, bomba de seringa, seringa e acessórios para a montagem do circuito. A figura (3.14) apresenta a montagem do sistema de injeção. 

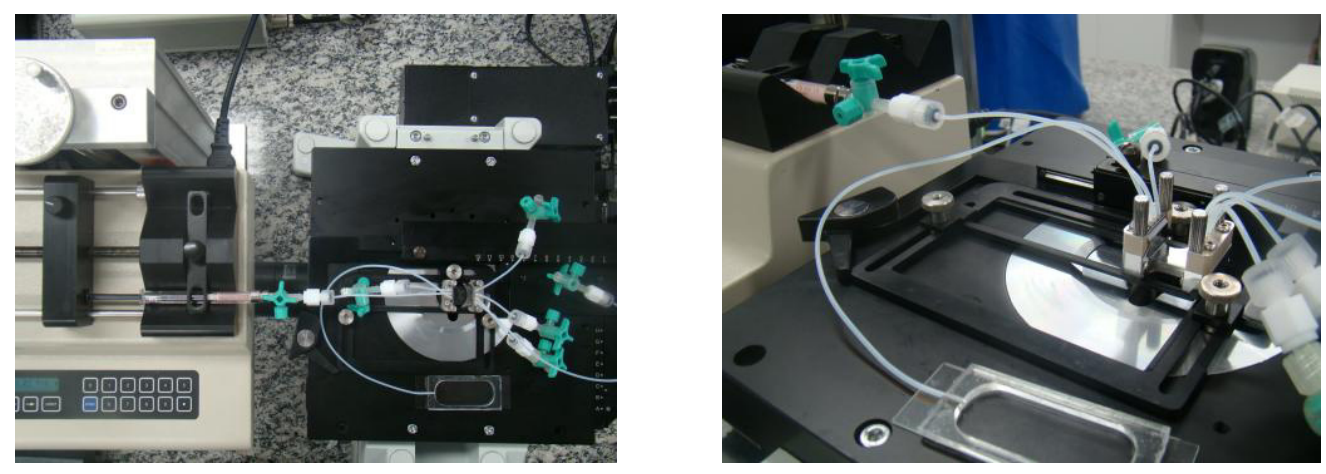

Figura 3.14: Montagem do sistema de injeção da fase contínua no sistema $\mu$-PIV.

O micro capilar de vidro utilizado foi fabricado pela DOLOMITE CENTRE LTD, UK. A sua geometria apresenta micro canais de seção transversal oval e tem as mesmas dimensões em todo o seu comprimento, com exceção na parte da garganta, que apresenta uma largura do canal diferente. O comprimento da garganta foi de $70 \mu \mathrm{m}$. O diâmetro máximo e mínimo na garganta foi de $110 \mu \mathrm{m}$ e $85 \mu \mathrm{m}$ respectivamente. Este dispositivo abrange uma ampla faixa de aplicações, como por exemplo: mistura de fluidos, formação de gotas e canais para medições de pressão. O micro capilar é apresentado na figura (3.15), junto com os seus acessórios e algumas dimensões principais.

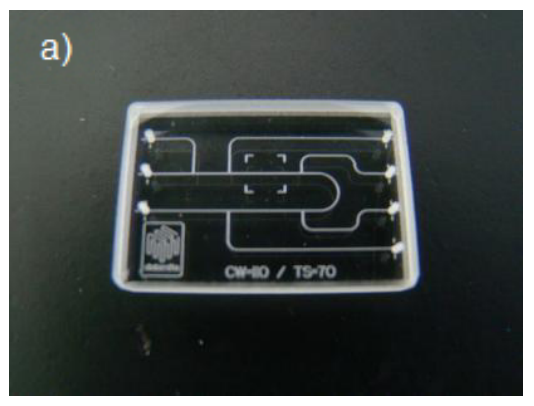

b)

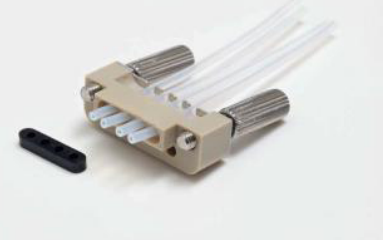

c)

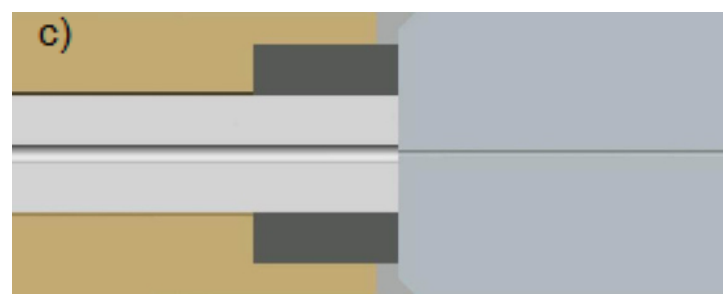



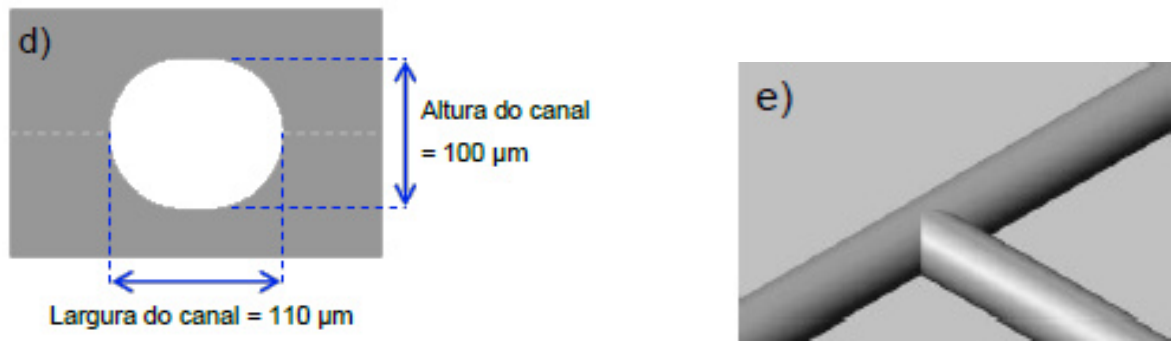

f)

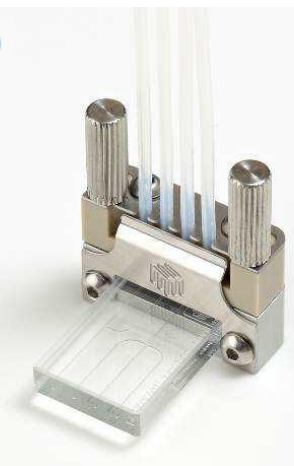

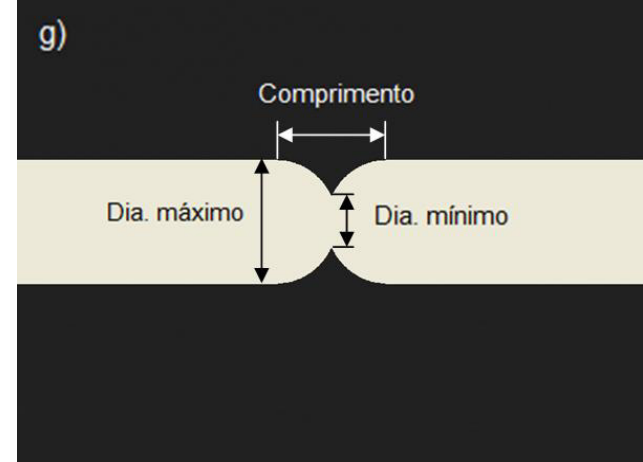

Figura 3.15: a) Micro capilar. b) Conector linear com tubos e selo. c) Seção transversal da montagem. d) Seção transversal dos canais. e) Vista da junção T. f) Micro capilar montado. g) Geometria e dimensões da garganta [37].

A bomba de seringa COLE-PARMER ${ }^{\circledR}$ de modelo 78-0200C foi utilizada para a injeção da fase contínua, ou seja, a mistura de água destilada com partículas fluorescentes. O seu funcionamento é através de um motor de passo de engrenagens controlado por um microprocessador, que permite variar a taxa volumétrica de injeção, apresentando $\pm 0.5 \%$ de exatidão e $\pm 0.2 \%$ de reprodutibilidade [38]. A figura (3.16) mostra a bomba usada nesta bancada experimental.

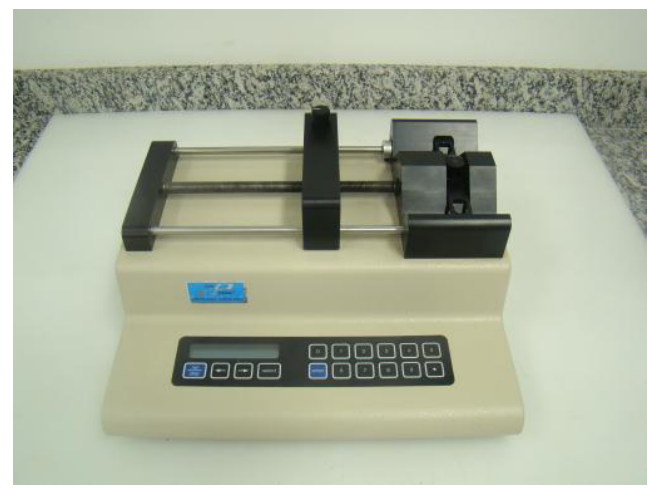

Figura 3.16: Bomba de seringa Cole-Parmer ${ }^{\circledR}$ Mod. 78-0200C. 
A seringa utilizada para a injeção da fase contínua foi a HAMILTON GASTIGHT de volume $1 \mathrm{ml}$, mostrada na figura (3.17a). A seringa tem um corpo de vidro e ponta de teflon com conexão tipo "luer lock", que garante estabilidade e previne vazamento de liquido.

A torneira três vias EMBRAMED ${ }^{\circledR}$ de plástico com conexão "Iuer lock" permitiu usar o menor número de elementos entre a seringa e o micro-capilar, minimizando o risco de vazamentos e acelerando o efeito da bomba na formação do escoamento, figura (3.17b).

a)

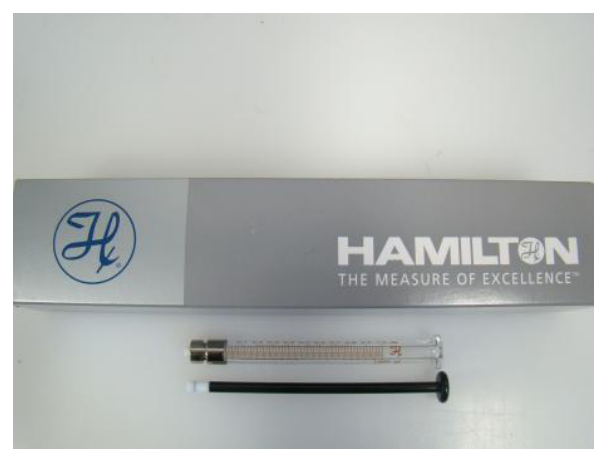

b)

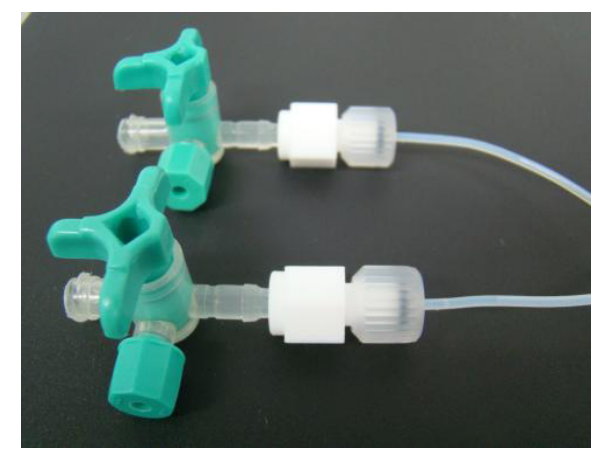

Figura 3.17: a) Seringa Hamilton Gastight $1 \mathrm{ml}$. b) Conexões entre a seringa e 0 micro-capilar.

\subsubsection{2.}

\section{Sistema $\mu \mathrm{PIV}$}

O sistema $\mu$-PIV fabricado pela TSI ${ }^{\circledR}$ é composto pelo microscópico de fluorescência Olympus, a câmera CCD, o laser de Nd: YAG, o sincronizador LaserPulse, e o software Insight $3 \mathrm{G}^{\mathrm{TM}}$. Este último tem por função armazenar, capturar e processar as imagens obtidas.

O microscópio OLYMPUS ${ }^{\circledR}$ de modelo IX71S1F-3 foi utilizado na visualização do escoamento, mostrado na figura (3.18). O microscópio dispõe de uma objetiva Olympus ${ }^{\circledR}$ UPlanFLN 10x/0,30 e um cubo de filtro, como ilustrado figura (3.19). 


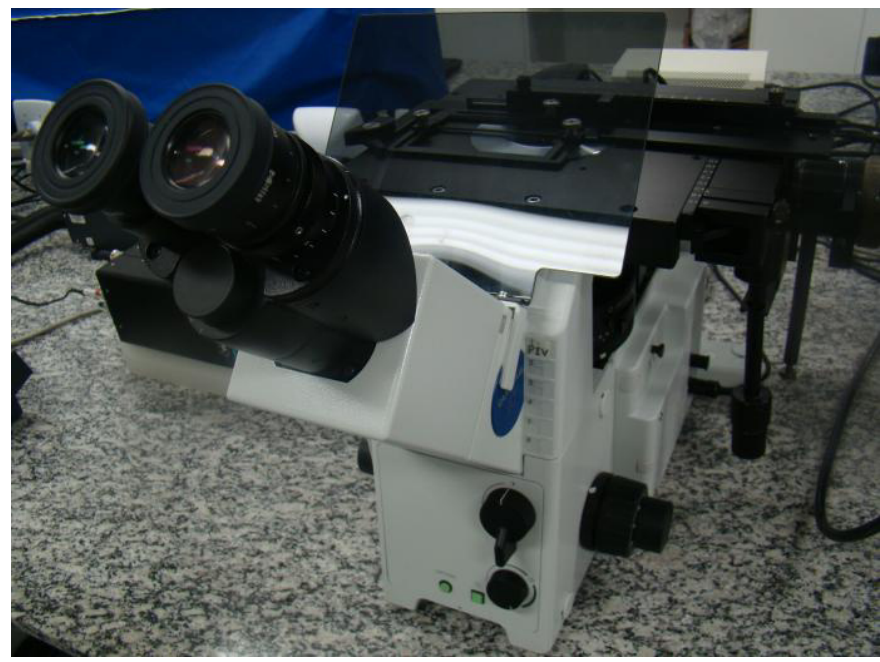

Figura 3.18: Microscópio de Fluorescência Olympus ${ }^{\circledR}$ - Mod. IX71S1F-3.

a)

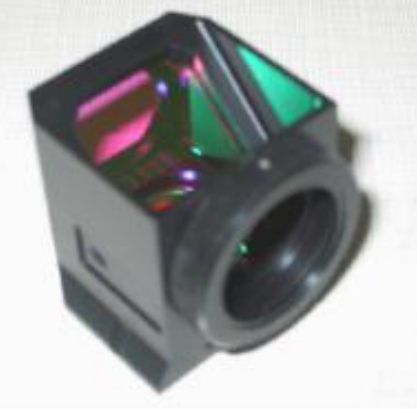

b)

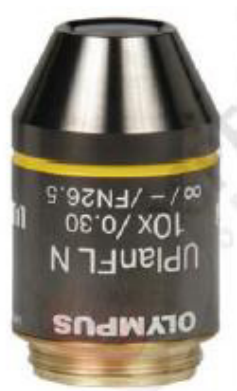

Figura 3.19: a) Cubo de Filtro. b) Objetiva Olympus ${ }^{\circledR} 10 x / 0,30$.

O cubo de filtro é um grupo de filtros ópticos inserido no microscópio, que separa a luz de fluorescência espalhada pelas partículas da luz de iluminação, sendo composto pelo espelho dicróico, o filtro de barreira e o filtro de excitação.

A luz de iluminação emitida pelo laser (comprimentos de ondas de 510 até $535 \mathrm{~nm}$ ) é refletida pelo espelho dicróico, e logo passa através da objetiva até atingir as partículas fluorescentes dispersas no fluido.

A luz refletida pelas partículas (comprimentos de ondas de 510 até 535 $\mathrm{nm}$ ) é refletida pelo espelho dicróico, voltando na direção de entrada. Uma pequena quantidade de luz refletida pelas partículas passará através do espelho dicróico, mas o filtro de barreira bloqueará esta luz remanescente.

A luz emitida pelas partículas fluorescentes (comprimentos de onda de 560 $\mathrm{nm}$ para acima) é transmitida pelo espelho dicróico e o filtro de barreira até atingir à câmera. As figuras (3.20a), (3.20b) e (3.20c) mostram os processos descritos acima. 
a) Luz iluminação do laser

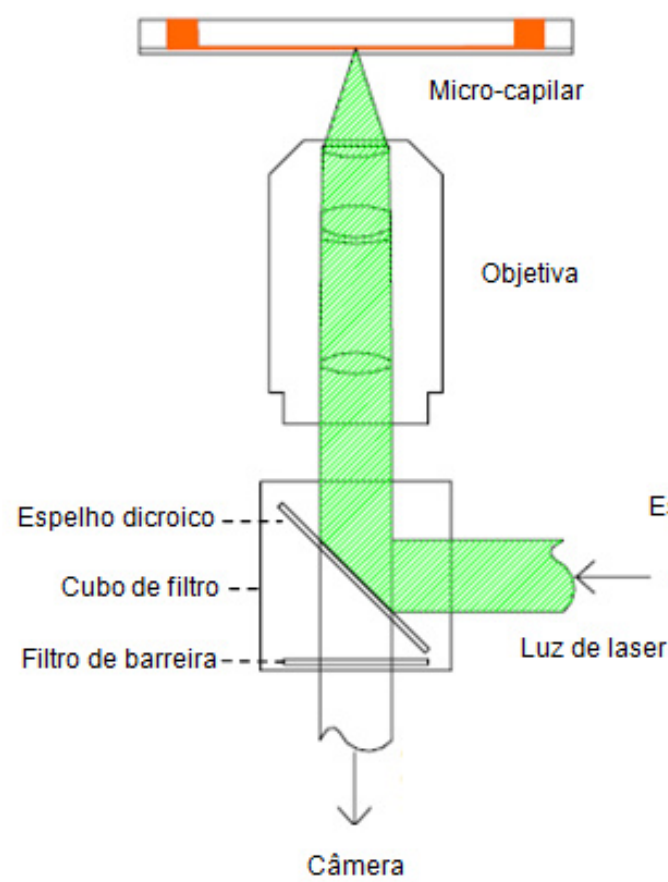

b) Luz refletida pelas particulas

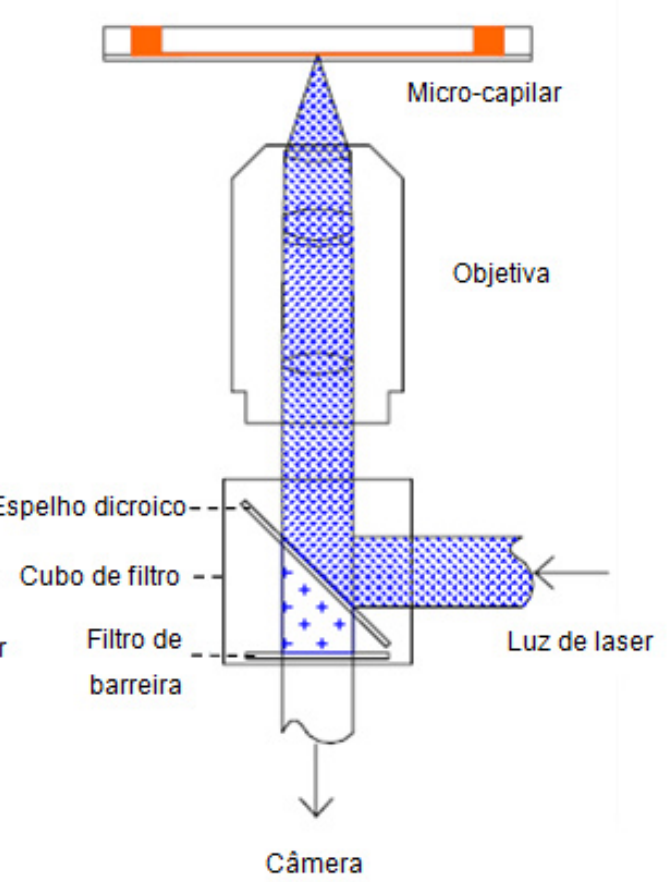

c) Luz fluorescências pelas particulas

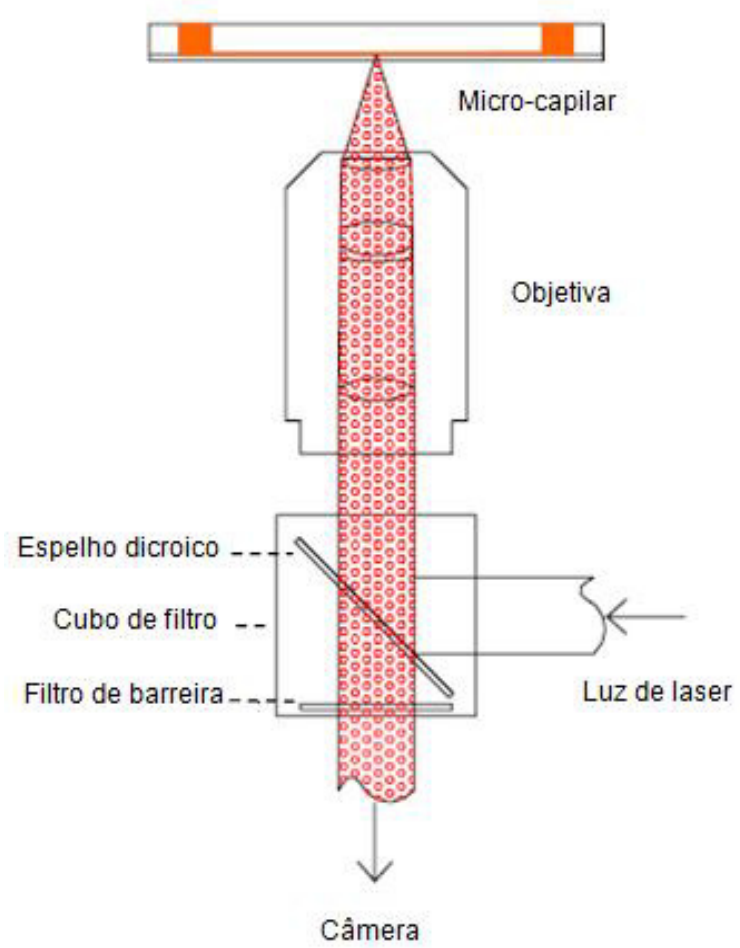

Figura 3.20: a) Luz de iluminação emitida pelo laser. b) Luz refletida pelas partículas. c) Luz emitida pelas partículas fluorescentes [39]. 
A câmera CCD POWERVIEW ${ }^{\text {TM }}$ de 1,4MP Sensicam Mod. 630066 acoplada no microscópio foi utilizada na captura das imagens das partículas fluorescentes, mostrada na figura (3.21). A câmera PowerView 1,4MP apresenta as seguintes características [40]:

- Frequência 10 frames/seg;

- Resolução espacial 1,4 megapixel;

- Formato da imagem 1376 x 1040 pixeles ou 8,8 x 6,6 mm;

- Tamanho de pixel 6,45 x 6,45 $\mu$ m;

- Intensidade de cinza 12 bits.

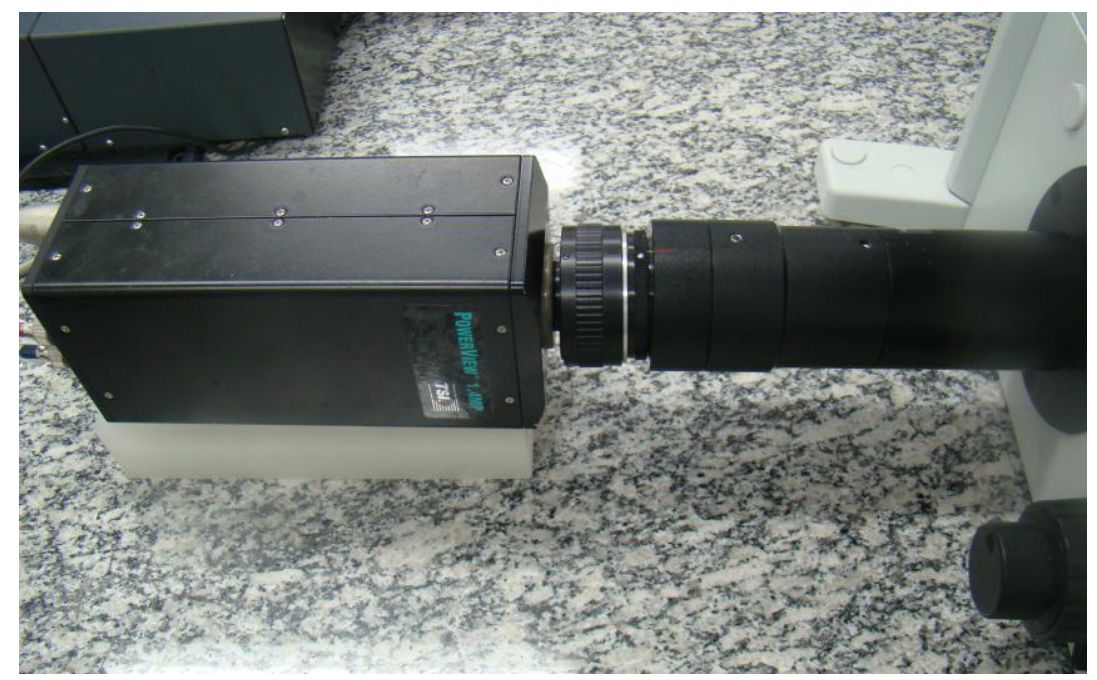

Figura 3.21: Câmera CCD Powerview ${ }^{\mathrm{TM}}$ de 1,4MP Sensicam Mod. 630066.

O laser Nd:YAG - Modelo Gemini PIV 15 foi utilizado para iluminar o escoamento no micro capilar. Este laser é um sistema compacto de dupla cabeça fabricado pela NEW WAVE ${ }^{T M}$. Este dispositivo emite luz verde altamente estável usada nas aplicações de velocimetria por imagem de partícula. O laser Gemini PIV 15 apresenta as seguintes características [41]:

- Energia por pulso $120 \mathrm{~mJ}$;

- Comprimento de onda $532 \mathrm{~nm}$;

- Frequência máxima $15 \mathrm{~Hz}$;

- Estabilidade da energia $\pm 3,5 \%$;

- Largura do pulso 3-5 ns.

A sua fonte de energia é constituída de três níveis: superior, intermediário e inferior. O nível superior possui o sistema de controle lógico eletrônico. O nível 
intermediário possui o sistema elétrico de alta voltagem. O nível inferior possui o sistema de resfriamento. A figura (3.22) apresenta os componentes do laser Gemini PIV 15.

b)

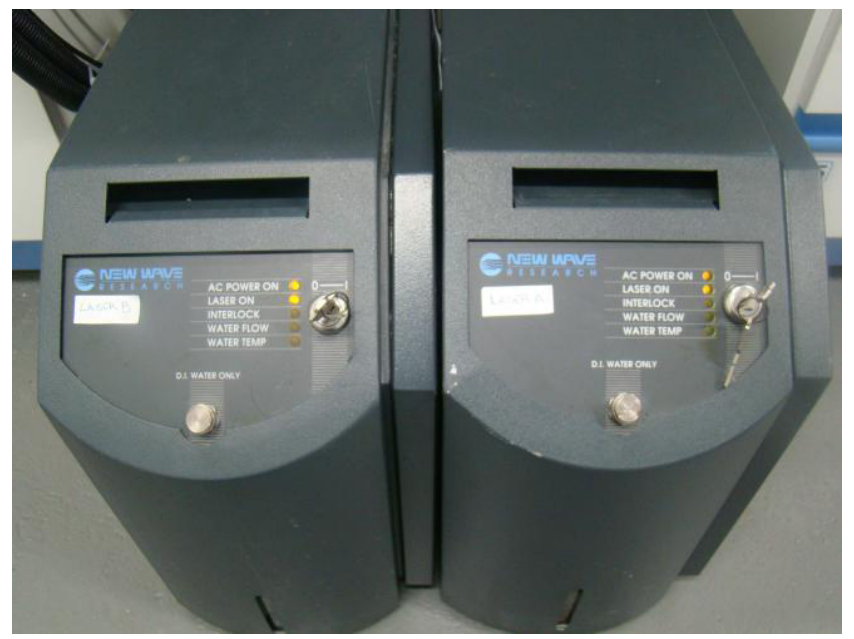

c)

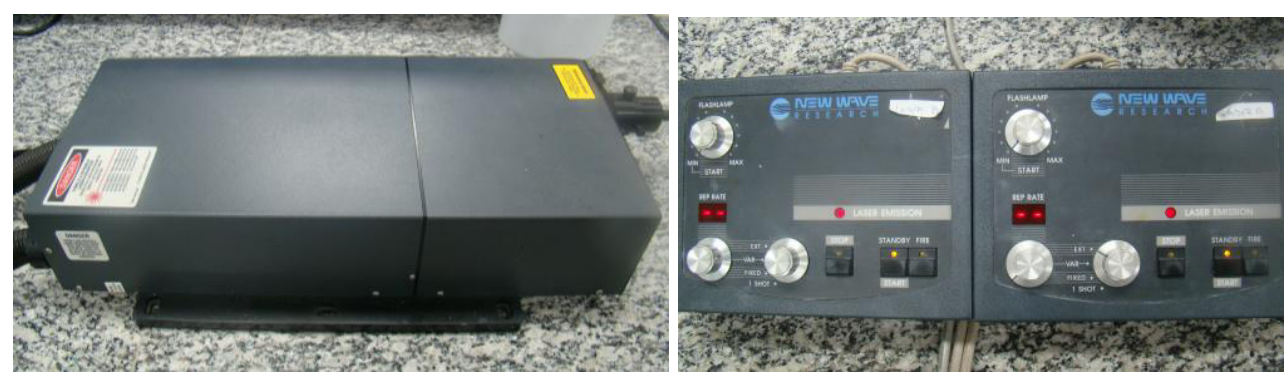

Figura 3.22: a) Fontes de Energia. b) Cabeça do laser. c) Controles do laser.

Os lasers Gemini PIV-15 dispõem de uma alta energia, e alguns acessórios do sistema $\mu$-PIV, como a fibra óptica possuem uma capacidade máxima de trabalho de $50 \mathrm{~mJ}$. A energia dos lasers deve ser limitada para a segurança dos equipamentos. O procedimento consistiu na mudança do tempo de atraso de disparo de cada laser (Q-Switch delay laser) e na medição da sua potência usando um medidor eletrônico. Finalmente, os valores anotados foram configurados no programa Insight $3 \mathrm{G}^{\mathrm{TM}}$. A equação (3.7) foi utilizada para calcular a energia por pulso $E$ de cada laser, em função da frequência $f$ e a potência Pot. A câmera limita a frequência máxima a $4,83 \mathrm{~Hz}$ e a potência foi medida pelo medidor eletrônico.

$$
E=\frac{P o t}{f}
$$


Devido à limitação da capacidade máxima de trabalho do sistema $\mu$-PIV, três valores de energia foram selecionados a fim de encontrar os valores de QSwitch delay correspondentes, tabela (3.2). Tais valores foram configurados no programa Insight $3 \mathrm{G}^{\mathrm{TM}}$, como mostra a figura (3.23).

\begin{tabular}{|c|c|c|c|}
\cline { 3 - 4 } \multicolumn{2}{c|}{} & $\begin{array}{c}\text { Energy } \\
\text { (MJ/pulse) }\end{array}$ & $\begin{array}{c}\text { Q Switch delay } \\
(\mu \mathrm{s})\end{array}$ \\
\hline \multirow{3}{*}{ LASER A } & Hight & 45,5 & 250 \\
\cline { 2 - 4 } & Medium & 24,8 & 300 \\
\cline { 2 - 4 } & Low & 2,1 & 400 \\
\hline \multirow{3}{*}{ LASER B } & Hight & 47,6 & 300 \\
\cline { 2 - 4 } & Medium & 22,8 & 350 \\
\cline { 2 - 4 } & Low & 2,1 & 450 \\
\hline
\end{tabular}

Tabela 3.2: Valores selecionados de Energy e Q-Switch delay laser.

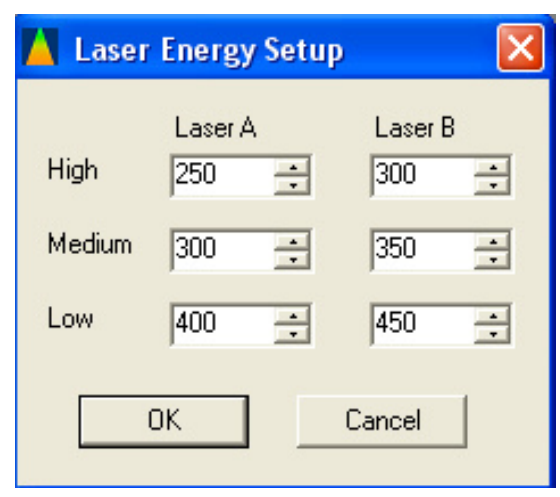

Figura 3.23: Valores configurados de Q-Switch delay no programa Insight $3 G^{\mathrm{TM}}$.

O sincronizador LASERPULSE - Modelo 610034 foi utilizado no sistema $\mu$ PIV para que o laser, a câmera CCD e o computador operem no tempo e na sequência correta. A figura (3.24) apresenta o sincronizador utilizado nesta bancada experimental. 


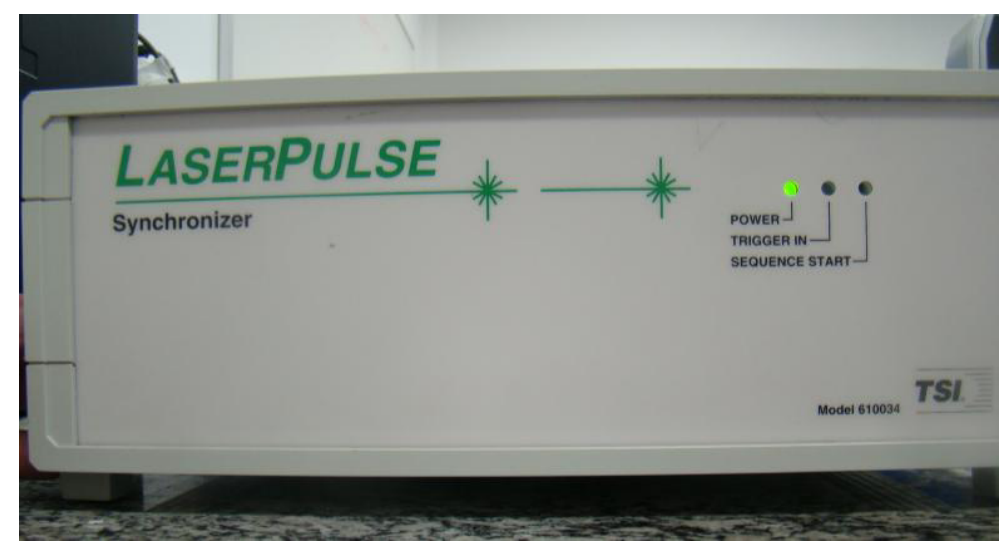

Figura 3.24: Sincronizador LaserPulse - Modelo 610034.

O software INSIGHT $3 G^{\mathrm{TM}}$ foi utilizado na configuração da captura, processamento e visualização das imagens. Este software desenvolvido pela $\mathrm{TSI}^{\circledR}$ foi utilizado para processar as imagens e obter os campos de velocidades.

$\mathrm{O}$ Insight $3 \mathrm{G}^{\mathrm{TM}}$ está dividido em quatro partes. A figura (3.25a) mostra a janela principal onde é visualizada a imagem em tempo real. Na figura (3.25b), a aba "Exp. Tree" armazena os arquivos e configurações das imagens. Na figura (3.25c), a aba "Capture" permite configurar, iniciar e deter a captura das imagens. Na figura (3.25d), a aba "Processing" permite realizar aplicações de pré-processamento, processamento, pós-processamento, calibração e máscaras de processamento das imagens capturadas.

a)

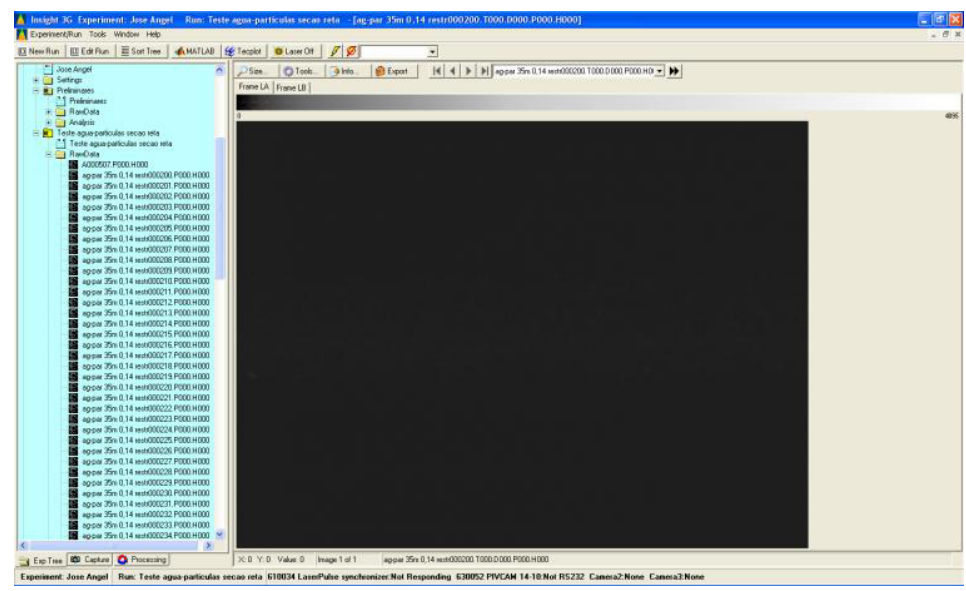


b)

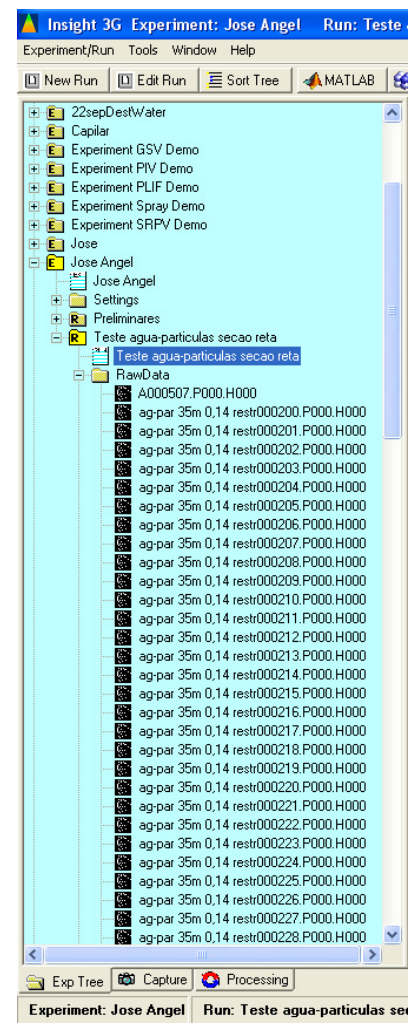

c)

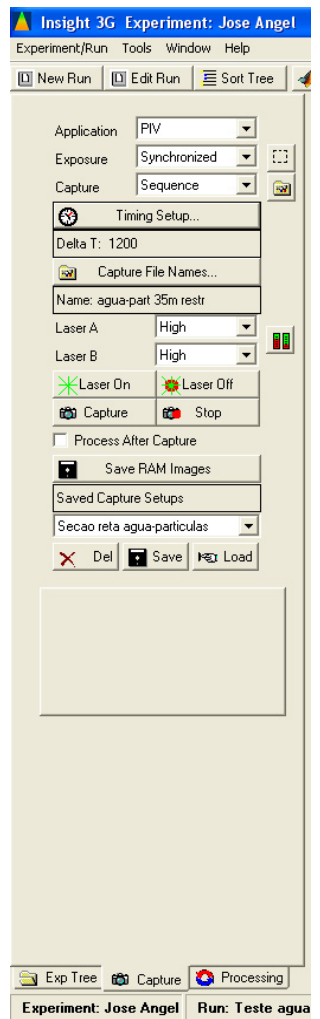

d)

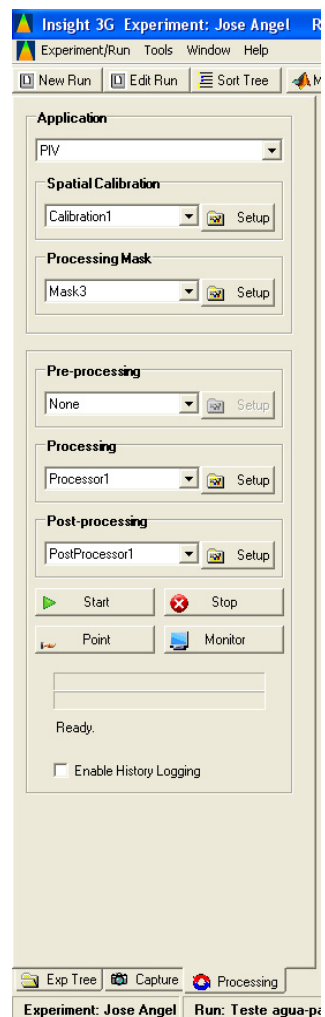

Figura 3.25: a) Janela principal do programa Insight $3 G^{T M}$. b) Aba "Exp. Tree." c) Aba "Capture". d) Aba "Processing".

As micro-esferas de poliestireno FLUORO-MAX ${ }^{\mathrm{TM}}$ fornecida pela THERMO SCIENTIFIC foram suspensas na fase contínua, ou seja, na água destilada. Estas micro-esferas apresentam as seguintes características [12]:

- Diâmetro das micro-esferas de $1 \mu \mathrm{m}$;

- Suspensão aquosa com 1\% de concentração de sólidos;

- Micro esferas de Fluorescência vermelha;

- Pico de fluorescência de absorção e emissão 542 / 612 nm.

A figura (3.26) mostra as micro-esferas utilizadas nos experimentos, e a figura (3.27), os picos de fluorescência de absorção e emissão das partículas [12]. 


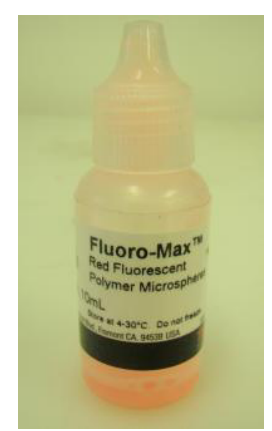

Figura 3.26: Micro-esferas de poliestireno Fluoro-Max ${ }^{\mathrm{TM}}$.

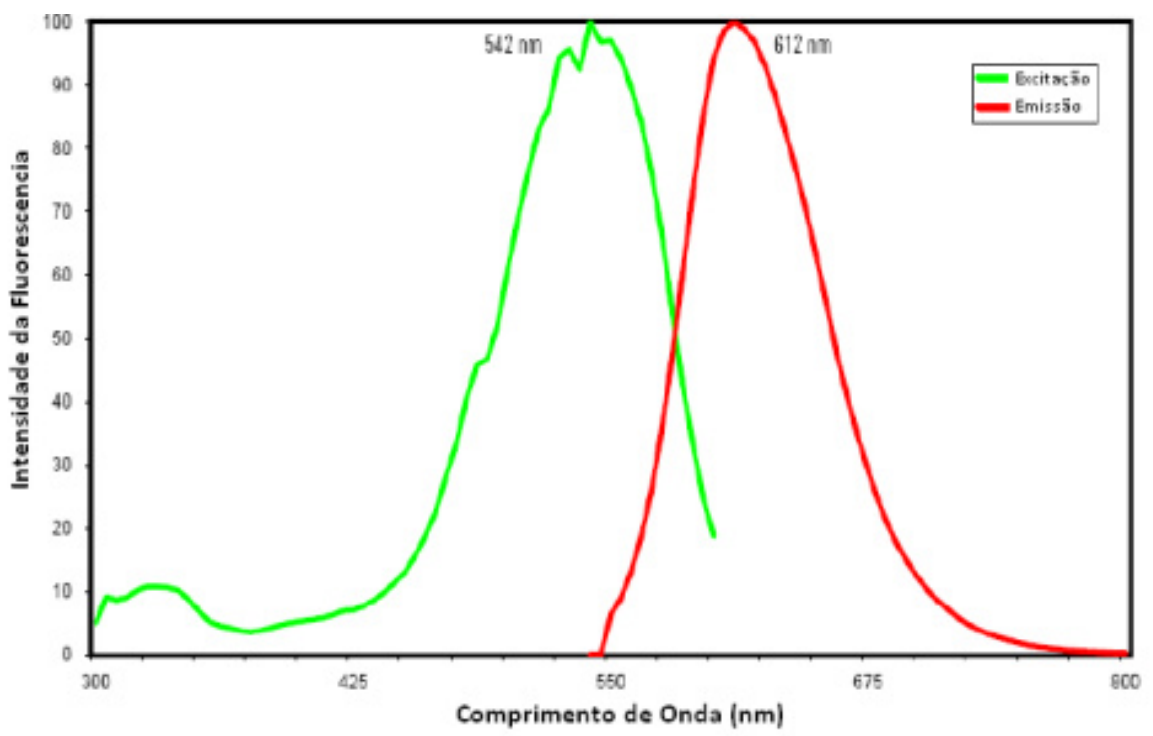

Figura 3.27: Picos de fluorescência de absorção e emissão das partículas [12].

\subsection{2.}

Fluido de Trabalho

Nesta primeira abordagem experimental, água destilada foi usada como fase contínua nas medições dos campos de velocidade do escoamento monofásico, através do micro canal de seção reta constante e do canal com uma garganta. 


\subsubsection{1.}

\section{Preparação da fase}

Todo o procedimento da preparação da fase contínua foi efetuado sob as mesmas condições de medição, para garantir a sua repetitividade.

A fase contínua foi preparada filtrando água destilada através de uma membrana de 0,45 $\mu \mathrm{m}$ de malha (NALGENE ${ }^{\circledR} 150-\mathrm{ml}$ ) e uma bomba de vácuo QUIMIS modelo Q355D2, como mostrado na figura (3.28), evitando a presença de qualquer possível impureza no escoamento através do micro capilar.

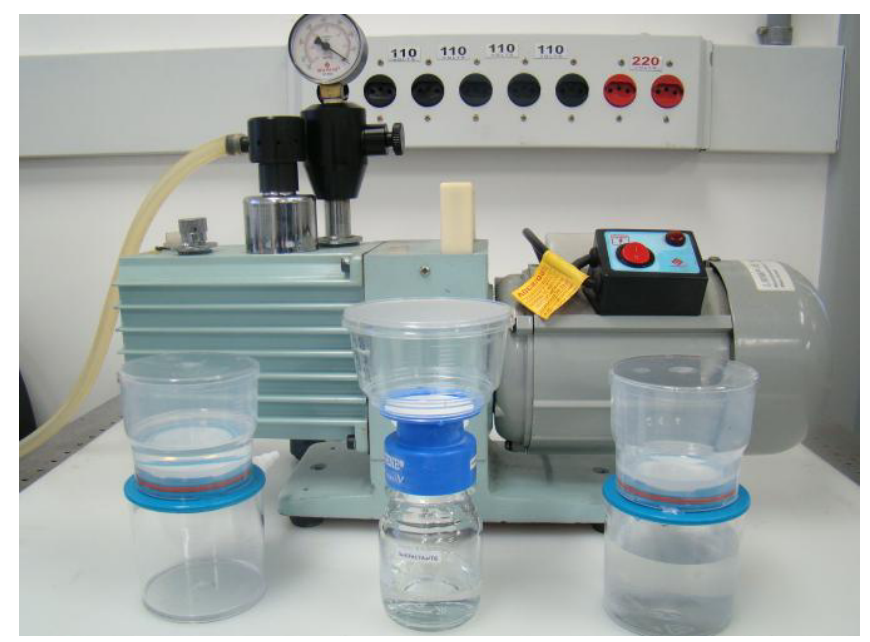

Figura 3.28: Bomba de vácuo Quimis Mod. Q355D2 e o filtro com malha 0,45 $\mu$ m.

\subsubsection{2.}

\section{Caracterização da fase}

$\mathrm{Na}$ tabela (3.3) são apresentados os valores das propriedades do fluido, em que $\rho$ é a massa especifica, $v$ é a viscosidade cinemática, $\mu$ é a viscosidade

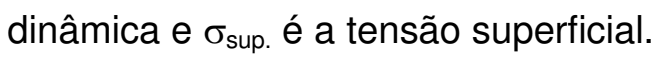

\begin{tabular}{|c|c|c|c|c|c|}
\hline Fase & Descrição & $\begin{array}{c}\rho \\
{\left[\mathrm{Kg} / \mathrm{m}^{3}\right]}\end{array}$ & $\begin{array}{c}v \\
{\left[\mathrm{~mm}^{2} / \mathrm{s}\right]}\end{array}$ & $\begin{array}{c}\mu \\
{[\mathrm{mPa} . \mathrm{s}]}\end{array}$ & $\begin{array}{c}\sigma_{\text {Sup. }} \\
{[\mathrm{mN} / \mathrm{m}]}\end{array}$ \\
\hline Contínua & Água destilada & 997,4 & 0,942 & 0,94 & 72,3 \\
\hline
\end{tabular}

Tabela 3.3: Propriedades da fase contínua a 23ํㅡ [42]. 


\subsection{3.}

\section{Procedimento Experimental}

O procedimento experimental consiste em uma série de ações, desde a montagem até os ensaios preliminares. Logo abaixo é descrito um conjunto de condições usadas nos experimentos.

- A sequência de ligamento dos equipamentos foi a seguinte: lasers / câmera / sincronizador e o programa Insight 3G ${ }^{\mathrm{TM}}$;

- Antes de começar os testes, o tempo de espera de aquecimento dos lasers (temperatura ótima de trabalho) foi aproximadamente de 10 minutos;

- Temperatura do laboratório $\mathrm{T}=23^{\circ} \mathrm{C}$;

- A vazão de injeção da fase contínua foi de $Q=0,03 \mathrm{ml} / \mathrm{h}$.

A figura (3.29) mostra o percurso do fluido e as posições onde as medições do campo de velocidade foram realizadas. O fluido ingressa no micro capilar pela abertura №1 e saí pela №2, e as aberturas №3, 4, 5, 6 e 7 são fechadas pelas respectivas torneiras. A posição "A" foi utilizada na medição do campo de velocidade em um micro canal de seção reta transversal constante, e a posição "B" o escoamento nas proximidades da garganta. Para garantir que 0 escoamento avaliado esteja completamente desenvolvido, como é apresentado na figura (3.30), as imagens no microcanal reto foram capturadas a uma distância de 2 mm à montante da entrada №1. Langhaar (1942) propôs uma correlação para o cálculo do comprimento de entrada hidrodinâmico $L_{e}$ para um escoamento laminar desenvolvido [43]:

$$
\mathrm{L}_{\mathrm{e}}=0,0575 \mathrm{D}_{\mathrm{h}} \operatorname{Re}_{\mathrm{Dh}},
$$

em que $D_{h}$ representa o diâmetro interno do tubo circular e $R e_{D h}$ o número de Reynolds. Para nossa análise, a vazão de injeção foi de $0,03 \mathrm{ml} / \mathrm{h}$ e o diâmetro interno $D_{h}$ da seção aproximadamente circular foi de $0,11 \mathrm{~mm}$, resultando em um $R e_{D h} \approx 0,1$. O comprimento de entrada hidrodinâmico $L_{e}$ foi menor que a distância escolhida para a captura das imagens, garantindo um escoamento totalmente desenvolvido, tanto no microcanal reto como na garganta do micro capilar. 


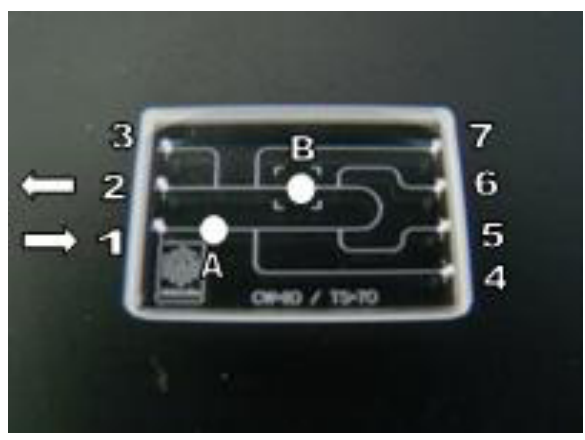

Figura 3.29: Micro capilar utilizado, apresentando a entrada e saída do escoamento monofásico e a região de observação.

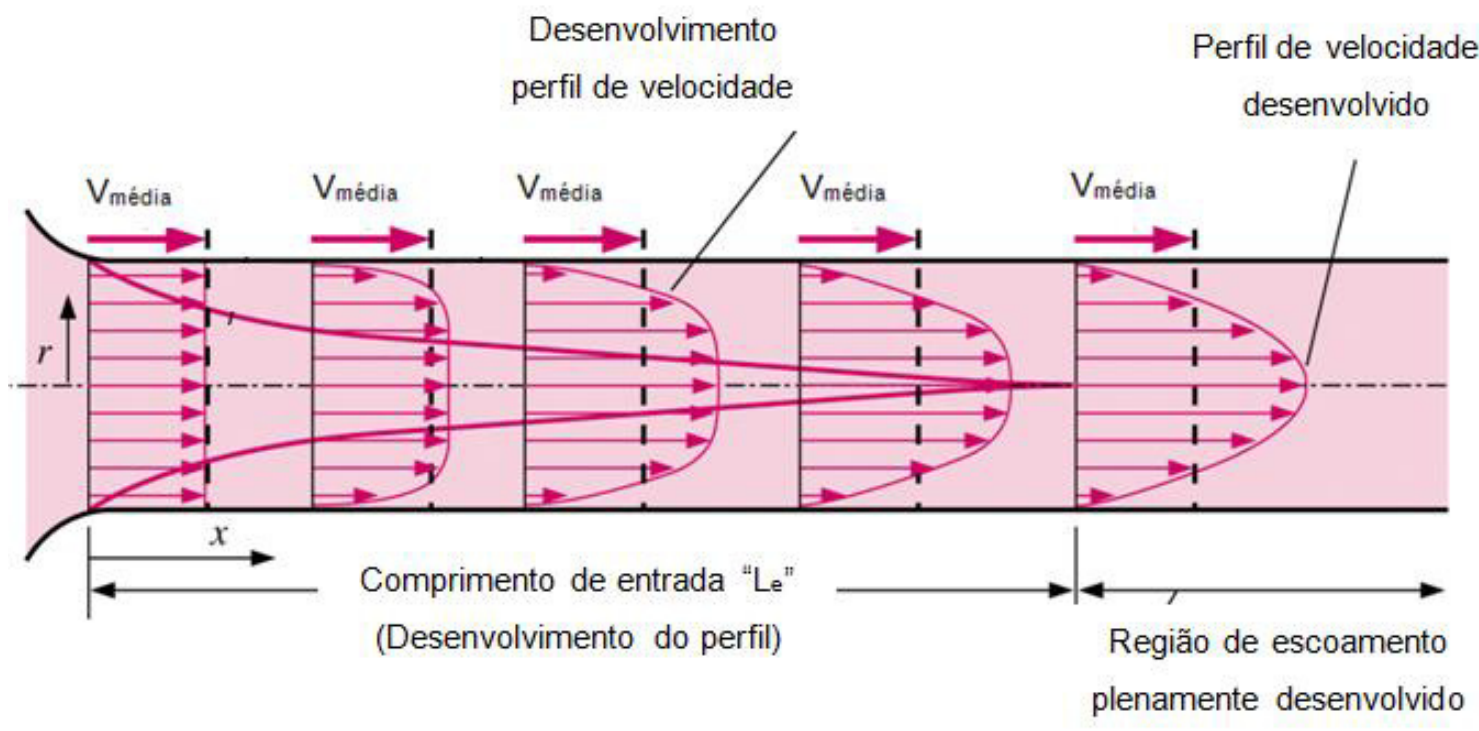

Figura 3.30: Desenvolvimento do perfil de velocidade na região de entrada de um escoamento em um duto circular [44].

Iniciou-se com a montagem do micro capilar utilizando mangueiras e torneiras, para abrir e/ou fechar a passagem do escoamento pelas diferentes aberturas; e um coletor de amostra, para armazenar o fluido saindo do dispositivo, mostrado na figura (3.31). 


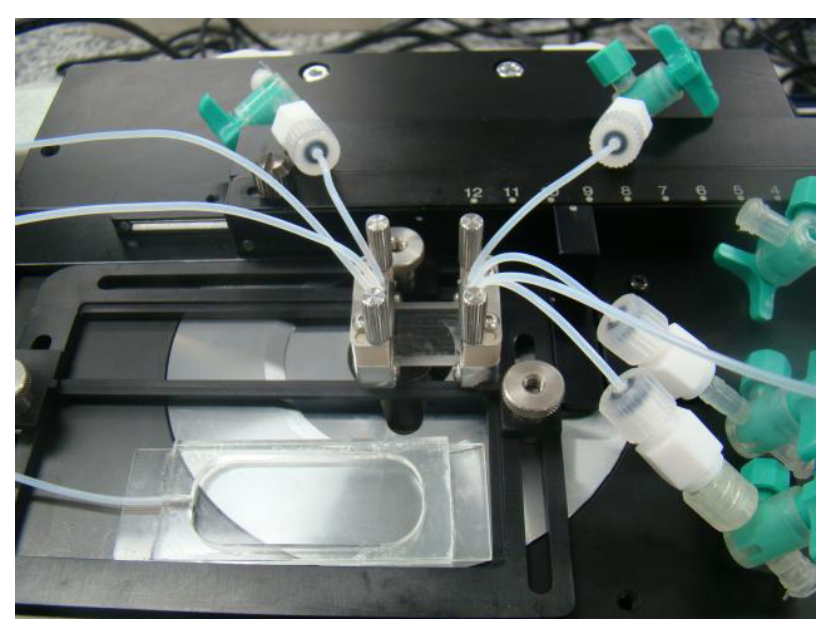

Figura 3.31: Montagem do micro capilar.

Primeiro, o sistema foi preenchido somente com água destilada, para expulsar o ar do micro capilar e das mangueiras. $O$ volume da fase contínua (água destilada com as partículas fluorescentes) de $1 \mathrm{ml}$ foi inserido lentamente na seringa Hamilton Gastight de $1 \mathrm{ml}$ conectada à torneira três vias EMBRAMED ${ }^{\circledR}$ de plástico. Foi necessário também expulsar o ar na seringa e na torneira, a fim de evitar a presença de bolhas de ar, que possam comprometer a medição do campo de velocidade do escoamento.

A bomba, seringa e o micro capilar foram nivelados com respeito à mesa de trabalho do microscópio, para evitar deslocamentos durante as medições, mostrados na figura (3.14).

Os seguintes ensaios preliminares foram feitos para determinar alguns parâmetros de trabalho que foram usados nos ensaios principais.

O sistema $\mu$-PIV utiliza dois campos de visualização. O campo de visualização do microscópio, que possui dois sistemas de ampliação composto por uma objetiva e uma ocular. O microscópio utilizado apresenta um campo de visualização circular de 2,2 mm.

A câmera CCD utilizada possui uma resolução espacial de $8,8 \times 6,6 \mathrm{~mm}$, e apresenta um campo de visualização de $0,88 \mathrm{~mm}$ de largura e 0,66 $\mathrm{mm}$ de altura.

É importante conhecer estes dois campos de visualização para conferir se a área de interesse no micro-capilar poderá ser visualizada. Lembrar que só o campo de visualização da câmera é visualizado na tela do computador. 
A centralização do micro-capilar na tela do computador foi realizada usando os eixos do microscópio, e como referência uma cruz na tela do programa Insight $3 \mathrm{G}^{\mathrm{TM}}$. Uma vez centralizado o micro-capilar foi fixado a sua posição, através das réguas de referência posicionadas na base do microscópio, mostrado na figura (3.32).

a)

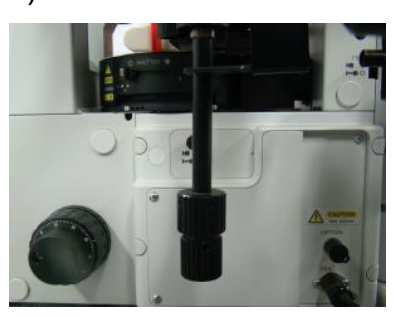

d)

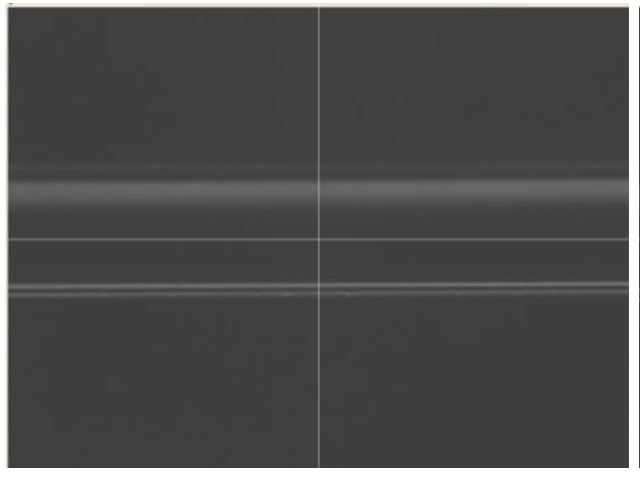

b)

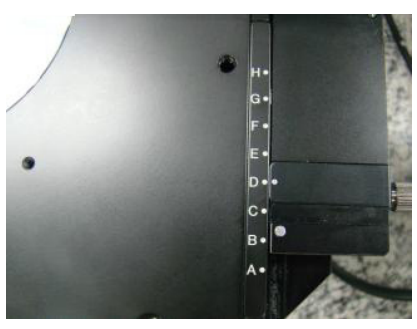

e) c)
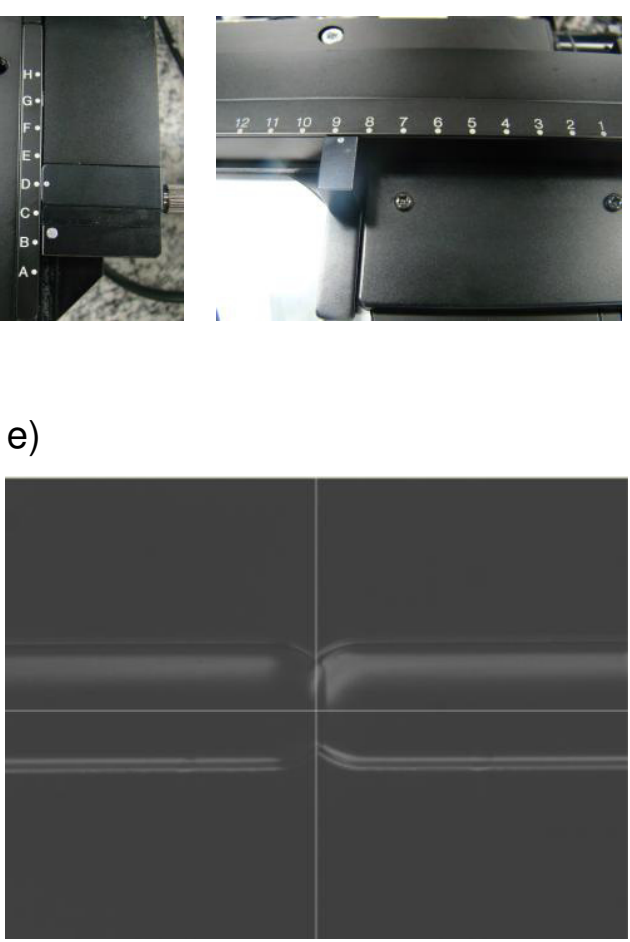

Figura 3.32: a) Eixo do microscópio. b) Régua vertical na base do microscópio. c) Régua horizontal na base do microscópio. d) A centralização do microcanal reto no programa Insight $3 G^{T M}$. e) A centralização do microcanal com uma garganta no programa Insight $3 G^{\mathrm{TM}}$.

O plano focal do escoamento foi medido na largura máxima do canal do micro capilar de $110 \mu \mathrm{m}$, mostrada na figura (3.33), e posicionado utilizando o ajuste macrométrico (grosseiro) e micrométrico (fino) do microscópio, figura (3.34). 


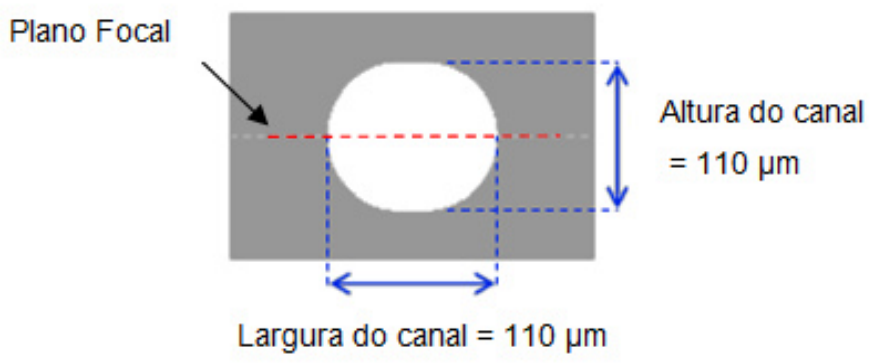

Figura 3.33: Posição do plano focal do escoamento para a captura das imagens.

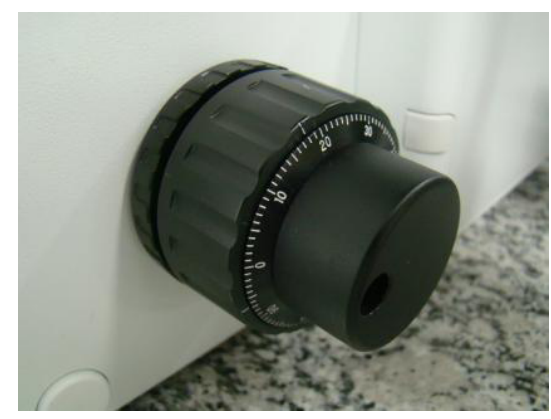

Figura 3.34: Ajuste macrométrico e micrométrico do microscópio.

A calibração foi realizada usando a geometria do micro capilar especificada pela DOLOMITE. As dimensões do dispositivo foram conferidas utilizando o microscópio invertido Carl Zeiss Axiovert 40MAT. Logo o micro capilar foi visualizado no sistema $\mu$-PIV no modo "livre de aquisição de imagem". Uma foto foi tirada e mediu-se a largura do canal $(0,11 \mathrm{~mm})$ obtendo 269 pixels. O valor de calibração foi de $0,41 \mu \mathrm{m} /$ pixel, figura (3.35).

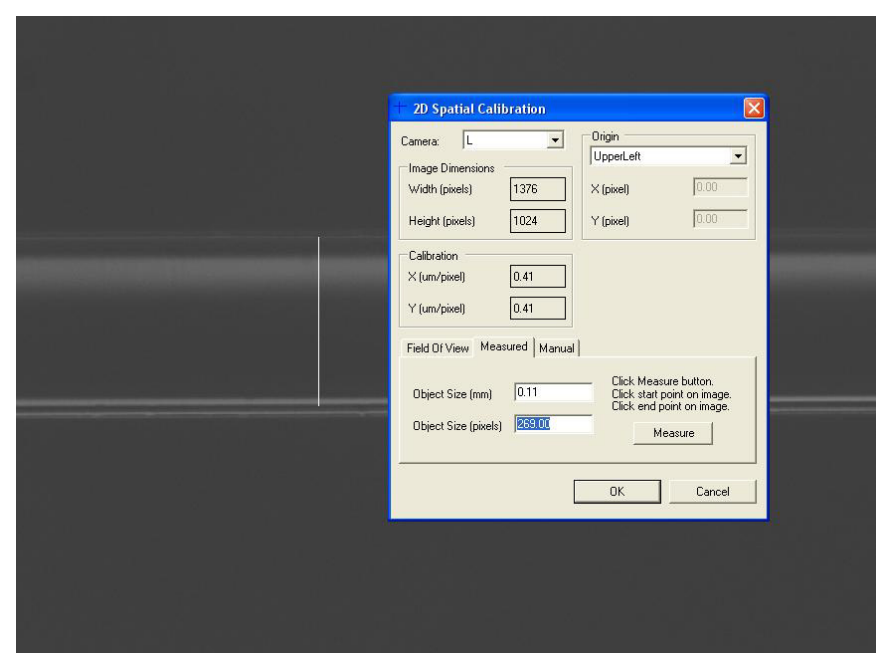

Figura 3.35: Calibração no sistema $\mu$-PIV. 
A concentração de partículas adequadas foi obtida diluindo a concentração de $1 \%$ sólidos das micro-esferas de poliestireno FLUORO-MAX ${ }^{\mathrm{TM}}$ em água destilada, para a medição do campo de velocidade através do micro canal de seção reta constante e no microcanal com uma garganta. Diferentes relações de volumes foram feitas desde 10:0,5 até 10:2. A relação de volume adequada foi de 10:1,4, ou seja, $0,14 \%$ de concentração de partículas suspensas em água destilada. $\mathrm{O}$ volume utilizado foi de $1 \mathrm{ml}$, então, o volume da água destilada foi de $0,86 \mathrm{ml}$ e das partículas fluorescentes de $0,14 \mathrm{ml}$.

Para conferir se a concentração escolhida foi ótima, devem-se cumprir algumas regras básicas de PIV, que são imprescindíveis para obter uma boa medição do campo de velocidade.

- Tamanho das partículas suspensas entre 3-5 pixels de diâmetro [45], [23];

- De 5-12 partículas suspensas em cada janela de interrogação [23].

Tirou-se uma foto no microcanal reto, a imagem foi dividida em janelas de interrogação de 32 × 32 pixels. As partículas tiveram um diâmetro aproximado de 3 pixels, e ó número de partículas por janela de interrogação foi de aproximadamente de 4 a 10 partículas, cumprindo as regras básicas de PIV, como é possível observar na figura (3.36).

a)

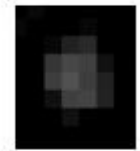

b)
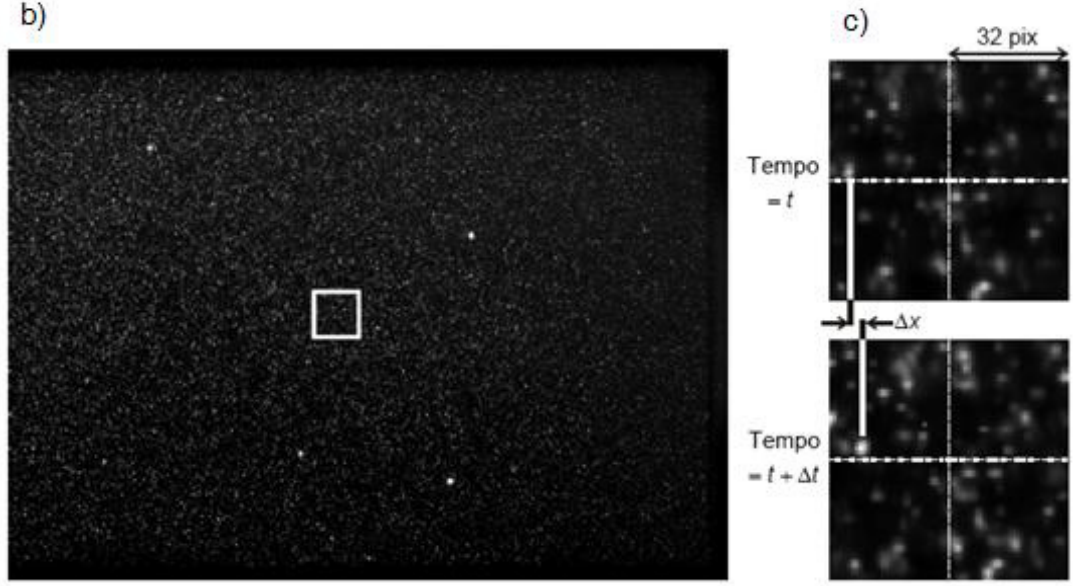

Figura 3.36: a) Tamanho das partículas em pixels. b) Imagem do microcanal reto. c) Imagem dividida em janelas de interrogação de $32 \times 32$. 


\section{4.}

\section{Medição do Campo de Velocidade do Escoamento Bifásico óleo-água}

Primeiramente, a descrição do experimento consistiu em determinar a vazão de injeção da fase dispersa, de tal forma que ocorra a criação de gotas em um regime repetitivo e estável na junção microfluídica $T$ do micro capilar. $A$ bancada experimental esquematizada na figura (3.37) foi utilizada para a visualização da quebra de gota.

Uma vez garantida à formação de gotas de óleo de forma repetitiva foi realizada a medição do campo de velocidade da fase contínua, e a velocidade de uma gota da fase dispersa no escoamento bifásico, em duas seções dos microcanais: reta e ao redor da garganta.

A descrição do experimento foi dividida em três partes principais: (i) Bancada experimental, (ii) Fluido de trabalho, (iii) Procedimento experimental.

\subsection{1.}

\section{Bancada Experimental}

A figura (3.38) apresenta um esquema simples dos equipamentos utilizados na bancada experimental para a visualização da quebra da gota, a aquisição e análise das imagens obtidas, e para a medição dos campos de velocidade.

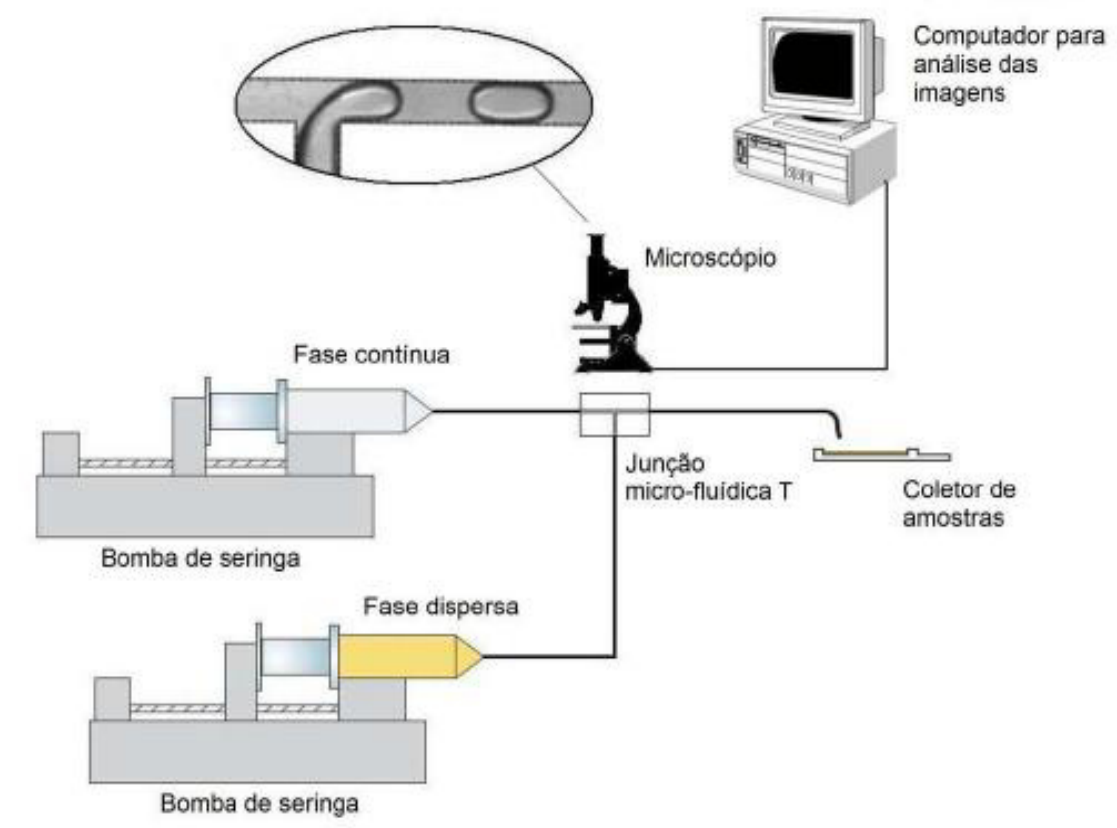




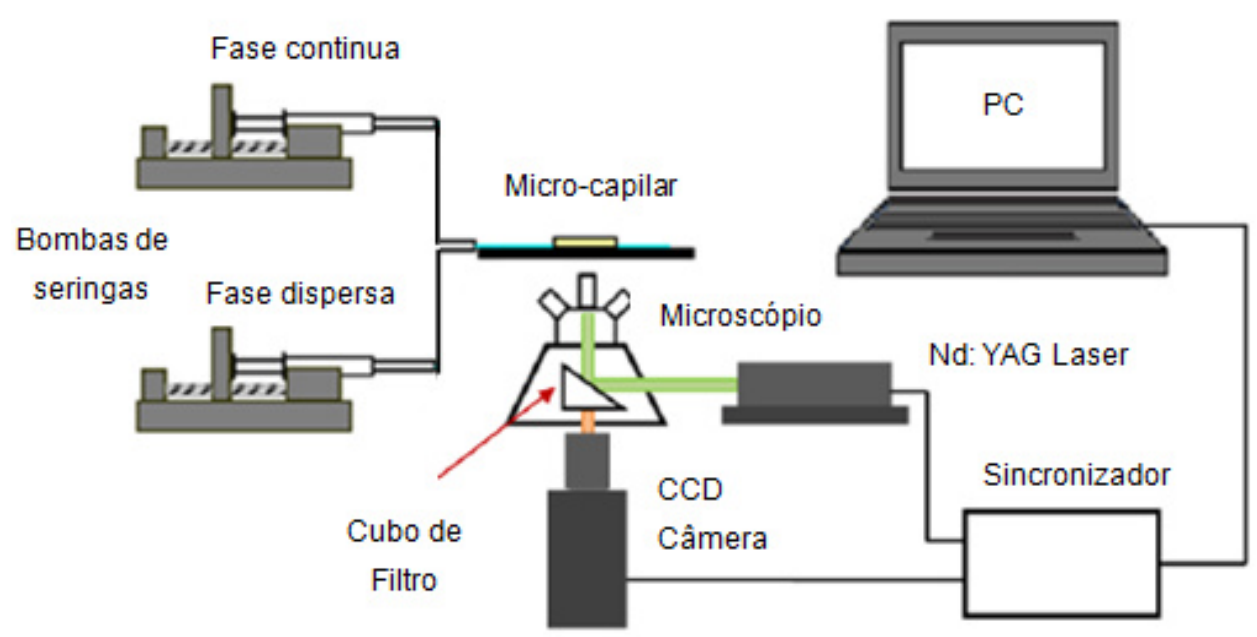

Figura 3.37 Esquema da bancada experimental para a visualização da quebra da gota, e a medição do campo de velocidade.

\subsubsection{1. \\ Sistema de Injeção}

O sistema de injeção é composto por micro-capilares, bombas de seringa, seringas e acessórios para a montagem do circuito. A figura (3.38) apresenta à montagem do sistema de injeção no sistema da visualização da quebra da gota, e na figura (3.39) a montagem do sistema de injeção no sistema $\mu$-PIV.

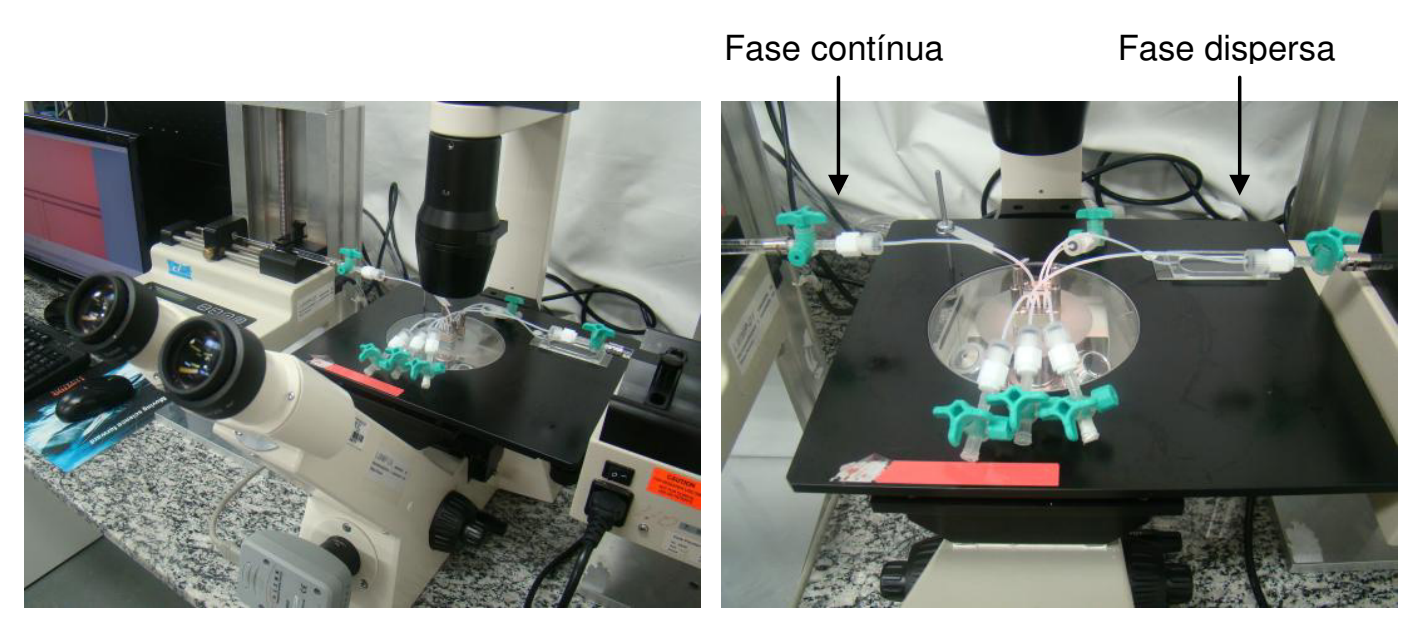

Figura 3.38: Montagem do sistema de injeção no sistema de visualização da quebra da gota. 


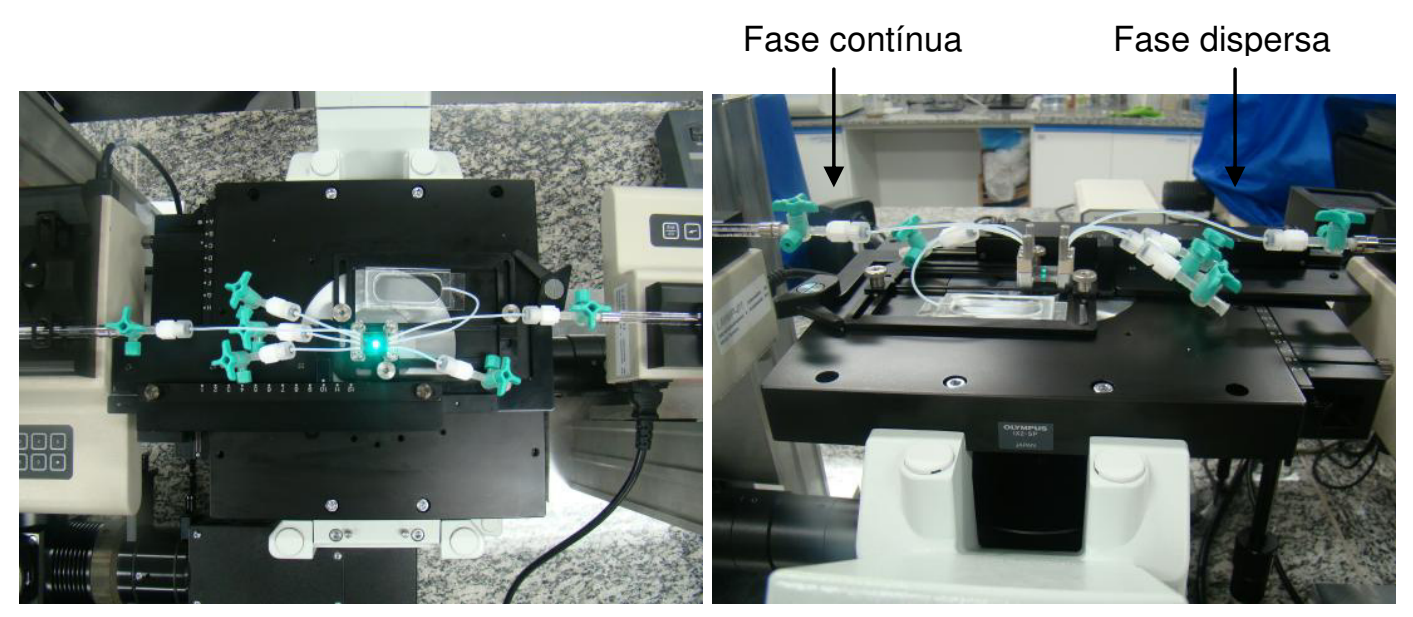

Figura 3.39: Montagem do sistema de injeção da fase contínua e a fase dispersa no sistema $\mu$-PIV.

Neste sistema de injeção foram usados 2 micro capilares. O primeiro micro capilar foi o mesmo do experimento do escoamento monofásico. O segundo micro capilar, o comprimento da garganta foi de $100 \mu \mathrm{m}$. O diâmetro máximo e mínimo foi de $110 \mu \mathrm{m}$ e $46 \mu \mathrm{m}$ respectivamente, com a diferença que foram utilizadas as duas bombas de seringa, uma para cada fase.

A fase contínua, ou seja, a mistura de água destilada com surfactante e partículas fluorescentes foi preenchida no sistema utilizando uma bomba de seringa COLE-PARMER ${ }^{\circledR}$ de modelo 78-0100C. A fase dispersa, ou seja, o óleo foi preenchido no sistema utilizando uma bomba de seringa COLE-PARMER ${ }^{\circledR}$ de modelo 78-0200C. A figura (3.40) apresenta as bombas utilizadas nesta bancada experimental.

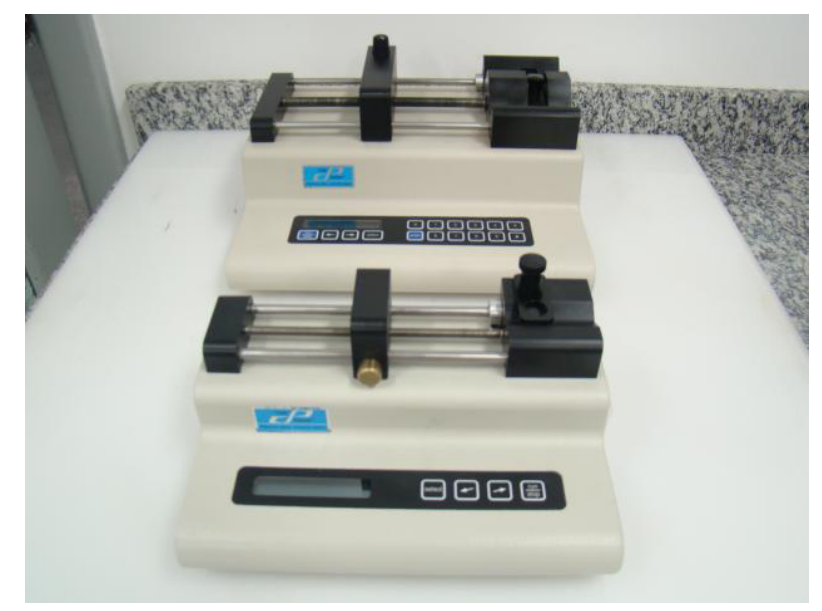

Figura 3.40: Bombas de seringa Cole-Parmer ${ }^{\circledR}$ Mod. 78-0100C e Mod. 78-0200C. 
A seringa utilizada na injeção da fase contínua e a fase dispersa foram a Hamilton Gastight de volume $0,10 \mathrm{ml}$, e é mostrada na figura (3.41a). Estas seringas têm um corpo de vidro e ponta de teflon com conexão tipo "luer lock", que garante estabilidade e não permite vazamento de liquido.

A torneira três vias EMBRAMED ${ }^{\circledR}$ de plástico, com conexão "luer lock" foi o mesmo da primeira bancada experimental, mostrada na figura (3.41b).

a)

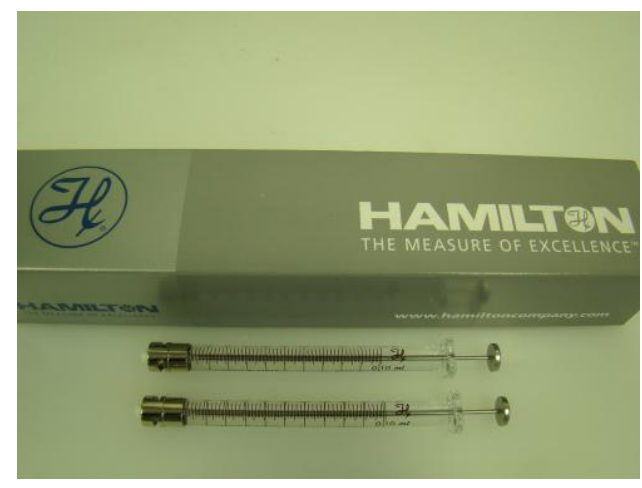

b)

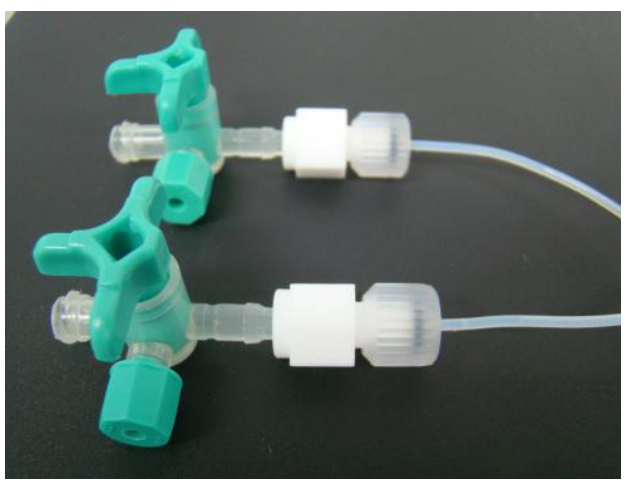

Figura 3.41: a) Seringas Hamilton Gastight 0,10 ml. b) Conexões entre as seringas e 0 micro capilar.

\subsubsection{2.}

\section{Sistema de Visualização na formação da gota}

O sistema de visualização na formação da gota é composto pelo microscópio ótico invertido Zeiss, a câmera PixeLink e o software "AxioVision 4.7". Este último foi empregado para o armazenamento, captura e processamento das imagens.

O microscópio ótico invertido Carl Zeiss Axiovert 40MAT foi utilizado para visualizar a formação de gotas de óleo na junção $T$ do micro capilar, como é mostrado na figura (3.42). 


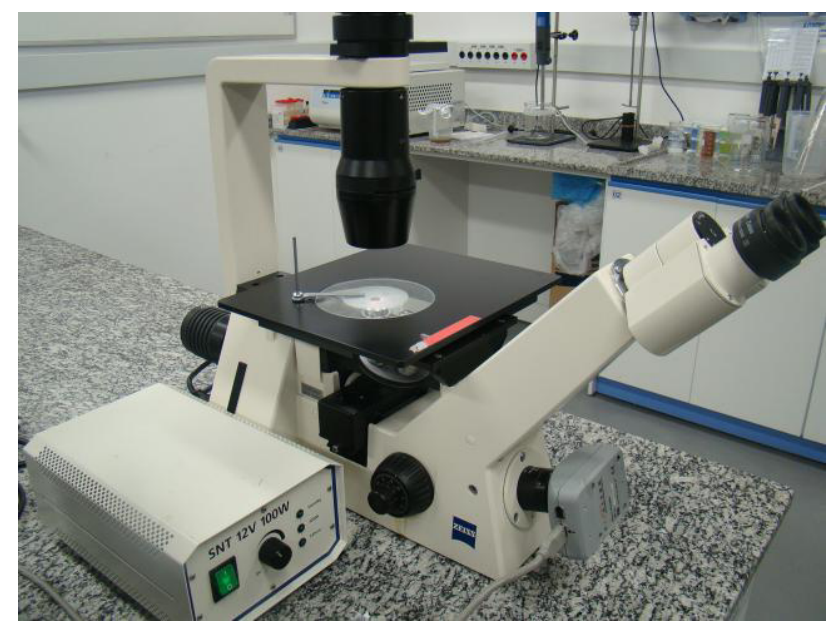

Figura 3.42: Microscópio ótico invertido Carl Zeiss 40MAT.

A câmera PixeLink PL-A662 acoplada ao microscópio ótico invertido Zeiss foi utilizada para capturar as imagens em tempo real, mostrada na figura (3.43). A câmera PixeLink apresenta as seguintes características [46]:

- Frequência 12 frames/seg;

- Resolução espacial 1,3 megapixel;

- Formato da imagem $1280 \times 1024$ pixel;

- Tamanho de pixel 6,0 x 6,0 $\mu \mathrm{m}$.

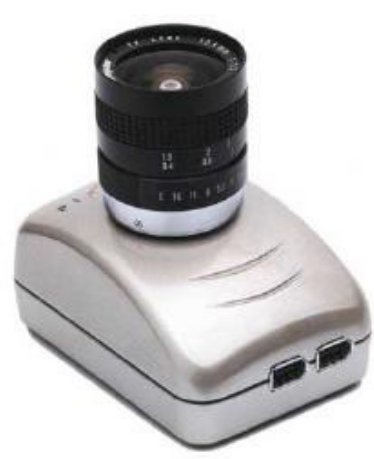

Figura 3.43: Câmera PixeLink PL-A662.

O software AxioVision 4.7 foi utilizado para visualizar, armazenar e analisar as imagens capturadas na formação de gotas de óleo na junção T do dispositivo, mostrado na figura (3.44). 


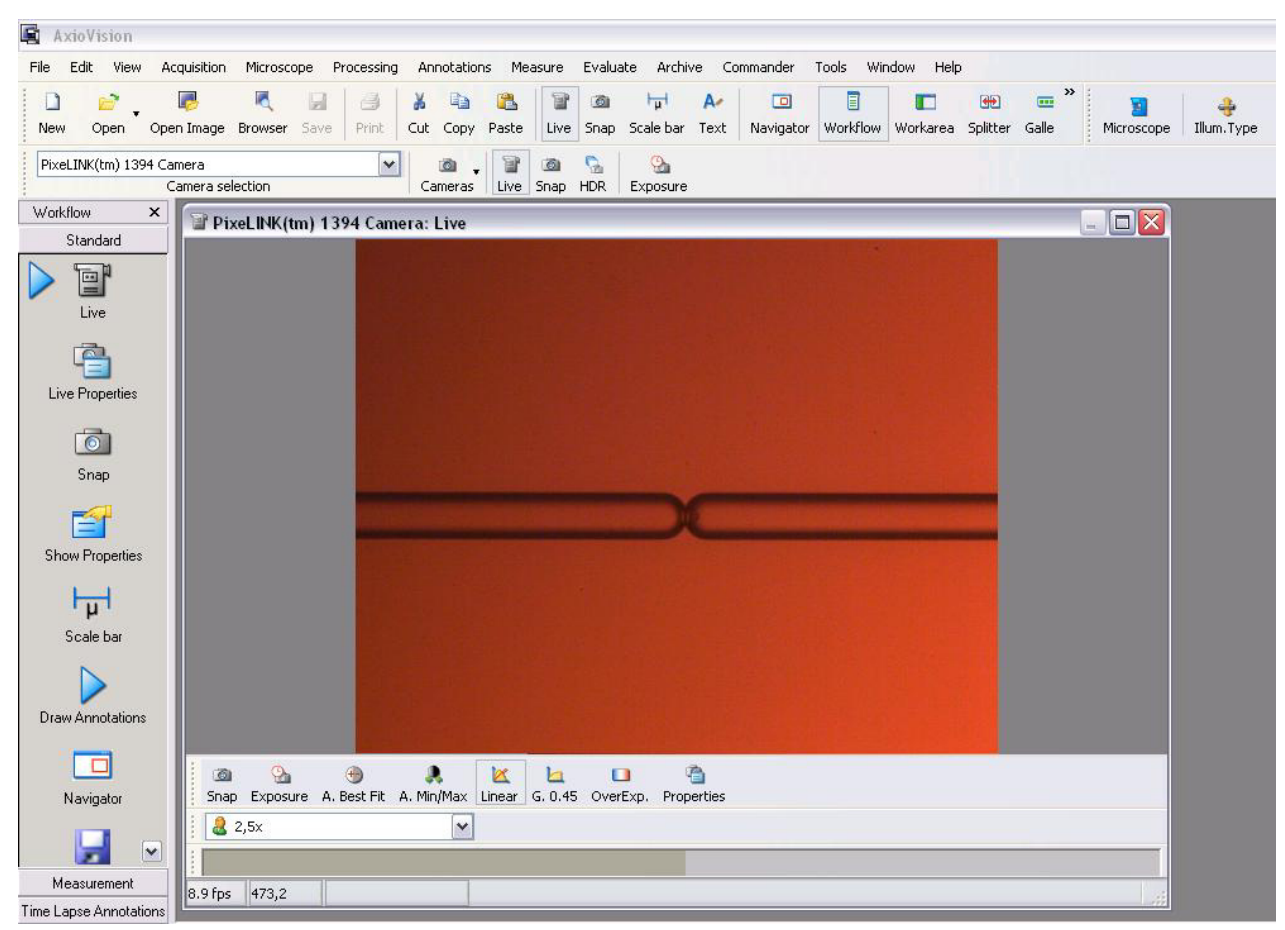

Figura 3.44: Software AxioVision 4.7.

\subsubsection{3. \\ Sistema $\mu$ PIV}

O sistema $\mu$-PIV é composto pelo microscópico de fluorescência Olympus, a câmera CCD, o laser de Nd: YAG, o sincronizador LaserPulse, e o software Insight $3 \mathrm{G}^{\mathrm{TM}}$. Os mesmos usados no primeiro experimento, i.e. escoamento monofásico.

\subsection{2.}

\section{Fluido de Trabalho}

Nesta segunda abordagem experimental, a mistura da água destilada com o surfactante Sódio Dodecil Sulfato $\mathrm{C}_{12} \mathrm{H}_{25} \mathrm{NaSO}_{4}$ foi selecionada como fase contínua. O óleo Agecom Drakeol 7 foi selecionado como fase dispersa, para efetuar as medições dos campos de velocidade do escoamento, através dos microcanais de seção reta constante e com uma garganta do micro capilar. 


\subsubsection{1.}

\section{Preparação da fase}

Todo o procedimento da preparação da fase contínua e dispersa foi efetuado sob as mesmas condições de medição, para garantir a sua repetitividade.

Primeiramente, a fase contínua foi preparada filtrando água destilada através de uma membrana de 0,45 $\mu \mathrm{m}$ de malha $\left(\mathrm{NALGENE}^{\circledR}\right.$ 150-ml) e a bomba de vácuo QUIMIS modelo Q355D2, para evitar a presença de qualquer possível impureza no escoamento dentro do dispositivo, figura (3.28).

Em seguida, a quantidade de surfactante Sódio Dodecil Sulfato $\mathrm{C}_{12} \mathrm{H}_{25} \mathrm{NaSO}_{4}$ usado na fase contínua foi de $6,9 \mathrm{~g} / \mathrm{l}$, ou seja, três vezes a sua concentração micelar critica, a qual foi utilizada a mesma quantidade em todas as preparações, para evitar um possível efeito do surfactante sobre o deslocamento e deformação da gota [47]. A preparação tem por finalidade estabilizar a solução, reduzir a tensão superficial entre as fases e evitar a coalescência de gotas da fase dispersa. O surfactante foi pesado usando a balança QUIMIS Mod. Q-500L210C de $\pm 0,0001 \mathrm{~g}$ de precisão, mostrado na figura (3.45).

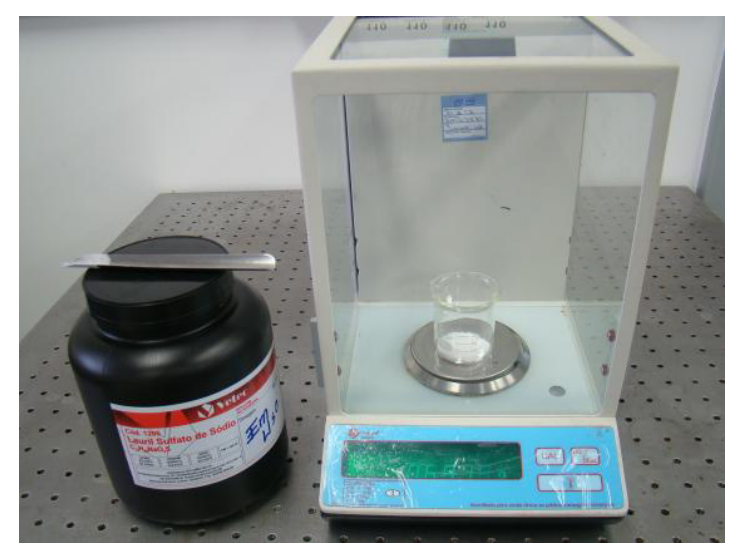

Figura 3.45: Balança Quimis Mod. Q-500L210C e o surfactante Sódio Dodecil Sulfato $\mathrm{C}_{12} \mathrm{H}_{25} \mathrm{NaSO}_{4}$.

Adicionou-se $30 \mathrm{ml}$ de água destilada filtrada ao béquer onde estava o surfactante, e foram misturados usando o agitador magnético CORNING Mod. PC-420D com velocidade de 280 RPM e durante 1 hora. Após 1 hora no agitador magnético, a mistura de $30 \mathrm{ml}$ foi inserida lentamente no béquer cônico, e 
adicionou-se água destilada filtrada até atingir o volume de um 1 litro. Novamente, o agitador magnético foi utilizado a 280 RPM e durante 30 minutos, para garantir a completa dissolução do surfactante, como é apresentado na figura (3.46).

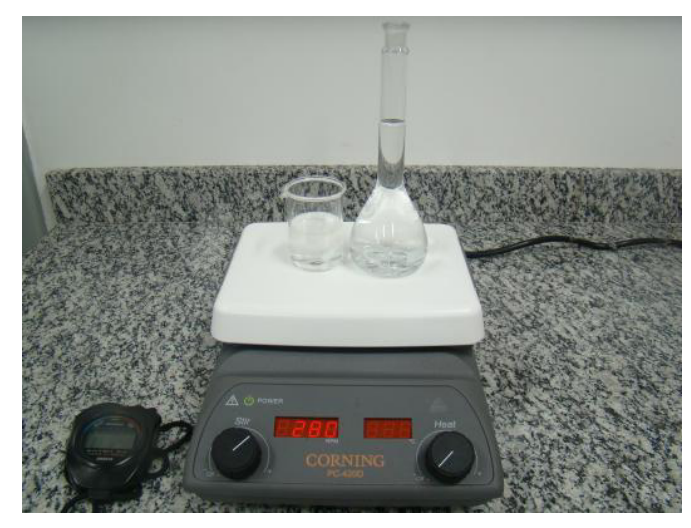

Figura 3.46: Agitador magnético Corning Mod. PC-420D.

Finalmente, a fase contínua obtida foi filtrada através de uma membrana de 0,20 $\mu \mathrm{m}$ de malha (NALGENE ${ }^{\circledR}$ Mod. 596-4520) e a bomba de vácuo QUIMIS modelo Q355D2, mostrado na figura (3.28).

A fase dispersa foi preparada filtrando o óleo Agecom Drakeol 7, através de uma membrana de 0,22 $\mu$ m de malha (NALGENE ${ }^{\circledR} 150-\mathrm{ml}$ ) e a bomba de vácuo QUIMIS modelo Q355D2, para evitar a presença de qualquer possível impureza no escoamento pelo dispositivo microfluídico, figura (3.28).

\subsubsection{2.}

\section{Caracterização da fase}

$\mathrm{Na}$ tabela (3.4) são apresentados os valores das propriedades dos fluidos caracterizados.

\begin{tabular}{|c|c|c|c|c|c|}
\hline Fase & Descrição & $\begin{array}{c}\rho \\
{\left[\mathrm{Kg} / \mathrm{m}^{3}\right]}\end{array}$ & $\begin{array}{c}v \\
{\left[\mathrm{~mm}^{2} / \mathrm{s}\right]}\end{array}$ & $\begin{array}{c}\mu \\
{[\mathrm{mPa} . \mathrm{s}]}\end{array}$ & $\begin{array}{c}\sigma_{\text {Sup. }} \\
{[\mathrm{mN} / \mathrm{m}]}\end{array}$ \\
\hline Contínua & $\begin{array}{c}\text { Água com } \\
\text { surfactante } \\
\text { Dispersa }\end{array}$ & 998,7 & 0,971 & 0,97 & 33,8 \\
\hline
\end{tabular}

Tabela 3.4: Propriedade da fase contínua e dispersa a $23^{\circ} \mathrm{C}$ [42]. 
em que $\rho$ é a massa especifica, $\nu$ é a viscosidade cinemática, $\mu$ é a

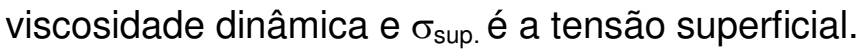

\subsection{3. Procedimento Experimental}

Ensaios preliminares foram realizados a fim de relacionar a vazão de óleo com o tamanho de gota de óleo obtido na junção T. As condições foram os seguintes:

- A vazão de injeção da fase contínua $Q=0,03 \mathrm{ml} / \mathrm{h}$;

- Temperatura do laboratório $\mathrm{T}=23^{\circ} \mathrm{C}$.

Os micros dispositivos utilizados na análise do escoamento bifásico são mostrados na figura (3.47).

A fase contínua é injetada através da porta marcada com o número 1 na figura, e fase dispersa, pela porta número 4. A saída do escoamento é feita pela porta número 2. As demais portas são fechadas durante os experimentos.

A formação das gotas de óleo ocorre na junção $T$, região $A$. A medição do campo de velocidade próximo à gota no escoamento, através do canal de seção reta constante foi realizada na região marcada como B na figura. A garganta está localizada na região marcada com $\mathrm{C}$.

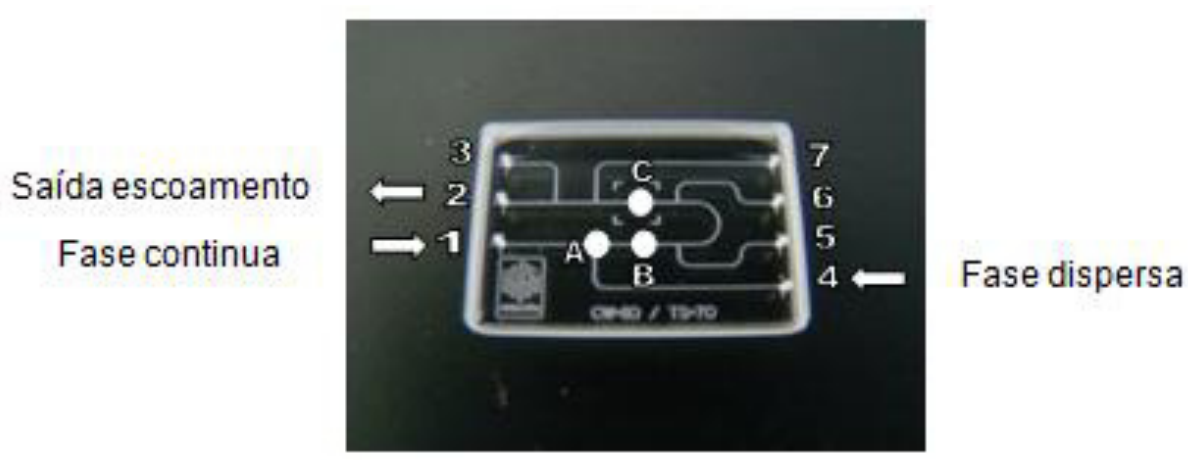

Figura 3.47: Micro capilar utilizado, apresentando a entrada e saída do escoamento bifásico, a região de formação da gota de óleo e as regiões avaliadas no escoamento.

Para a montagem do dispositivo microfluídico, utilizou-se a mesma montagem das mangueiras e torneiras da figura (3.31). 
O sistema foi preenchido com a mistura de água destilada e surfactante, para expulsar o ar do dispositivo e das mangueiras, depois o volume da fase contínua (água destilada com surfactante) e da fase dispersa (óleo), de 0,10 ml cada um, foi inserido lentamente nas seringas Hamilton Gastight de 0,10 ml conectadas as torneiras três vias Embramed ${ }^{\circledR}$ de plástico.

As bombas, seringas e o dispositivo microfluídico foram nivelados com respeito à mesa de trabalho do microscópio ótico invertido Carl Zeiss 40MAT, para evitar deslocamentos durante as medições, como foi mostrado na figura (3.38).

O dispositivo microfluídico foi centralizado e focalizado através do microscópio Carl Zeiss. O sofware AxioVision 4.7 dispõe de uma configuração específica para cada objetiva (uma calibração pré-definida). A objetiva utilizada foi a Zeiss 2,5x/0,075.

As bombas foram ligadas em modo de injeção contínua. Antes de iniciar a captura das imagens, o tempo aproximado de estabilização foi de 10 minutos. A fase contínua foi injetada a uma vazão de $Q=0,03 \mathrm{ml} / \mathrm{h}$, enquanto a vazão da fase dispersa foi modificada com o objetivo de obter gotas de diferentes tamanhos de forma repetitiva. A vazão obtida para a formação de gotas pequenas de comprimento $213 \mu \mathrm{m}$ (520 pixels) foi de $\mathrm{Q}=0,003 \mathrm{ml} / \mathrm{h}$ e para as gotas médias de comprimento $273 \mu \mathrm{m}$ (666 pixels) foi de $\mathrm{Q}=0,02 \mathrm{ml} / \mathrm{h}$. As figuras (3.48a) e (3.48b) apresentam a formação e tamanho da gota pequena e média.

a)

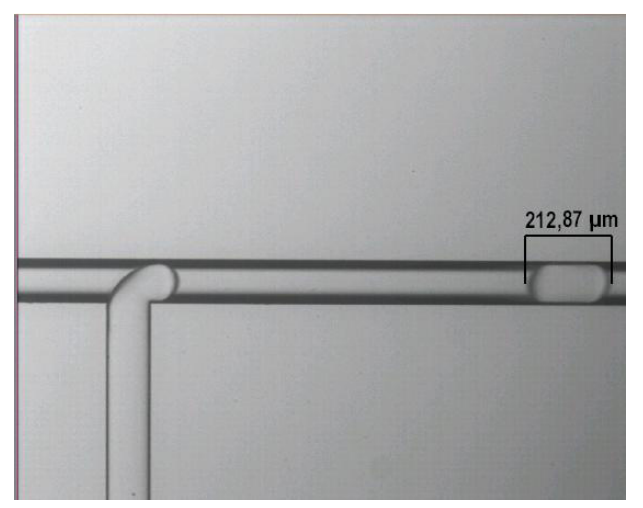

b)

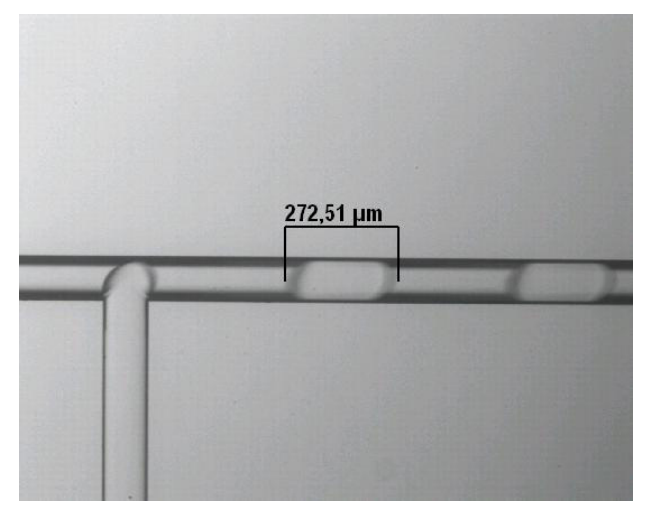

Figura 3.48: a) Formação da gota pequena na junção microfluídica T. b) Formação da gota média na junção microfluídica T. 
Uma vez determinada à vazão de injeção da fase dispersa (óleo) e o comprimento do tamanho de gota, realizou-se o procedimento experimental no sistema $\mu$-PIV, utilizando a bancada experimental da figura (3.39). Para todos os ensaios preliminares e principais no sistema $\mu$-PIV, tanto no micro canal de seção reta constante e na garganta dos micros capilares foram utilizadas as seguintes condições:

- A sequência de ligamento dos equipamentos foi a seguinte: lasers / câmera / sincronizador e o programa Insight $3 \mathrm{G}^{\mathrm{TM}}$;

- Antes de começar os testes, o tempo de espera de aquecimento dos lasers (temperatura ótima de trabalho) foi aproximadamente de 10 minutos.

- Temperatura do laboratório $\mathrm{T}=23^{\circ} \mathrm{C}$;

- A vazão de injeção da fase contínua $Q=0,03 \mathrm{ml} / \mathrm{h}$;

- A vazão de injeção da fase dispersa foi de $Q=0,003 \mathrm{ml} / \mathrm{h}$ para a formação de gotas pequenas e para as gotas médias foi de $Q=0,02$ $\mathrm{ml} / \mathrm{h}$.

Em um primeiro momento, a mistura de água destilada com surfactante foi preenchida no sistema para poder expulsar o ar do dispositivo e das mangueiras. Em seguida, o volume da fase contínua (água destilada, surfactante e partículas fluorescentes) e da fase dispersa (óleo), de 0,10 $\mathrm{ml}$ cada um, foram inseridas lentamente nas seringas Hamilton Gastight de $0,10 \mathrm{ml}$ conectadas as torneiras "três vias" Embramed ${ }^{\circledR}$ de plástico. Foi necessário expulsar o ar nas seringas e nas torneiras, a fim de evitar a presença de bolhas que comprometeriam a medição do campo de velocidade.

As bombas, seringas e o micro capilar foram nivelados com respeito à mesa de trabalho do microscópio de fluorescência Olympus ${ }^{\circledR}$ Mod. IX71S1F-3, para evitar deslocamentos durante as medições.

Finalmente, os equipamentos foram ligados na sequência seguinte: lasers / câmera / sincronizador e o programa Insight $3 \mathrm{G}^{\mathrm{TM}}$.

Nesta segunda abordagem experimental foram utilizados os mesmos parâmetros da primeira abordagem experimental no sistema $\mu$-PIV: campo de visualização do microscópio de diâmetro $2,2 \mathrm{~mm}$; o campo de visualização da câmera $0,88 \mathrm{~mm}$ de largura e $0,66 \mathrm{~mm}$ de altura. A centralização do micro capilar foi achada usando os mesmos acessórios do microscópio e ferramentas do computador. O plano focal do escoamento foi obtido na largura máxima do 
canal do dispositivo microfluídico de $110 \mu \mathrm{m}$. A resolução do sistema $\mu$-PIV foi de $0,41 \mu \mathrm{m} /$ pixel. No caso da concentração das partículas fluorescentes a relação de volume foi de 10:1,4, ou seja, 0,14\% de concentração de partículas suspensas na mistura de água destilada com surfactante. $O$ volume utilizado foi de $1 \mathrm{ml}$, então, o volume da mistura de água destilada com surfactante foi de $0,86 \mathrm{ml}$ e das partículas $0,14 \mathrm{ml}$, tanto no microcanal de seção reta constante assim como no microcanal com uma garganta do micro capilar. Finalmente as imagens foram divididas em janelas de interrogação de 32 × 32 pixels.

\section{5 .}

\section{Limitações e dificuldades encontradas nos processos experimentais}

Durante os testes, tanto na formação de gotas como na medição do campo de velocidade, pequenos movimentos externos às bancadas de trabalho ou perturbações no funcionamento das bombas alteravam a estabilidade na formação das gotas e a velocidade do escoamento. Por isso, que estas duas bancadas experimentais devem estar separadas, um espaço livre e exclusivo para todos os equipamentos utilizados nos dois sistemas.

A preparação das fases, a instalação e, sobretudo, a limpeza do dispositivo microfluídico e os seus acessórios foram um fator importante, para evitar partículas estranhas que possam comprometer a obstrução do dispositivo ou as medições.

Durante a montagem, o micro capilar tinha que ficar completamente fixo e em uma posição horizontal à base do microscópio, para garantir que as partículas avaliadas estejam no mesmo plano de foco no escoamento. Os suportes de fixação do microscópio não o fixavam completamente. Para isso, usou-se de meios de fixação adicionais para evitar qualquer vibração ou movimento externo que podia modificar o campo de visualização das partículas.

O número de partículas fluorescentes foi variado nas janelas de interrogação das imagens adquiridas. Na maioria das janelas de interrogação tinham de 4-8 partículas, mas onde a velocidade era alta, sobretudo na formação da gota média, foram menores. Assim, para compensar a quantidade insuficiente de partículas [48], tirou-se a maior quantidade de imagens e utilizaram-se algoritmos avançados de processamento de imagens, para poder obter campos de velocidades com a maior porcentagem de vetores bons (good vectors). 
A luz emitida pelas partículas fluorescentes não tinham a intensidade suficiente nas imagens devido à limitação de acessórios, como a fibra ótica e o microscópio (50 mJ). Essa restrição impediu que os lasers utilizassem suas máximas capacidades (70 $\mathrm{mJ}$ e $90 \mathrm{~mJ})$.

Devido ao escoamento transiente na formação da gota de óleo, usaram-se imagens que correspondiam a diferentes gotas do mesmo tamanho localizadas na mesma posição. A seleção foi realizada comparando as imagens com uma máscara previamente feita para cada posição da gota, tanto no microcanal de seção reta constante, assim como, no microcanal com garganta do micro capilar. 


\section{Resultados}

Este capítulo apresenta os resultados dos campos de velocidade de um escoamento monofásico (água) e bifásico (gota de óleo suspensa em água), através de um micro canal de seção reta constante e de um micro canal com uma garganta. Os campos de velocidade foram obtidos a partir da captura e processamento das imagens utilizando o software Insight $3 \mathrm{G}^{\mathrm{TM}}$. A figura (4.1) apresenta um resumo dos experimentos realizados no escoamento monofásico e bifásico desta abordagem experimental.
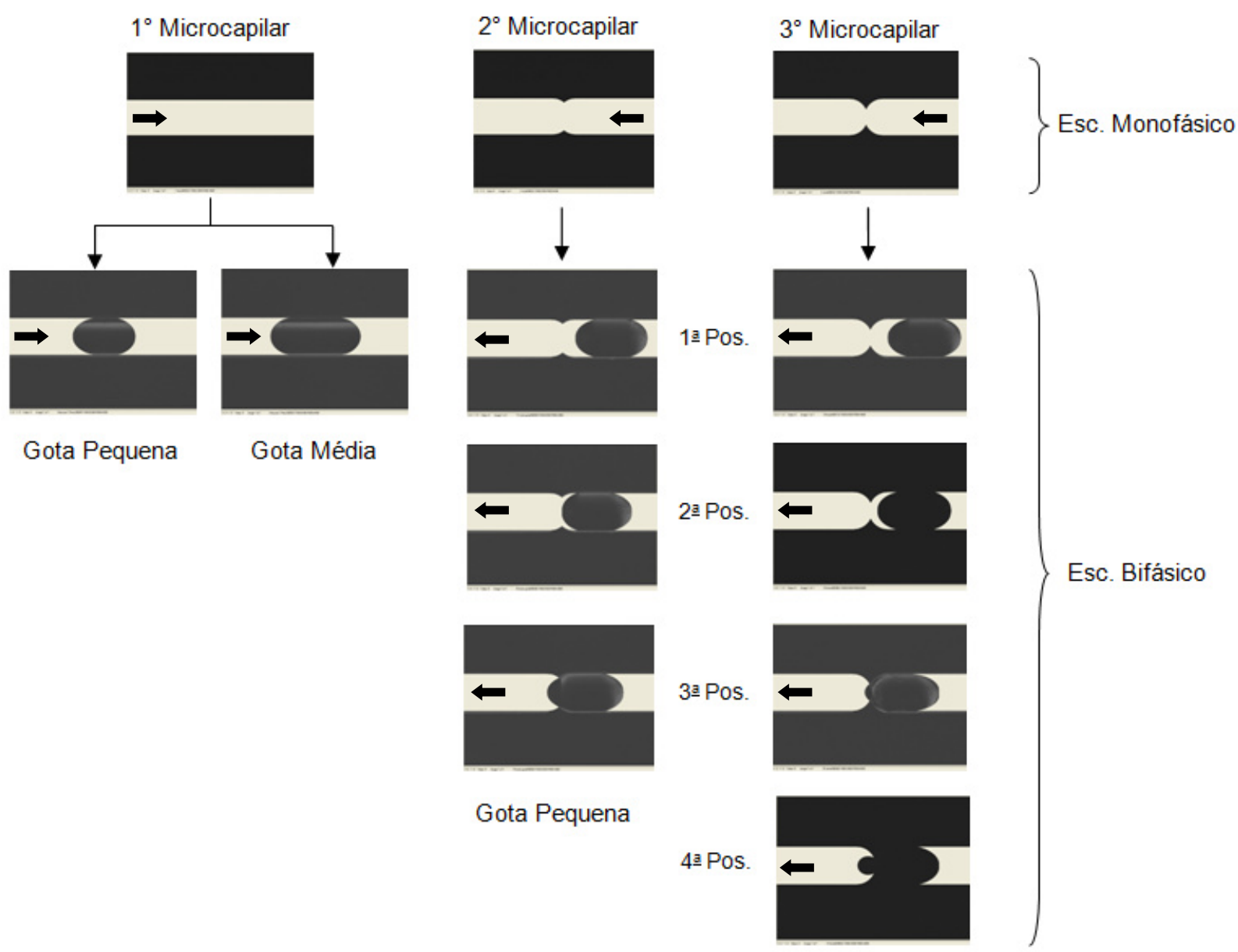

Gota Pequena

Figura 4.1: Resumo dos experimentos realizados. 


\section{1. Medição do campo de velocidade do escoamento monofásico}

Nesta primeira abordagem, determinou-se o campo de velocidade do escoamento monofásico através de um micro canal com seção reta constante e de um micro canal com uma garganta, localizados em posições diferentes no micro dispositivo, como mostrado na figura (3.30). O campo de velocidade foi obtido a partir da captura de imagens, das técnicas de pré-processamento, processamento, pós-processamento, e de máscaras utilizadas para processar a área do escoamento desejada.

Ademais, os resultados obtidos com o sistema $\mu$-PIV foram comparados com a solução analítica do escoamento laminar completamente desenvolvido, no caso do capilar com seção reta constante.

A análise do escoamento monofásico foi importante no desenvolvimento do trabalho, pois serviu de caso base para comparação com o escoamento com uma gota suspensa e quantificou a precisão das medições do campo de velocidade, já que o caso do escoamento com seção reta constante pode ser comparado com a solução analítica do problema.

\subsection{1. \\ Medição do campo de velocidade do escoamento monofásico no micro canal de seção reta constante}

A bomba foi ligada em modo de injeção contínua a uma vazão de $Q=0,03$ $\mathrm{ml} / \mathrm{h}$, devido a efeitos de inércia e ao comprimento das mangueiras, o tempo aproximado de estabilização foi de 15 minutos, após o qual se iniciou a captura das imagens.

Uma área selecionada foi definida através de uma máscara para o processamento das imagens, cujas dimensões foram de 1376 × 269 pixels, ou seja, $564 \mu \mathrm{m}$ de comprimento por $110 \mu \mathrm{m}$ de altura no micro canal de seção reta constante do dispositivo microfluídico. A máscara é mostrada na figura (4.2). 


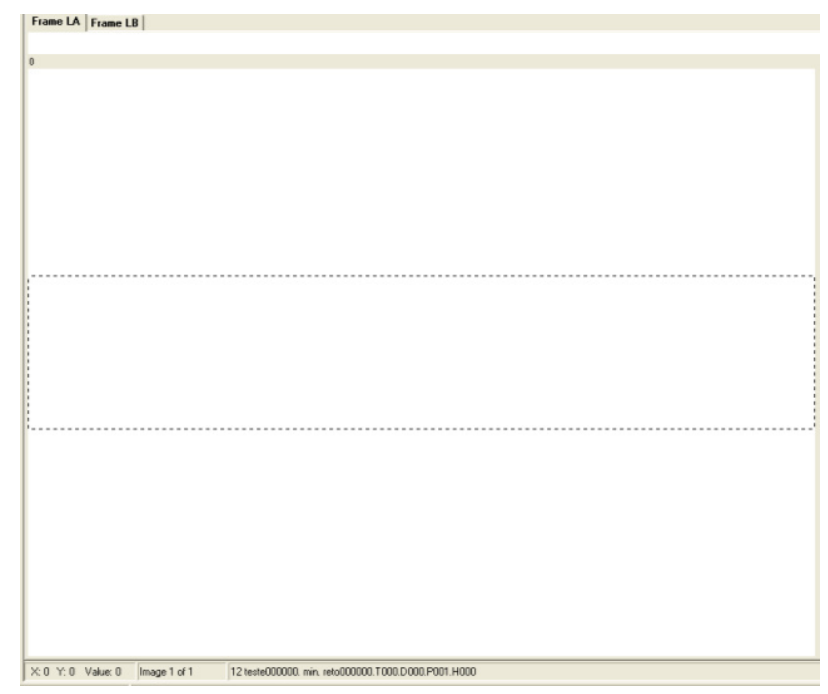

Figura 4.2: Máscara do micro canal de seção reta constante.

Para a captura das imagens, no programa Insight $3 \mathrm{G}^{\mathrm{TM}}$ foram configurados os seguintes parâmetros:

- 100 pares de imagens capturadas consecutivamente;

- Modo de aquisição da imagem "sincronizado";

- Tempo de espera do primeiro pulso laser de $800 \mu \mathrm{s}$;

- Tempo de exposição do sensor da câmera CCD de 1300 Hs;

- Taxa de repetição da frequência dos lasers 4,83 Hz;

- Energia dos lasers em "high".

Para determinar o tempo de separação $\Delta$ t ótimo entre o par de imagens (Frame A e Frame B), ou seja, o tempo de atraso entre os pulsos lasers foi ajustado de tal forma que os deslocamentos das partículas fluorescentes não devem exceder de $25 \%$ da dimensão da área da janela de interrogação [20]. Testou-se, tirando uma foto para diferentes tempos, e o valor ótimo encontrado foi de $1400 \mu$ s. Nosso caso, a janela de interrogação foi de $32 \times 32$ pixels, assim, o deslocamento máximo permitido foi de $0,25 \times 32$ pixels $=8$ pixels. As janelas de interrogação onde às velocidades foram maiores, o deslocamento das partículas foi de 6-7 pixels, cumprindo a regra básica de PIV.

Após a captura das imagens, um pré-processamento foi feito na sequência de imagens. As imagens de fundo de intensidade mínimo/médio (Minimum Intensity Image/ Average Intensity Image) foram usadas para detectar partículas fixas, paredes e manchas no escoamento avaliado, que contribuem para o ruído 
de fundo. Essa intensidade de fundo foi removida de cada imagem original utilizando a técnica de subtração de fundo "background subtraction", para aumentar a relação sinal/ruído e obter uma melhor qualidade das imagens originais.

Para o processamento das imagens, no programa Insight $3 G^{\mathrm{TM}}$ foram configurados os seguintes parâmetros:

- O tamanho das janelas de interrogação ou resolução espacial foi de $32 \times 32$ pixels $\left(13,1 \times 13,1 \mu \mathrm{m}^{2}\right)$;

- O máximo deslocamento das partículas foi de "25\% do tamanho da janela de interrogação";

- A calibração do sistema foi de 0,41 $\mu \mathrm{m} /$ pixel.

A técnica de processamento de imagens "ensemble average" foi utilizada para determinar o campo de velocidade do escoamento analisado. Esta técnica consiste em criar um campo vetorial, a partir da média amostral de vários campos instantâneos [21]. É utilizado na análise de escoamentos de fluxos constantes em geometrias de escala micrométrica, a fim de minimizar os problemas de um número insuficiente de partículas nas imagens, reduzir a porcentagem de erro devido ao movimento Browniano das partículas [21], e aumentar a relação sinal/ruído na correlação de picos.

O processamento foi feito através de um só passo de processamento e dividindo a imagem em um grid de pontos para formar o campo vetorial "Nyquist Grid', sendo as janelas de interrogação inicial e final iguais. Para a correlação do mapeamento foi utilizada o método clássico da transformada rápida de Fourier "FFT Correlator", e para a localização do pico foi utilizada a função gaussiana "Gaussian Peak".

Depois do processamento realizado, um pós-processamento foi feito na sequência de imagens para remover os falsos vetores, preencher buracos e suavizar o campo vetorial. Primeiro, utilizou-se a técnica "Vector Local Median Validation", que utiliza a mediana de todos os seus vetores de vizinhança de cada vetor, para calcular um vetor de referência para validação. Finalmente, a técnica "Vector Conditioning", que utiliza a média dos vetores de vizinhança ao redor do buraco para preenchê-los, e um filtro passa baixa tipo gaussiano para suavizar o campo vetorial. Ambas as técnicas disponíveis no programa Insight $3 G^{T M}$. 
A figura (4.3) apresenta os campos de vetores de velocidade de 1, 5, 10, 20 e 100 pares de imagens consecutivas processadas no programa Insight $3 G^{T M}$, através do micro canal de seção reta constante do micro capilar. A porcentagem de vetores válidos aumentou no campo vetorial conforme mais imagens foram processadas (método ensemble average), cujos valores foram de $61,25 \%, 93,7 \%, 97,16 \%, 98,68 \%$ e $100 \%$ de vetores válidos. Além disso, a figura (4.4) mostra os perfis experimentais para os diferentes pares de imagens processadas, observando-se que para 100 pares de imagens o perfil experimental é bastante próximo ao perfil parabólico.

(1) $\longmapsto$

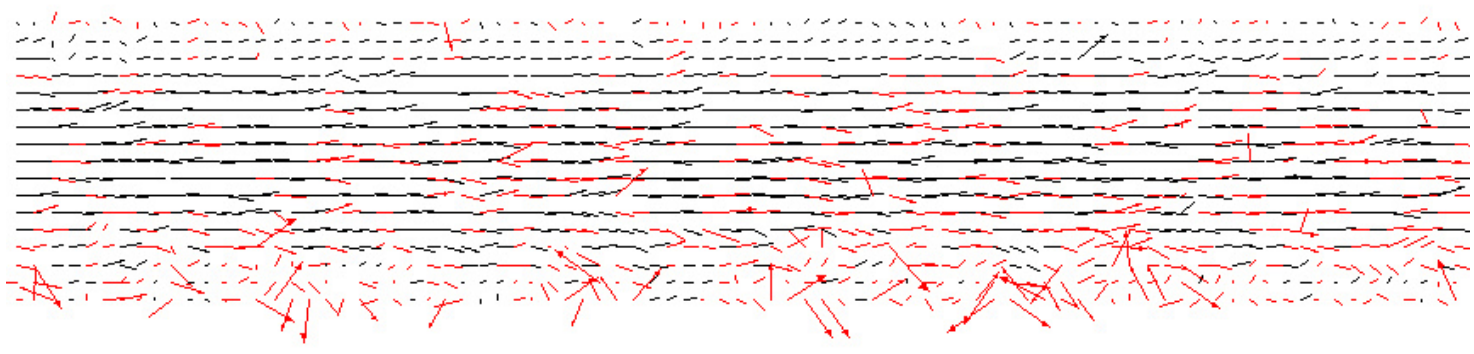

(5)

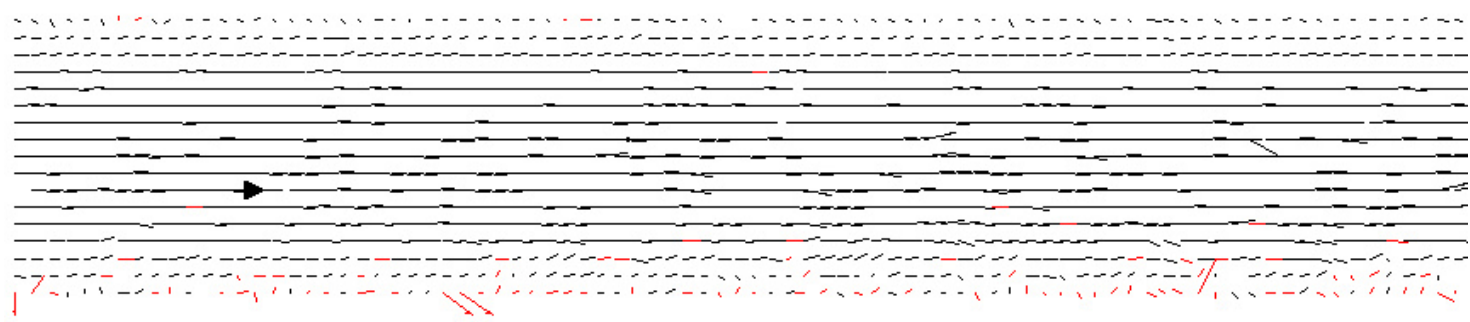

(10)

.

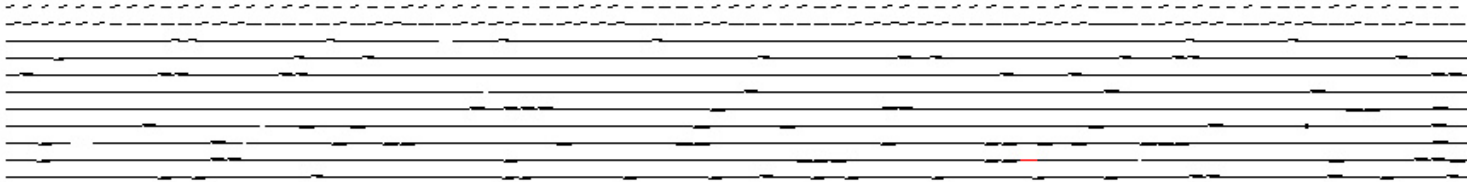
(1) 
(20)

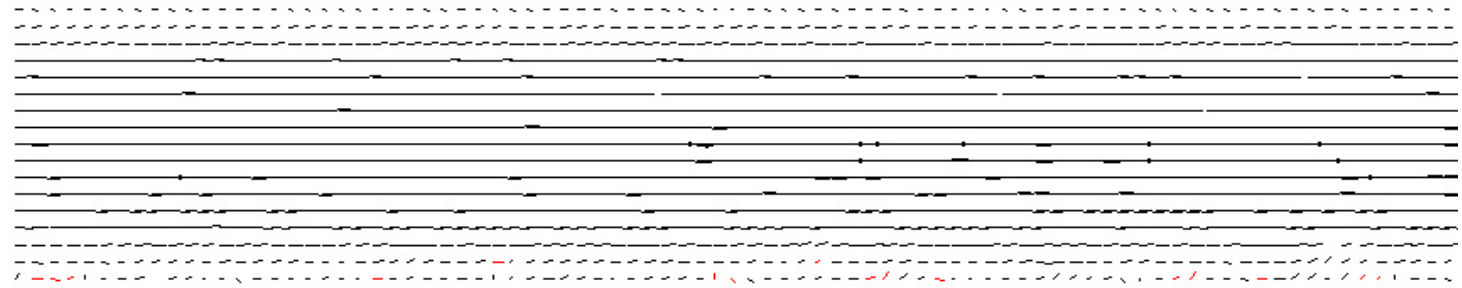

(100)
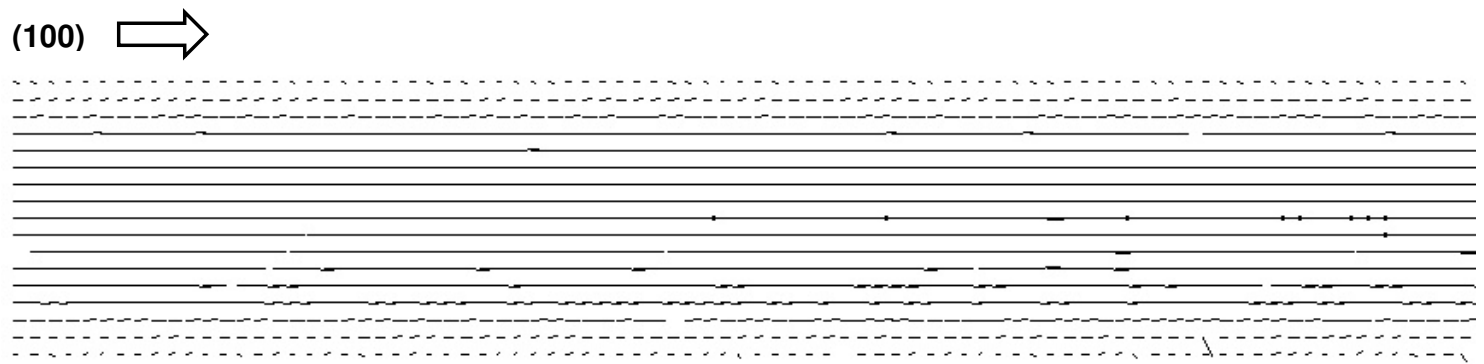

Figura 4.3: Campos de vetores de velocidade produzido do processamento de 1, 5, 10, 20 e 100 pares de imagens, realizado no software Insight $3 G^{T M}$, através do micro canal de seção reta constante.

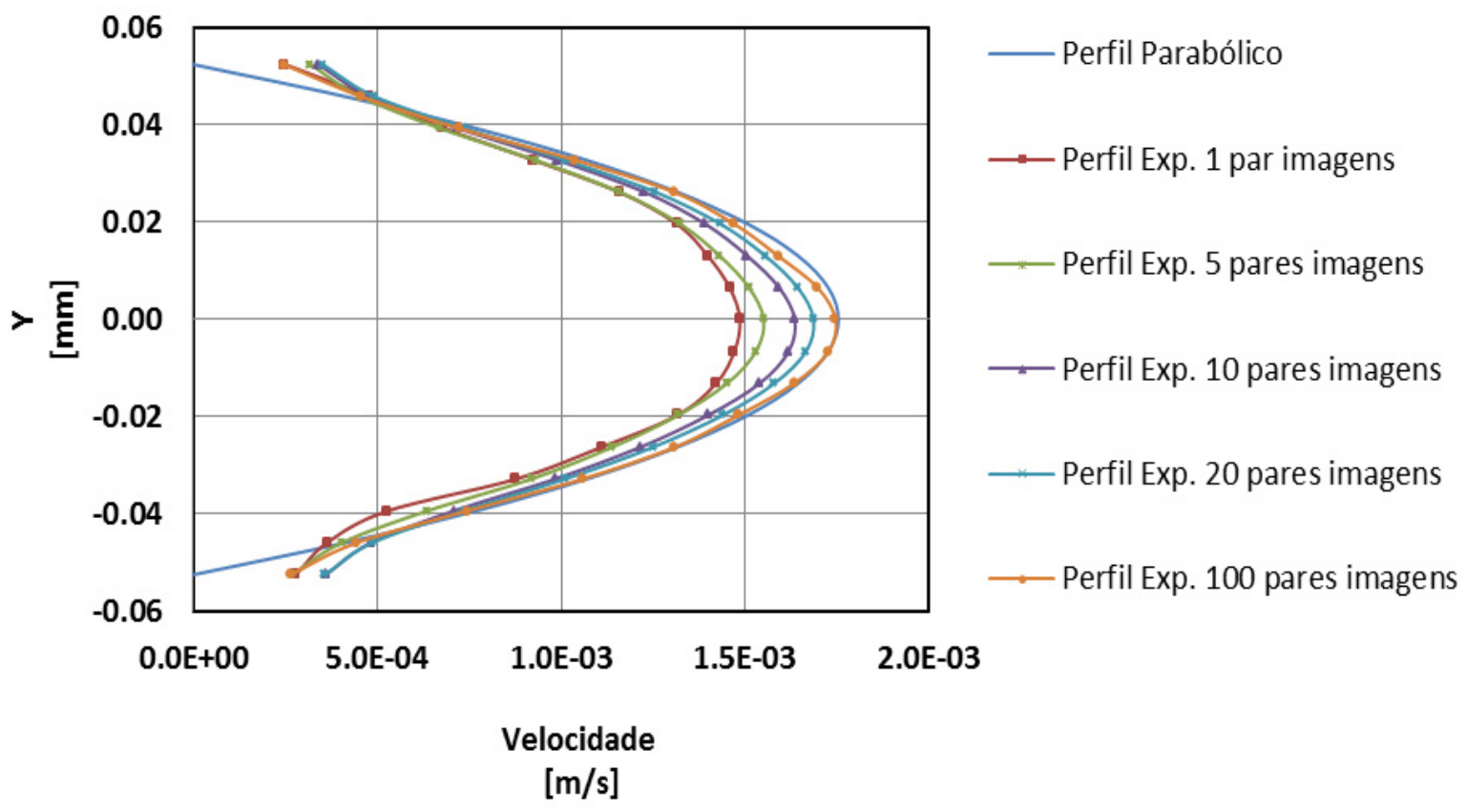

Figura 4.4: Comparação do perfil parabólico e experimental para diferentes pares de imagens através do micro canal de seção reta constante.

O Insight $3 \mathrm{G}^{\mathrm{TM}}$ fornece dados no formato utilizado pelo software de visualização de escoamento "Tecplot ${ }^{\circledR}$, que tem como funções visualizar, 
administrar os dados obtidos e calcular as propriedades do fluxo. A figura (4.5) apresenta o campo de velocidade do escoamento monofásico em unidades de $\mathrm{m} / \mathrm{s}$. O número de perfis de velocidade obtido foi de 85 , e o número de vetores velocidade por perfil foi de 17. Na figura (4.6) é mostrada a metade dos perfis de velocidade, onde o escoamento apresenta claramente a forma parabólica esperada nesta situação.
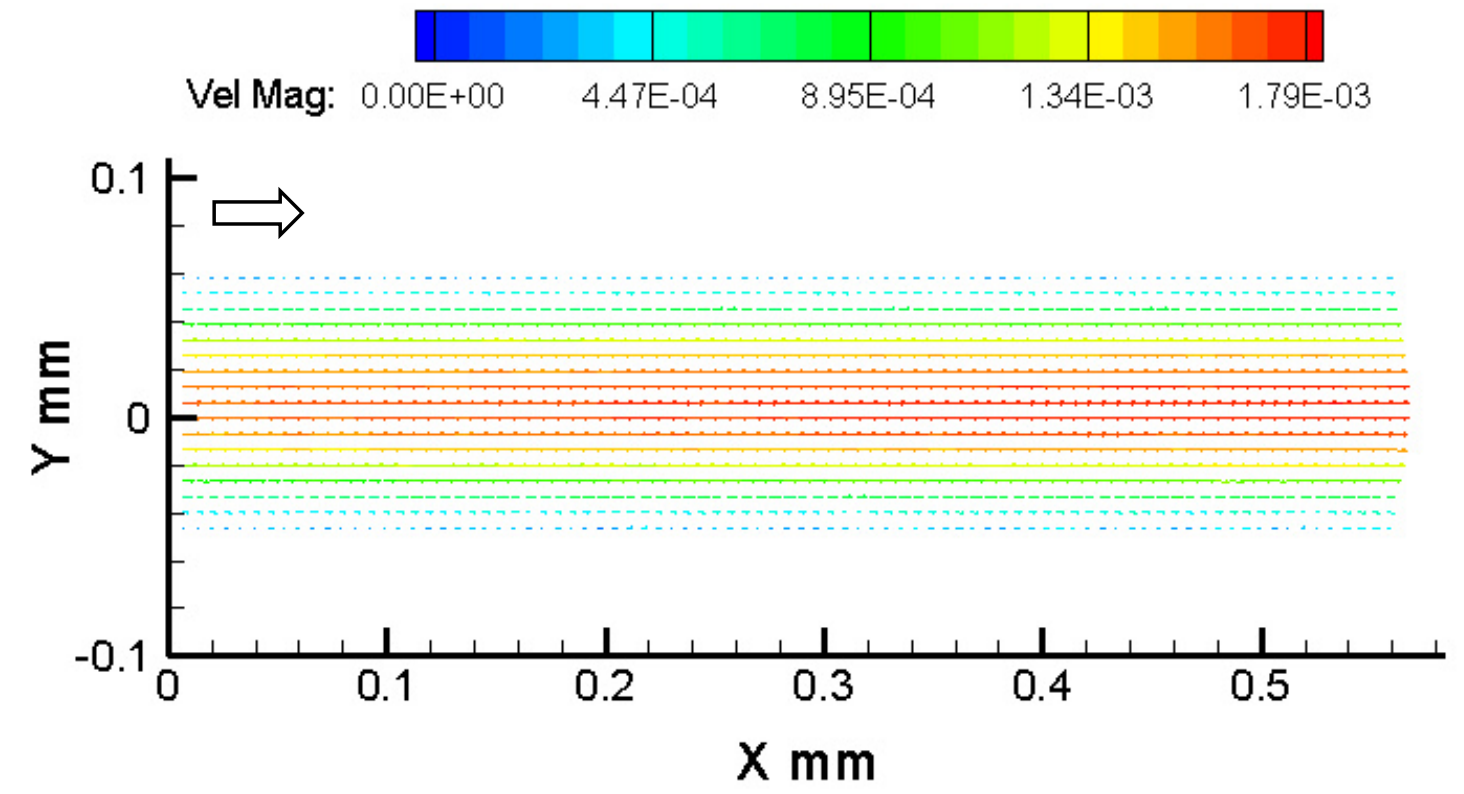

Figura 4.5: Campo de velocidade do escoamento monofásico de 100 pares de imagens,

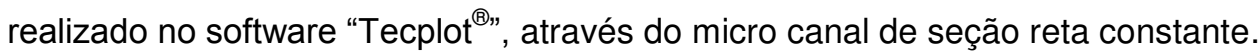

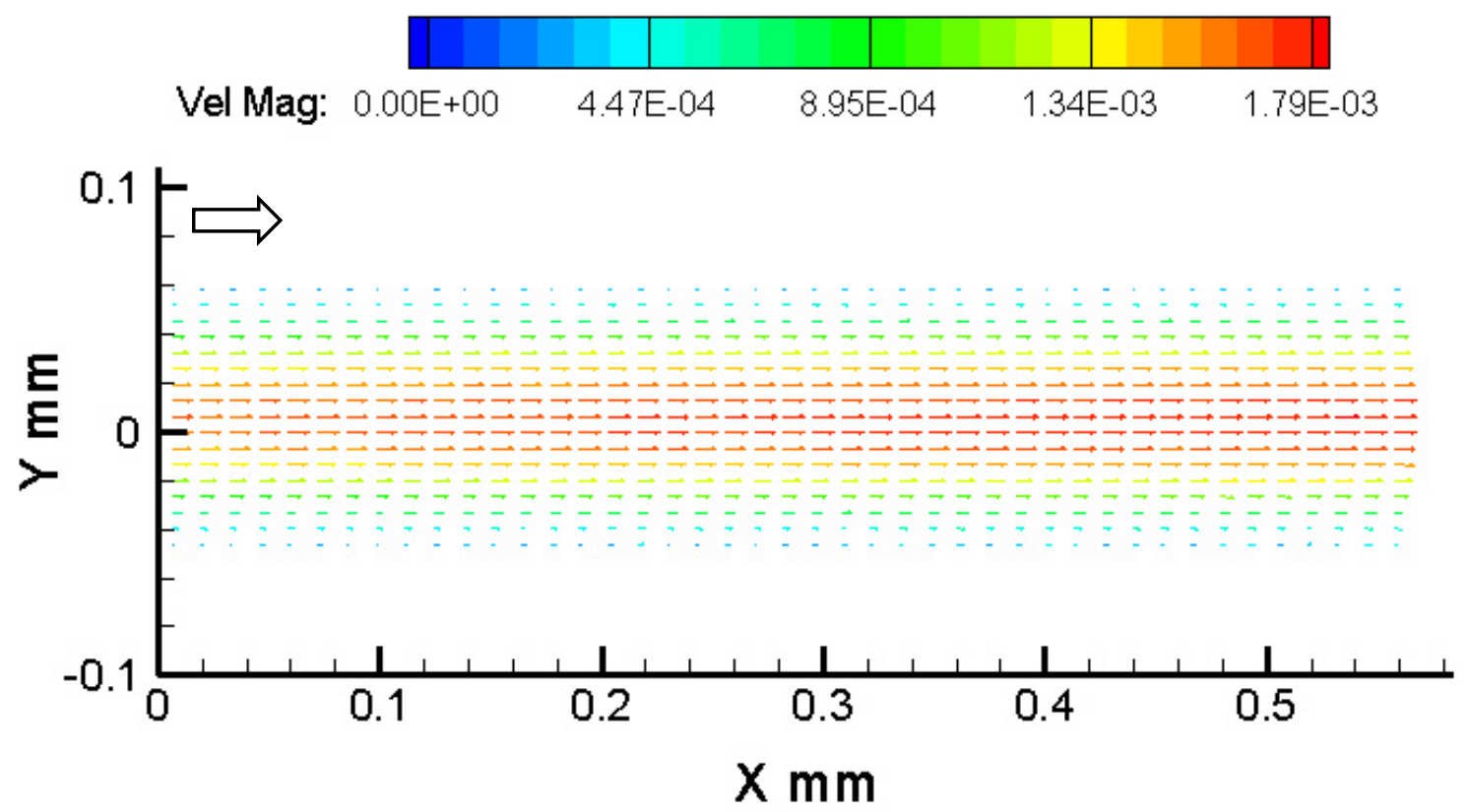


Figura 4.6 Campo de velocidade do escoamento monofásico mostrando $50 \%$ dos perfis de velocidade, através do micro canal de seção reta constante.

O campo de velocidade resultante da figura (4.5) foi avaliado segundo dois critérios:

A velocidade experimental média do campo vetorial foi comparada com a velocidade média injetada pela bomba de seringa. A velocidade experimental média obtida da integração dos perfis de velocidade foi de $8,73 \times 10^{-4} \mathrm{~m} / \mathrm{s}$, enquanto a velocidade de injeção real foi de $8,76 \times 10^{-4} \mathrm{~m} / \mathrm{s}$. O erro percentual da velocidade média foi de apenas de $0,44 \%$.

O perfil de velocidade medido experimentalmente foi comparado com o perfil teórico obtido através da solução analítica do escoamento desenvolvido (perfil parabólico) [49]. Os valores de velocidade experimentais média foram determinados para cada posição, na direção vertical, ao longo dos seus 85 perfis no campo de velocidade. Os perfis de velocidade experimental (media, mínimo e máximo) e analítico (parabólico) são apresentados na figura (4.7), confirmando a forma parabólica do perfil de velocidade experimental média, e os valores calculados analítica e experimentalmente são bastante próximos.

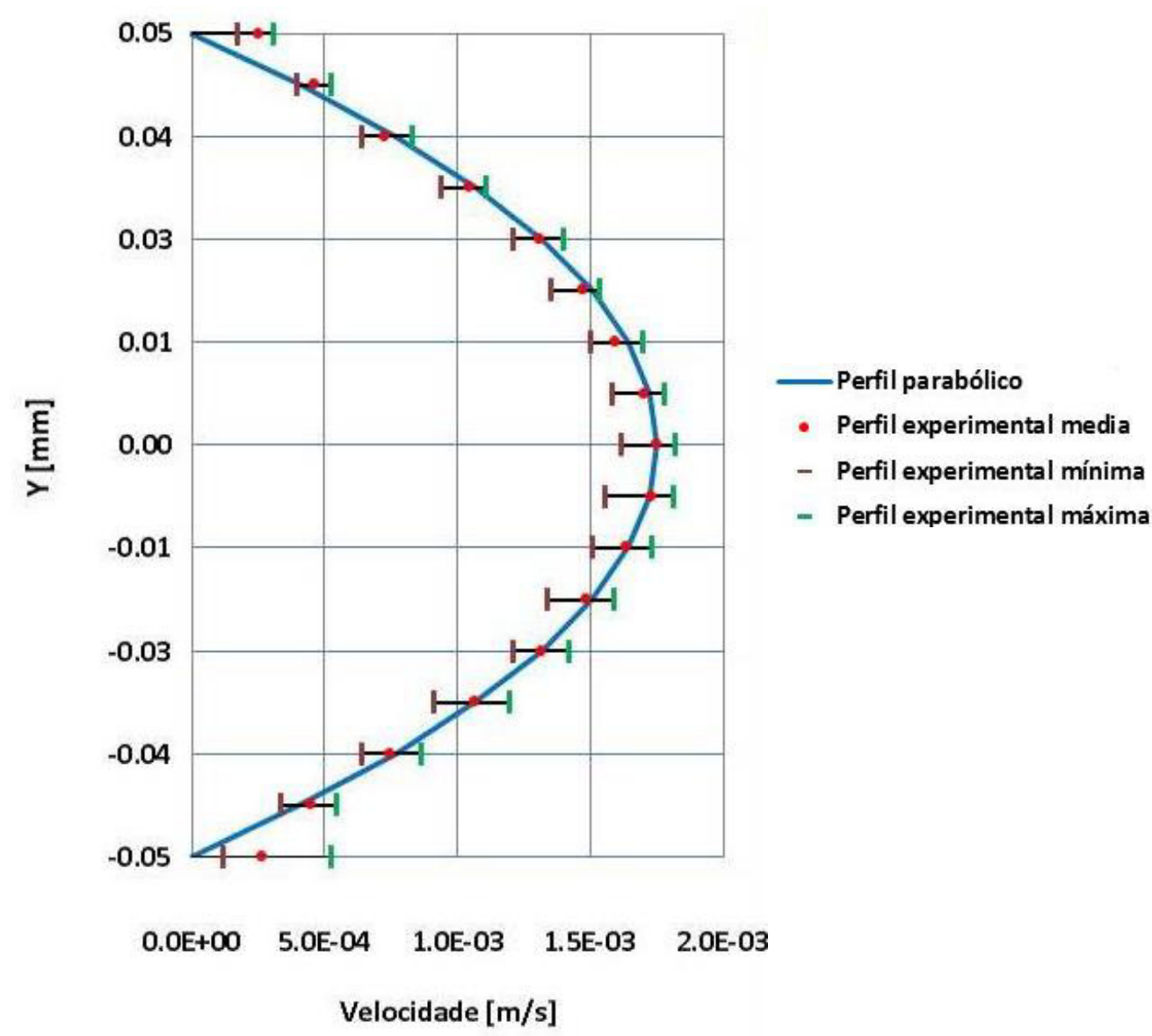


Figura 4.7: Comparação do perfil parabólico e experimental média, mínima e máxima através do micro canal de seção reta constante.

\subsection{2. \\ Medição do campo de velocidade do escoamento monofásico no micro canal com garganta}

$\mathrm{Na}$ análise no micro canal com garganta, a bomba foi ligada em modo de injeção contínua a uma vazão de $Q=0,03 \mathrm{ml} / \mathrm{h}$, e o tempo aproximado de estabilização foi de 15 minutos, após o qual iniciou-se a captura das imagens. A medição do campo de velocidade foi realizada para 2 micro capilares de diferentes diâmetros de garganta.

O primeiro micro capilar utilizado tem um comprimento na garganta de 70 $\mu \mathrm{m}$, e um diâmetro máximo e mínimo de $110 \mu \mathrm{m}$ e $85 \mu \mathrm{m}$ respectivamente. $\mathrm{O}$ segundo micro capilar utilizado tem um comprimento na garganta de $100 \mu \mathrm{m}$, e um diâmetro máximo e mínimo de $110 \mu \mathrm{m}$ e $46 \mu \mathrm{m}$ respectivamente. A área selecionada para o processamento das imagens foi definida através de uma máscara. A máscara do primeiro micro capilar cujas dimensões foram de $1376 \mathrm{x}$ 269 pixels, ou seja, $564 \mu \mathrm{m}$ de comprimento por $110 \mu \mathrm{m}$ de altura. A máscara foi ajustada de forma a seguir a geometria da garganta, com $85 \mu \mathrm{m}$ de diâmetro mínimo, conforme mostrado na figura (4.8). A máscara do segundo micro capilar cujas dimensões foram de $1376 \times 269$ pixels, ou seja, $564 \mu \mathrm{m}$ de comprimento por $110 \mu \mathrm{m}$ de altura, a máscara foi ajustada também na geometria da garganta, com $46 \mu \mathrm{m}$ de diâmetro mínimo, conforme mostrado na figura (4.9).

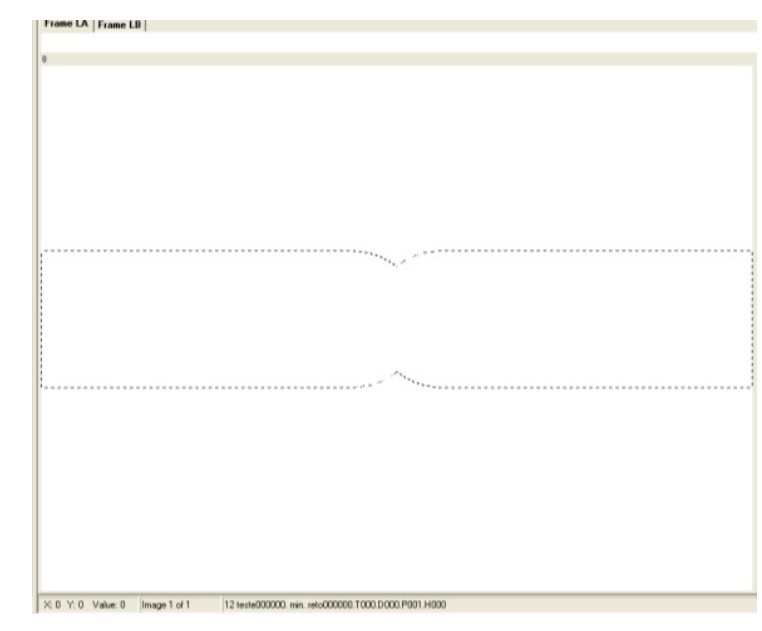

Figura 4.8: Máscara do micro canal com garganta do primeiro micro capilar. 


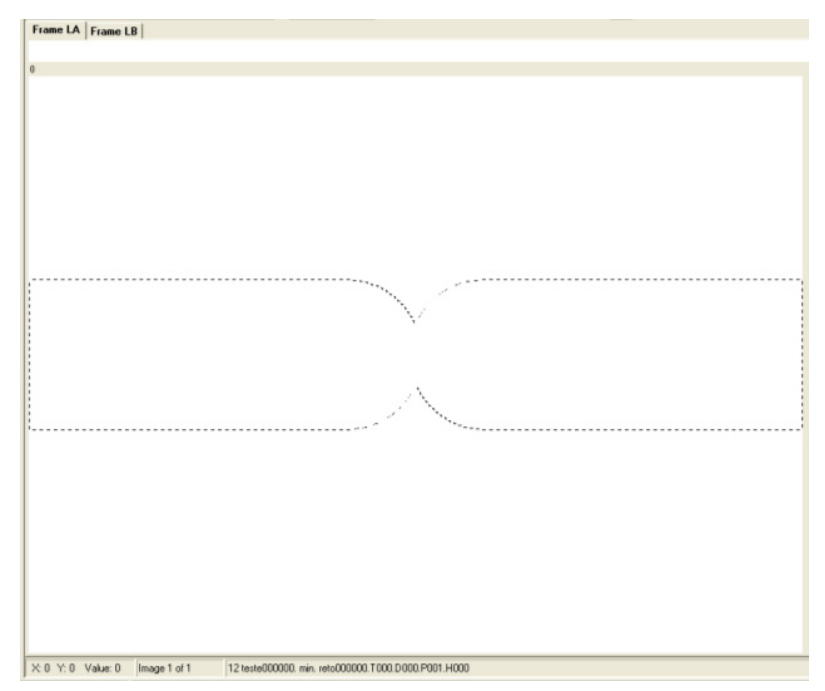

Figura 4.9: Máscara do micro canal com garganta do segundo micro capilar.

Na captura das imagens no programa Insight $3 G^{T M}$, foram configurados os mesmos parâmetros usados no primeiro experimento do escoamento monofásico, com a diferença que o tempo de separação $\Delta$ t entre o par de imagens foi de $1200 \mu$ s para o primeiro micro capilar, e de $600 \mu$ s para o segundo micro capilar. Ambos os micro canais com garganta foi utilizado uma janela de interrogação de $32 \times 32$ pixels. O deslocamento máximo permitido foi de 0,25 × 32 pixels $=8$ pixels. A imagem mostrou ao longo da garganta onde a velocidade foi maior, um deslocamento das partículas entre 5-7 pixels no primeiro micro canal com garganta.

Para o pré-processamento de uma sequência de 100 pares de imagens consecutivas foram usadas as técnicas "Imagem de intensidade mínimo/médio" e "subtração de fundo", para ambos os microcanais com garganta.

Para o processamento das imagens, no programa Insight $3 G^{\mathrm{TM}}$ foram configurados os seguintes parâmetros:

- O tamanho das janelas de interrogação ou resolução espacial foi de $32 \times 32$ pixels $\left(13,1 \times 13,1 \mu \mathrm{m}^{2}\right)$;

- O máximo deslocamento das partículas foi de " $25 \%$ do tamanho da janela de interrogação";

- A calibração do sistema foi de 0,41 $\mu \mathrm{m} /$ pixel.

As técnicas "Média Amostral", "Nyquist Grid", "Correlação da Transformada da Fourier" e "Pico Gaussiano" foram usados para o processamento de uma 
sequência de 100 pares de imagens consecutivas, nos 2 micro canais com garganta.

Para o pós-processamento dos 100 pares de imagens coletadas foram utilizados a técnica "Validação do vetor mediana local" e "Vetor condição", para ambos os microcanais com garganta.

As figuras (4.10) e (4.11) apresentam o campo de vetores de velocidade (obtido a partir dos 100 pares de imagens consecutivas processadas no software Insight $3 \mathrm{G}^{\mathrm{TM}}$ ) no escoamento através do primeiro e segundo micro canal com garganta. A porcentagem de vetores válidos no campo vetorial foi de $99,44 \%$ e $99,57 \%$ antes do pós-processamento.

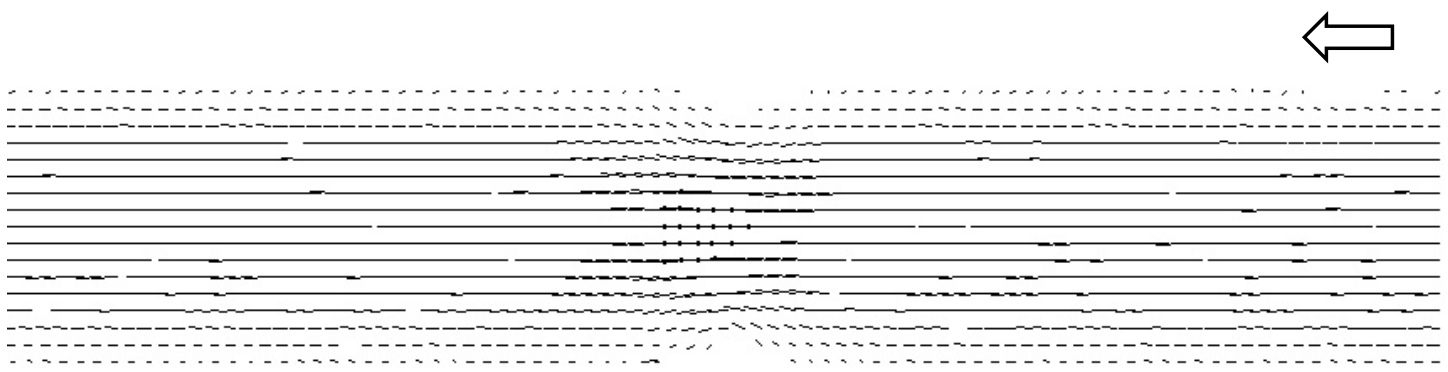

Figura 4.10: Campo de vetores de velocidade produzido do processamento de 100 pares de imagens, realizado no software Insight $3 G^{T M}$, através do primeiro micro canal com garganta.

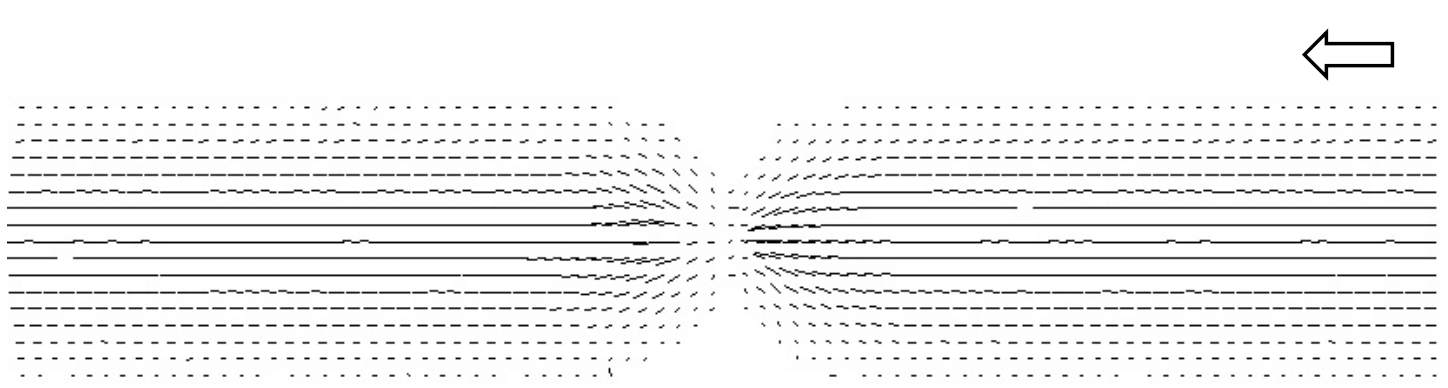

Figura 4.11: Campo de vetores de velocidade produzido do processamento de 100 pares de imagens, realizado no software Insight $3 G^{\mathrm{TM}}$, através do segundo micro canal com garganta. 


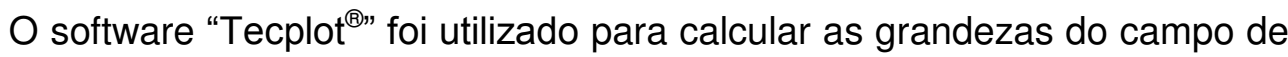
velocidade da fase contínua. A figura (4.12) apresenta o campo de velocidade do escoamento monofásico através do primeiro micro canal com garganta. O campo vetorial obtido depois do pós-processamento foi de 85 perfis de velocidade. $\mathrm{Na}$ região de maior diâmetro, o número de vetores velocidade em cada linha vertical foi de 17 , e na região menor (garganta) foi de 13 vetores de velocidade. $\mathrm{Na}$ figura (4.13) é possível observar o comportamento parabólico do escoamento monofásico; a metade dos perfis de velocidade foi retirada para facilitar a visualização.

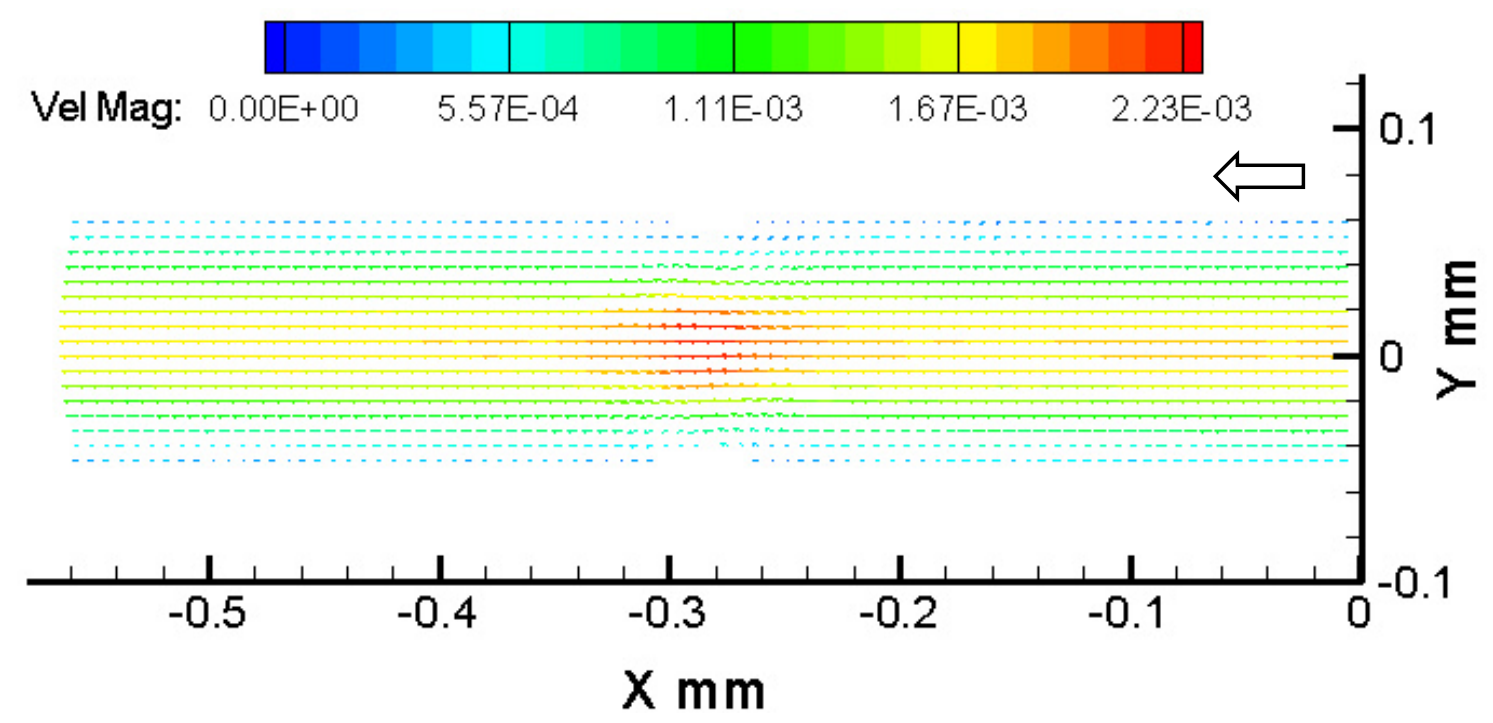

Figura 4.12 Campo de velocidade do escoamento monofásico de 100 pares de imagens, realizado no software Tecplot ${ }^{\circledR}$, através do primeiro micro canal com garganta.

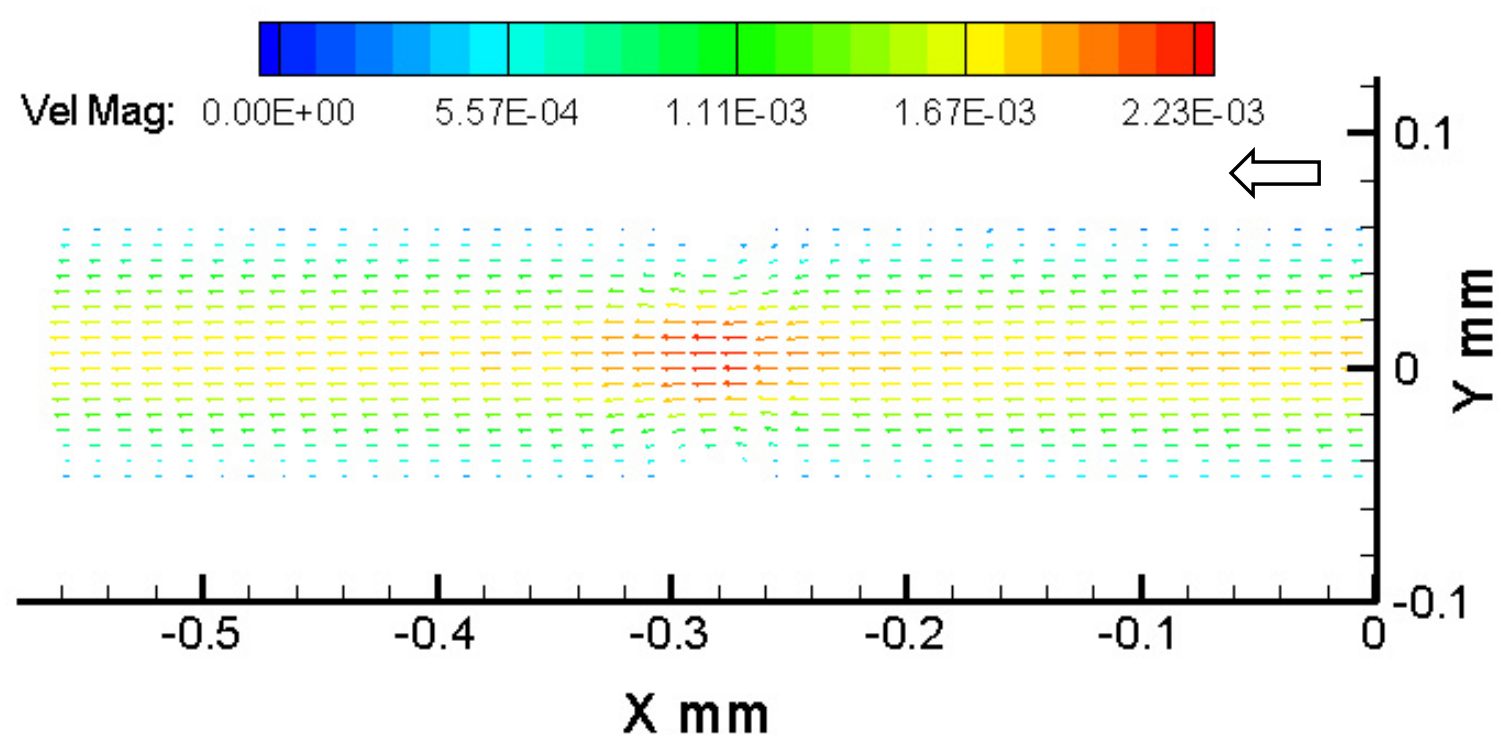


Figura 4.13: Campo de velocidade do escoamento monofásico mostrando $50 \%$ dos perfis de velocidade, através do primeiro micro canal com garganta.

As figuras (4.14) e (4.15) apresentam o campo de velocidade do escoamento monofásico através do segundo micro canal com garganta, mostrando também $50 \%$ dos perfis de velocidade para facilitar a visualização. $O$ escoamento monofásico é composto de 85 perfis de velocidade. Na região de maior diâmetro, o número de vetores velocidade em cada linha vertical foi de 17 , e na região menor (garganta) foi de 7 vetores de velocidade.

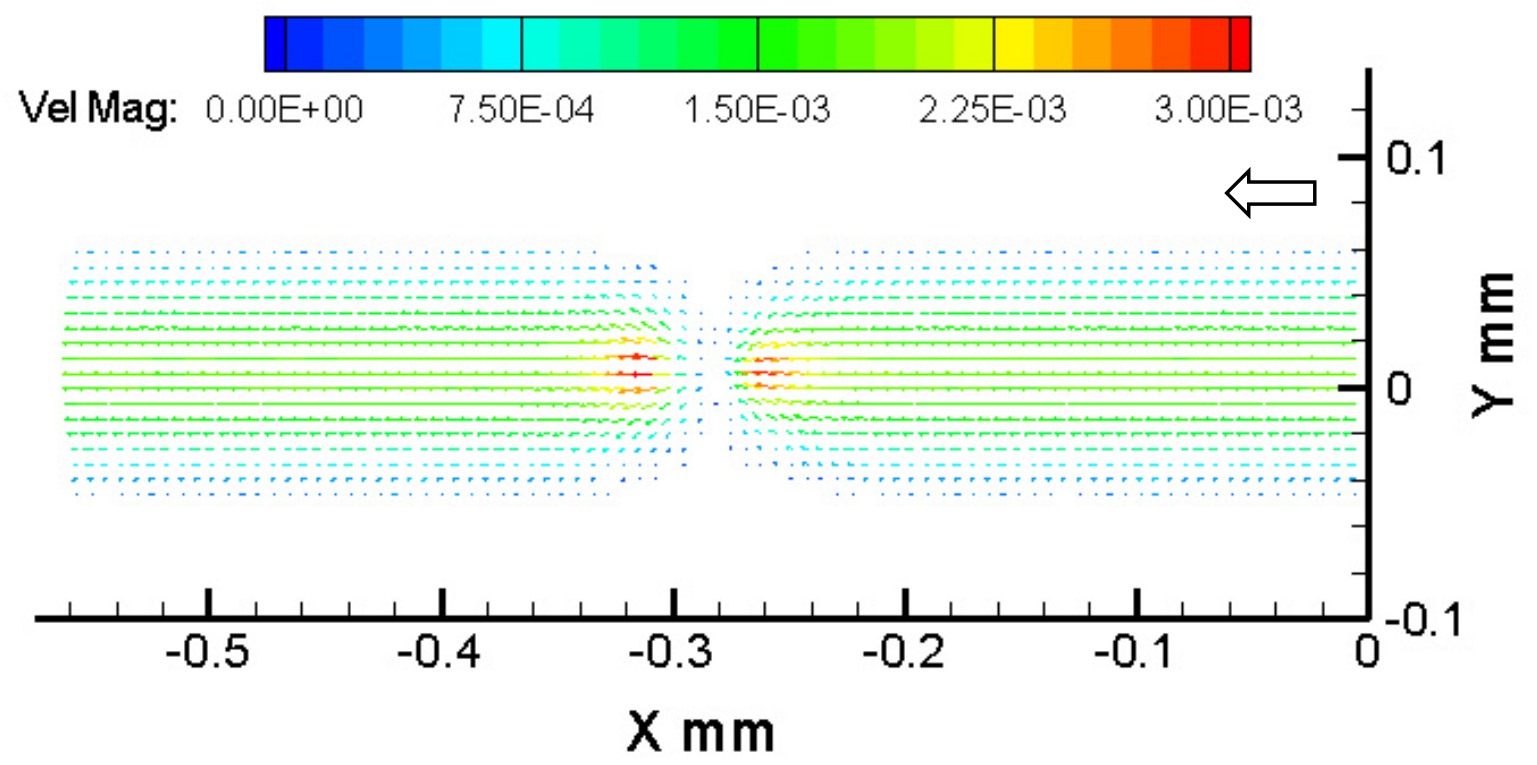

Figura 4.14 Campo de velocidade do escoamento monofásico de 100 pares de imagens, realizado no software Tecplot ${ }^{\circledR}$, através do segundo micro canal com garganta.

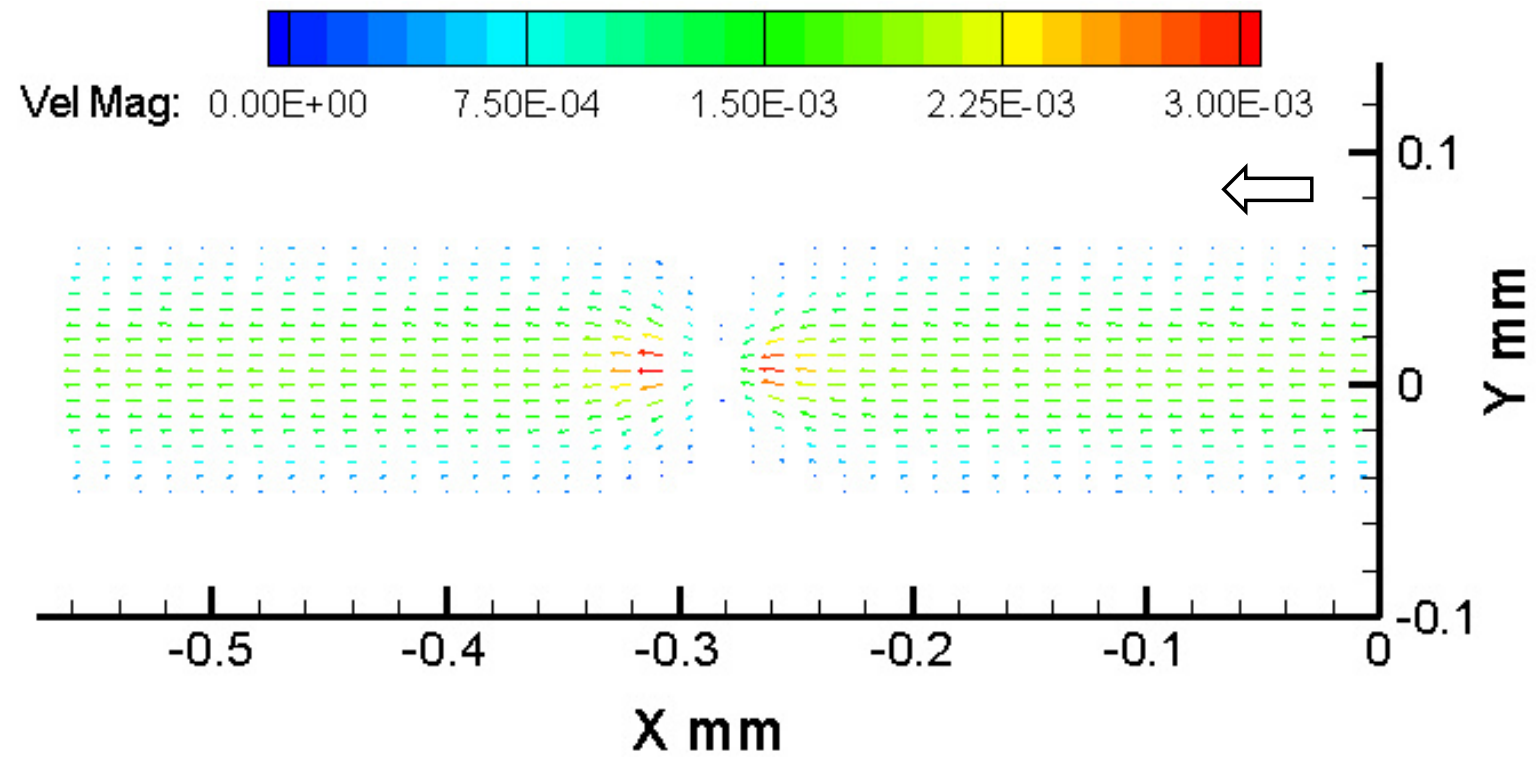


Figura 4.15: Campo de velocidade do escoamento monofásico mostrando $50 \%$ dos perfis de velocidade, através do segundo micro canal com garganta.

$\mathrm{Na}$ parte convergente (entrada) da garganta do primeiro micro canal, a velocidade média do escoamento aumenta conforme decresce o diâmetro do dispositivo microfluídico, e na parte divergente (saída), a velocidade média do escoamento diminui conforme cresce o diâmetro. Tal comportamento pode ser melhor visualizado na figura (4.16), que apresenta um zoom na região da garganta. A figura (4.17) apresenta a variação da velocidade média em cada seção ao longo do capilar.

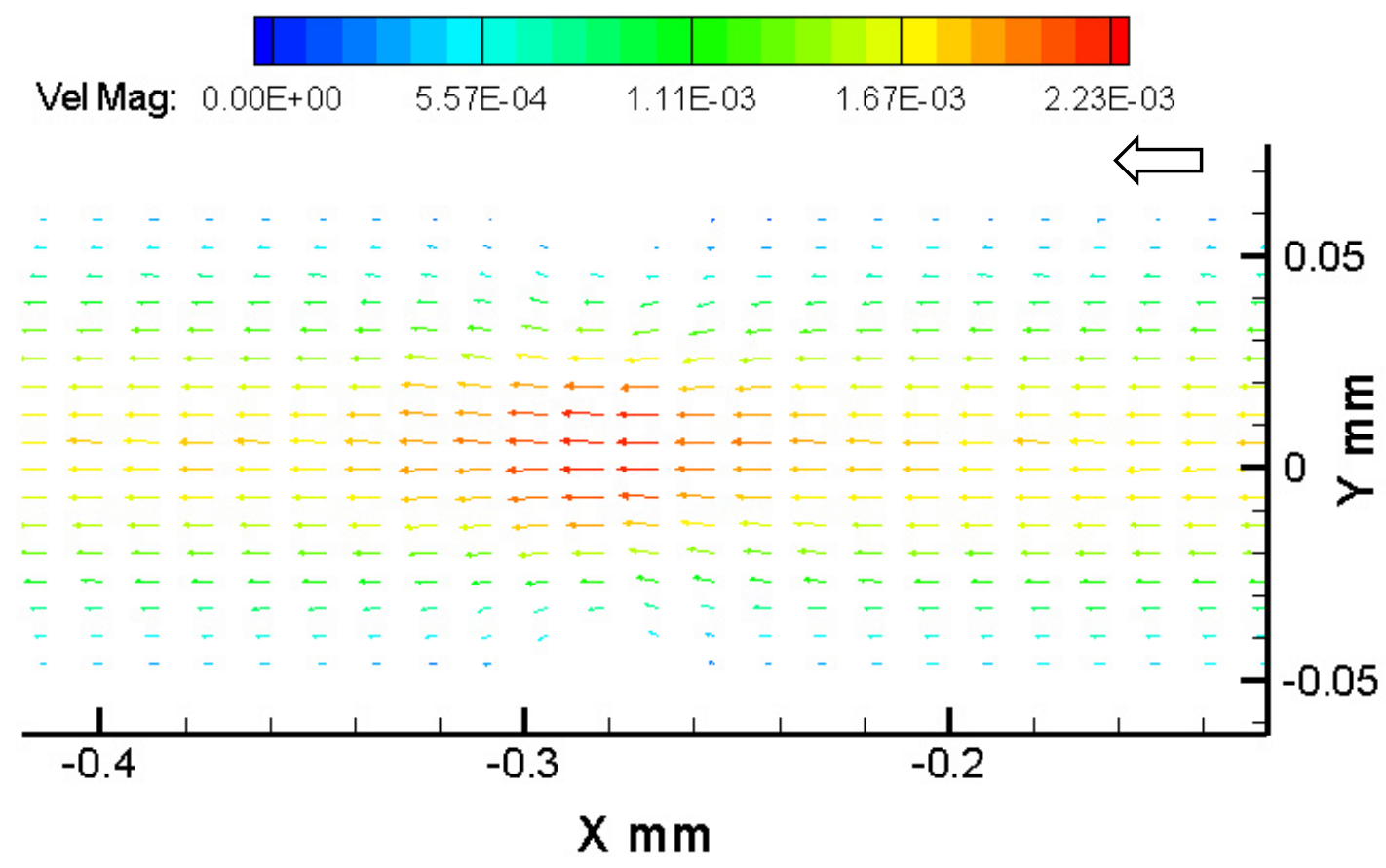

Figura 4.16: Região convergente e divergente na garganta do primeiro micro canal.

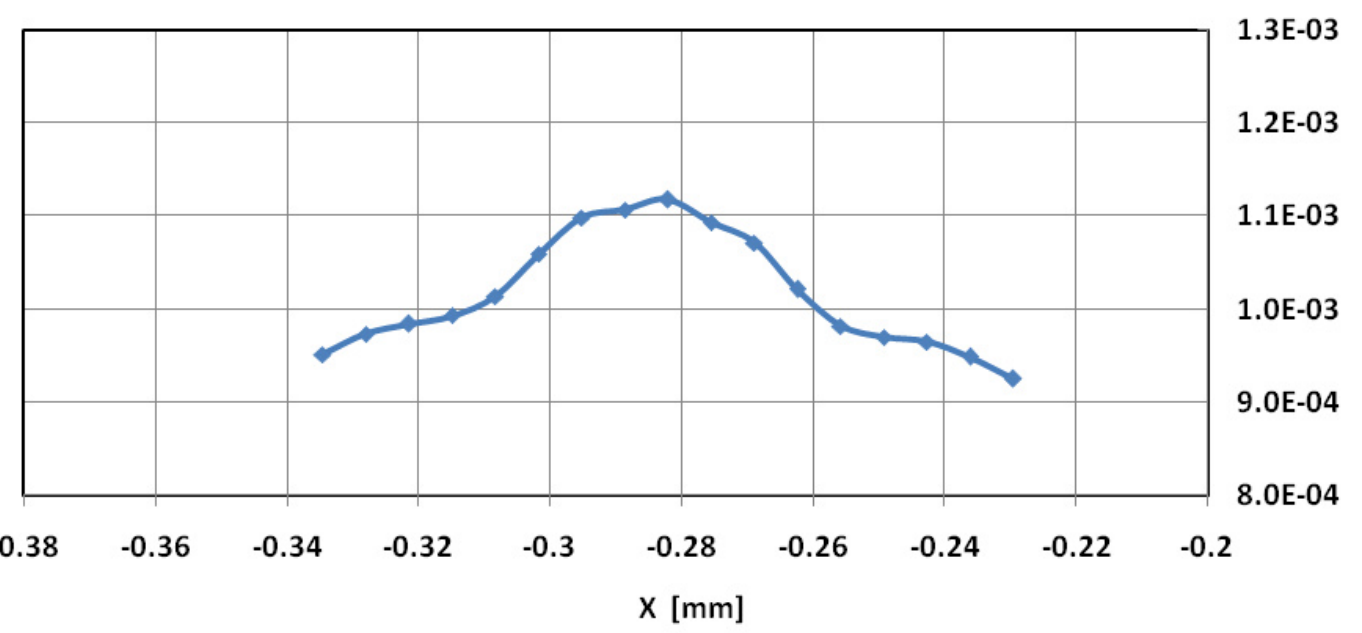


Figura 4.17: Variação da velocidade média do escoamento através da garganta.

Wereley [50] apresentou o campo de velocidade de um escoamento através de um micro-bocal (convergente-divergente) de $50 \mu \mathrm{m}$ de profundidade. Uma sequência de 10 pares de imagens foi processada. A resolução espacial utilizada foi de 10,9 $\mu \mathrm{m}$ na direção horizontal e de 5,4 $\mu \mathrm{m}$ na vertical, a lente da objetiva foi de $40 x$ e a vazão de injeção foi de $4 \mathrm{ml} / \mathrm{h}$. Os campos obtidos neste trabalho são bastante similares ao apresentado na figura (4.18).

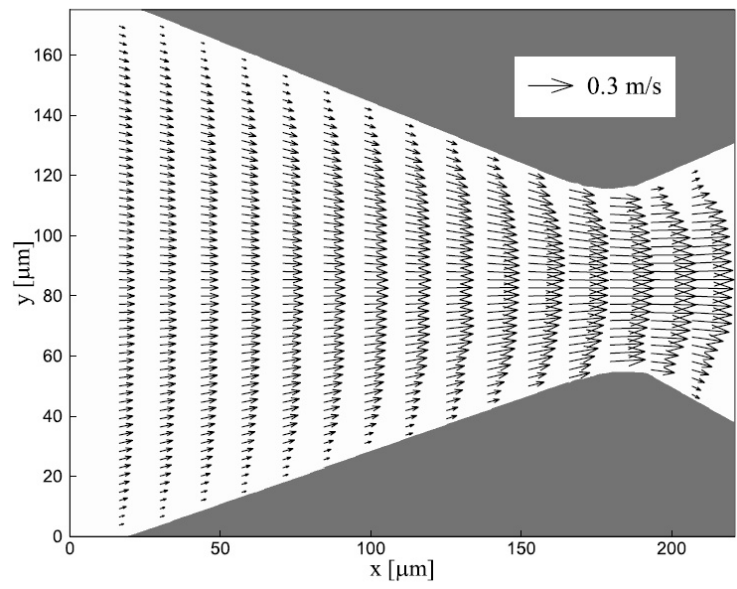

Figura 4.18: Campo de vetor de velocidade produzido de 10 pares de imagens sobrepostas realizada por Wereley em 2002 [50].

$\mathrm{Na}$ figura (4.19) apresenta um zoom na região da garganta do segundo microcanal, percebe-se que as velocidades são quase nulas em $x \approx-0,28$, o que certamente viola o principio de conservação de massa. Provavelmente a velocidade nesta seção é tão maior que no resto do escoamento, que o intervalo de tempo utilizado na técnica de $\mu$-PIV não foi pequeno o suficiente para obter uma medida precisa do campo nesta região. 


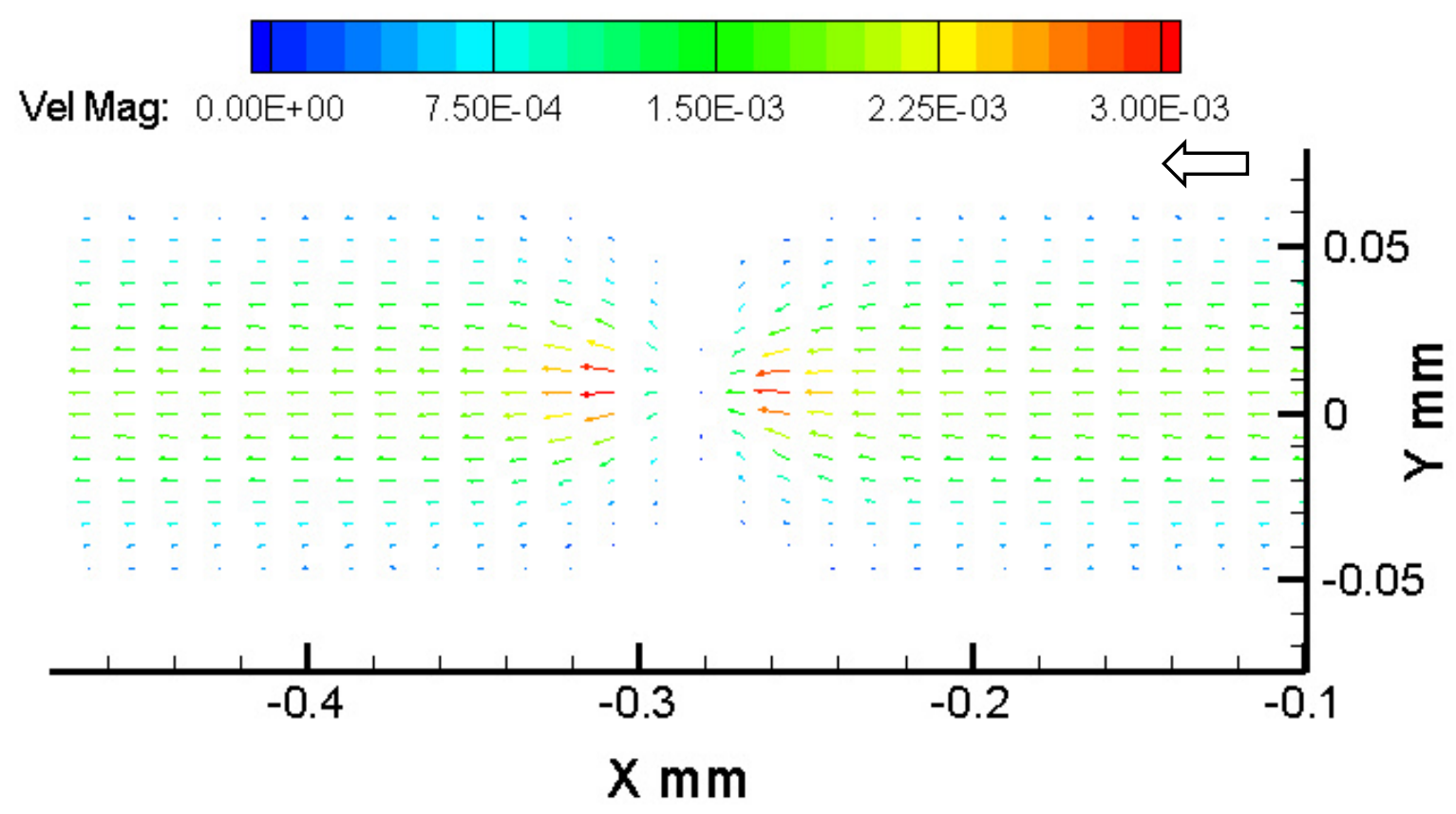

Figura 4.19: Região convergente e divergente na garganta do segundo micro canal.

Os campos vetoriais apresentados nas figuras (4.12) e (4.14) foram avaliados comparando as velocidades experimentais médias na entrada e na saída do escoamento, com a velocidade de injeção imposta. Este método foi utilizado, devido que não se encontrou na bibliografia uma solução analítica, que possa ser utilizada para estimar a precisão das medições efetuadas com o sistema $\mu$-PIV. As velocidades experimentais foram calculadas, integrando os perfis na entrada e na saída do escoamento monofásico para ambos os micro canais com garganta, cujos valores são apresentados nas tabelas (4.1) e (4.2). Observa-se que 0 erro percentual máximo da velocidade foi de aproximadamente $4 \%$.

\begin{tabular}{|l|c|c|c|}
\cline { 2 - 4 } \multicolumn{1}{c|}{} & $\begin{array}{c}\mathbf{V}_{\text {média }} \\
\text { Injeção }\left(\times 10^{-4} \mathrm{~m} / \mathrm{s}\right)\end{array}$ & $\begin{array}{c}\mathrm{V}_{\text {média }} \\
\text { Experimental }\left(\times 10^{-4} \mathrm{~m} / \mathrm{s}\right)\end{array}$ & $\begin{array}{c}\text { Erro } \\
\%\end{array}$ \\
\hline Perfil de entrada & 8,76 & 9,07 & 3,43 \\
\hline Perfil de saída & 8,76 & 8,64 & 1,47 \\
\hline
\end{tabular}

Tabela 4.1: Valores de velocidades dos perfis de entrada e de saída do escoamento, através do primeiro micro canal com garganta. 


\begin{tabular}{|l|c|c|c|}
\cline { 2 - 4 } \multicolumn{1}{c|}{} & $\begin{array}{c}\mathbf{V}_{\text {média }} \\
\text { Injeção }\left(\times 10^{-4} \mathrm{~m} / \mathrm{s}\right)\end{array}$ & $\begin{array}{c}\mathbf{V}_{\text {média }} \\
\text { Experimental }\left(\times 10^{-4} \mathrm{~m} / \mathrm{s}\right)\end{array}$ & $\begin{array}{c}\text { Erro } \\
\%\end{array}$ \\
\hline Perfil de entrada & 8,76 & 8,90 & 1,49 \\
\hline Perfil de saída & 8,76 & 8,71 & 0,61 \\
\hline
\end{tabular}

Tabela 4.2: Valores de velocidades dos perfis de entrada e de saída do escoamento, através do segundo micro canal com garganta.

Os perfis de velocidades experimentais na entrada e na saída do escoamento, e o perfil de velocidade teórico (perfil parabólico) são apresentados nas figuras (4.20) e (4.21), para ambos os microcanais com garganta. Pode-se observar que o perfil medido é muito próximo da resposta teórica. Novamente, o erro é maior perto das paredes.

ENTRADA

$X=-6.56 \times 10^{-3} \mathrm{~mm}$

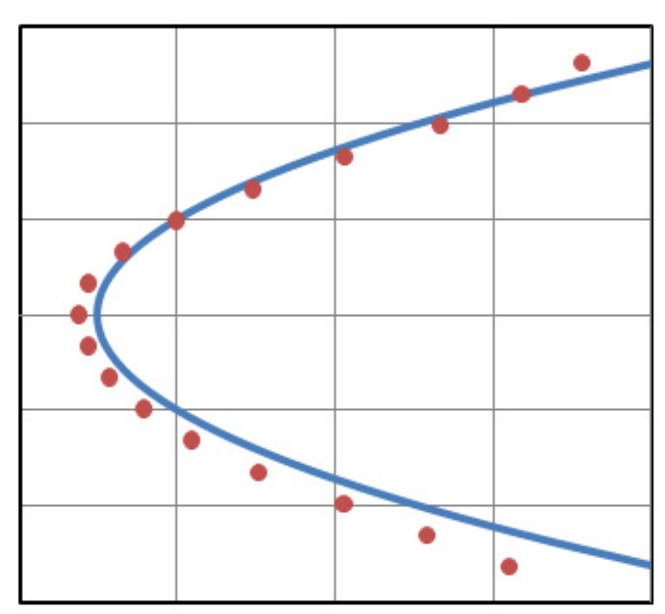

0.06

0.04

0.02

$0.00>\underline{\underline{\xi}}$

$-0.02$

$-0.04$

$-0.06$

$\begin{array}{lllll}2.0 \mathrm{E}-03 & 1.5 \mathrm{E}-03 \quad 1.0 \mathrm{E}-03 \quad 5.0 \mathrm{E}-04 \quad 0.0 \mathrm{E}+00\end{array}$

Velocidade

$[\mathrm{m} / \mathrm{s}]$ 


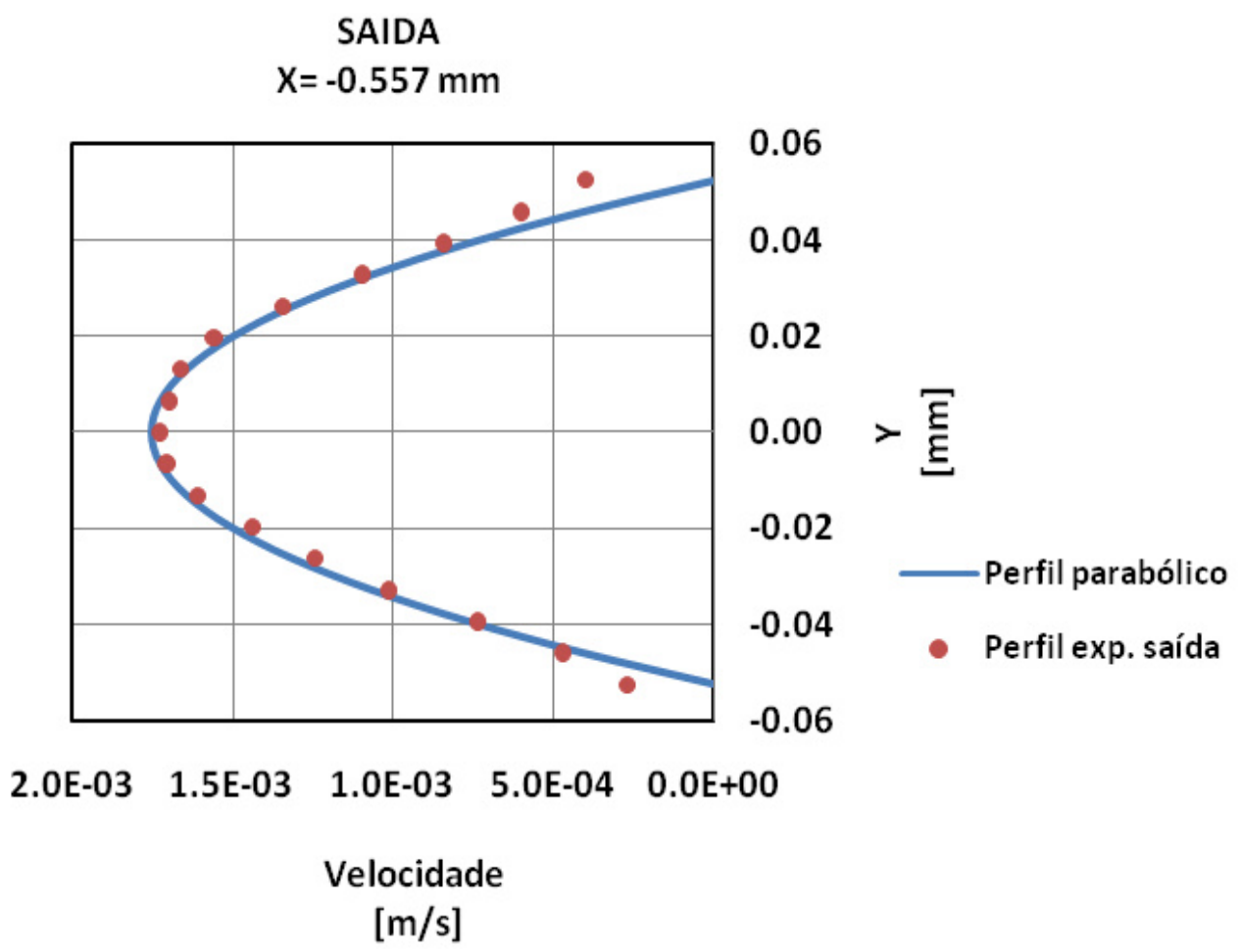

Figura 4.20: Comparação dos perfis parabólicos e experimentais na entrada e na saída do primeiro micro canal com garganta.

ENTRADA

$X=-6.56 \times 10^{-3} \mathrm{~mm}$

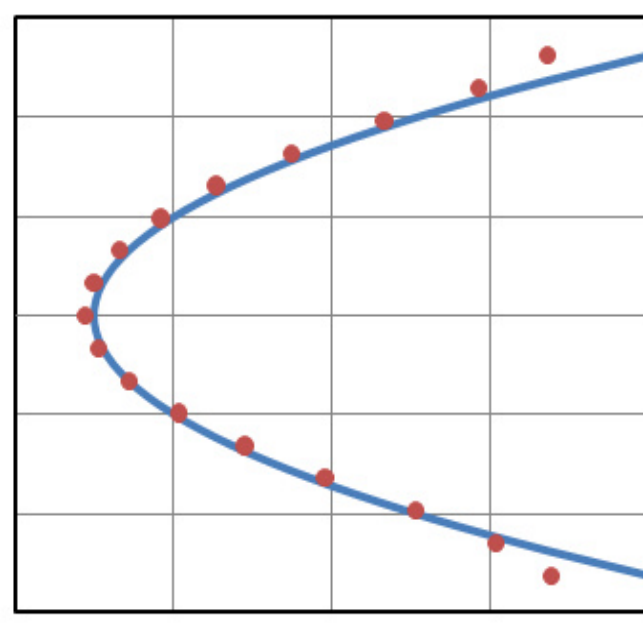

0.06

0.04

0.02

$0.00>\bar{\xi}$

$-0.02$

$-0.04-$ Perfil parabólico
- Perfil exp. entrada

$-0.06$

$2.0 \mathrm{E}-03 \quad 1.5 \mathrm{E}-03 \quad 1.0 \mathrm{E}-03 \quad 5.0 \mathrm{E}-04 \quad 0.0 \mathrm{E}+00$

Velocidade

[m/s] 
SAIDA

$X=-0.557 \mathrm{~mm}$

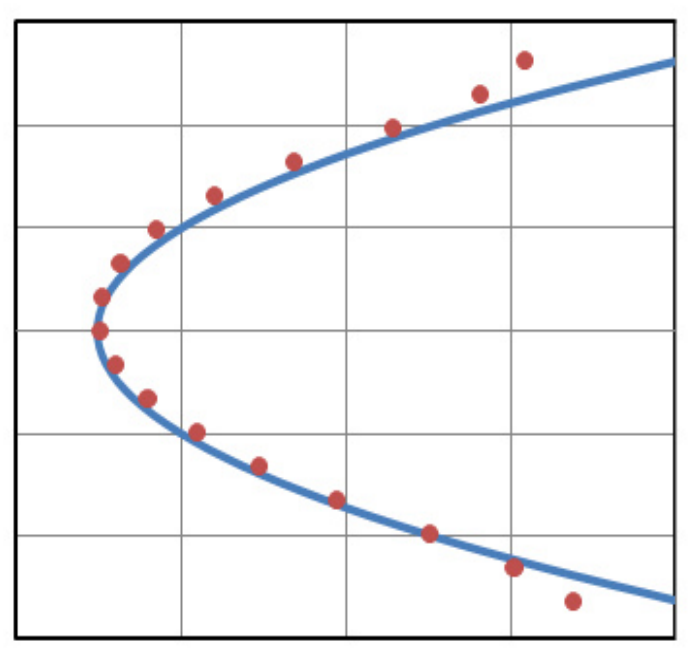

0.06

0.04

0.02

$0.00>\underline{\underline{\xi}}$

$-0.02$

$-0.04$

- Perfil parabólico

- Perfil exp. saída

$-0.06$

\section{$2.0 \mathrm{E}-03 \quad 1.5 \mathrm{E}-03 \quad 1.0 \mathrm{E}-03 \quad 5.0 \mathrm{E}-04 \quad 0.0 \mathrm{E}+00$}

\section{Velocidade}

$[\mathrm{m} / \mathrm{s}]$

Figura 4.21: Comparação dos perfis parabólicos e experimentais na entrada e na saída do segundo micro canal com garganta.

\section{2.}

Medição do campo de velocidade do escoamento bifásico óleo-água

No escoamento bifásico as partículas fluorescentes são dispersas apenas na fase aquosa. Desta forma as gotas de óleo aparecem nas imagens como uma região escura. O campo de velocidade da fase contínua (água) é determinado para diferentes tamanhos de gotas e geometria do capilar. A velocidade da gota é determinada através da medição da velocidade da fase contínua próxima a interface entre as fases.

Para ambos os casos (capilar de seção reta constante e com garganta), o campo de velocidade foi obtido da captura de imagens, das técnicas de préprocessamento, processamento, pós-processamento e de máscaras utilizadas para selecionar a área que será processada. 


\subsection{1. \\ Medição do campo de velocidade do escoamento bifásico óleo-água no micro canal de seção reta constante}

As duas bombas foram ligadas em modo de injeção contínua. Para a formação da gota pequena, a vazão de injeção da fase contínua foi de $Q=0,03$ $\mathrm{ml} / \mathrm{h}$ e da fase dispersa foi de $\mathrm{Q}=0,003 \mathrm{ml} / \mathrm{h}$. Para gerar a gota média, a vazão de injeção da fase contínua foi de $Q=0,03 \mathrm{ml} / \mathrm{h}$ e a vazão de injeção da fase dispersa foi de $\mathrm{Q}=0,02 \mathrm{ml} / \mathrm{h}$. Devido a efeitos de inércia e ao comprimento das mangueiras, o tempo aproximado de estabilização foi de 15 minutos, após o qual iniciou-se a captura das imagens.

O tamanho da gota foi caracterizado pelo raio da gota, se ela fosse esférica $R_{g}$, que é calculado através do volume da gota produzida $\gamma_{g}$, equação (4.1).

$$
\mathrm{R}_{\mathrm{g}}=\left(\frac{3 \gamma_{\mathrm{g}}}{4 \pi}\right)^{1 / 3}
$$

A razão $\alpha \equiv R_{g} / R_{c}\left(R_{c}\right.$ é raio do capilar) caracteriza o tamanho relativo da gota e o capilar. Para os casos analisados aqui, $\alpha=1,4$ (gota pequena) e $\alpha=1,5$ (gota média). A variação do valor de $\alpha$ foi pequena devido à dificuldade de formar gotas menores do que o diâmetro do capilar com a técnica empregada.

A área selecionada nas imagens onde o processamento é realizado foi definida através de uma máscara. As figuras (4.22) e (4.23) mostram a posição e a máscara utilizada para cada valor de $\alpha$.

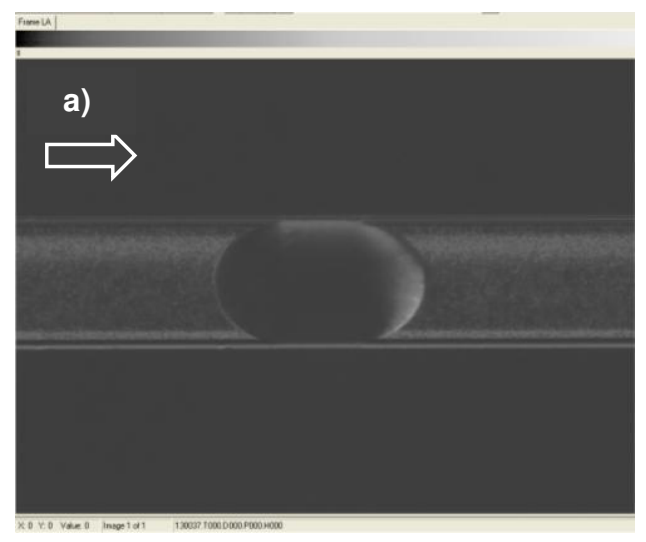


Figura 4.22: a) Posição da gota pequena $(\alpha=1,4)$ no micro canal de seção reta constante. b) Máscara da gota pequena no micro canal de seção reta constante.
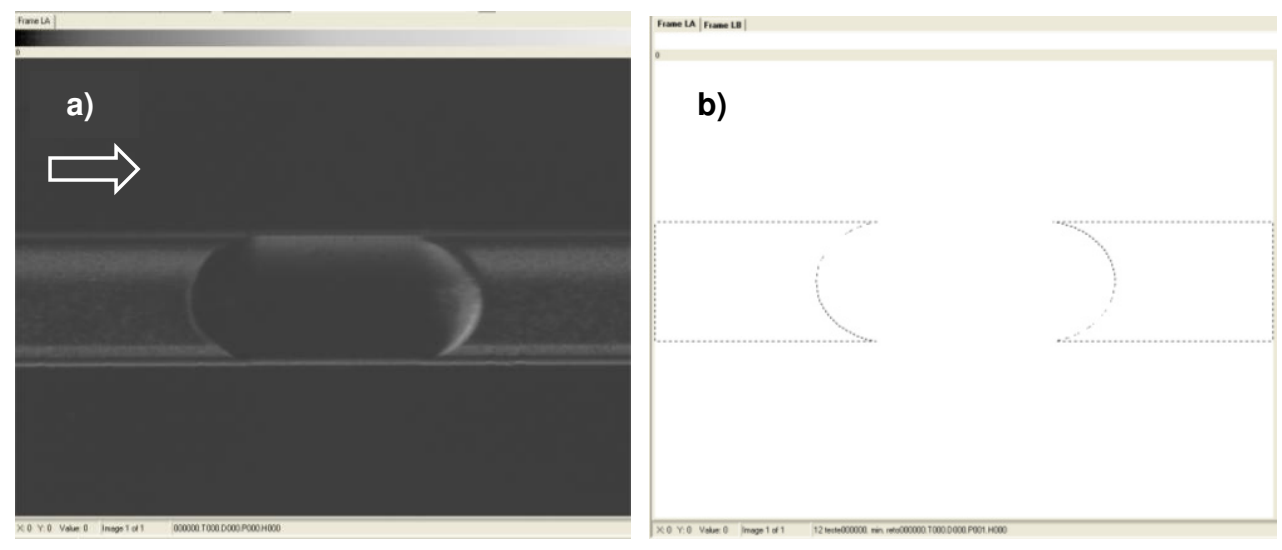

Figura 4.23: a) Posição da gota média $(\alpha=1,5)$ no micro canal de seção reta constante. b) Máscara da gota média no micro canal de seção reta constante.

Para a captura das imagens, no programa Insight $3 \mathrm{G}^{\mathrm{TM}}$ foram configurados os seguintes parâmetros:

- Modo de aquisição da imagem "sincronizado";

- Tempo de espera do primeiro pulso laser de $800 \mu \mathrm{s}$;

- Tempo de exposição do sensor da câmera CCD de 1300 Hs;

- Taxa de repetição da frequência dos lasers $4,83 \mathrm{~Hz}$;

- Energia dos lasers em "high".

A alta resolução dos campos de velocidade apresentados na análise do escoamento monofásico só foi possível pelo uso da técnica de processamento "Média Amostral" [21]. No caso do escoamento com gotas suspensas, o uso desta técnica é mais complicado, já que o escoamento é inerentemente transiente. Este problema foi transposto neste caso utilizando o fato que o escoamento é periódico e que todas as gotas são do mesmo tamanho. A média amostral foi realizada com imagens obtidas com diferentes gotas localizadas aproximadamente na mesma posição do canal.

Tiraram-se 200 imagens consecutivas, e depois foram escolhidas as imagens que correspondiam a diferentes gotas do mesmo tamanho e localizadas a uma diferença de posição de 2-3 pixels, que sumada ao deslocamento das patículas nas imagens não devem exceder ao deslocamento máximo permitido das partículas que foi de 8 pixels. Este procedimento foi realizado de 30 a 40 
vezes em um ensaio, e assim por diante, até conseguir a maior quantidade de imagens coletadas, para que posteriormente serem processadas.

O tempo de separação $\Delta t$ entre o par de imagens da gota pequena foi de $1000 \mu \mathrm{s}$, e da gota média foi de $900 \mu \mathrm{s}$. Ambos os casos foram utilizados a janela de interrogação de $32 \times 32$ pixels. O deslocamento máximo permitido foi de $0,25 \times 32$ pixels $=8$ pixels. As imagens da gota de óleo pequena mostraram um deslocamento máximo das partículas nas zonas de maior velocidade de 3-6 pixels, e as imagens da gota média entre 5-6 pixels. Esta janela de interrogação foi selecionada também, a fim de descrever a geometria da gota da fase dispersa, com a maior precisão possível.

Para o pré-processamento dos pares de imagens coletadas foram usados as técnicas "Imagem de intensidade mínimo/médio" e "Subtração de fundo", para ambas as gotas.

Para o processamento das imagens, no programa Insight $3 \mathrm{G}^{\mathrm{TM}}$ foram configurados os seguintes parâmetros:

- O tamanho das janelas de interrogação ou resolução espacial foi de 32 × 32 pixels $\left(13,1 \times 13,1 \mu \mathrm{m}^{2}\right)$;

- O máximo deslocamento das partículas foi de " $25 \%$ do tamanho da janela de interrogação";

- A calibração do sistema foi de 0,41 $\mu \mathrm{m} /$ pixel.

As técnicas "Média Amostral", "Nyquist Grid", "Correlação da Transformada de Fourier" e "Pico Gaussiano" foram usados para o processamento dos pares de imagens coletadas, tanto na gota pequena, assim como, na gota média.

Para o pós-processamento dos pares de imagens coletadas foram utilizados a técnica "Validação do Vetor mediana Local" e "Vetor Condição", para ambos tamanhos de gota.

Para ambos os casos, gota pequena $(\alpha=1,4)$ e gota média $(\alpha=1,5)$ foram coletadas um total de 100 pares de imagens. Foi realizado o processamento de 50 pares de imagens por separado obtendo 2 campos de vetores de velocidade para cada gota, como mostrados nas figuras (4.24) e (4.26), e o processamento dos 100 pares de imagens coletadas para cada caso obtendo o campo de vetores de velocidade mostrados nas figuras (4.25) e (4.27). 
A porcentagem de vetores válidos nos 3 campos de vetores de velocidade ao redor da gota pequena foi de $97,69 \%, 98,94 \%, 99,32 \%$, e na gota média foi de $98,54 \%$, 99,27\%, 99,39\%, ambos antes do pós-processamento. Pode-se observar uma pequena diferença entre os campos de vetores obtidos para cada gota, pois o propósito era encontrar a quantidade suficiente de imagens para uma boa correlação.
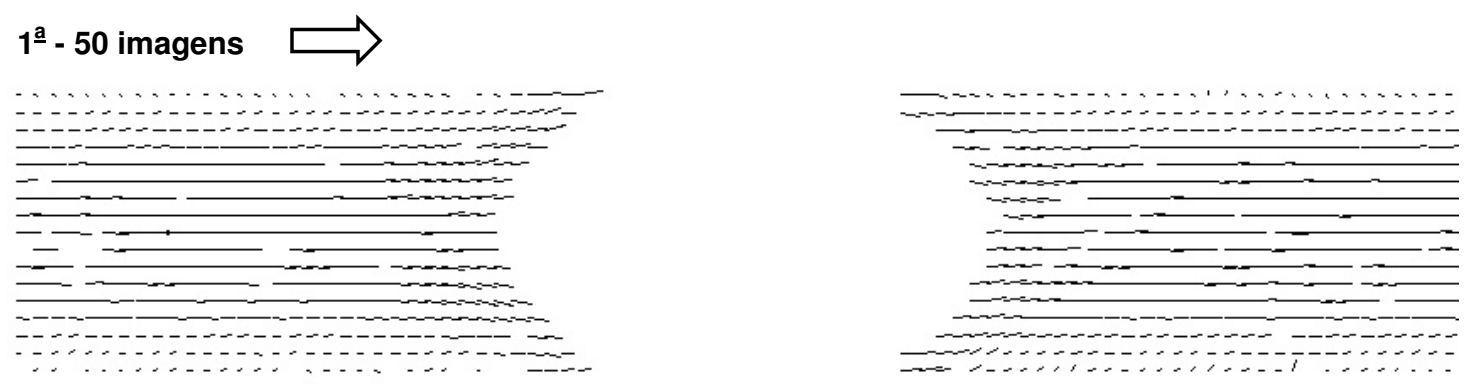

\section{$2^{\mathrm{a}}-50$ imagens $\longrightarrow$}
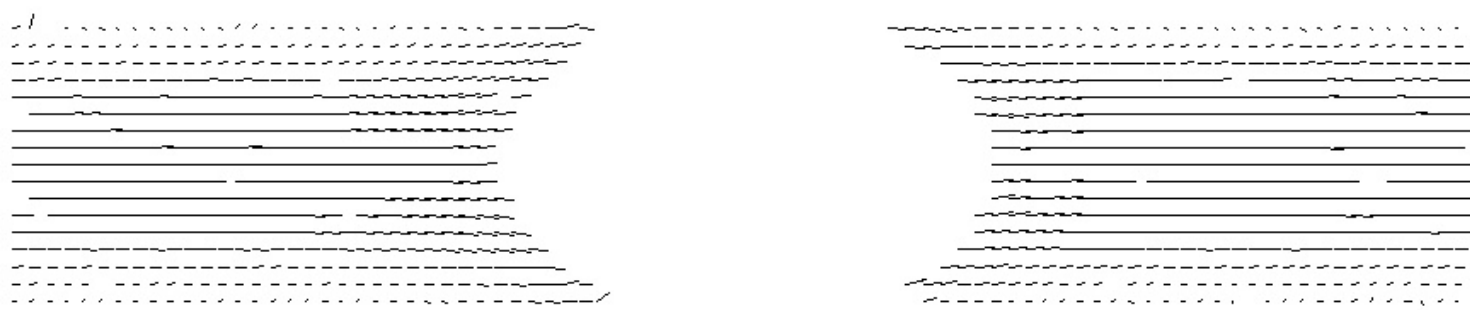

Figura 4.24: Campos de vetores de velocidade produzidos do processamento de 50 pares de imagens por separado ao redor da gota pequena, através do micro canal de seção reta constante.

\section{0 imagens $\square$}
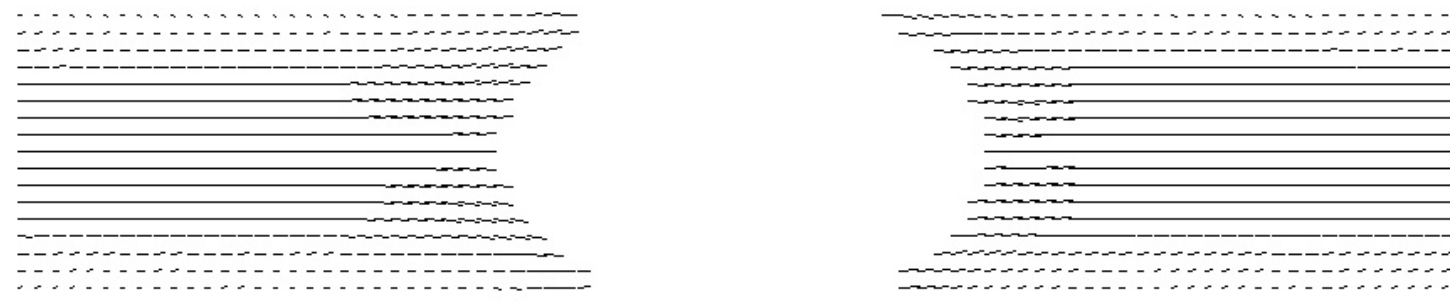

Figura 4.25: Campo de vetores de velocidade produzido do processamento de 100 pares de imagens ao redor da gota pequena, através do micro canal de seção reta constante. 

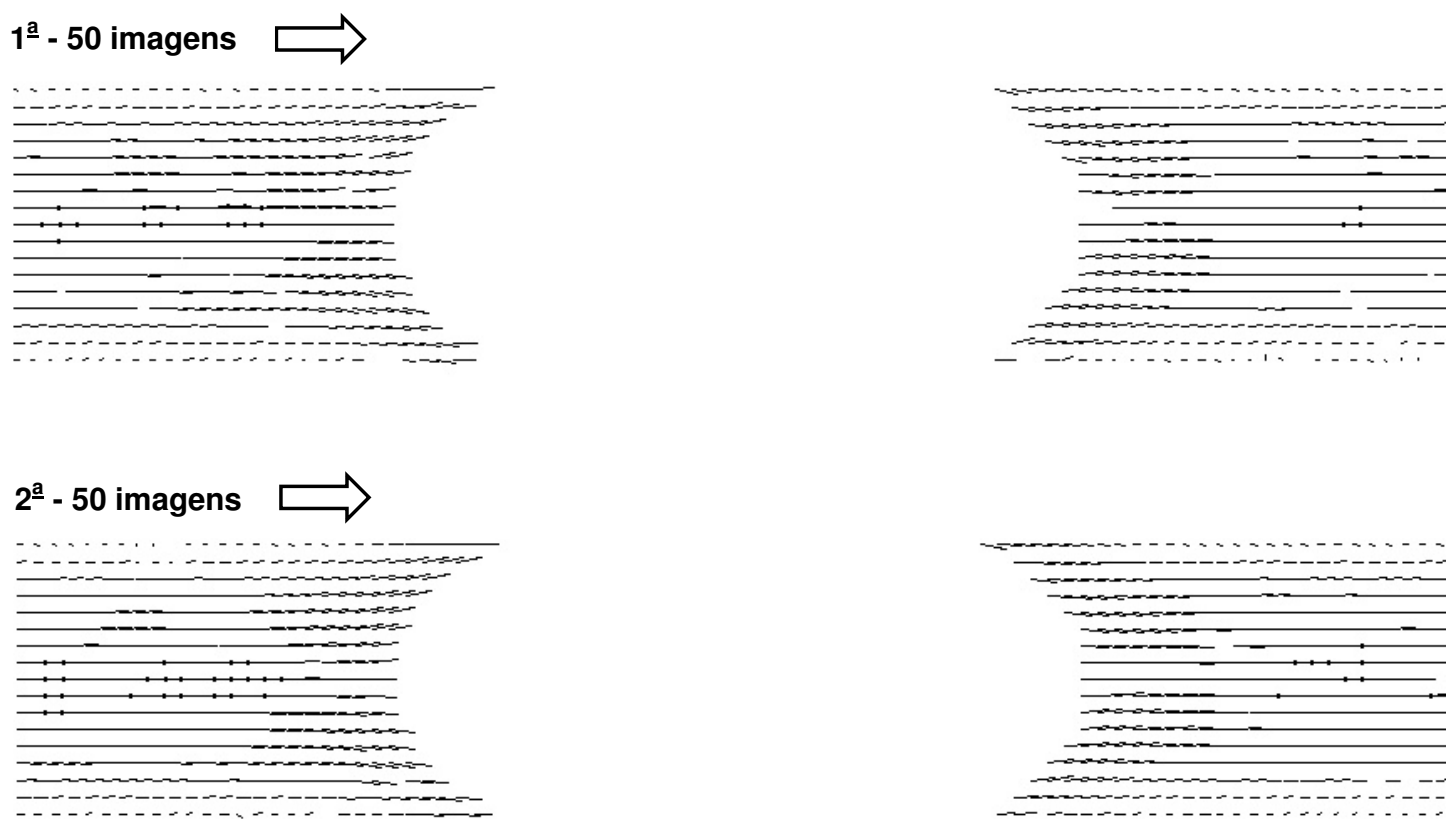

Figura 4.26: Campos de vetores de velocidade produzidos do processamento de 50 pares de imagens por separado ao redor da gota média, através do micro canal de seção reta constante.
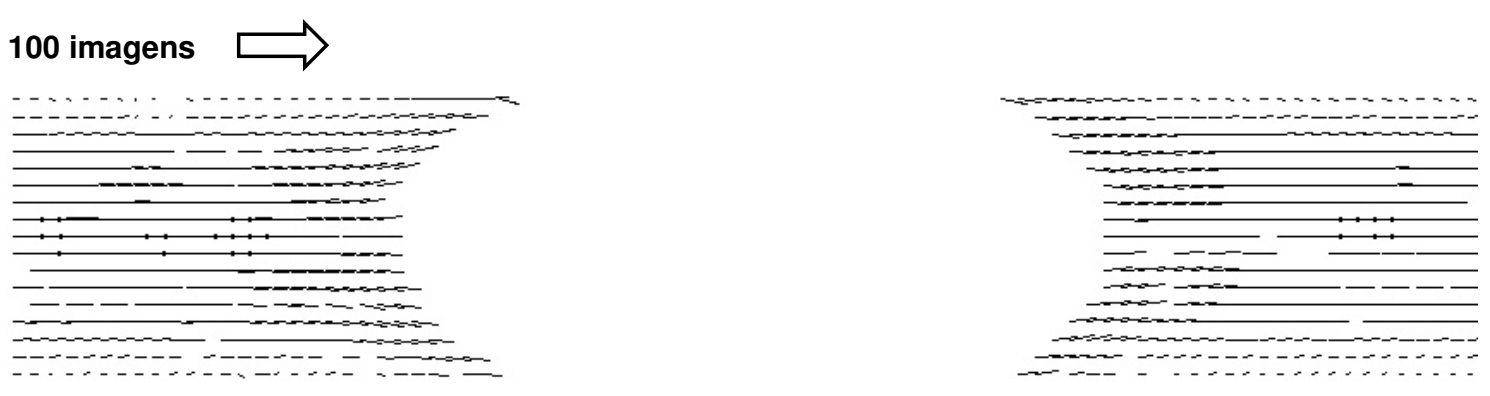

Figura 4.27: Campo de vetores de velocidade produzido do processamento de 100 pares de imagens ao redor da gota média, através do micro canal de seção reta constante.

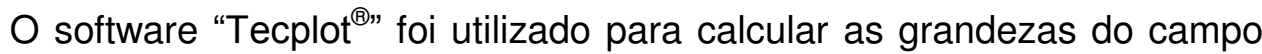
de velocidade da fase contínua. As figuras (4.28) e (4.29) apresentam os campos de velocidade do escoamento ao redor da gota pequena $(\alpha=1,4)$, mostrando também $50 \%$ dos perfis de velocidade a fim de facilitar a visualização do campo. Os escoamentos bifásicos são compostos de 56 perfis de velocidade, e o número de vetores por perfil foi de 17. É importante ressaltar, que as partículas fluorescentes foram suspensas só na fase contínua, por isso, que a gota aparece como uma mancha escura no campo de velocidade. 


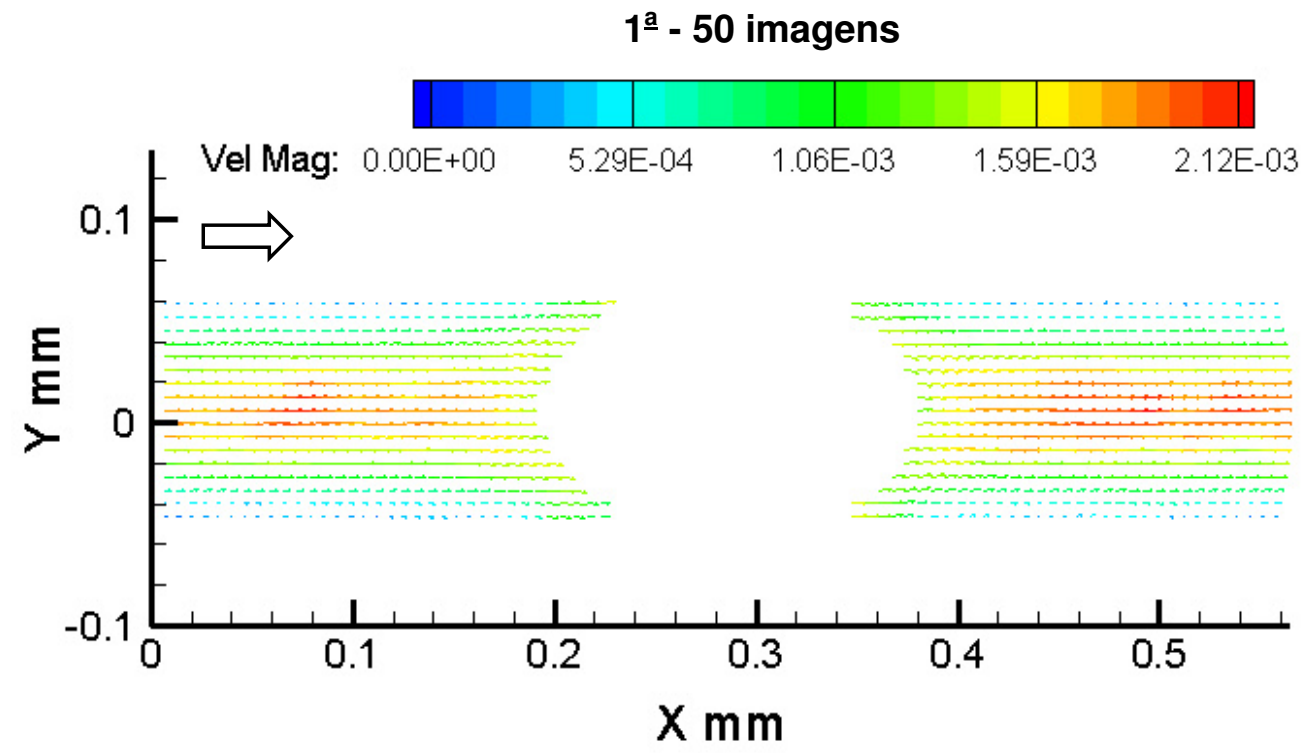

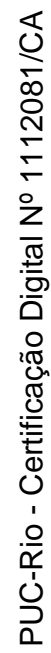
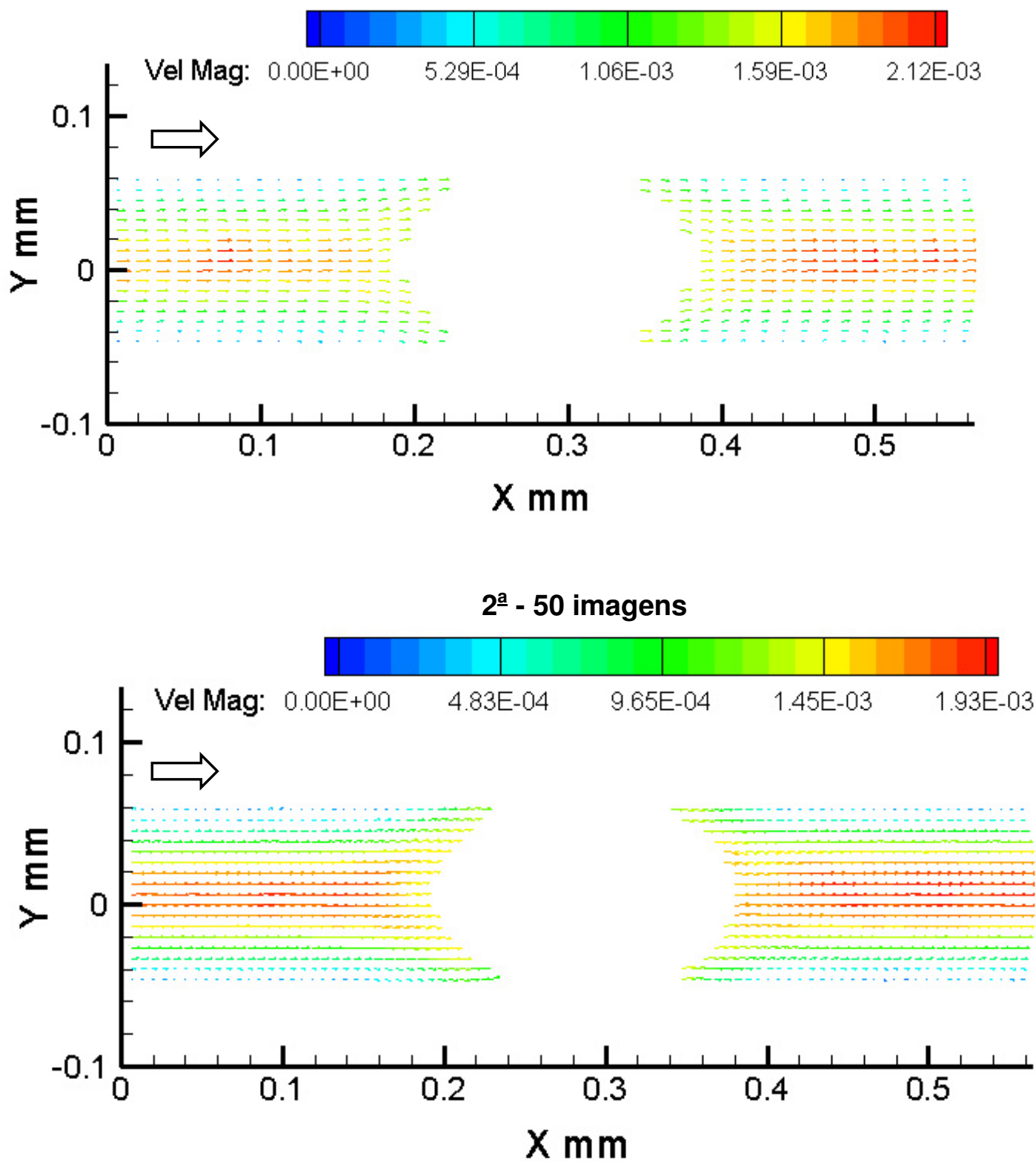


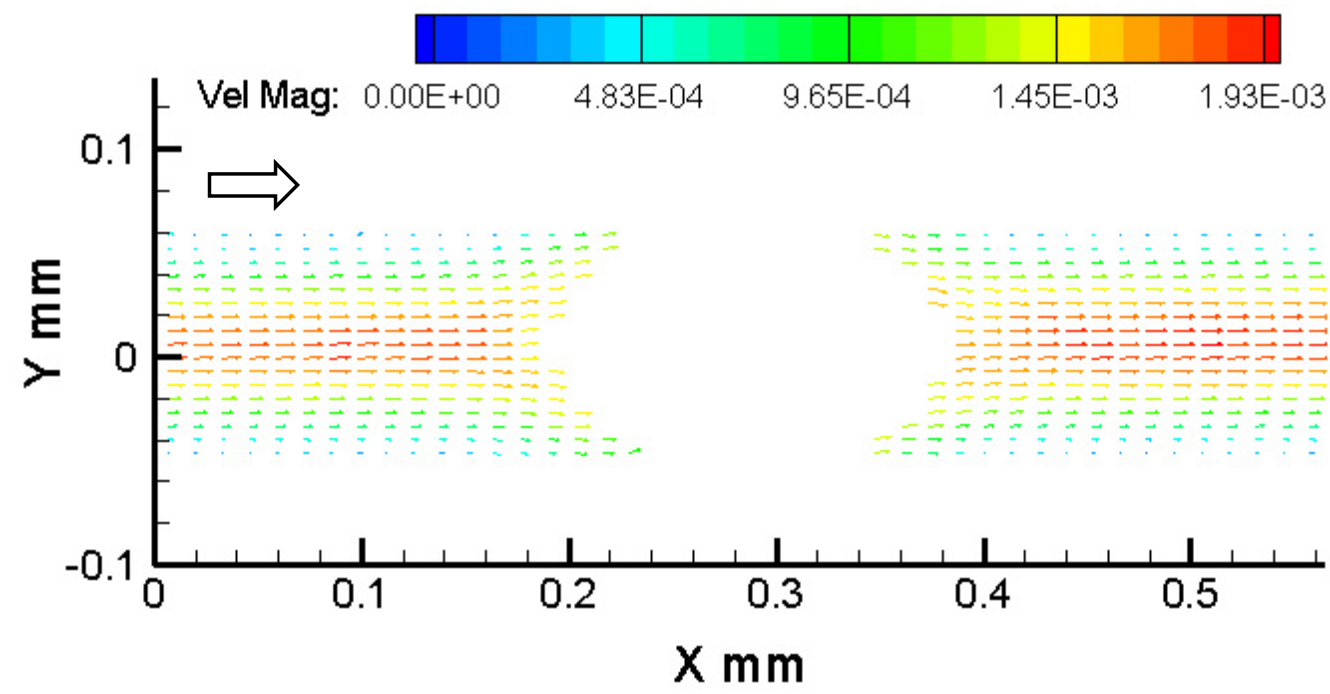

Figura 4.28: Campos de velocidade do escoamento bifásico de 50 pares de imagens por separado ao redor da gota pequena $(\alpha=1,4)$, através do micro canal de seção reta constante.

100 imagens
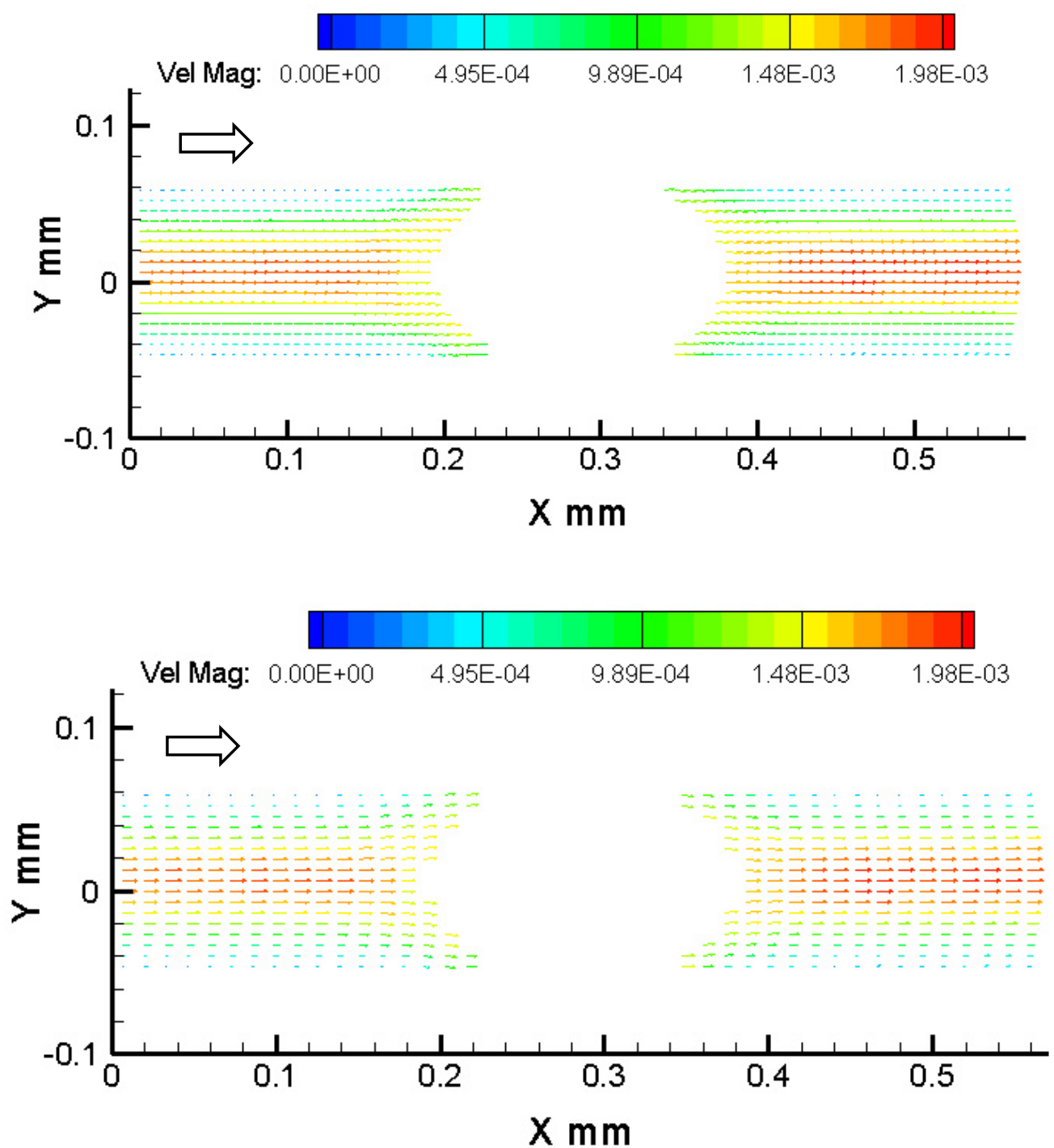
Figura 4.29: Campo de velocidade do escoamento bifásico de 100 pares de imagens ao redor da gota pequena $(\alpha=1,4)$, através do micro canal de seção reta constante.

As figuras (4.30) e (4.31) mostram os campos de velocidades do escoamento ao redor da gota média $(\alpha=1,5)$, mostrando também $50 \%$ dos perfis de velocidade para facilitar a visualização. Os escoamentos bifásicos são compostos de 44 perfis de velocidade, e o número de vetores por perfil foi de 17 .
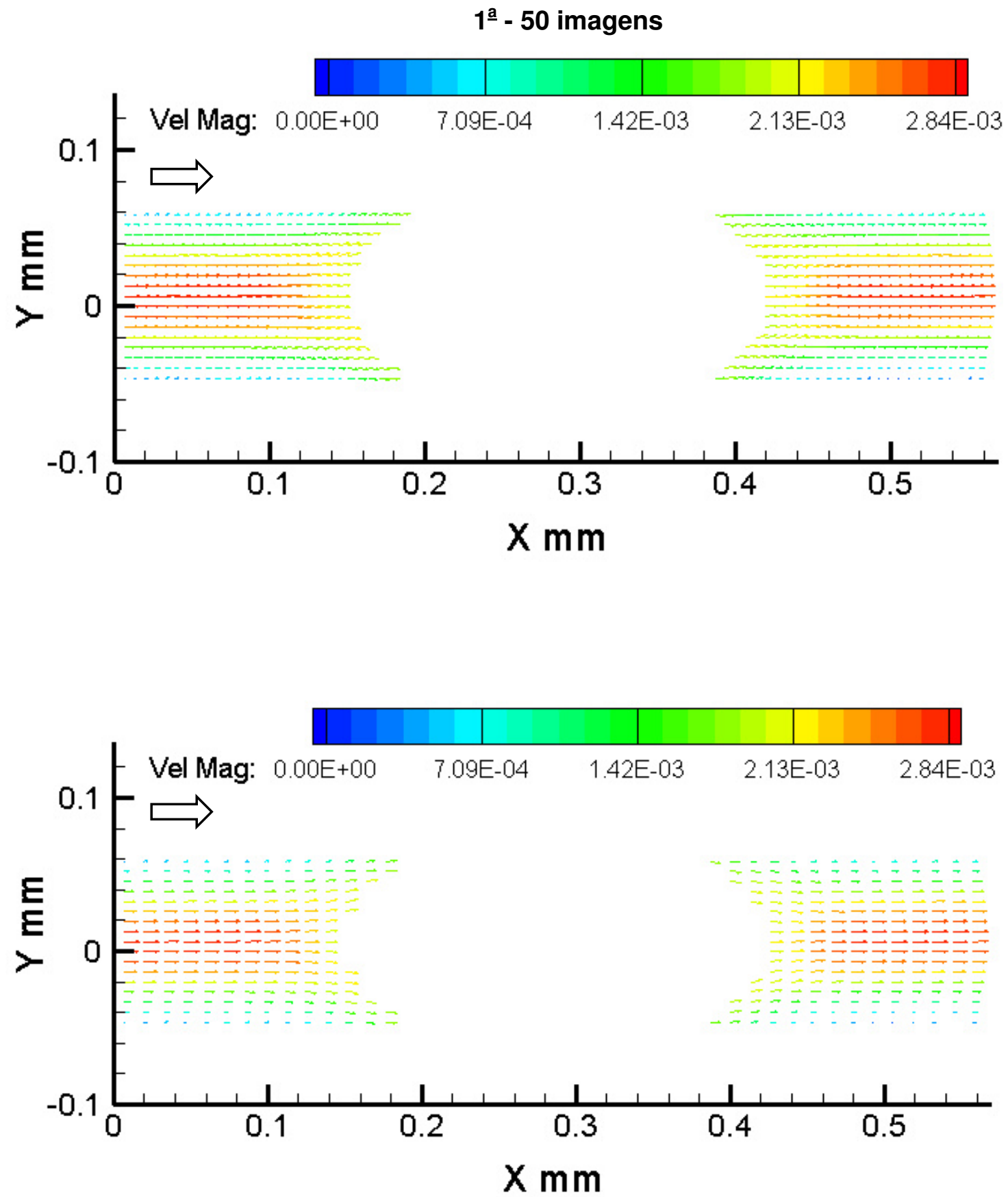

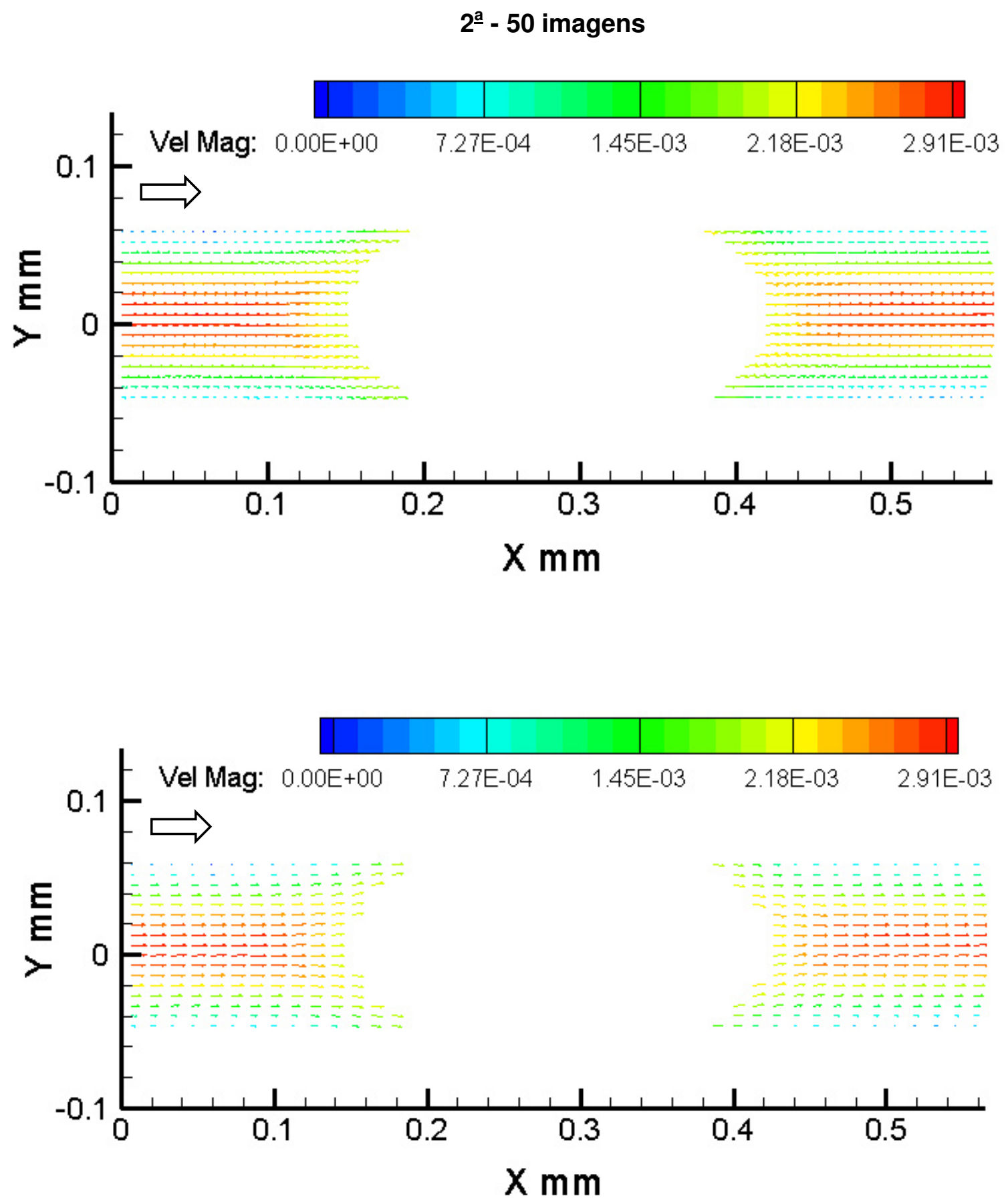

Figura 4.30: Campos de velocidade do escoamento bifásico de 50 pares de imagens por separado ao redor da gota média $(\alpha=1,5)$, através do micro canal de seção reta constante. 

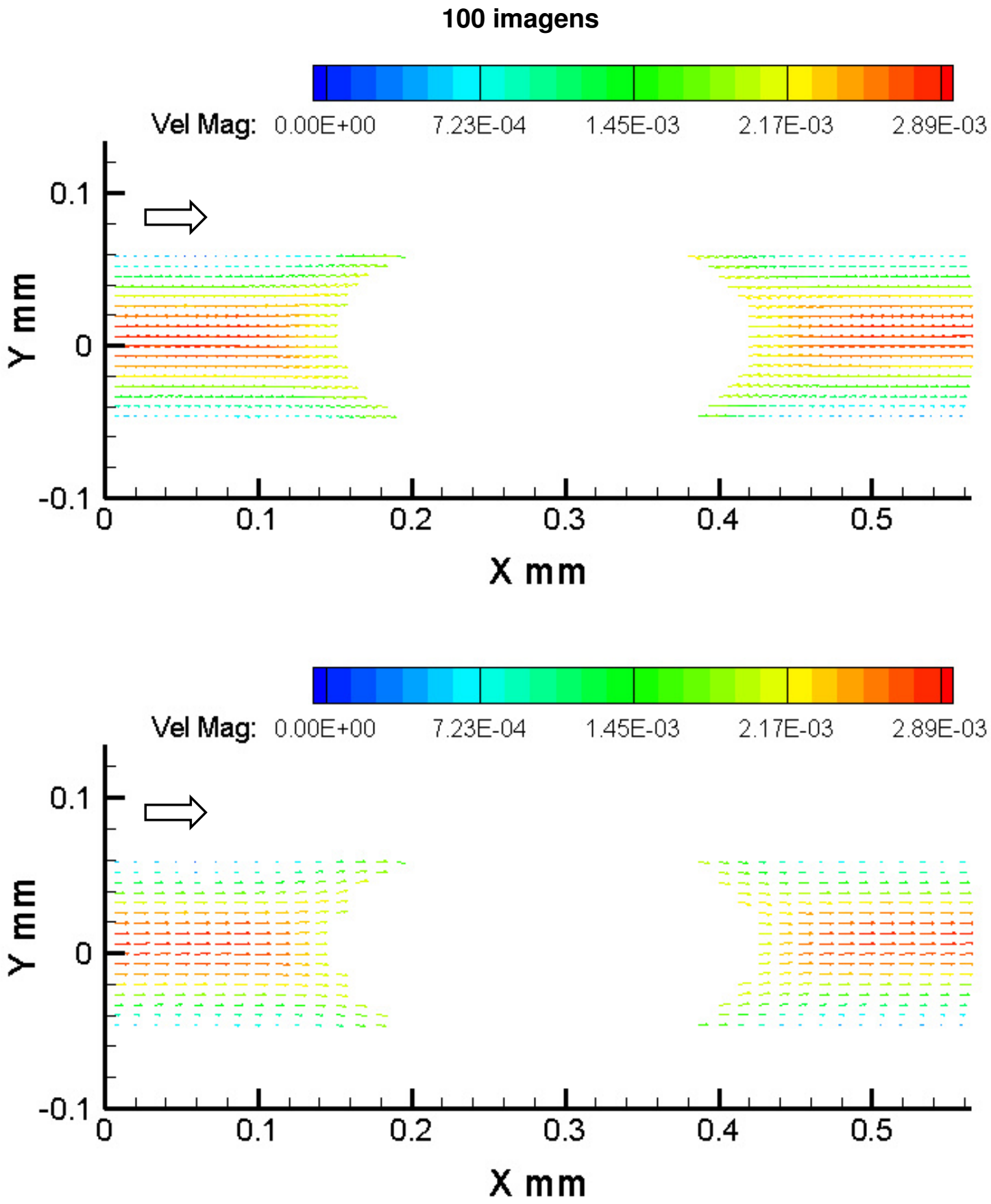

Figura 4.31: Campo de velocidade do escoamento bifásico de 100 pares de imagens ao redor da gota média $(\alpha=1,5)$, através do micro canal de seção reta constante.

As medidas mostram a velocidade máxima na linha de simetria do canal a certa distância da gota. Como a gota move-se sem se deformar, o campo de velocidade ao redor dela é constante, conforme esperado. A velocidade da gota é obtida desta forma. Longe da gota o escoamento da fase contínua recupera o 
perfil parabólico de escoamento desenvolvido. Para determinar a precisão destas medidas, as medições longe da gota foram comparadas com a solução de perfil desenvolvido, conforme apresentado nas tabelas (4.3) e (4.4). Observase que o erro percentual máximo da velocidade foi de aproximadamente $5 \%$.

\begin{tabular}{|c|l|c|c|c|}
\cline { 2 - 5 } \multicolumn{1}{c|}{} & \multicolumn{1}{c|}{$\begin{array}{c}\text { Gota Pequena } \\
\boldsymbol{\alpha}=\mathbf{1 , 4}\end{array}$} & $\begin{array}{c}\mathbf{V}_{\text {média }} \\
\text { Esc. injetado } \\
\left(\times 10^{-4} \mathbf{m} / \mathbf{s}\right)\end{array}$ & $\begin{array}{c}\mathbf{V}_{\text {média }} \\
\text { Experimental } \\
\left(\times 10^{-4} \mathbf{m} / \mathbf{s}\right)\end{array}$ & $\begin{array}{c}\text { Erro } \\
\%\end{array}$ \\
\hline \multirow{2}{*}{$\begin{array}{c}\text { Perfil de } \\
\text { Entrada }\end{array}$} & $\mathbf{1}^{\text {a }}-\mathbf{5 0}$ imagens & 9,499 & 9,565 & 0,695 \\
\cline { 2 - 5 } & $\mathbf{2}^{\text {a }}-\mathbf{5 0}$ imagens & 9,499 & 9,010 & 5,148 \\
\cline { 2 - 5 } & $\mathbf{1 0 0}$ imagens & 9,499 & 9,080 & 4,411 \\
\hline \multirow{2}{*}{$\begin{array}{c}\text { Perfil de } \\
\text { Saída }\end{array}$} & $\mathbf{1}^{\text {a }}-\mathbf{5 0}$ images & 9,499 & 9,690 & 2,011 \\
\cline { 2 - 5 } & $\mathbf{2}^{\text {a }}-\mathbf{5 0}$ images & 9,499 & 9,170 & 3,464 \\
\cline { 2 - 5 } & $\mathbf{1 0 0}$ imagens & 9,499 & 9,270 & 2,411 \\
\hline
\end{tabular}

Tabela 4.3: Valores de velocidades médias experimentais dos perfis de entrada e saída do escoamento ao redor da gota pequena $(\alpha=1,4)$, através do micro canal de seção reta constante.

\begin{tabular}{|c|l|c|c|c|}
\cline { 2 - 5 } \multicolumn{1}{c|}{} & \multicolumn{1}{c|}{$\begin{array}{c}\text { Gota Média } \\
\boldsymbol{\alpha}=\mathbf{1 , 5}\end{array}$} & $\begin{array}{c}\mathbf{V}_{\text {média }} \\
\text { Esc. injetada } \\
\left(\times 10^{-4} \mathbf{m} / \mathbf{s}\right)\end{array}$ & $\begin{array}{c}\mathbf{V}_{\text {média }} \\
\text { Experimental } \\
\left(\times 10^{-4} \mathbf{m} / \mathbf{s}\right)\end{array}$ & $\begin{array}{c}\text { Erro } \\
\%\end{array}$ \\
\hline \multirow{2}{*}{$\begin{array}{c}\text { Perfil de } \\
\text { Entrada }\end{array}$} & $\mathbf{1}^{\text {a }}-\mathbf{5 0}$ imagens & 13,71 & 13,90 & 1,386 \\
\cline { 2 - 5 } & $\mathbf{2}^{\text {a }}-\mathbf{5 0}$ imagens & 13,71 & 14,25 & 3,939 \\
\cline { 2 - 5 } & $\mathbf{1 0 0}$ imagens & 13,71 & 13,90 & 1,386 \\
\hline \multirow{2}{*}{$\begin{array}{c}\text { Perfil de } \\
\text { Saída }\end{array}$} & $\mathbf{1}^{\text {a }}-\mathbf{5 0}$ images & 13,71 & 13,445 & 1,933 \\
\cline { 2 - 5 } & $\mathbf{2}^{\text {a }}-\mathbf{5 0}$ images & 13,71 & 14,24 & 3,866 \\
\cline { 2 - 5 } & $\mathbf{1 0 0}$ imagens & 13,71 & 13,975 & 1,933 \\
\hline
\end{tabular}

Tabela 4.4: Valores de velocidades médias experimentais dos perfis de entrada e saída do escoamento ao redor da gota média $(\alpha=1,5)$, através do micro canal de seção reta constante. 
Os perfis de velocidades experimentais na entrada e na saída do escoamento são apresentados nas figuras (4.32) e (4.33), juntamente com o perfil de velocidade teórico.
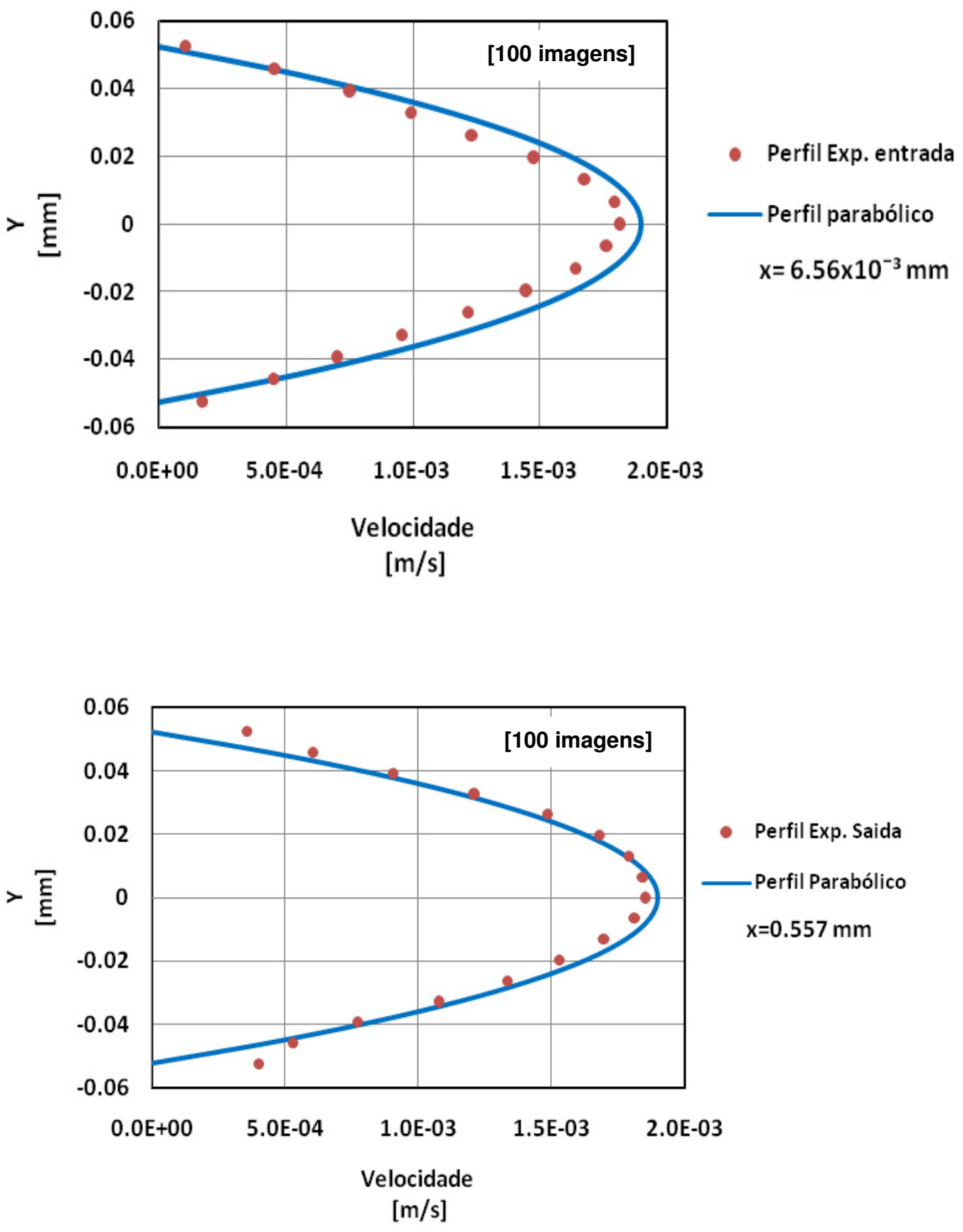

Figura 4.32: Comparação dos perfis parabólicos e experimentais na entrada e na saída do micro canal de seção reta constante, no escoamento bifásico de 100 pares de imagens ao redor da gota pequena $(\alpha=1,4)$. 

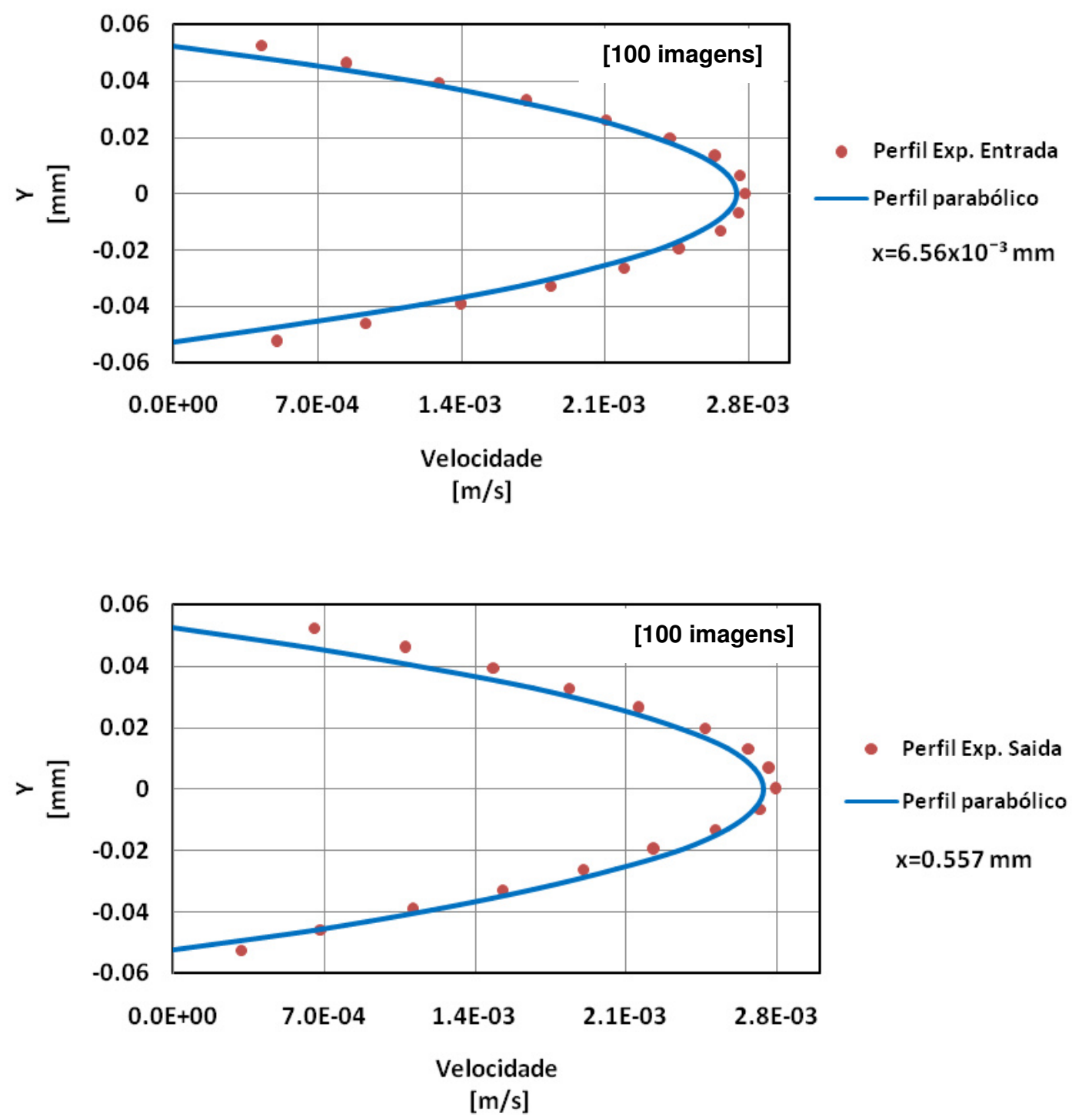

Figura 4.33: Comparação dos perfis parabólicos e experimentais na entrada e na saída do micro canal de seção reta constante, no escoamento bifásico de 100 pares de imagens ao redor da gota média $(\alpha=1,5)$.

Para avaliar, o efeito da gota de óleo sobre o escoamento ao redor dela, as figuras (4.34) e (4.35) apresentam a variação da velocidade na linha de simetria ao longo do comprimento do capilar. A região do gráfico sem pontos experimentais corresponde à gota. Notamos que a velocidade experimental máxima é maior na entrada e na saída do escoamento, e diminui na região próxima a gota. Para gota pequena $(\alpha=1,4)$ a velocidade da gota foi de aproximadamente $15 \times 10^{-4} \mathrm{~m} / \mathrm{s}$. Para gota grande $(\alpha=1,5)$ foi aproximadamente $20 \times 10^{-4} \mathrm{~m} / \mathrm{s}$. Vale lembrar que a vazão total dos dois casos não era a mesma. 
Vale ressaltar que a gota move-se com a mesma velocidade, isto é, a interface ela não se deforma.

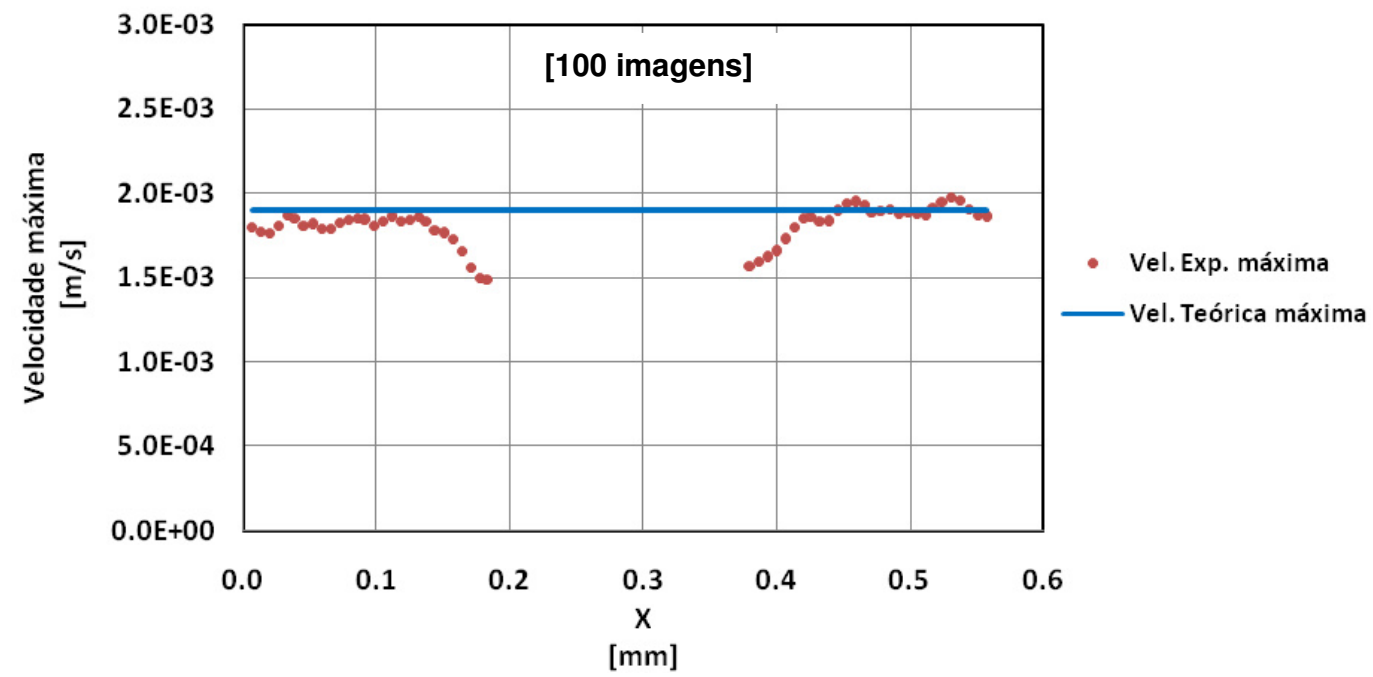

Figura 4.34: Variação da velocidade na linha de simetria ao longo do comprimento do micro canal de seção reta constante, no escoamento bifásico de 100 pares de imagens ao redor da gota pequena $(\alpha=1,4)$.

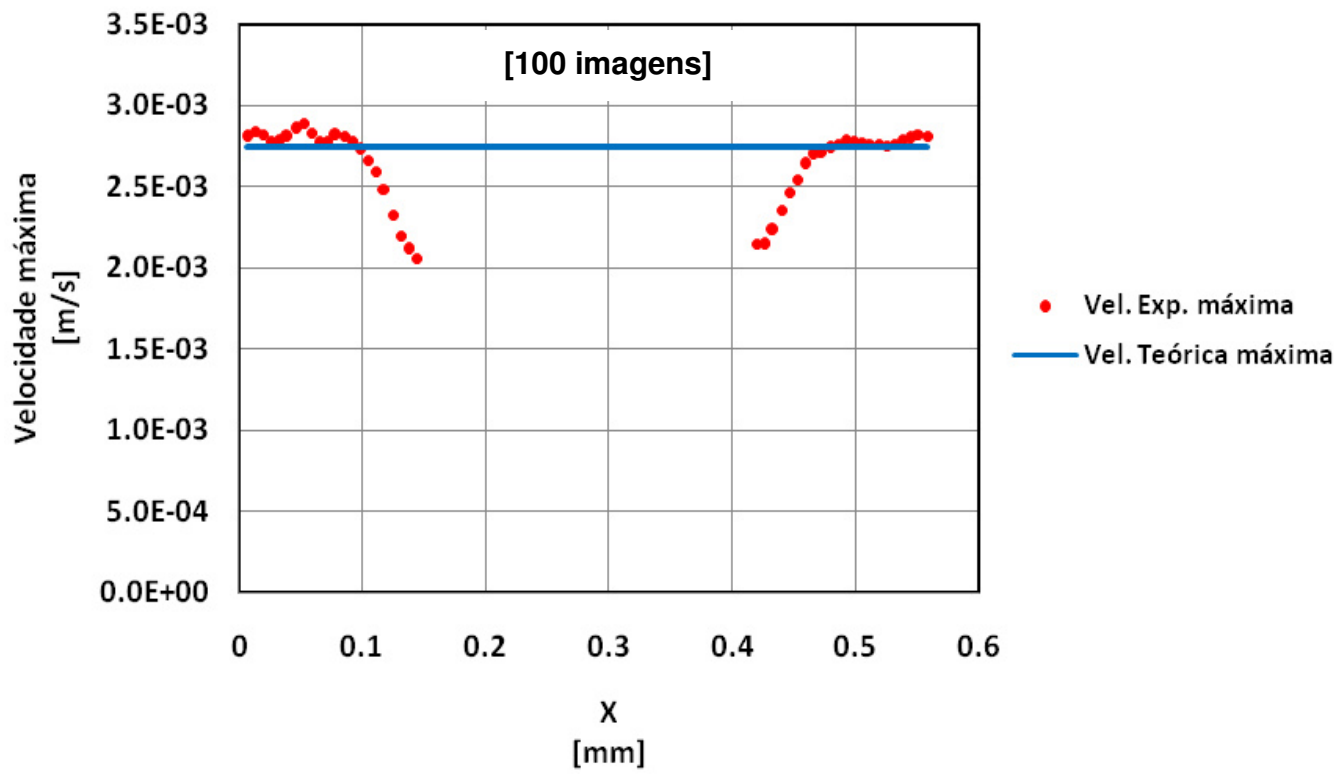

Figura 4.35: Variação da velocidade na linha de simetria ao longo do comprimento do micro canal de seção reta constante no escoamento bifásico de 100 pares de imagens ao redor da gota média $(\alpha=1,5)$.

A velocidade da gota foi calculada mediante a média da velocidade na interface óleo-água à montante da gota, como mostram as figuras (4.36) e 
(4.37). As tabelas (4.5) e (4.6) apresentam a velocidade da gota de óleo para cada caso.

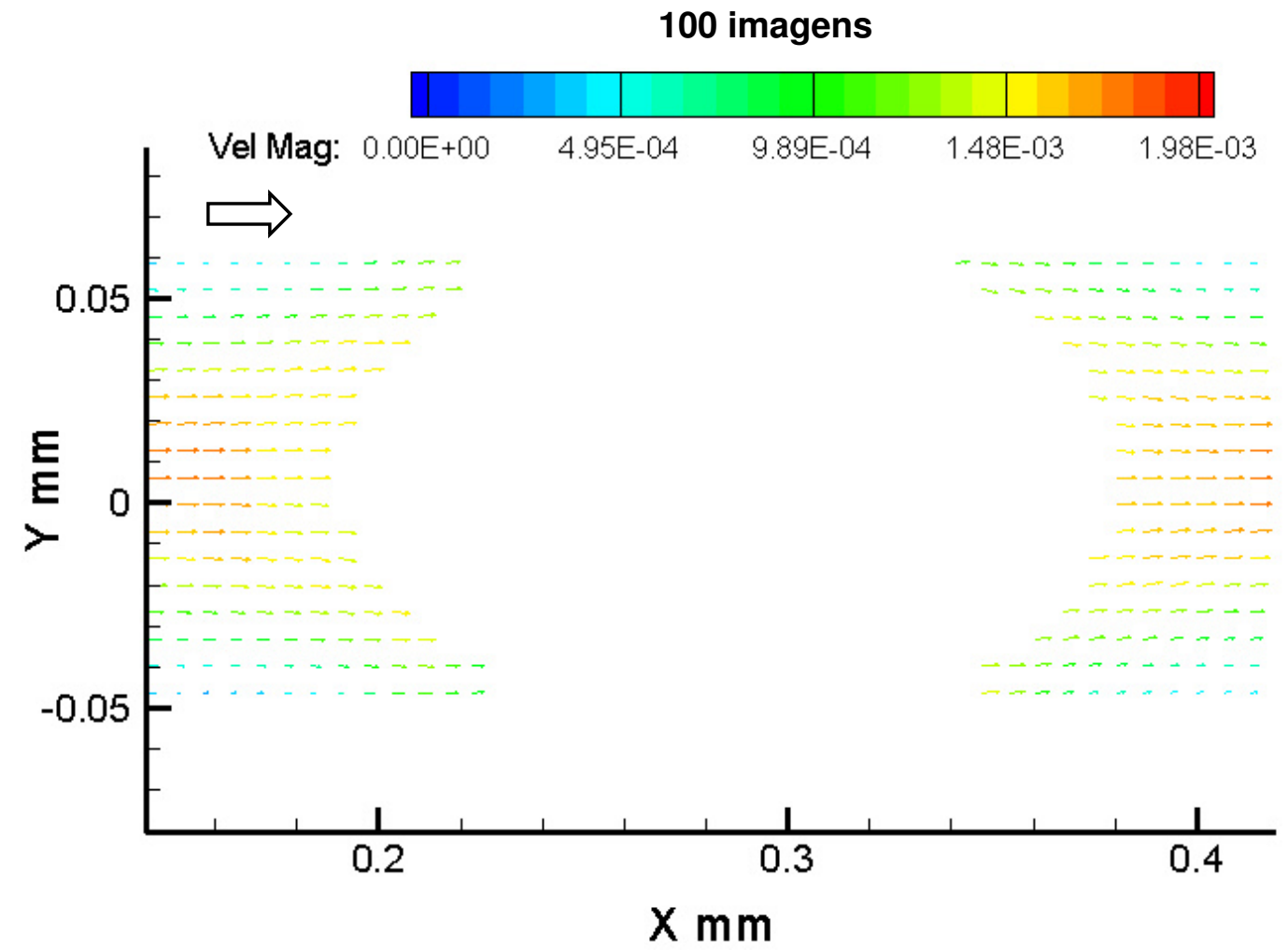

Figura 4.36: Campo de velocidade do escoamento bifásico de 100 pares de imagens, na interface óleo-água à montante da gota pequena $(\alpha=1,4)$, através do micro canal de seção reta constante.

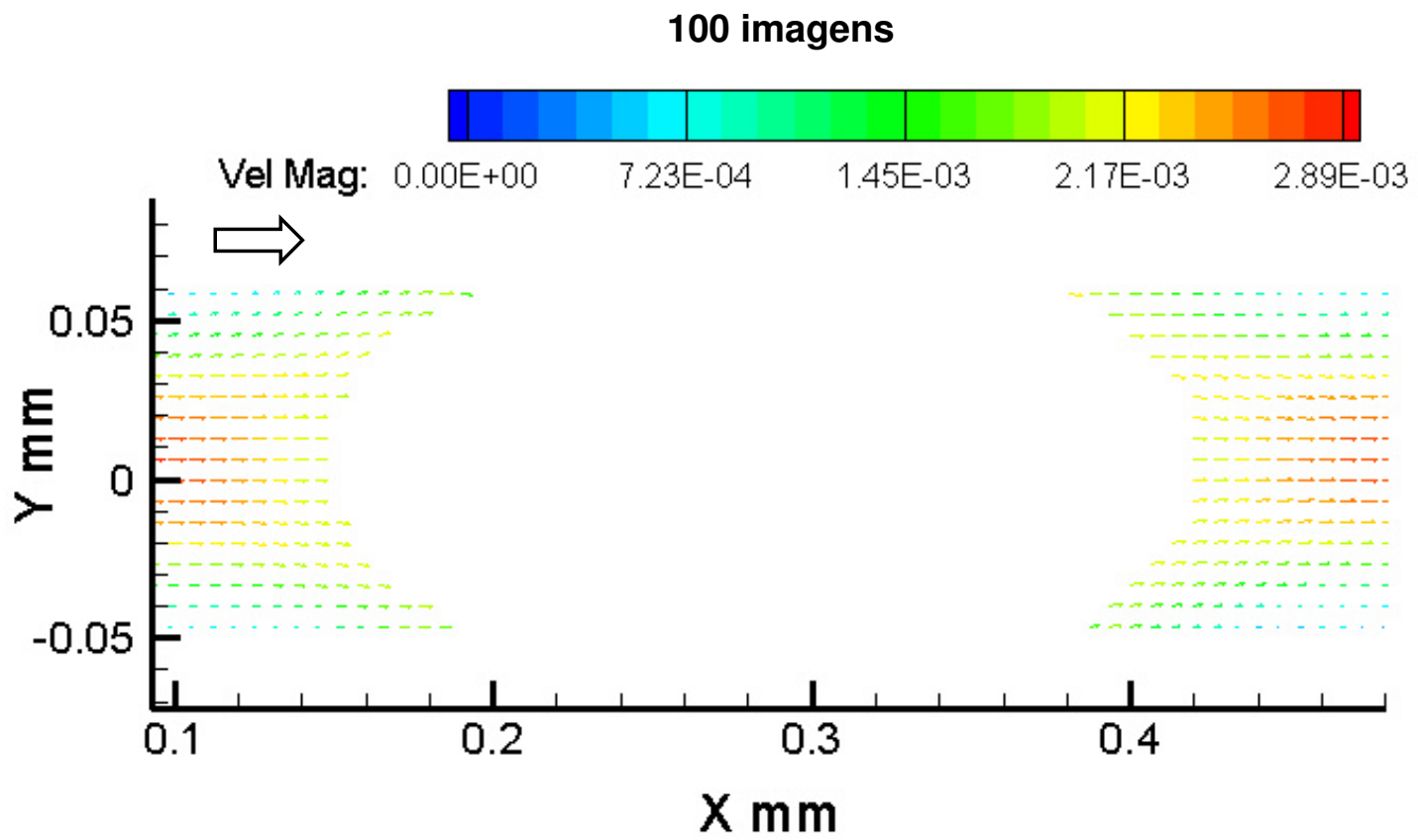


Figura 4.37: Campo de velocidade do escoamento bifásico de 100 pares de imagens, na interface óleo-água à montante da gota média $(\alpha=1,5)$, através do micro canal de seção reta constante.

\begin{tabular}{|c|c|c|c|c|c|}
\hline $\begin{array}{c}\text { Gota Pequena } \\
\qquad \alpha=1,4\end{array}$ & $\begin{array}{c}V_{\text {média }} \\
\text { Exp. perfil } \\
\text { entrada } \\
\left(\times 10^{-4} \mathrm{~m} / \mathrm{s}\right)\end{array}$ & $\begin{array}{c}V_{\text {média }} \\
\text { Exp. perfil } \\
\text { saída } \\
\left(\times 10^{-4} \mathrm{~m} / \mathrm{s}\right)\end{array}$ & $\begin{array}{c}\mathrm{V}_{\text {média }}\left(\mathrm{V}_{\mathrm{m}}\right) \\
\text { Escoamento } \\
\text { injetado } \\
\left(\times 10^{-4} \mathrm{~m} / \mathrm{s}\right)\end{array}$ & $\begin{array}{c}V_{\mathrm{g}} \\
\text { Gota } \\
\left(\times 10^{-4} \mathrm{~m} / \mathrm{s}\right)\end{array}$ & $V_{g} / V_{m}$ \\
\hline $1^{\mathrm{a}}-50$ imagens & $9,, 565$ & 9,690 & 9,499 & 14,75 & 1,55 \\
\hline $2^{\text {a }-50 ~ i m a g e n s}$ & 9,010 & 9,170 & 9,499 & 14,91 & 1,57 \\
\hline 100 imagens & 9,080 & 9,270 & 9,499 & 14,85 & 1,56 \\
\hline
\end{tabular}

Tabela 4.5: Valores de velocidade da gota pequena $(\alpha=1,4)$, através do micro canal de seção reta constante.

\begin{tabular}{|c|c|c|c|c|c|}
\hline $\begin{array}{l}\text { Gota Média } \\
\qquad \alpha=1,5\end{array}$ & $\begin{array}{c}V_{\text {média }} \\
\text { Exp. perfil } \\
\text { entrada } \\
\left(x 10^{-4} \mathrm{~m} / \mathrm{s}\right)\end{array}$ & $\begin{array}{c}V_{\text {média }} \\
\text { Exp. perfil } \\
\text { saída } \\
\left(\times 10^{-4} \mathrm{~m} / \mathrm{s}\right)\end{array}$ & $\begin{array}{c}\mathrm{V}_{\text {média }}\left(\mathrm{V}_{\mathrm{m}}\right) \\
\text { Escoamento } \\
\text { injetado } \\
\left(\times 10^{-4} \mathrm{~m} / \mathrm{s}\right)\end{array}$ & $\begin{array}{c}V_{g} \\
\text { Gota } \\
\left(\times 10^{-4} \mathrm{~m} / \mathrm{s}\right)\end{array}$ & $V_{g} / V_{m}$ \\
\hline $1^{\mathrm{a}}-50$ imagens & 13,90 & 13,445 & 13,71 & 20,63 & 1,50 \\
\hline $2^{a}-50$ imagens & 14,25 & 14,24 & 13,71 & 21,61 & 1,57 \\
\hline 100 images & 13,90 & 13,975 & 13,71 & 21,14 & 1,54 \\
\hline
\end{tabular}

Tabela 4.6: Valores de velocidade da gota média $(\alpha=1,5)$, através do micro canal de seção reta constante.

Para ambos os casos, a gota pequena e gota média se deslocam a uma velocidade maior que do escoamento médio.

A razão entre a velocidade da gota e velocidade média foi de $V_{g} / V_{m}=1,56$ para $\alpha=1,4$ e $V_{\mathrm{g}} / \mathrm{V}_{\mathrm{m}}=1,54$ para $\alpha=1,5$. O número de capilaridade do escoamento, definido como $\mathrm{Ca}=\mu_{\mathrm{c}} \mathrm{V}_{\mathrm{m}} / \sigma$ ( $\mu_{\mathrm{c}}$ é a viscosidade da fase contínua e $\sigma$ é a tensão interfacial entre as fases) foi de $\mathrm{Ca}=1,6 \times 10^{-4}(\alpha=1,4)$ e $\mathrm{Ca}=2,4 \times 10^{-4}(\alpha=1,5)$.

É importante notar que os valores medidos de $\mathrm{V}_{\mathrm{g}} / \mathrm{V}_{\mathrm{m}}$ são maiores dos que os valores apresentados na literatura [35]. Porém, a faixa de parâmetros nos 
estudos anteriores foi sempre para capilares de maiores diâmetros e número de capilaridade maiores (Ca >0,05).

Os resultados apresentados podem servir de importante base de comparação e validação para soluções numéricas em escala micrométrica e baixos valores de número de capilaridade.

Detalhes do escoamento podem ser melhor estudados analisando o escoamento da fase contínua relativo a gota.

Para obter o campo de velocidade relativo à gota, a velocidade da gota foi subtraída do campo de velocidade do escoamento bifásico das figuras (4.29) e (4.31) respectivamente. No caso da gota pequena a velocidade foi de $V_{g}=14,85 x$ $10^{-4} \mathrm{~m} / \mathrm{s}$ e a gota média de $\mathrm{V}_{\mathrm{g}}=21,14 \times 10^{-4} \mathrm{~m} / \mathrm{s}$. As figuras (4.38) e (4.39) mostram o campo de velocidade relativo à gota pequena $(\alpha=1,4)$ e à gota média $(\alpha=1,5)$, mostrando também $50 \%$ dos perfis de velocidade, para facilitar a visualização.
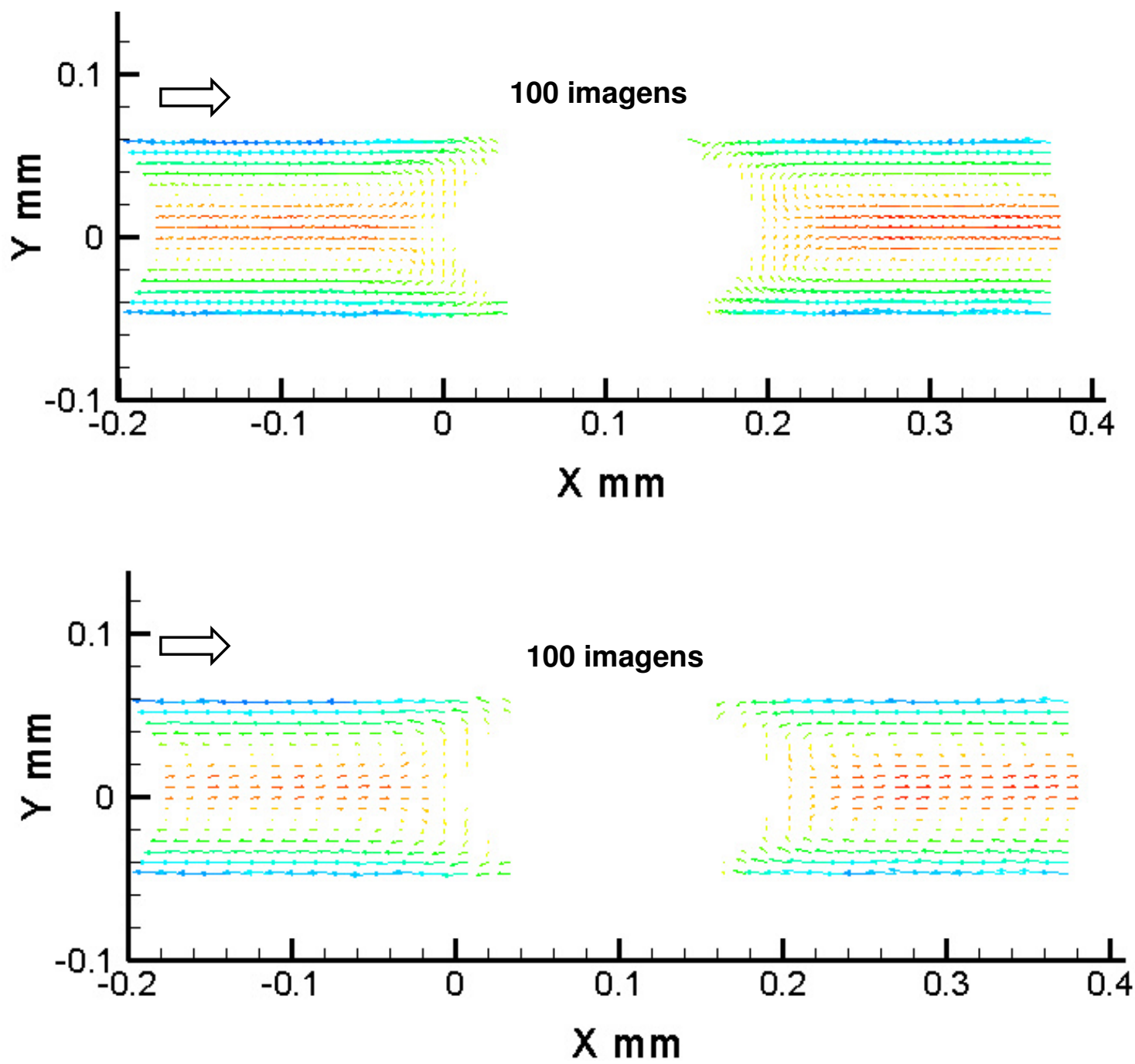
Figura 4.38: Campo de velocidade do escoamento bifásico dos 100 pares de imagens relativo à gota pequena $(\alpha=1,4)$, através do micro canal de seção reta constante.
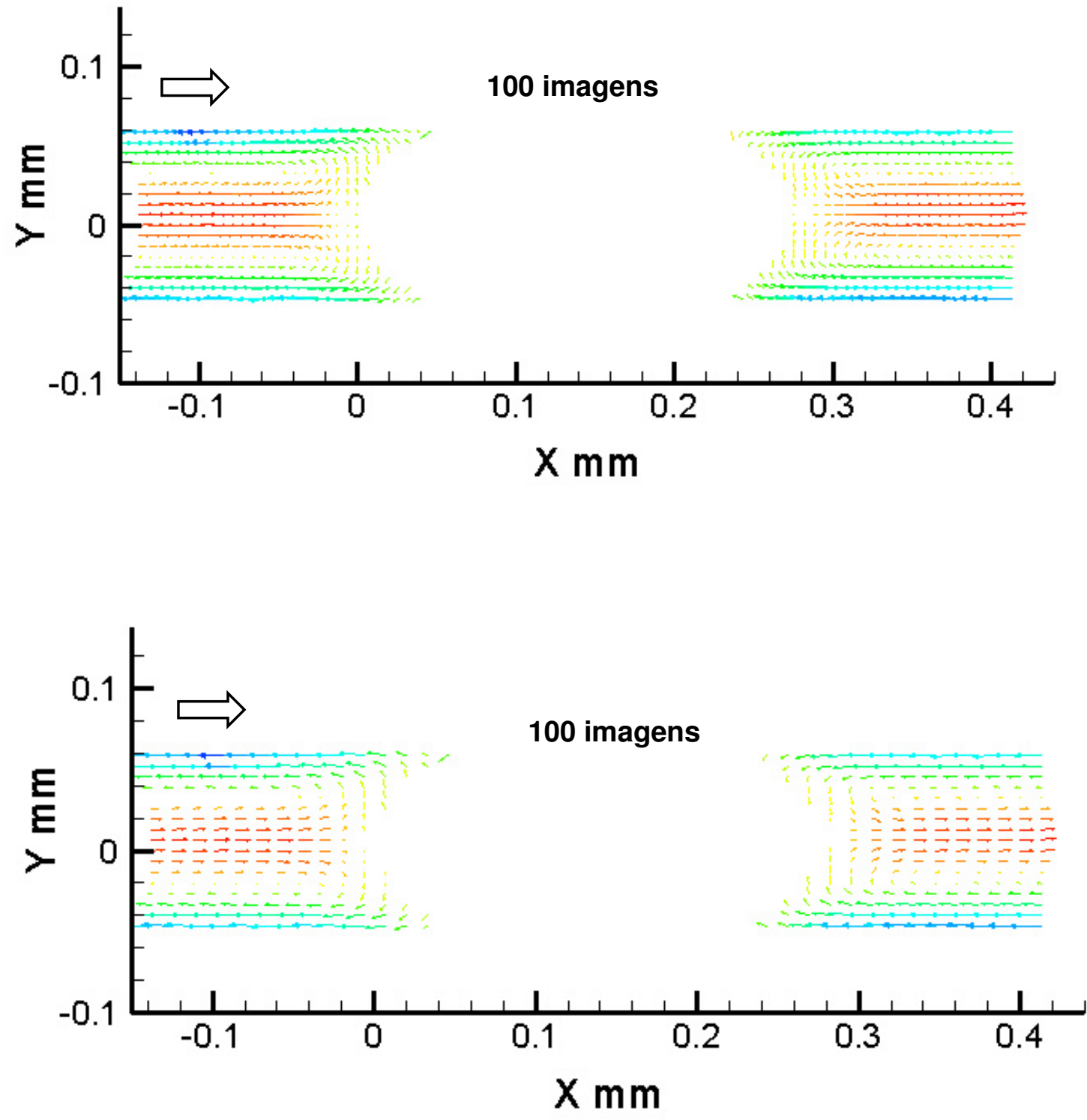

Figura 4.39: Campo de velocidade do escoamento bifásico dos 100 pares de imagens relativo à gota média $(\alpha=1,5)$, através do micro canal de seção reta constante.

Para melhor visualização do escoamento em estudo é apresentado um zoom na região do lado esquerdo (jusante) e direito (montante) de cada exemplo apresentado, como mostram as figuras (4.40) e (4.41) respectivamente. Pode-se observar que existem dois fluxos viajando em diferentes sentidos. O fluxo em suspensão na parte central do micro capilar se move a uma maior velocidade que a gota (na mesma direção da gota), e o fluido em suspensão contíguo à parede do micro capilar move-se a uma menor velocidade que a gota (no sentido oposto da gota). 


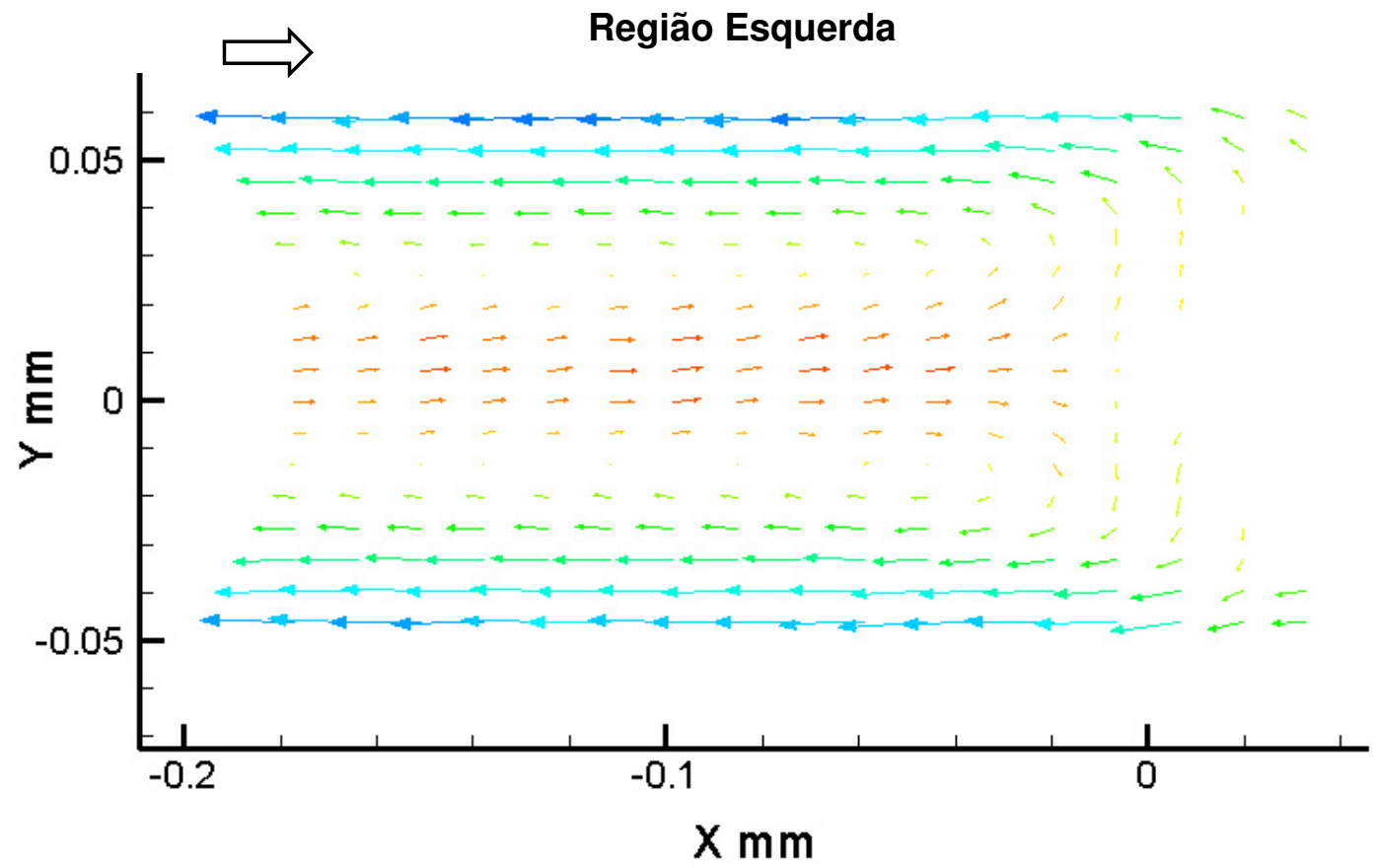

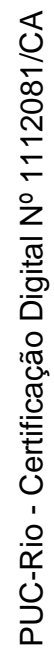

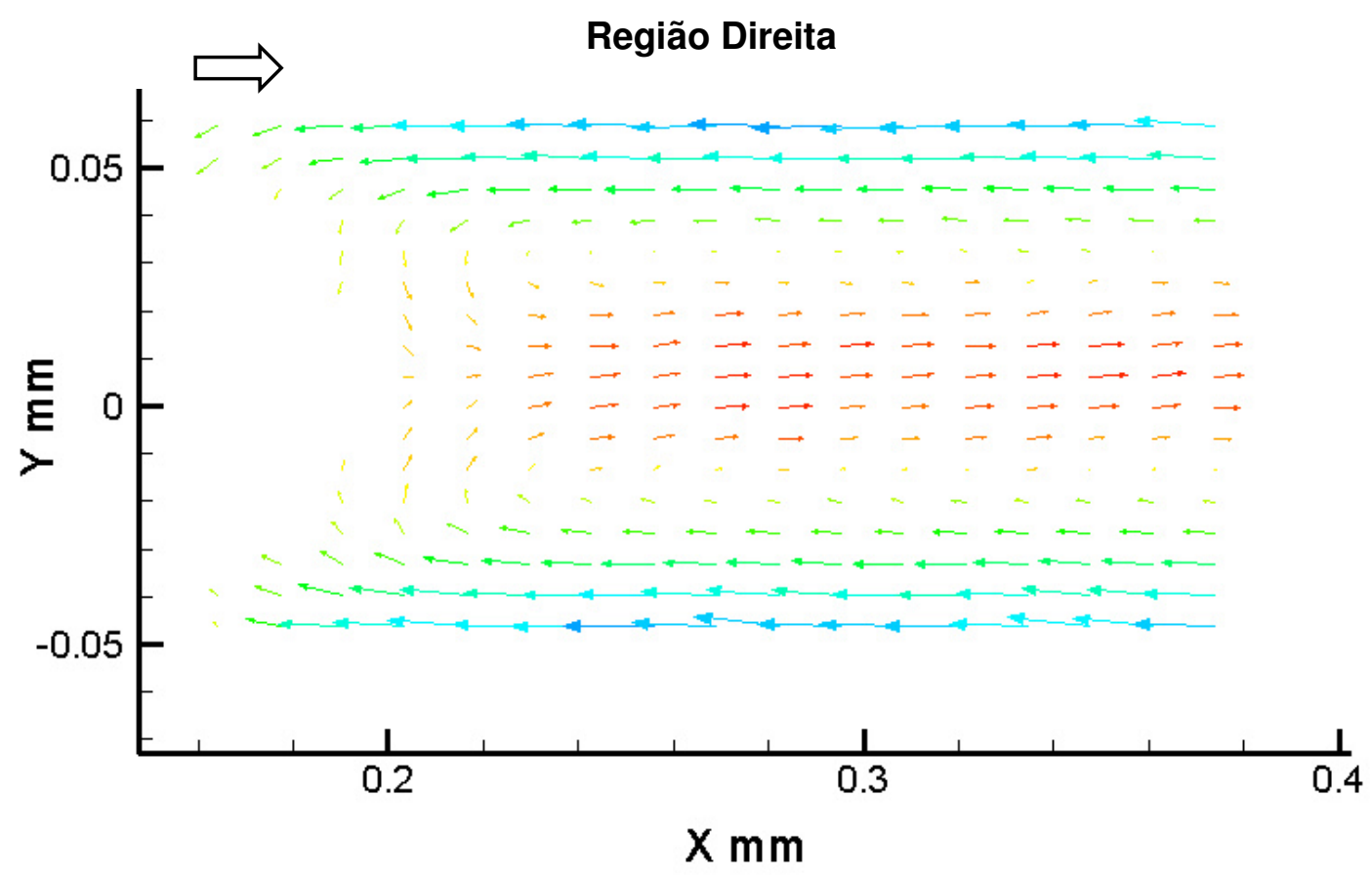

Figura 4.40: Região do lado esquerdo e direito do campo de velocidade relativo à gota pequena $(\alpha=1,4)$, através do micro canal de seção reta constante. 

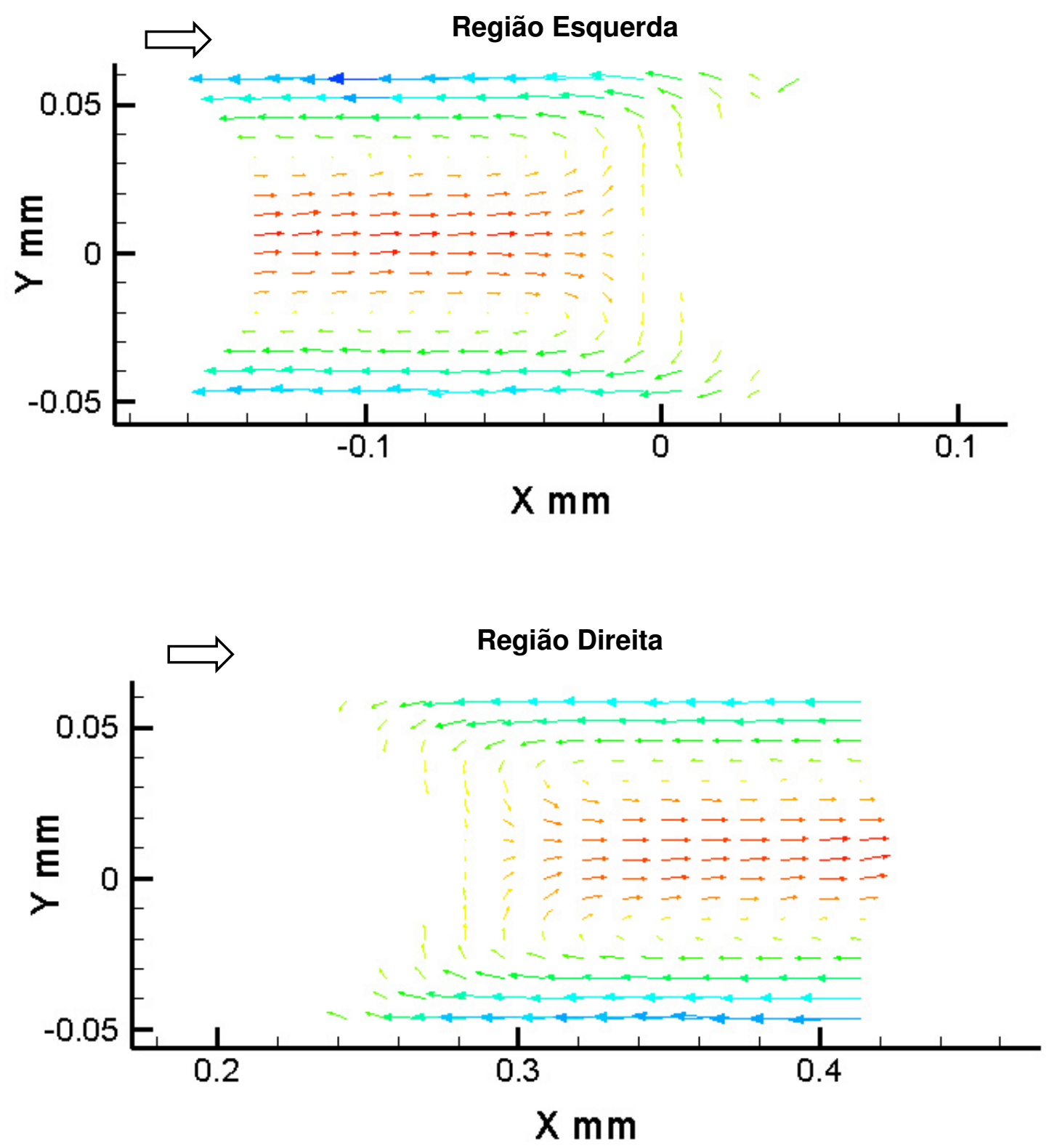

Figura 4.41: Região do lado esquerdo e direito do campo de velocidade relativo à gota média $(\alpha=1,5)$, através do micro canal de seção reta constante.

Martinez \& Udell [28] apresentaram o campo de velocidade relativo a uma gota pequena viscosa $(\alpha=0,726, \lambda=10, \mathrm{Ca}=0,1)$ e uma gota grande relativamente não viscosa $(\alpha=1,1, \lambda=0,19, \mathrm{Ca}=0,1)$ realizadas numericamente. Em que $\alpha$ é a relação do raio da gota e do micro capilar, $\lambda$ é a relação de viscosidade da gota $e$ o fluido suspenso, e Ca é o número de capilaridade.

No presente trabalho, o campo de velocidade relativo à gota pequena $\left(\alpha=1,4, \lambda=18,3, \mathrm{Ca}=1,6 \times 10^{-4}\right)$ e à gota média $\left(\alpha=1,5\right.$ e $\left.\lambda=18,3, \mathrm{Ca}=2,4 \times 10^{-4}\right)$ foi 
realizado experimentalmente através da técnica de $\mu$-PIV. Os campos obtidos são bastante similares ao apresentado na figura (4.42).
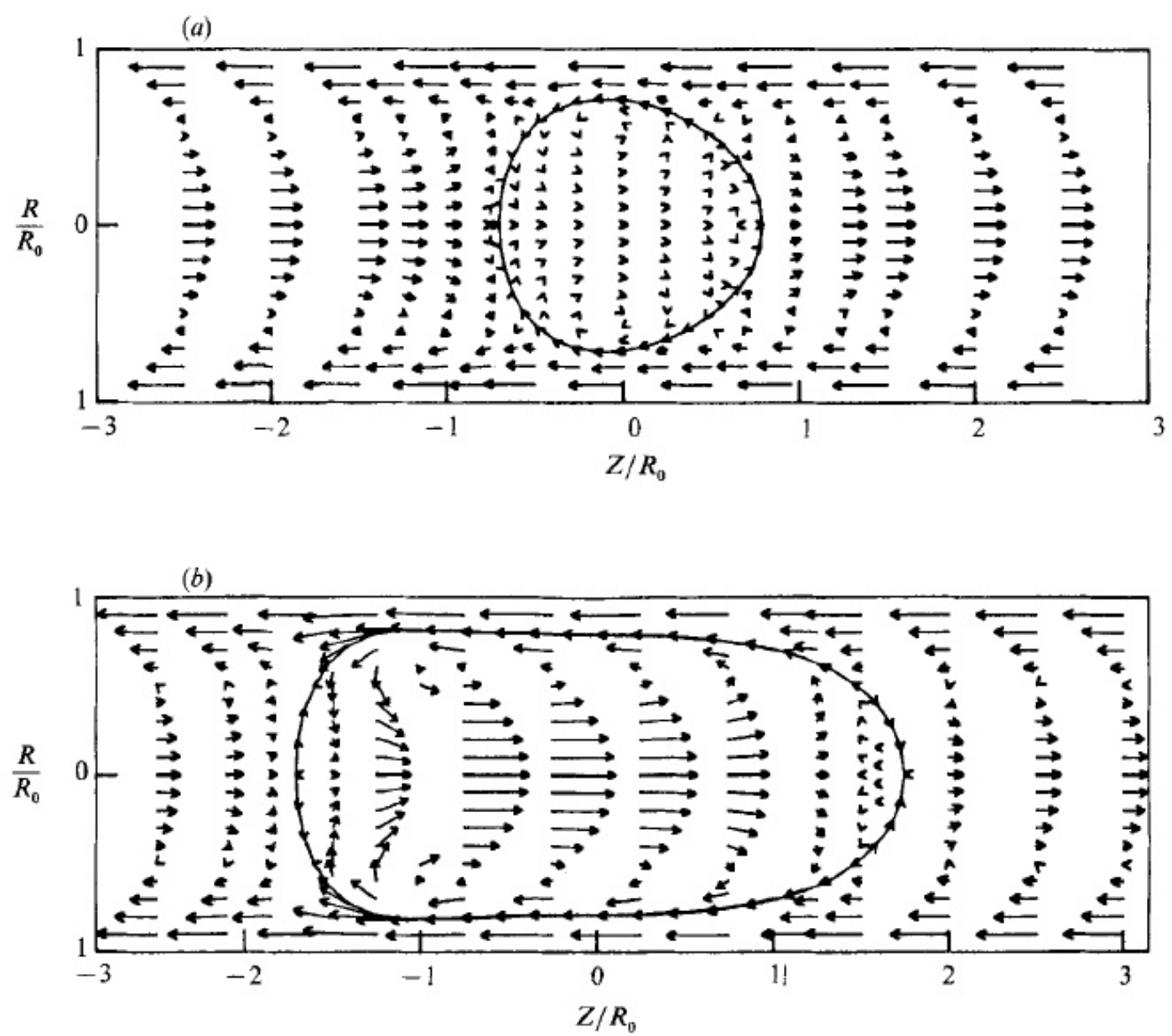

Figura 4.42: Campo de velocidade de uma gota pequena e grande realizada numericamente por Martinez \& Udell em 1989 [28].

Finalmente, as figuras (4.43) e (4.45) apresentam as linhas de corrente do escoamento da fase contínua no campo de velocidade relativo a cada gota, e também um zoom na região do lado esquerdo e direito para melhor visualização do escoamento, figuras (4.44) e (4.46). 


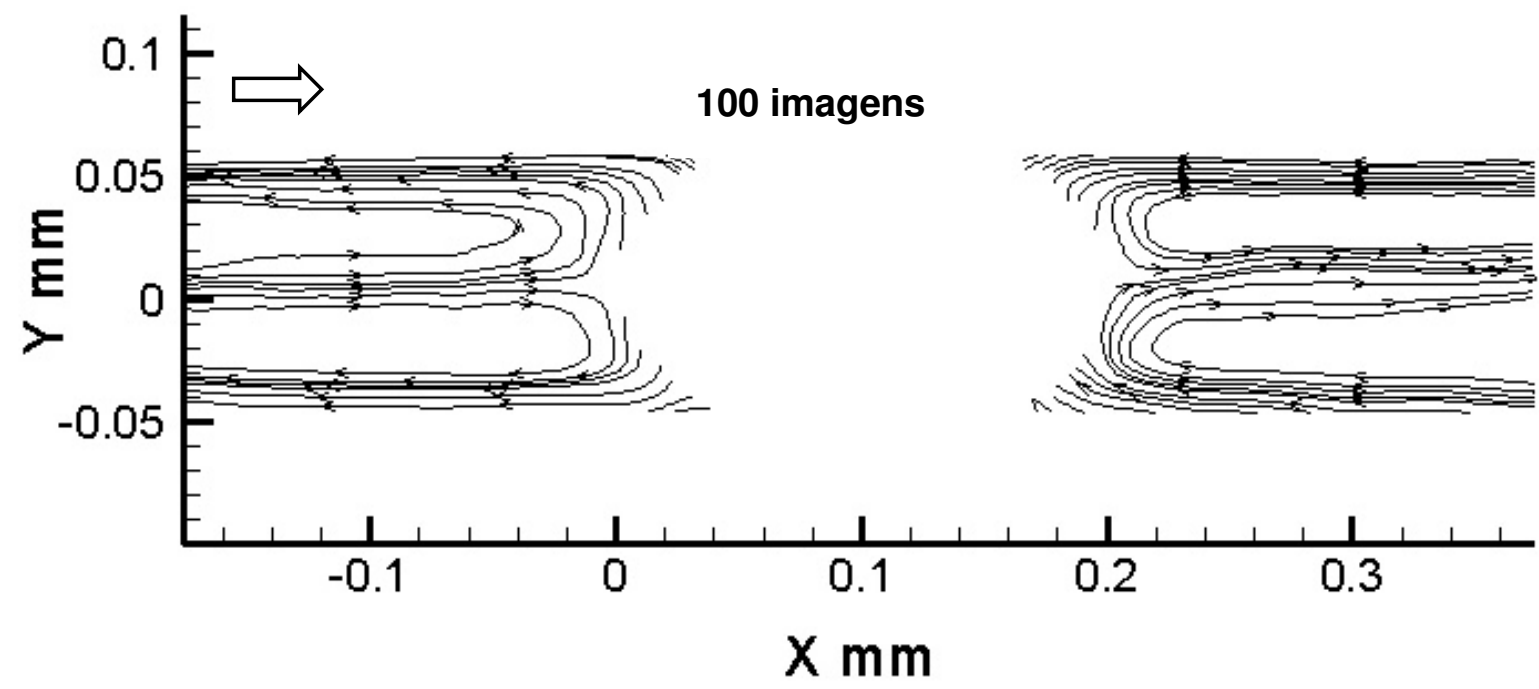

Figura 4.43: Linhas de corrente do campo de velocidade do escoamento bifásico dos 100 pares de imagens relativo à gota pequena $(\alpha=1,4)$.

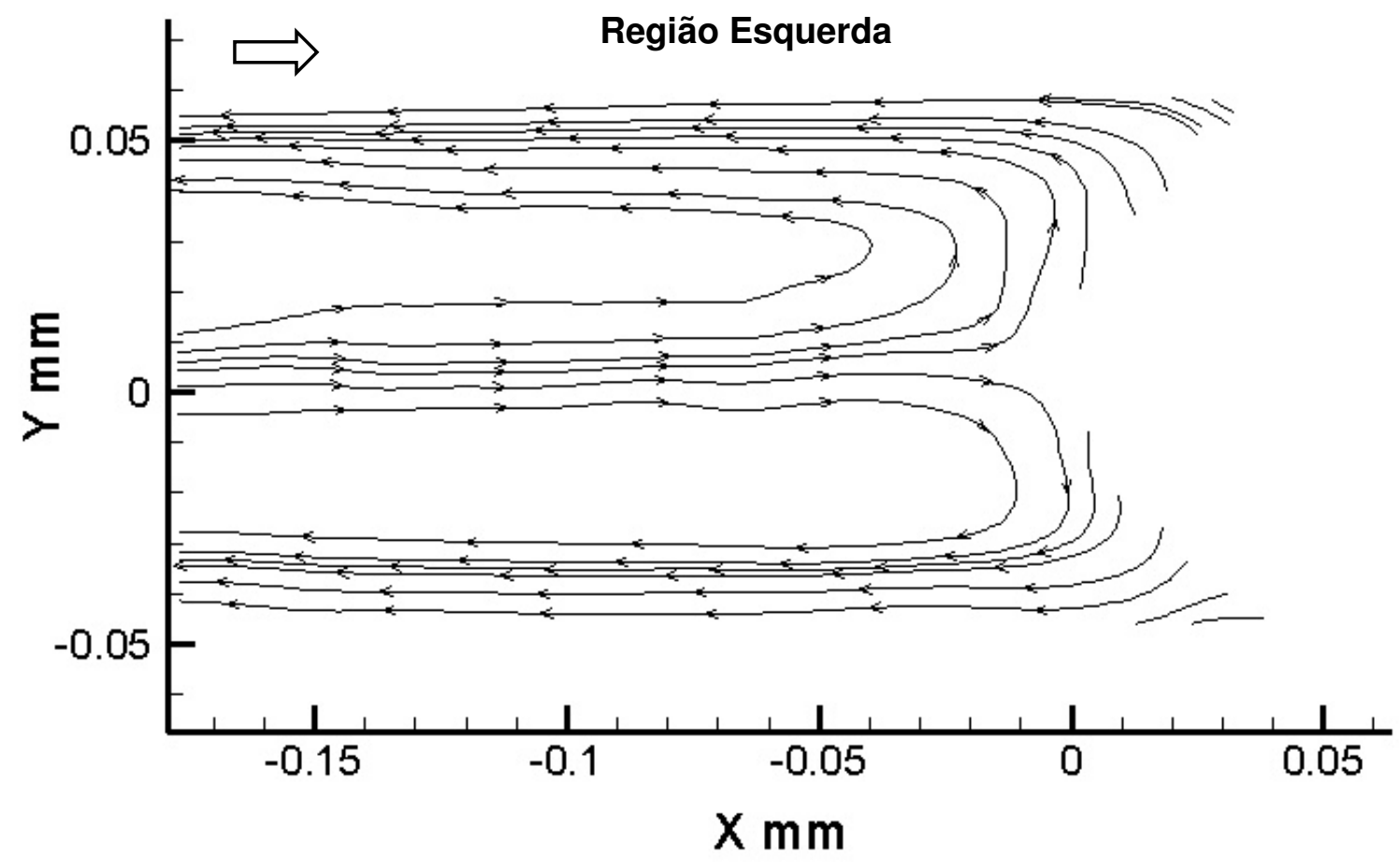




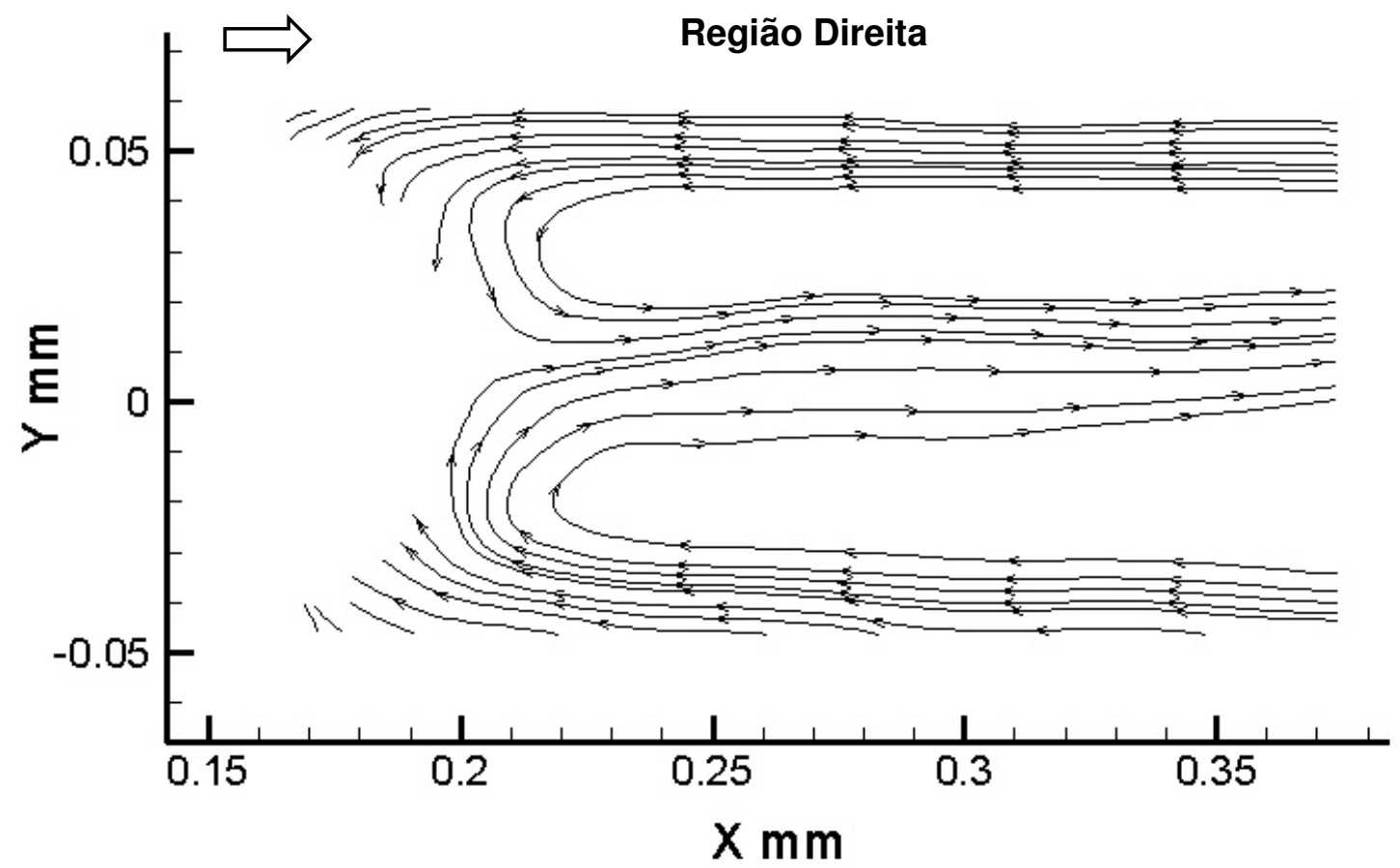

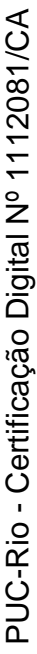

Figura 4.44: Região de linhas de corrente do lado esquerdo e direito do campo de velocidade do escoamento bifásico dos 100 pares de imagens relativo à gota pequena $(\alpha=1,4)$.

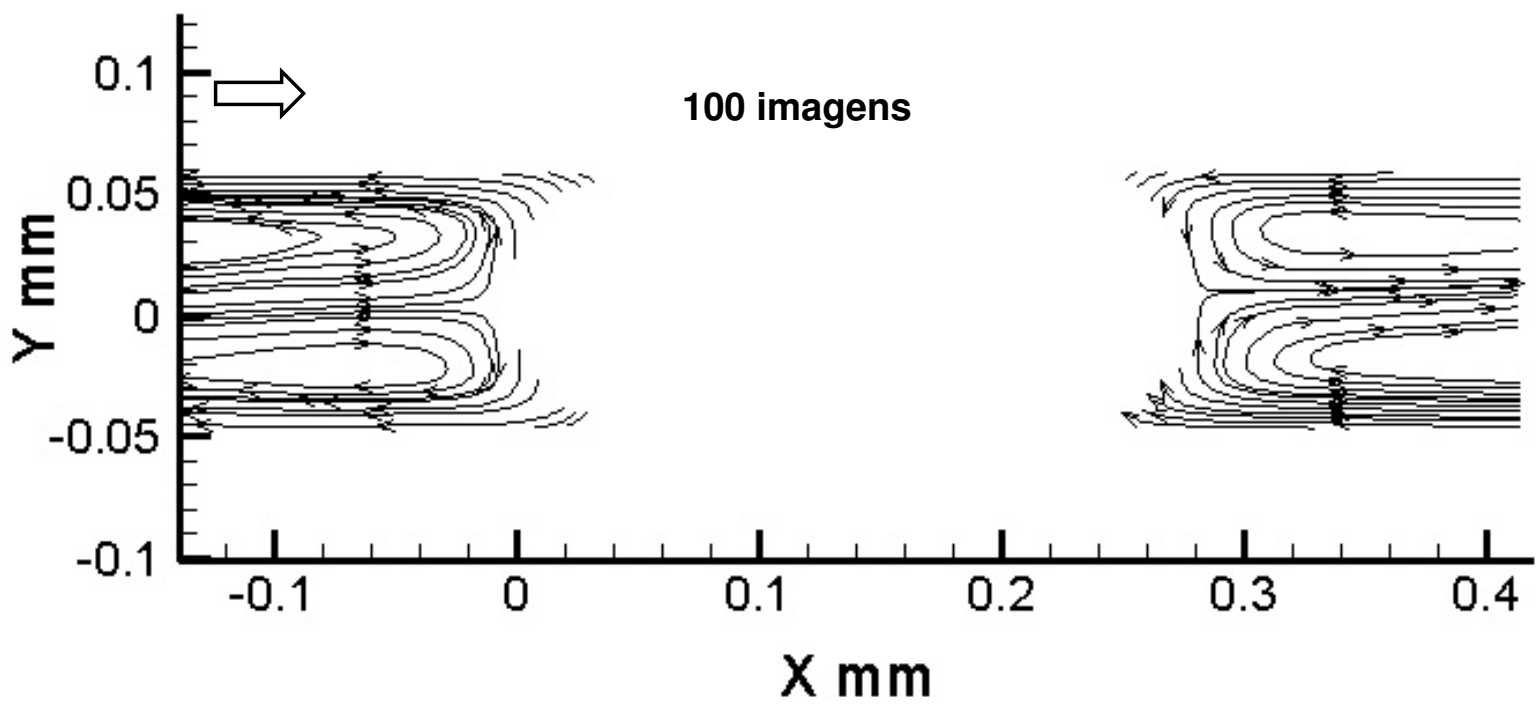

Figura 4.45: Linhas de corrente do campo de velocidade do escoamento bifásico dos 100 pares de imagens relativo à gota média $(\alpha=1,5)$. 


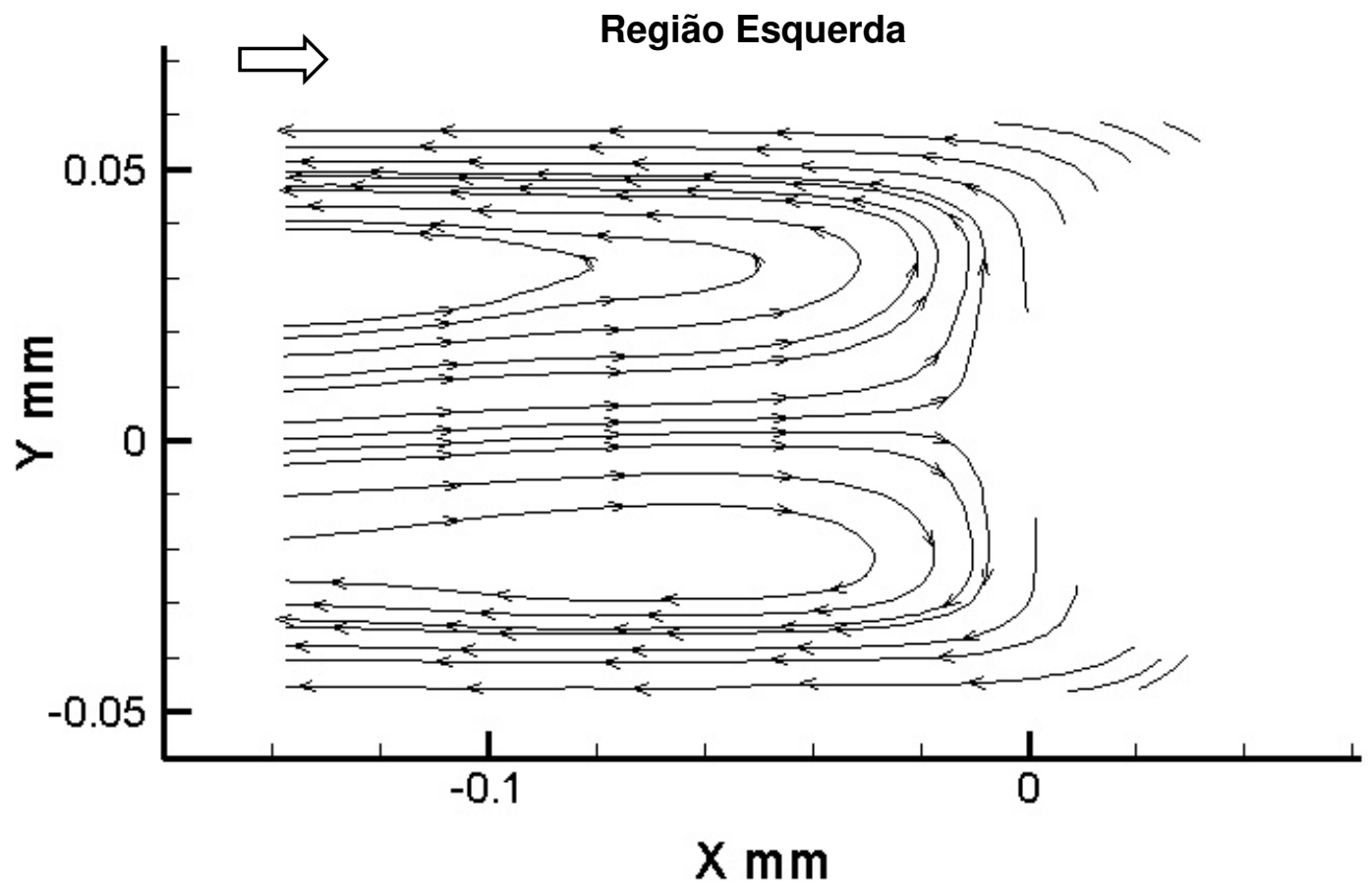

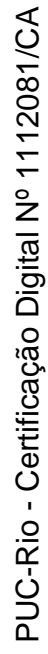

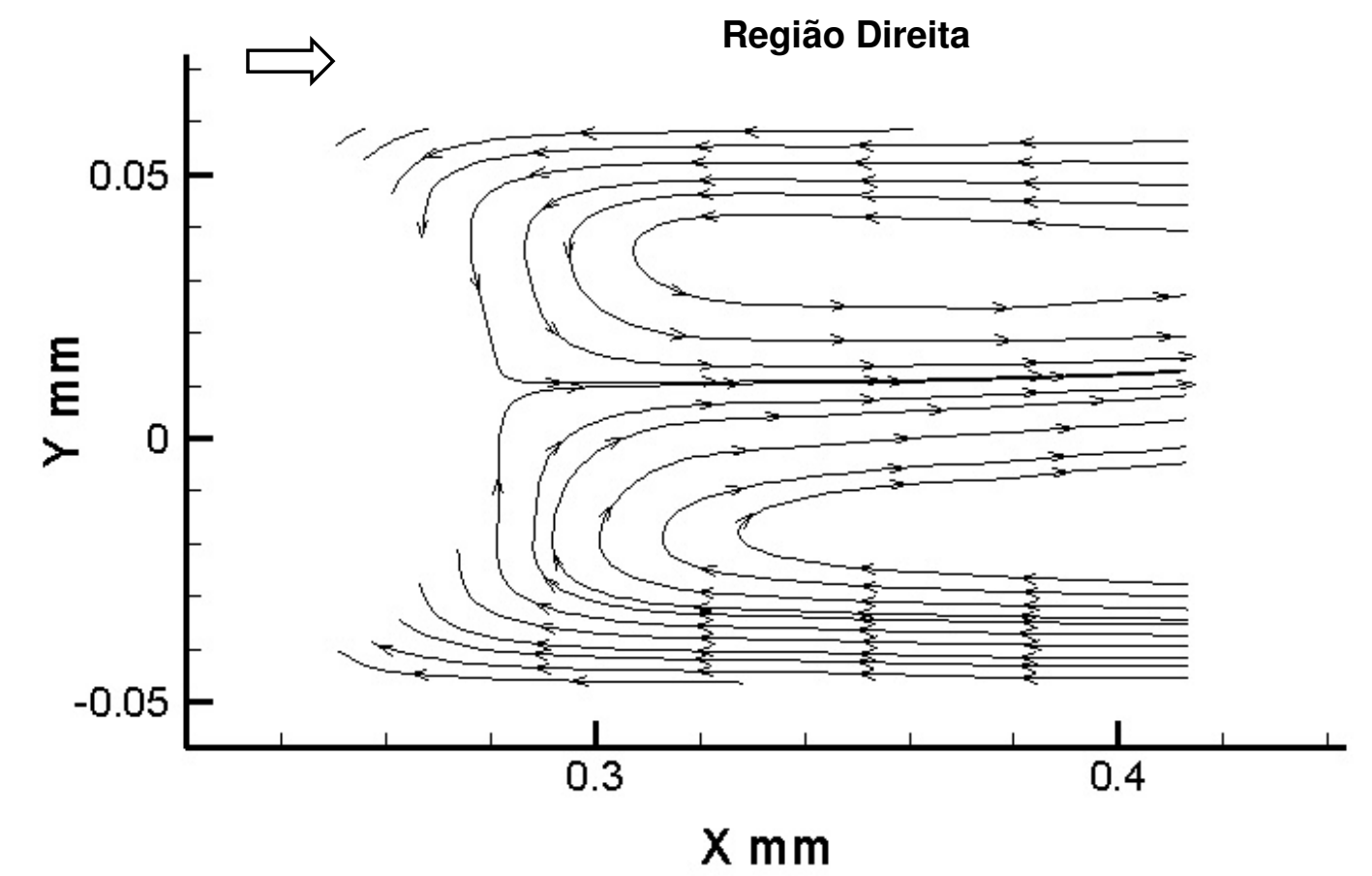

Figura 4.46 Região de linhas de corrente do lado esquerdo e direito do campo de velocidade do escoamento bifásico dos 100 pares de imagens relativo à gota média $(\alpha=1,5)$. 


\subsection{2. \\ Medição do campo de velocidade do escoamento bifásico óleo-água no micro canal com garganta}

As duas bombas foram ligadas em modo de injeção contínua. A injeção da fase contínua foi de $Q=0,03 \mathrm{ml} / \mathrm{h}$ e da fase dispersa foi de $Q=0,003 \mathrm{ml} / \mathrm{h}$ para gerar gotas pequenas $(\alpha=1,4)$. Devido aos efeitos inerciais e ao comprimento das mangueiras, o tempo aproximado de estabilização foi de 15 minutos, antes de iniciar a captura das imagens. Foram feitas as medições de campo de velocidades para 2 micro capilares diferentes diâmetros de garganta.

O primeiro micro capilar utilizado tem um comprimento na garganta de 70 $\mu \mathrm{m}$, e um diâmetro máximo e mínimo de $110 \mu \mathrm{m}$ e $85 \mu \mathrm{m}$ respectivamente. Para estudar a evolução do escoamento durante a passagem da gota pela garganta, o campo de velocidade foi determinado para 3 posições diferentes da gota ao longo da garganta. A área selecionada para o processamento das imagens foi definida através de uma máscara. As figuras (4.47), (4.48) e (4.49) mostram as posições e as máscaras utilizadas para a gota pequena: Na primeira posição, a ponta da gota encontra-se no inicio da garganta; na segunda posição, no plano de menor seção reta e na terceira posição, a ponta da gota encontra-se no final da garganta.
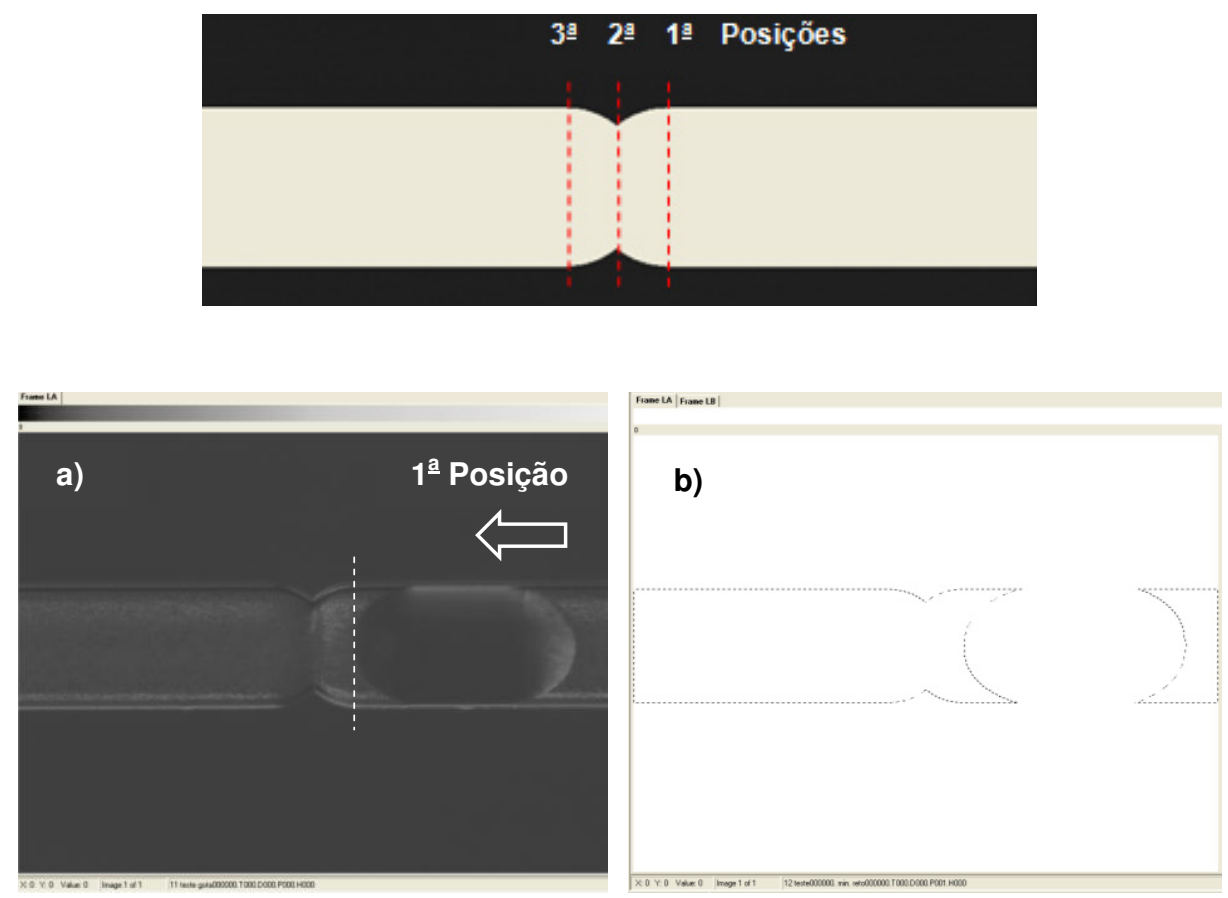
Figura 4.47: a) Primeira posição da gota pequena $(\alpha=1,4)$ no primeiro micro canal com garganta. b) Máscara da primeira posição da gota pequena no primeiro micro canal com garganta.
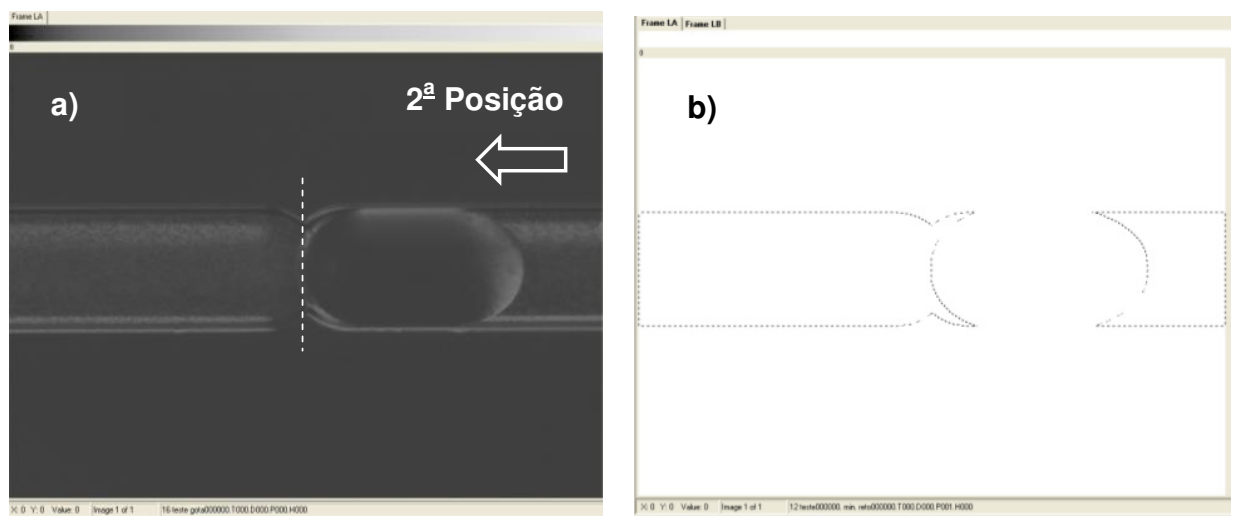

Figura 4.48: a) Segunda posição da gota pequena $(\alpha=1,4)$ no primeiro micro canal com garganta. b) Máscara da segunda posição da gota pequena no primeiro micro canal com garganta.
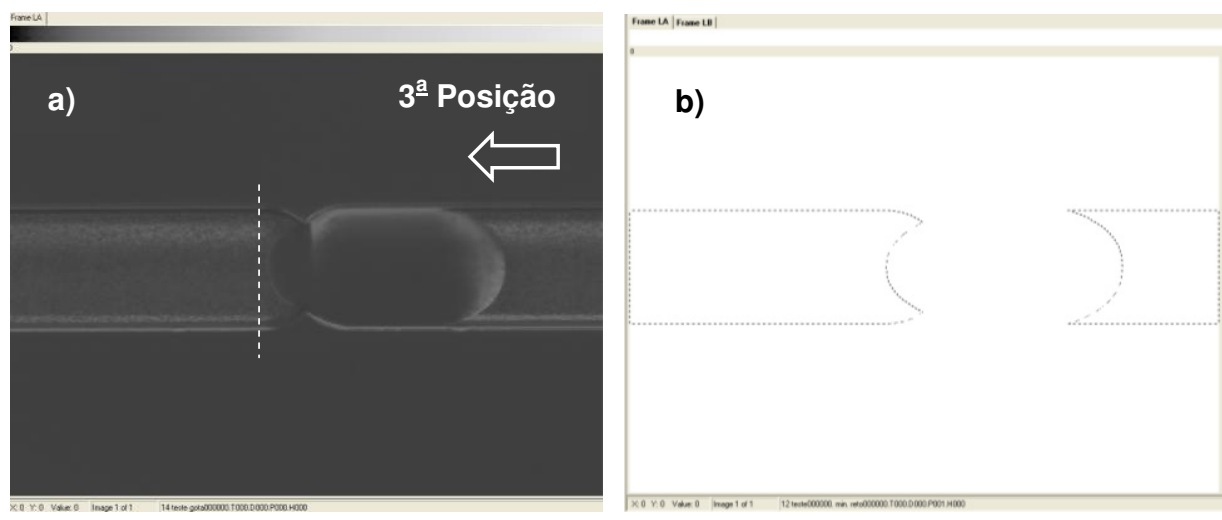

Figura 4.49: a) Terceira posição da gota pequena $(\alpha=1,4)$ no primeiro micro canal com garganta. b) Máscara da terceira posição da gota pequena no primeiro micro canal com garganta.

$\mathrm{Na}$ captura das imagens, o programa Insight $3 \mathrm{G}^{\mathrm{TM}}$ foi configurado com os seguintes parâmetros:

- Modo de aquisição da imagem "sincronizado";

- Tempo de espera do primeiro pulso laser de $800 \mu \mathrm{s}$;

- Tempo de exposição do sensor da câmera CCD de 1300 s;

- Taxa de repetição da frequência dos lasers 4,83 Hz;

- Energia dos lasers em "high". 
O procedimento de captura de imagens foi feita da mesma maneira que no micro canal de seção reta constante. O número de pares de imagens coletadas foi de 50 para cada posição.

O tempo de separação $\Delta$ t entre o par de imagens foi de $1000 \mu \mathrm{s}$. A janela de interrogação utilizada foi de $32 \times 32$ pixels. O deslocamento máximo permitido foi de $0,25 \times 32$ pixels=8 pixels. As imagens, sobretudo na segunda posição, onde a velocidade foi maior, apresenta um deslocamento máximo de partículas entre 6-8 pixels.

O pré-processamento dos 50 pares de imagens coletados para cada posição foi realizado usando as técnicas “Imagem de intensidade mínimo/médio" e "Subtração de fundo".

Para o processamento das imagens, no programa Insight $3 G^{T M}$, foram configurados os seguintes parâmetros:

- O tamanho das janelas de interrogação ou resolução espacial foi de $32 \times 32$ pixels $\left(13,1 \times 13,1 \mu \mathrm{m}^{2}\right)$;

- O máximo deslocamento das partículas foi de " $25 \%$ do tamanho da janela de interrogação";

- A calibração do sistema foi de $0,41 \mu \mathrm{m} /$ pixel.

As técnicas "Média Amostral", "Nyquist Grid", "Correlação da Transformada de Fourier" e "Pico Gaussiano" foram utilizados no processamento dos 50 pares de imagens coletados para cada posição.

O pós-processamento para obtenção do campo de velocidade em cada posição foi realizado utilizando as técnicas "Validação do Vetor Mediana Local" e "Vetor Condição".

As figuras (4.50), (4.51) e (4.52) apresentam os campos de vetores de velocidades dos 50 pares de imagens coletadas em cada posição, através do micro canal com garganta do dispositivo microfluídico. A porcentagem de vetores válidos foi de $93,30 \%$, 93,74\% e 97,22\% para cada posição da gota pequena, antes do pós-processamento. 


\section{1ㄹ Posição}
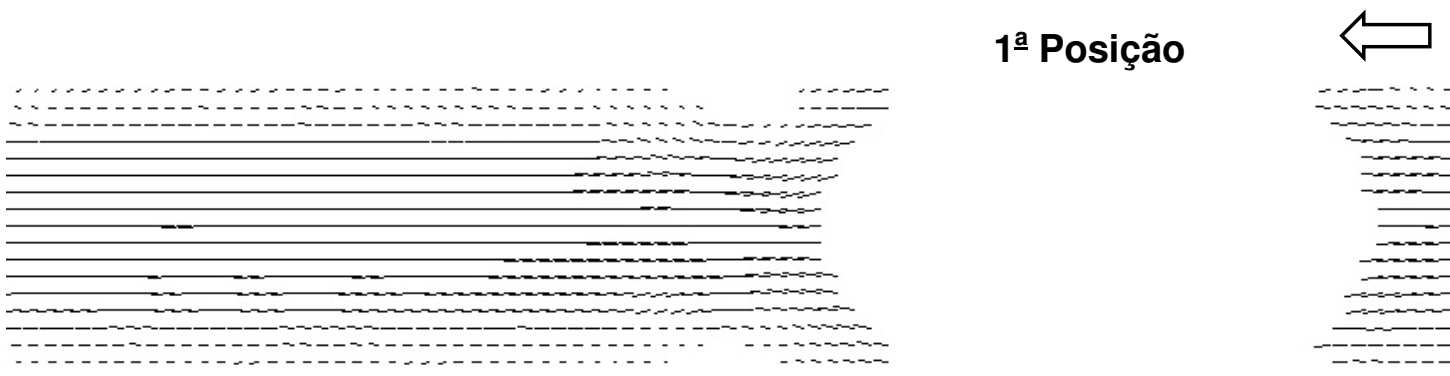

Figura 4.50: Campo de vetores de velocidade produzido do processamento dos 50 pares de imagens, ao redor da primeira posição da gota pequena, através do micro canal com garganta do primeiro micro capilar.

\section{$2^{\text {a }}$ Posição}

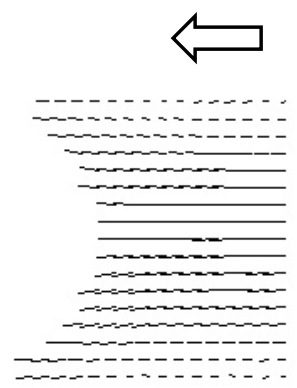

Figura 4.51: Campo de vetores de velocidade produzido do processamento dos 50 pares de imagens, ao redor da segunda posição da gota pequena, através do micro canal com garganta do primeiro micro capilar.

\section{3a Posição}

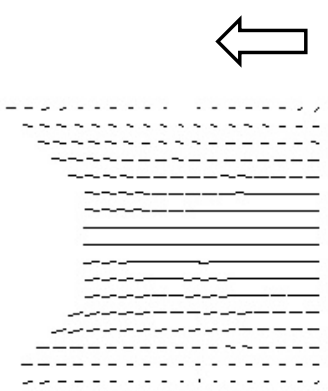

Figura 4.52: Campo de vetores de velocidade produzido do processamento dos 50 pares de imagens, ao redor da terceira posição da gota pequena, através do micro canal com garganta do primeiro micro capilar.

Aplicando o software "Tecplot ${ }^{\circledR ”}$, podemos melhor visualizar a intensidade do campo de velocidade da fase contínua ao redor da gota. As figuras (4.53), 
(4.54) e (4.55) apresentam os campos de velocidade do escoamento ao redor da gota pequena, mostrando também $50 \%$ dos perfis de velocidade para facilitar a visualização dos mesmos. O campo de velocidade para cada posição da gota é composto de 52 perfis de velocidade, e o número de vetores por perfil foi de 17 . As partículas fluorescentes foram suspensas na fase contínua, desta forma a gota aparece como uma mancha escura no campo de velocidade.
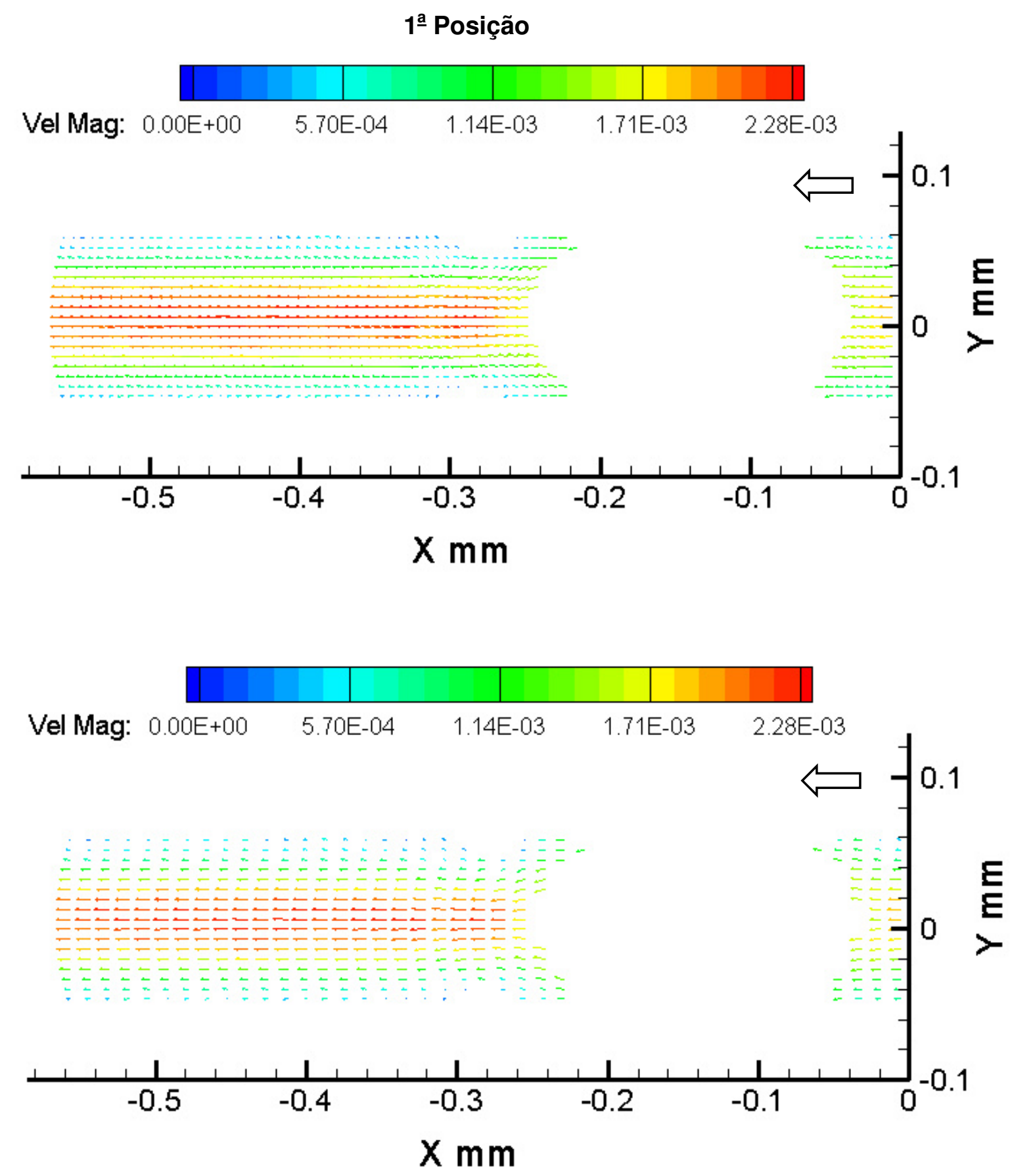
Figura 4.53: Campo de velocidade do escoamento bifásico dos 50 pares de imagens ao redor da primeira posição da gota pequena, através do micro canal com garganta do primeiro micro capilar.
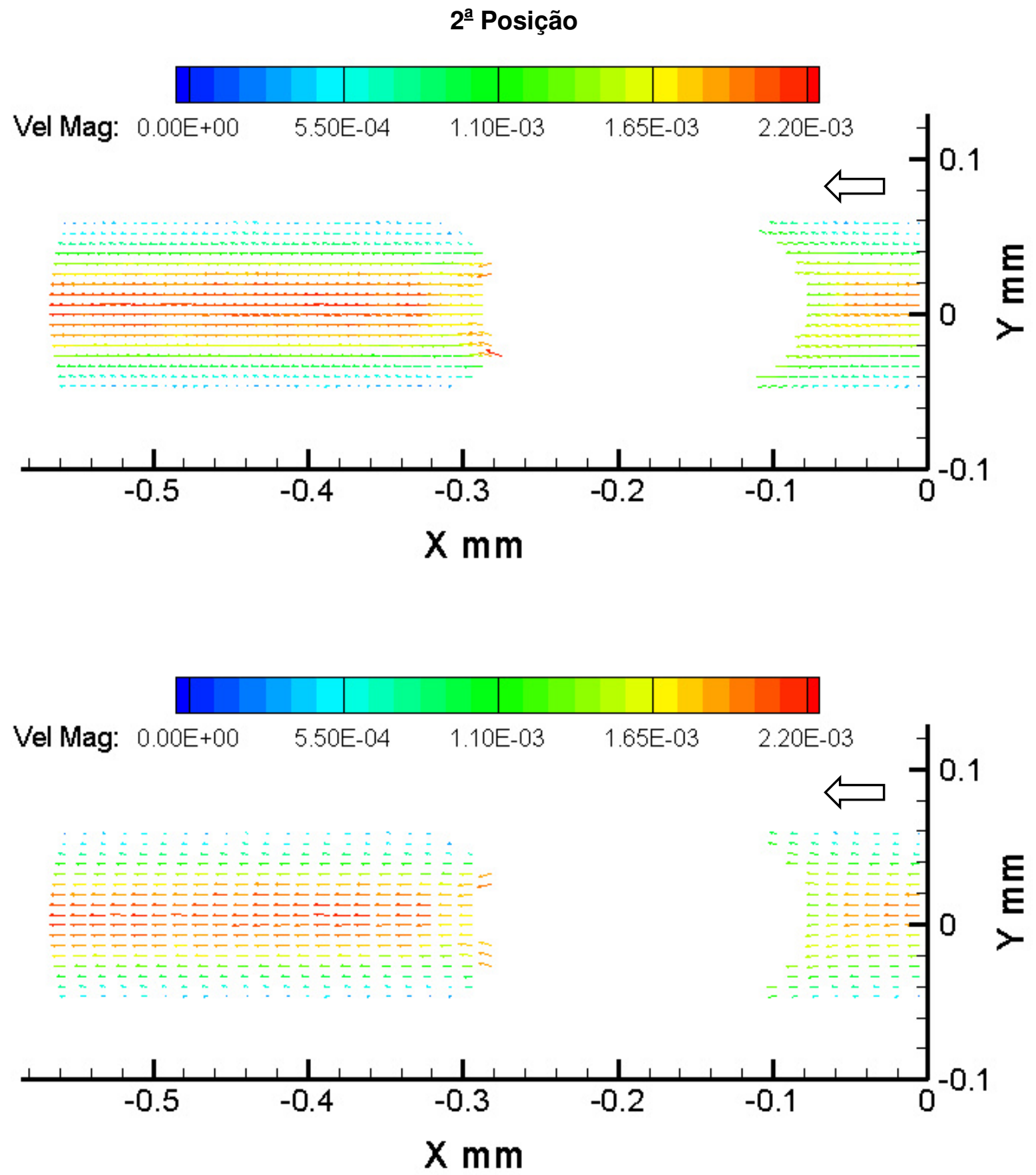

Figura 4.54: Campo de velocidade do escoamento bifásico dos 50 pares de imagens ao redor da segunda posição da gota pequena, através do micro canal com garganta do primeiro micro capilar. 

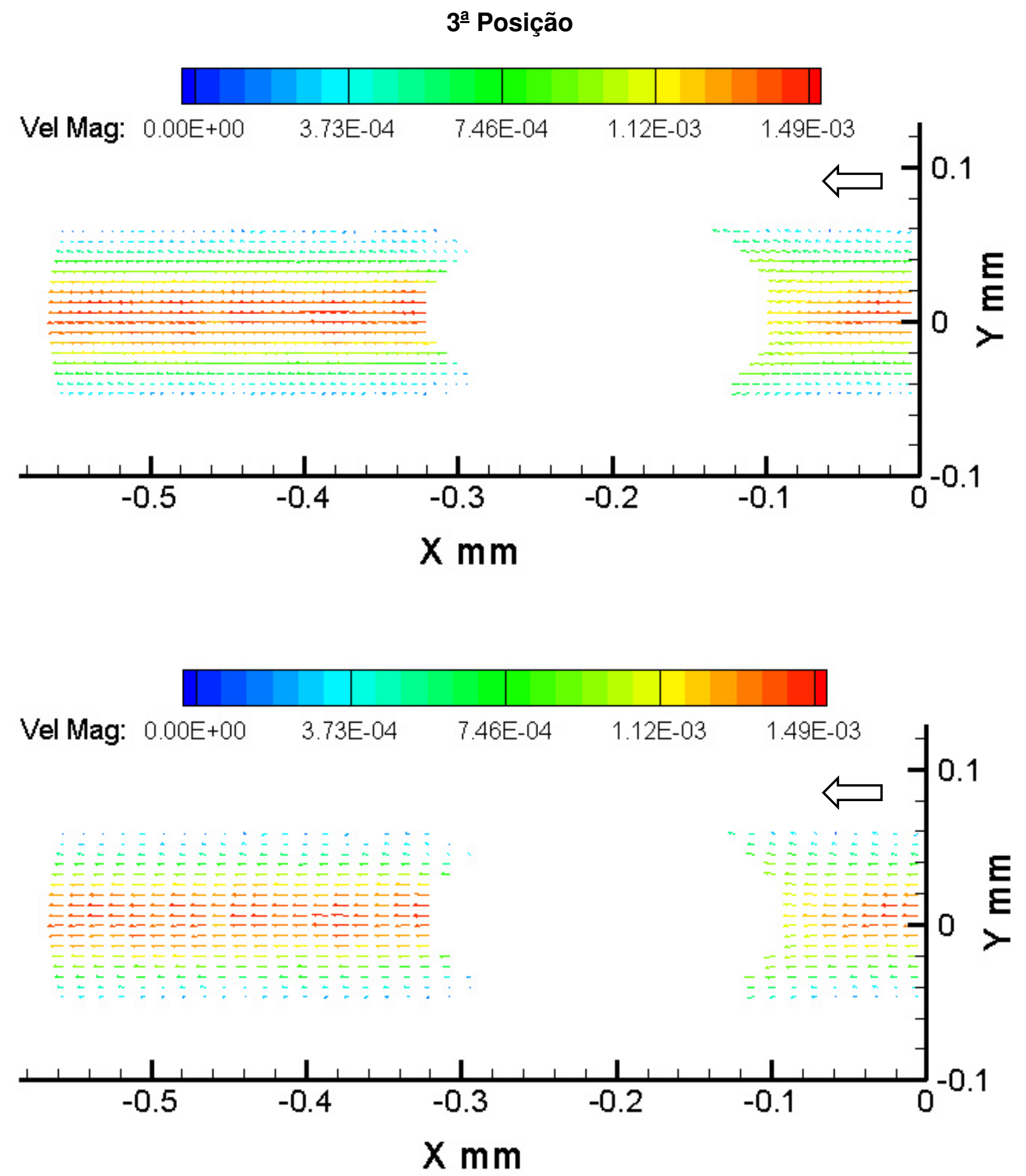

Figura 4.55: Campo de velocidade do escoamento bifásico dos 50 pares de imagens ao redor da terceira posição da gota pequena, através do micro canal com garganta do primeiro micro capilar.

Antes de avaliar o campo de velocidade na região próxima à gota, os perfis de velocidade na entrada e saída do capilar foram determinados e comparados com o perfil parabólico do escoamento desenvolvido. 
A tabela (4.7) apresenta a velocidade média do escoamento, calculada dividendo a vazão imposta pela área da seção reta do canal, e as velocidades médias do escoamento na entrada e saída do canal, obtidas experimentalmente. Os resultados são apresentados para as três posições da gota em relação à garganta. Observa-se que, ao contrário do capilar de seção reta, as velocidades médias calculadas através do perfil de velocidade experimental, não são iguais à velocidade média imposta. Além do mais, a velocidade média varia com o tempo (posição da gota).

\begin{tabular}{|l|c|c|c|}
\hline $\begin{array}{c}\text { Gota Pequena } \\
\boldsymbol{\alpha}=\mathbf{1 , 4}\end{array}$ & $\begin{array}{c}\mathbf{V}_{\text {média }} \\
\text { Escoamento } \\
\text { injetado } \\
\left(\times 10^{-4} \mathrm{~m} / \mathrm{s}\right)\end{array}$ & $\begin{array}{c}\mathbf{V}_{\text {média }} \\
\text { Exp. Perfil } \\
\text { Entrada } \\
\left(\times 10^{-4} \mathrm{~m} / \mathrm{s}\right)\end{array}$ & $\begin{array}{c}\mathbf{V}_{\text {média }} \\
\text { Exp. Perfil } \\
\text { Saída } \\
\left(\times 10^{-4} \mathrm{~m} / \mathrm{s}\right)\end{array}$ \\
\hline $\mathbf{1}^{\text {a }}$ - Posição & 9,499 & 9,89 & 10,265 \\
\hline $\mathbf{2}^{\text {a }}$ - Posição & 9,499 & 9,795 & 10,565 \\
\hline $\mathbf{3}^{\text {a }}$ - Posição & 9,499 & 7,255 & 6,86 \\
\hline
\end{tabular}

Tabela 4.7: Valores de velocidades experimentais médias dos perfis de entrada e saída do escoamento, ao redor das 3 posições da gota pequena, através do micro canal com garganta do primeiro micro capilar.

$\mathrm{Na}$ terceira posição, a velocidade experimental média na entrada e na saída foi menor que a velocidade média do escoamento, a gota de óleo diminuiu drasticamente o fluxo, afetando o escoamento ao redor dela. As figuras (4.56) e (4.57) apresentam os perfis de velocidades experimentais na entrada e na saída do escoamento, e o perfil de velocidade teórico, para cada posição da gota na garganta. 


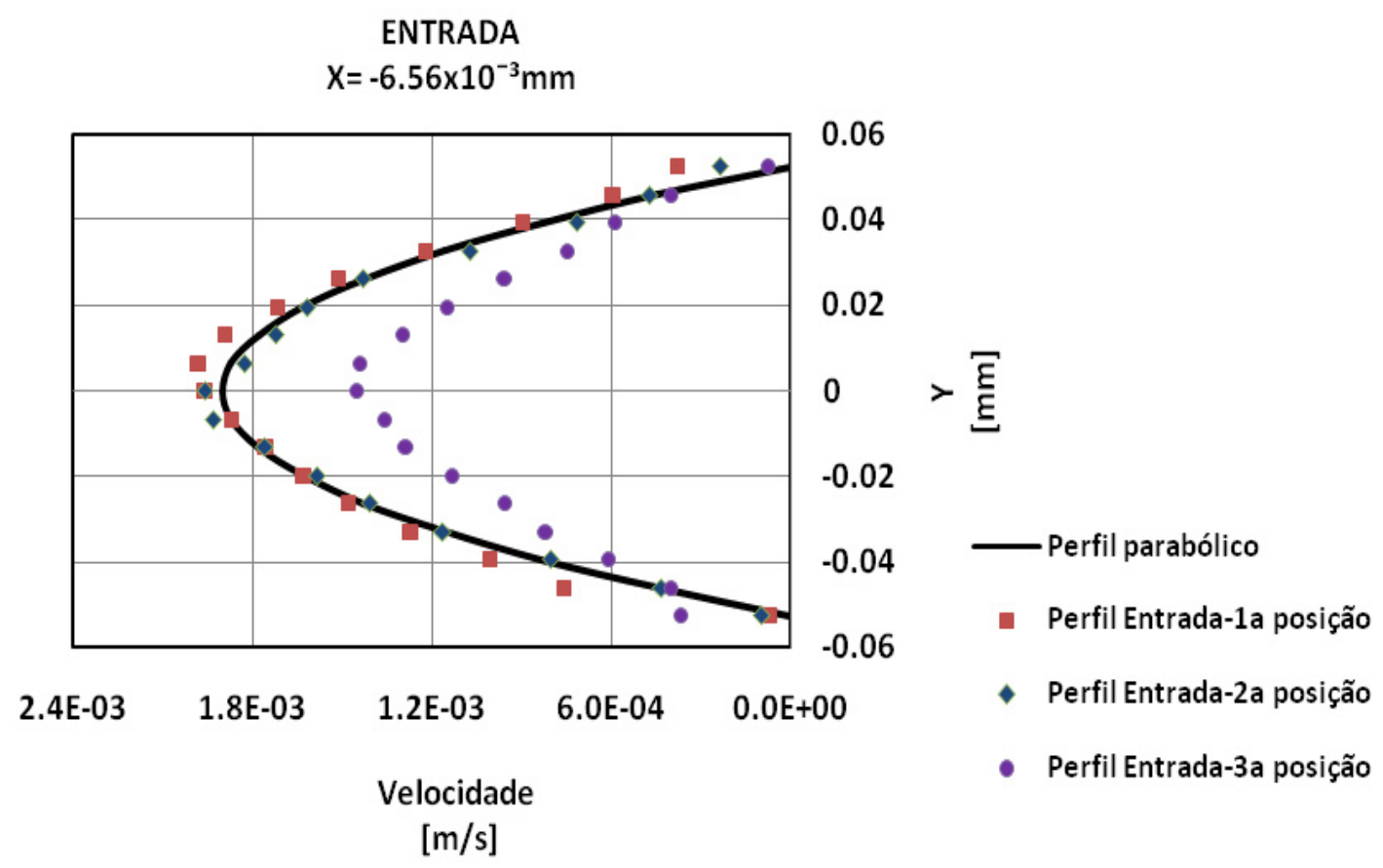

Figura 4.56: Comparação dos perfis parabólicos e experimentais na entrada do micro canal com garganta do primeiro micro capilar, nas 3 posições da gota pequena.

SAIDA

$X=-0.557 \mathrm{~mm}$

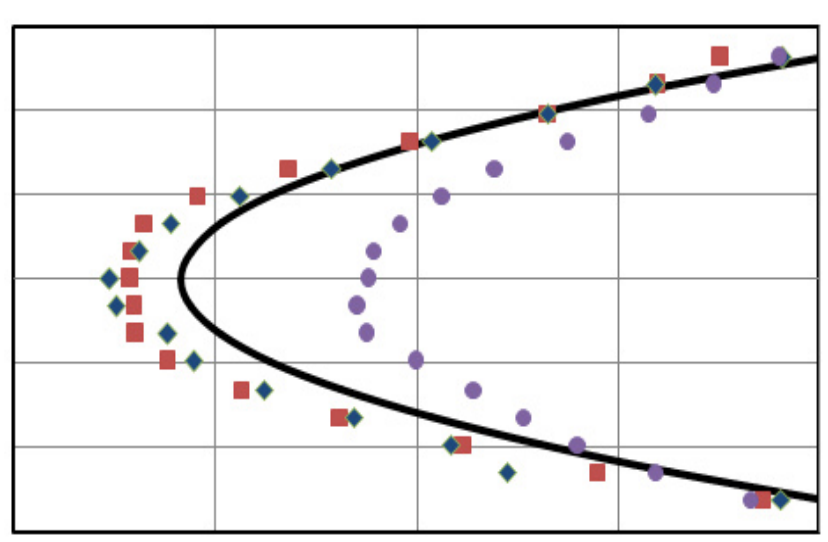

0.06

0.04

0.02

문

\section{$0>\bar{\xi}$}

$-0.02$

- Perfil parabólico

$-0.06$

- Perfil saida-1a posição

- Perfil saida-2a posição

2.4E-03

$1.8 \mathrm{E}-03$

$1.2 \mathrm{E}-03$

$6.0 \mathrm{E}-04$

$0.0 \mathrm{E}+00$

- Perfil saida-3a posição

\section{Velocidade \\ $[\mathrm{m} / \mathrm{s}]$}

Figura 4.57: Comparação dos perfis parabólicos e experimentais na saída do micro canal com garganta do primeiro micro capilar, nas 3 posições da gota pequena. 
Os resultados mostram que apesar a vazão imposta ser constante, o escoamento apresenta um claro comportamento transiente. Ao passar pela garganta, a gota sofre grande deformação. A redução do raio de curvatura da interface leva a um aumento considerável da diferença de pressão para manter a vazão constante.

Tipicamente escoamentos de água são considerados incompressíveis, já que o fator de compressibilidade da água é extremamente baixo $\left(E \approx 4 \times 10^{-10} \mathrm{~Pa}\right.$ $\left.{ }^{1}\right)$. Porém, como a vazão do escoamento estudado neste trabalho é muito baixa, $Q \approx 10^{-11} \mathrm{~m}^{3} / \mathrm{s}$, efeitos de compressibilidade do liquido passam a ser importantes. A variação da vazão observada é uma manifestação do efeito de compressibilidade do líquido. A passagem da gota pela garganta leva a um aumento significativo da pressão à jusante da gota e a vazão cai. Quando a diferença de pressão torna-se alta o suficiente, a gota passa pela garganta. Neste momento, a vazão é maior do que a vazão imposta, como apresentado na figura (4.57).

A variação da velocidade ao longo da linha de simetria do canal para as três posições da gota é apresentada nas figuras (4.58 - 4.60). Observa-se que a velocidade na terceira posição é menor do que nas outras duas configurações.

- Veloc. Exp. 1a posição

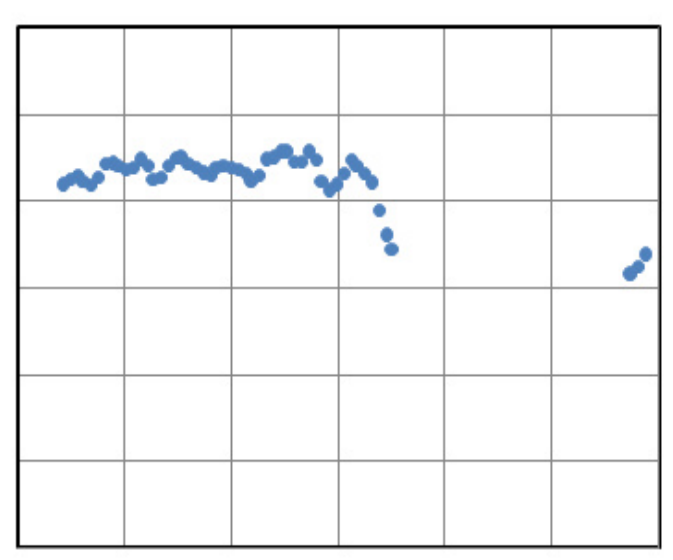

$3.0 \mathrm{E}-03$

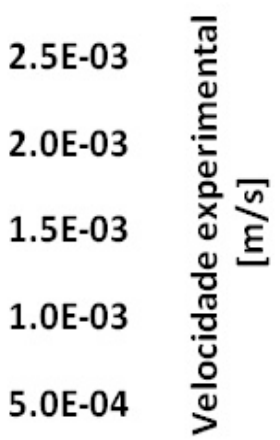

$\begin{array}{lllllll}-0.6 & -0.5 & -0.4 & -0.3 & -0.2 & -0.1 & 0\end{array}$

$0.0 \mathrm{E}+00$

$$
\mathrm{X}
$$

$[\mathrm{mm}]$

Figura 4.58: Variação da velocidade na linha de simetria do micro canal com garganta do primeiro micro capilar, ao redor da primeira posição da gota pequena. 
- Veloc. Exp. 2a posição

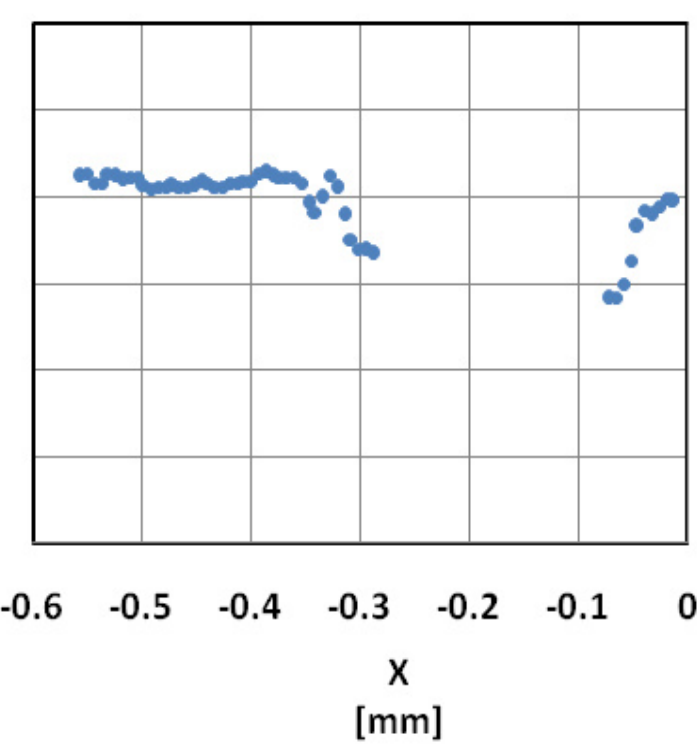

$3.0 \mathrm{E}-03$

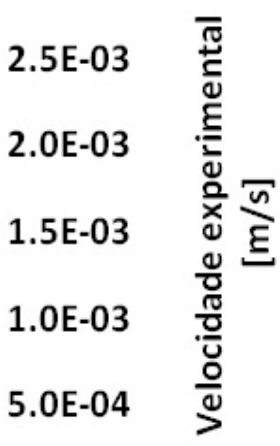

$0.0 \mathrm{E}+00$

Figura 4.59: Variação da velocidade na linha de simetria do micro canal com garganta do primeiro micro capilar, ao redor da segunda posição da gota pequena.

- Veloc. Exp. 3a posição

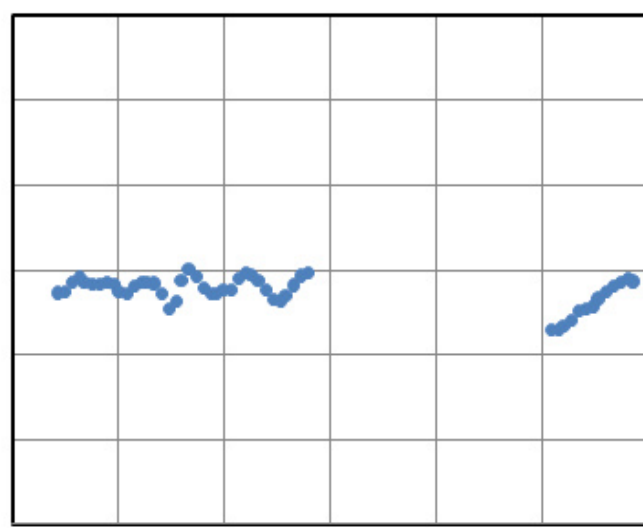

$3.0 \mathrm{E}-03$

2.5E-03

2.0E-03

1.5E-03

$1.0 \mathrm{E}-03$

$5.0 \mathrm{E}-04$

$0.0 \mathrm{E}+00$

$\begin{array}{lllllll}-0.6 & -0.5 & -0.4 & -0.3 & -0.2 & -0.1 & 0\end{array}$

$\mathrm{X}$

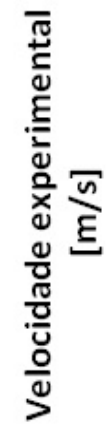

$[\mathrm{mm}]$

Figura 4.60: Variação da velocidade na linha de simetria do micro canal com garganta do primeiro micro capilar, ao redor da terceira posição da gota pequena. 
O campo de velocidade ao redor da gota nas três posições é apresentado nas figuras (4.61), (4.62) e (4.63). Pode-se observar que a velocidade ao longo da interface não é constante; a gota é deformada durante a sua passagem pela garganta.

Como explicados anteriormente, a velocidade da parte dianteira e traseira da gota é calculada pela média das velocidades dos pontos localizados ao longo de cada interface. A tabela (4.8) apresenta os resultados obtidos paras as três posições da gota. Como referência, a velocidade média do escoamento injetado, e as velocidades experimentais médias na entrada e na saída do capilar também são apresentadas.

\section{1' Posição}

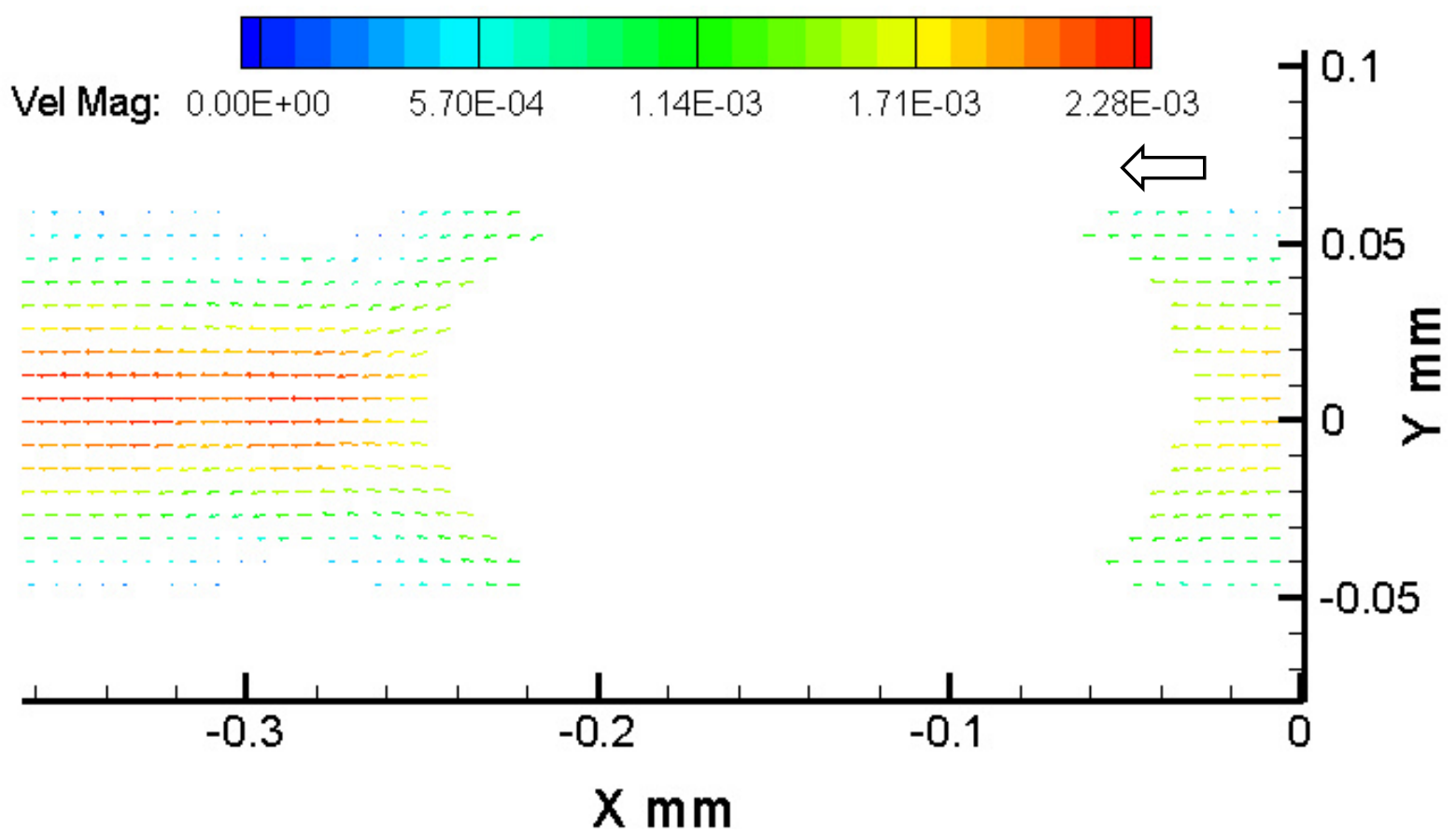

Figura 4.61: Campo de velocidade do escoamento bifásico dos 50 pares de imagens, na interface óleo-água à montante da primeira posição da gota pequena, através do micro canal com garganta do primeiro micro capilar. 


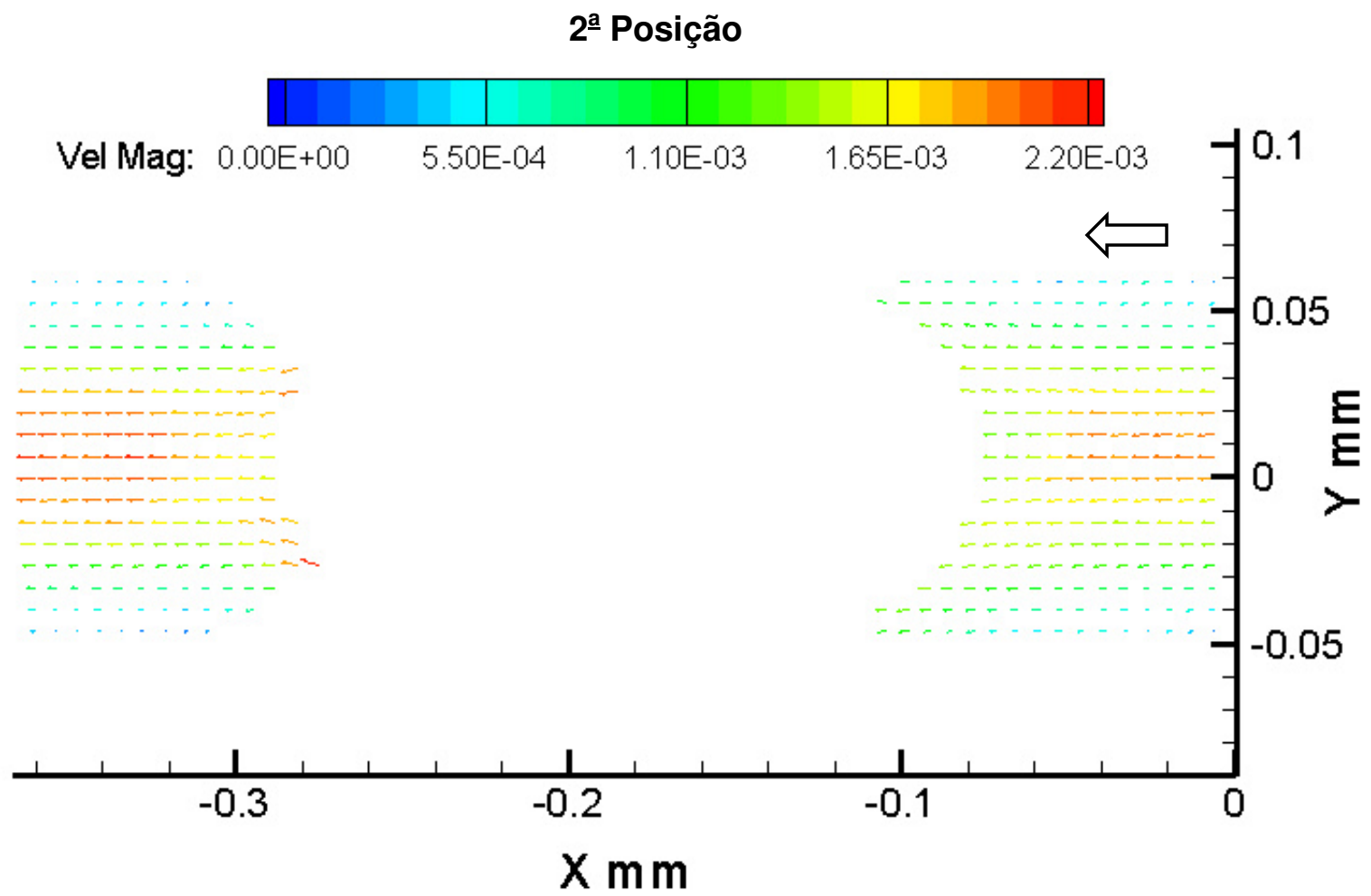

Figura 4.62: Campo de velocidade do escoamento bifásico dos 50 pares de imagens, na interface óleo-água à montante da segunda posição da gota pequena, através do micro canal com garganta do primeiro micro capilar.

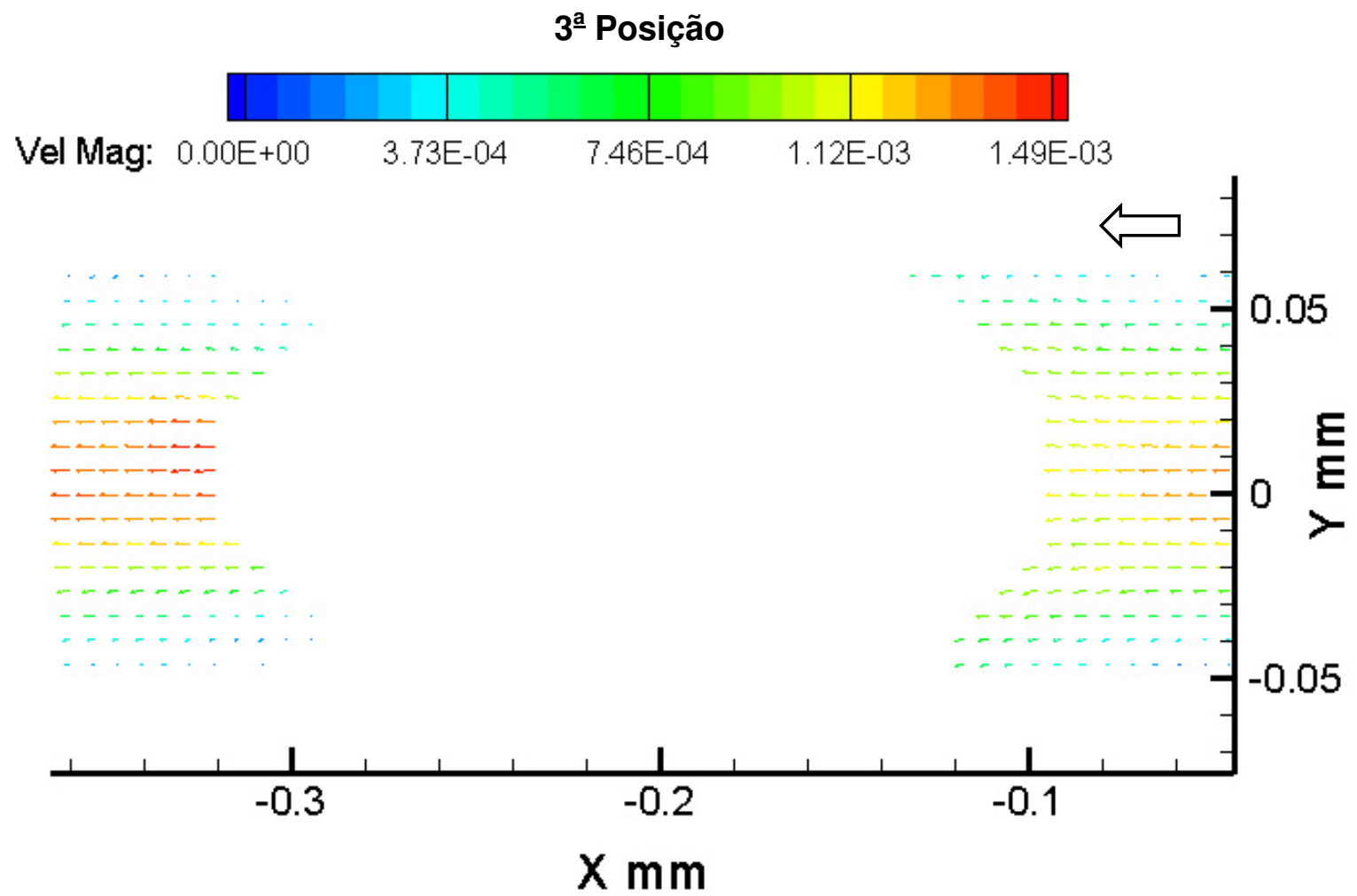


Figura 4.63: Campo de velocidade do escoamento bifásico dos 50 pares de imagens, na interface óleo-água à montante da terceira posição da gota pequena, através do micro canal com garganta do primeiro micro capilar.

\begin{tabular}{|c|c|c|c|c|c|}
\hline $\begin{array}{c}\text { Gota Pequena } \\
\qquad \alpha=1,4\end{array}$ & $\begin{array}{c}V_{\text {média }} \\
\text { Escoamento } \\
\text { injetado } \\
\left(\times 10^{-4} \mathrm{~m} / \mathrm{s}\right)\end{array}$ & $\begin{array}{c}V_{\text {média }} \\
\text { Exp. Perfil } \\
\text { Entrada } \\
\left(\times 10^{-4} \mathrm{~m} / \mathrm{s}\right)\end{array}$ & $\begin{array}{c}V_{\text {média }} \\
\text { Exp. Perfil } \\
\text { Saída } \\
\left(\times 10^{-4} \mathrm{~m} / \mathrm{s}\right)\end{array}$ & $\begin{array}{c}\left(\mathrm{V}_{\mathrm{g}}\right)_{\mathrm{d}} \\
\text { Parte dianteira } \\
\text { da gota } \\
\left(\times 10^{-4} \mathrm{~m} / \mathrm{s}\right)\end{array}$ & $\begin{array}{c}\left(\mathrm{V}_{\mathrm{g}}\right)_{\mathrm{t}} \\
\text { Parte traseira } \\
\text { da gota } \\
\left(\times 10^{-4} \mathrm{~m} / \mathrm{s}\right)\end{array}$ \\
\hline 1' - Posição $^{\text {a }}$ & 9,499 & 9,890 & 10,265 & 17,085 & 16,093 \\
\hline $2^{\mathrm{a}}$ - Posição & 9,499 & 9,795 & 10,565 & 17,136 & 14,579 \\
\hline $3^{a}$ - Posição & 9,499 & 7,255 & 6,860 & 14,135 & 10,930 \\
\hline
\end{tabular}

Tabela 4.8: Valores de velocidade da gota pequena, para cada posição, através do micro canal com garganta do primeiro micro capilar.

Nas 3 posições relativas à garganta, a velocidade da gota foi maior que a velocidade média do escoamento e na terceira posição, conforme já observado no escoamento através do capilar de seção reta constante.

$\mathrm{Na}$ primeira posição, as velocidades na parte dianteira e traseira são bem próximas, o efeito da garganta no escoamento ao redor e deformação da interface da gota ainda é pequeno. Na segunda posição, a parte dianteira da gota é acelerada, já que a mesma se encontra em uma seção reta menor (na garganta). O mesmo ocorre na terceira posição. A velocidade da gota a terceira posição é menor devido ao efeito da diminuição da vazão, causado pelo bloqueio parcial da garganta, já discutido anteriormente.

O segundo micro capilar utilizado tem um comprimento na garganta de 100 $\mu \mathrm{m}$, e um diâmetro máximo e mínimo de $110 \mu \mathrm{m}$ e $46 \mu \mathrm{m}$ respectivamente. $\mathrm{O}$ campo de velocidade foi avaliado para 4 posições diferentes da gota em relação à garganta. A área selecionada para o processamento das imagens foi definida através de uma máscara. As figuras (4.64), (4.65), (4.66) e (4.67) mostram as posições e as máscaras utilizadas para a gota pequena. Na primeira posição, a ponta da gota encontra-se no inicio da garganta; na segunda posição, entre a primeira posição e o plano de menor seção reta; na terceira posição onde a gota 
ficou presa na garganta, e na quarta posição a ponta da gota encontra-se no final da garganta.
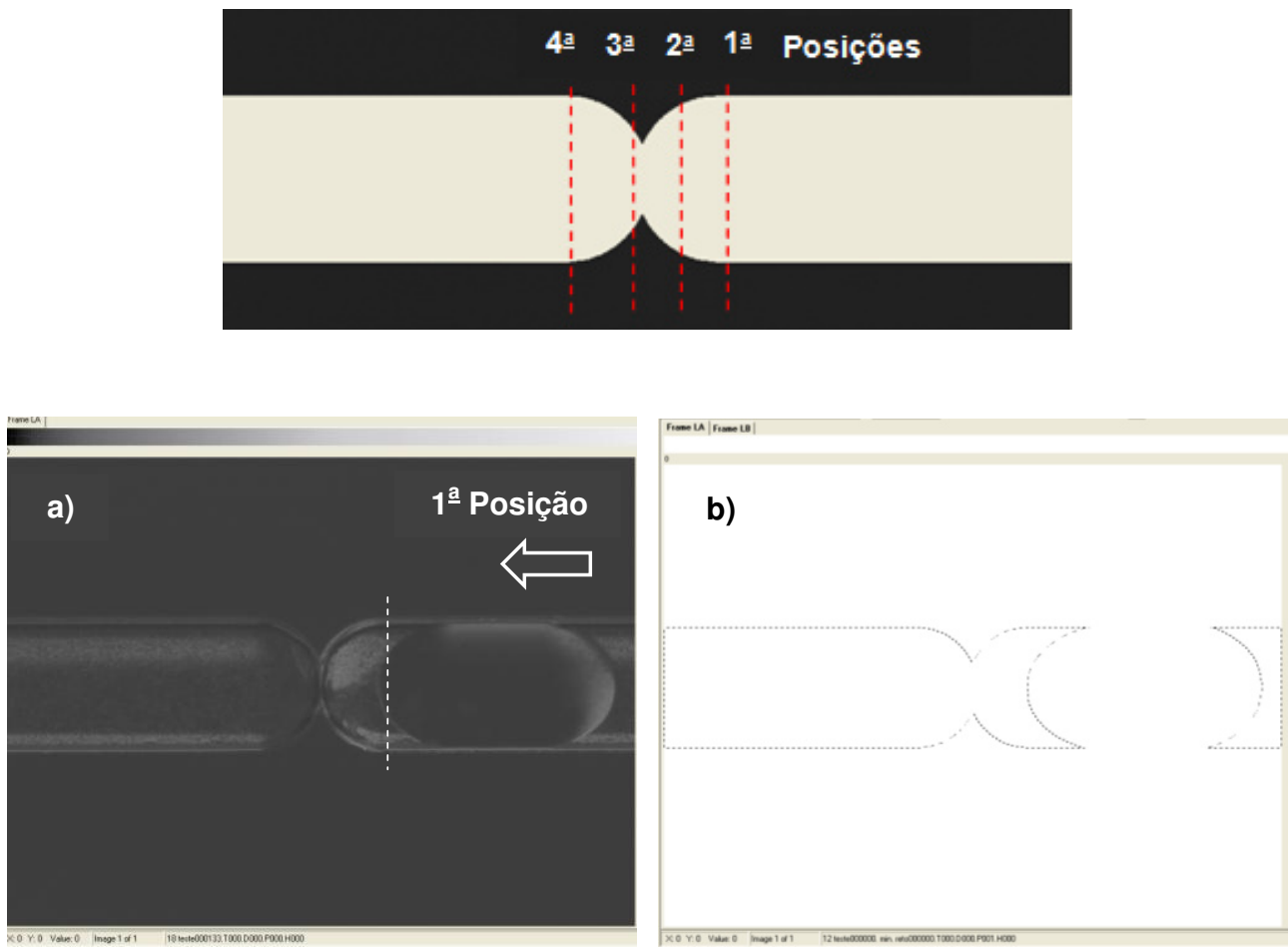

Figura 4.64: a) Primeira posição da gota pequena $(\alpha=1,4)$ no segundo micro canal com garganta. b) Máscara da primeira posição da gota pequena no segundo micro capilar com garganta.
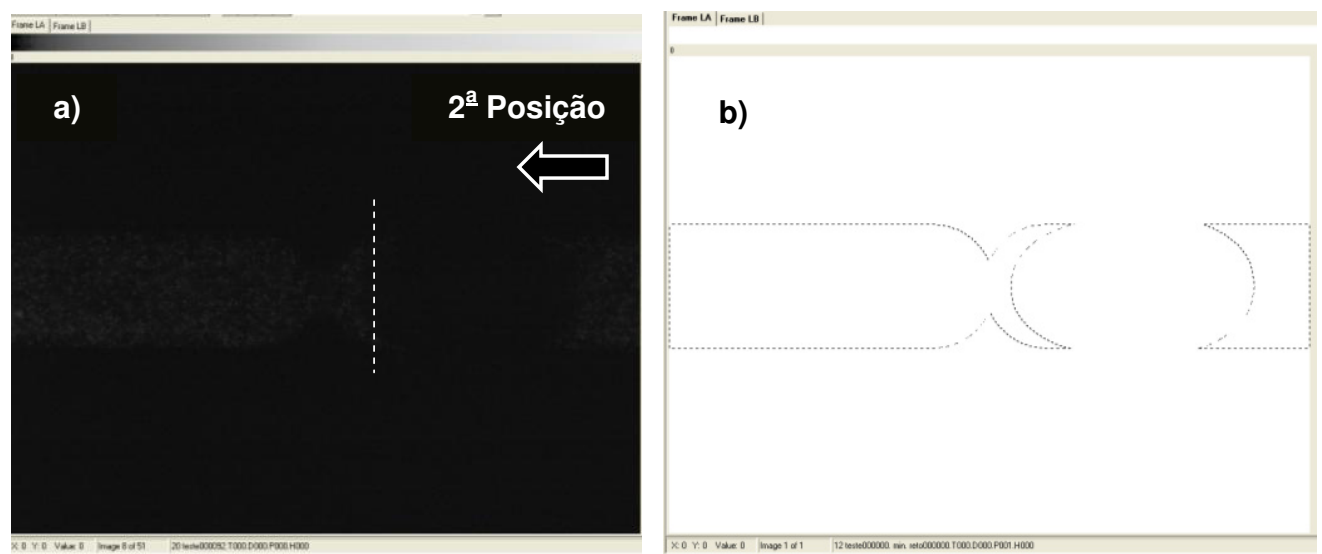

Figura 4.65: a) Segunda posição da gota pequena $(\alpha=1,4)$ no segundo micro canal com garganta. b) Máscara da segunda posição da gota pequena no segundo micro canal com garganta. 

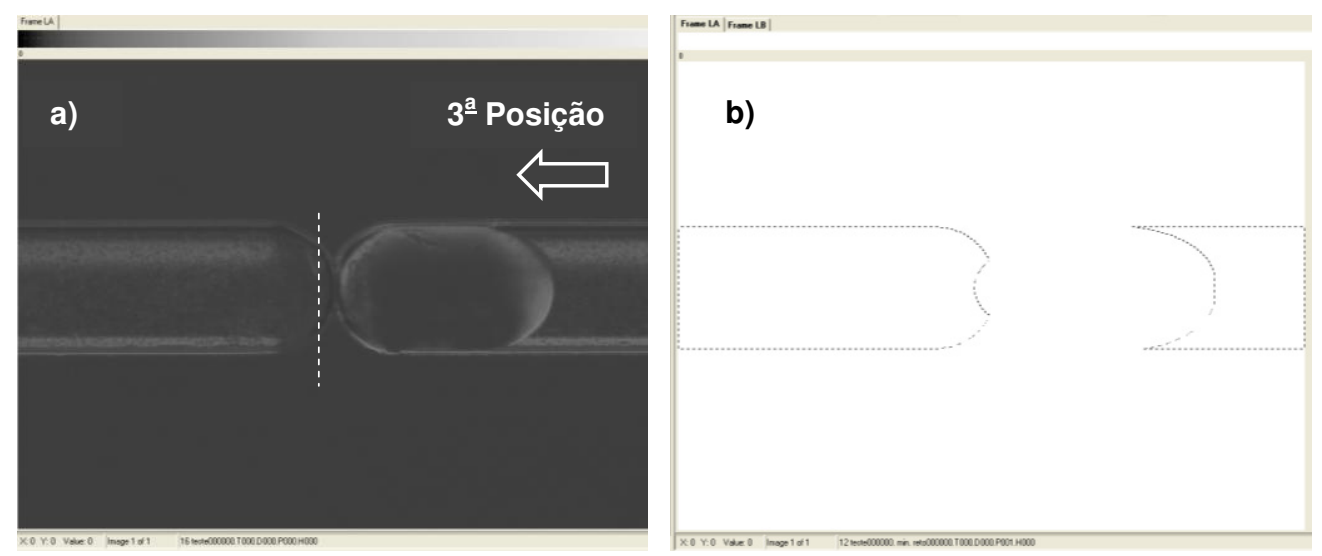

Figura 4.66: a) Terceira posição da gota pequena $(\alpha=1,4)$ no segundo micro canal com garganta. b) Máscara da terceira posição da gota pequena no segundo micro canal com garganta.
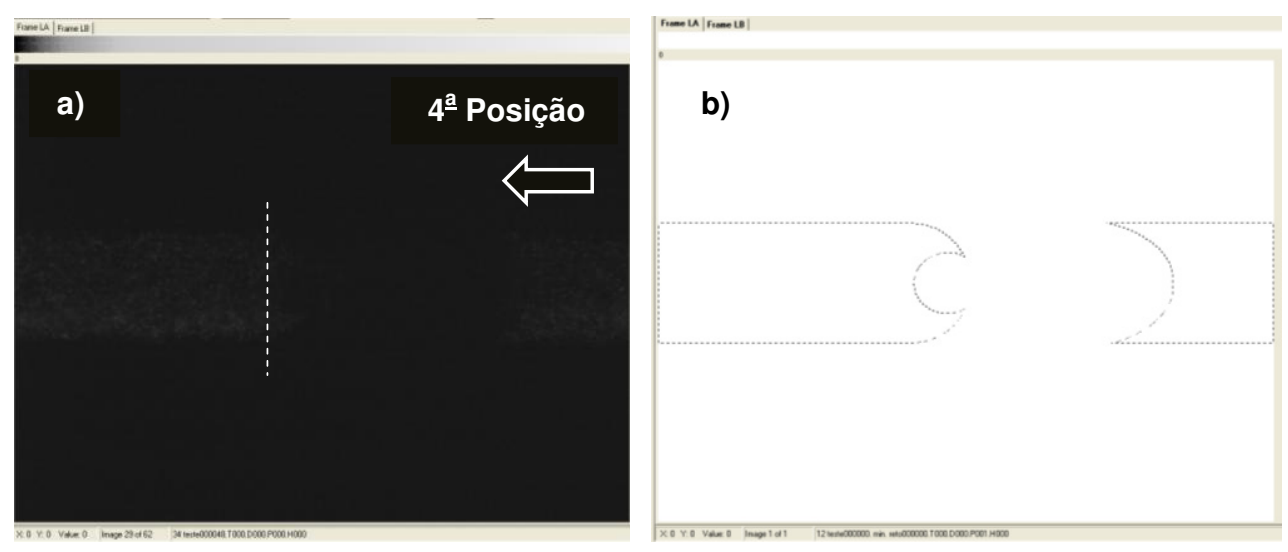

Figura 4.67: a) Quarta posição da gota pequena $(\alpha=1,4)$ no segundo micro canal com garganta. b) Máscara da quarta posição da gota pequena no segundo micro canal com garganta.

$\mathrm{Na}$ captura das imagens, o programa Insight $3 \mathrm{G}^{\mathrm{TM}}$ foi configurado com os seguintes parâmetros:

- Modo de aquisição da imagem "sincronizado";

- Tempo de espera do primeiro pulso laser de $800 \mu \mathrm{s}$;

- Tempo de exposição do sensor da câmera CCD de 1300 нs;

- Taxa de repetição da frequência dos lasers $4,83 \mathrm{~Hz}$;

- Energia dos lasers em "high".

O procedimento de captura de imagens foi feita da mesma maneira que no primeiro micro capilar com garganta. O número de imagens coletadas foi de 50 para cada posição. 
O tempo de separação $\Delta$ t entre o par de imagens foi de $600 \mu \mathrm{s}$. A janela de interrogação utilizada foi de $32 \times 32$ pixels. $O$ deslocamento máximo permitido foi de $0,25 \times 32$ pixels $=8$ pixels.

O pré-processamento dos 50 pares de imagens coletados para cada posição foi realizado usando também as técnicas "Imagem de intensidade mínimo/médio" e "Subtração de fundo".

Para o processamento das imagens, no programa Insight $3 G^{\mathrm{TM}}$ foram configurados os seguintes parâmetros:

- O tamanho das janelas de interrogação ou resolução espacial foi de $32 \times 32$ pixels $\left(13,1 \times 13,1 \mu \mathrm{m}^{2}\right)$;

- O máximo deslocamento das partículas foi de " $25 \%$ do tamanho da janela de interrogação";

- A calibração do sistema foi de 0,41 $\mu \mathrm{m} /$ pixel.

As técnicas "Média Amostral', "Nyquist Grid", "Correlação da Transformada de Fourier" e "Pico Gaussiano" foram utilizados no processamento dos 50 pares de imagens coletados para cada posição.

O pós-processamento dos 50 pares de imagens obtidas para cada posição foi realizada utilizando as técnicas "Validação do Vetor Mediana Local" e "Vetor Condição".

Nas figuras (4.68), (4.69) e (4.70) são apresentados os campos de vetores de velocidades obtidos pela análise dos 50 pares de imagens coletados para cada posição. A porcentagem de vetores válidos foi de $99,78 \%$ ( $1^{\circ}$ posição), $99,45 \%$ ( $3^{\circ}$ posição) e 99,78\% (4 posição), antes do pós-processamento.

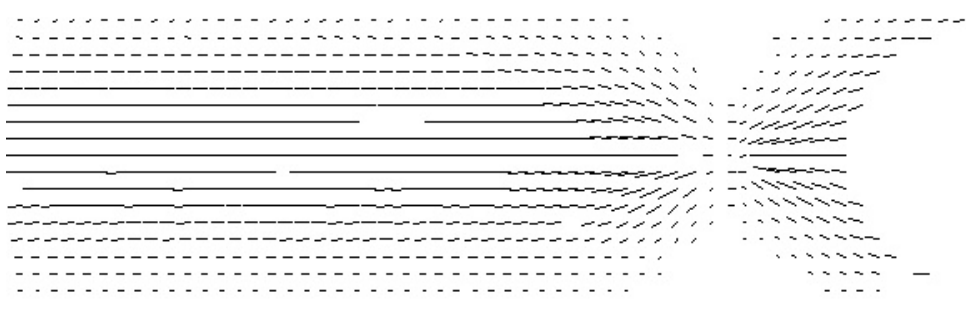


Figura 4.68: Campo de vetores de velocidade do processamento dos 50 pares de imagens, ao redor da primeira posição da gota pequena, através do micro canal com garganta do segundo micro capilar.
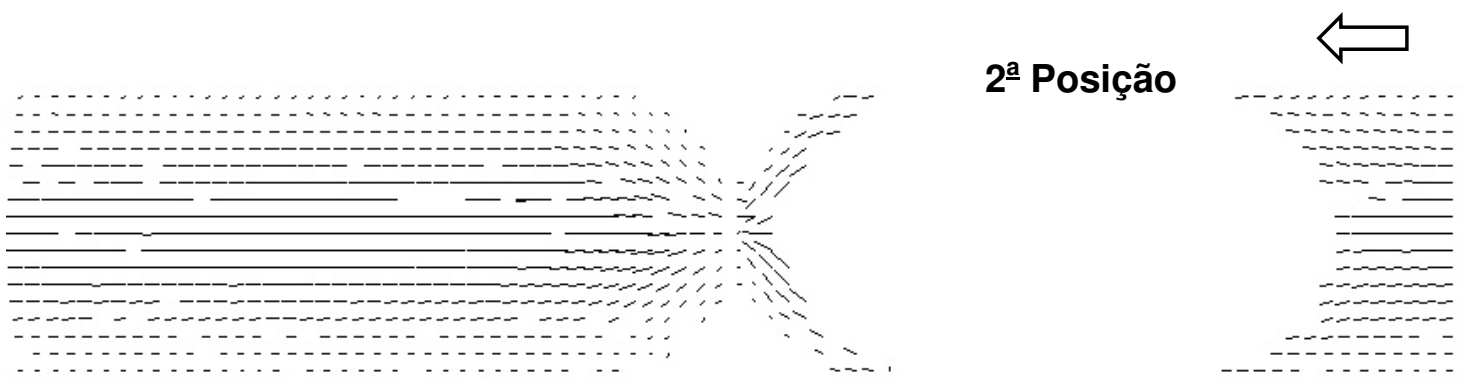

Figura 4.69: Campo de vetores de velocidade do processamento dos 50 pares de imagens, ao redor da segunda posição da gota pequena, através do micro canal com garganta do segundo micro capilar.

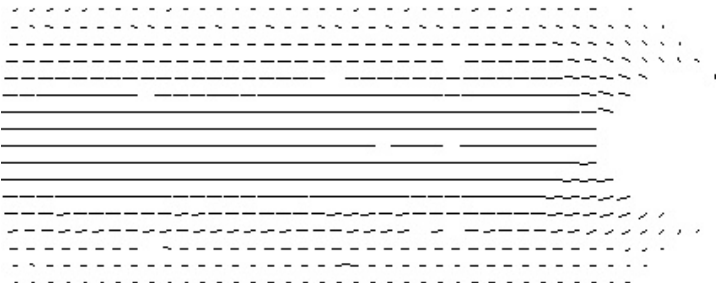

4⿳亠口冋口- Posição

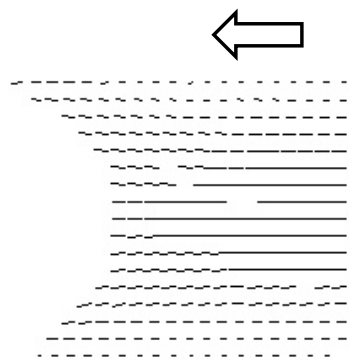

Figura 4.70: Campo de vetores de velocidade do processamento dos 50 pares de imagens, ao redor da quarta posição da gota pequena, através do micro canal com garganta do segundo micro capilar.

Aplicando o software "Tecplot ${ }^{\circledR}$, podemos melhor visualizar a intensidade do campo de velocidade da fase contínua ao redor da gota. As figuras (4.71), (4.72), (4.73) e (4.74) apresentam os campos de velocidade do escoamento ao redor da gota pequena, mostrando também $50 \%$ dos perfis de velocidade para facilitar a visualização dos mesmos. O campo de velocidade para a primeira, segunda e terceira posição da gota é composto de 52 perfis de velocidade, e o número de vetores por perfil foi de 17. Para a quarta posição da gota, é composto de 49 perfis de velocidade, e o número de vetores por perfil foi de 17 . 
1a Posição

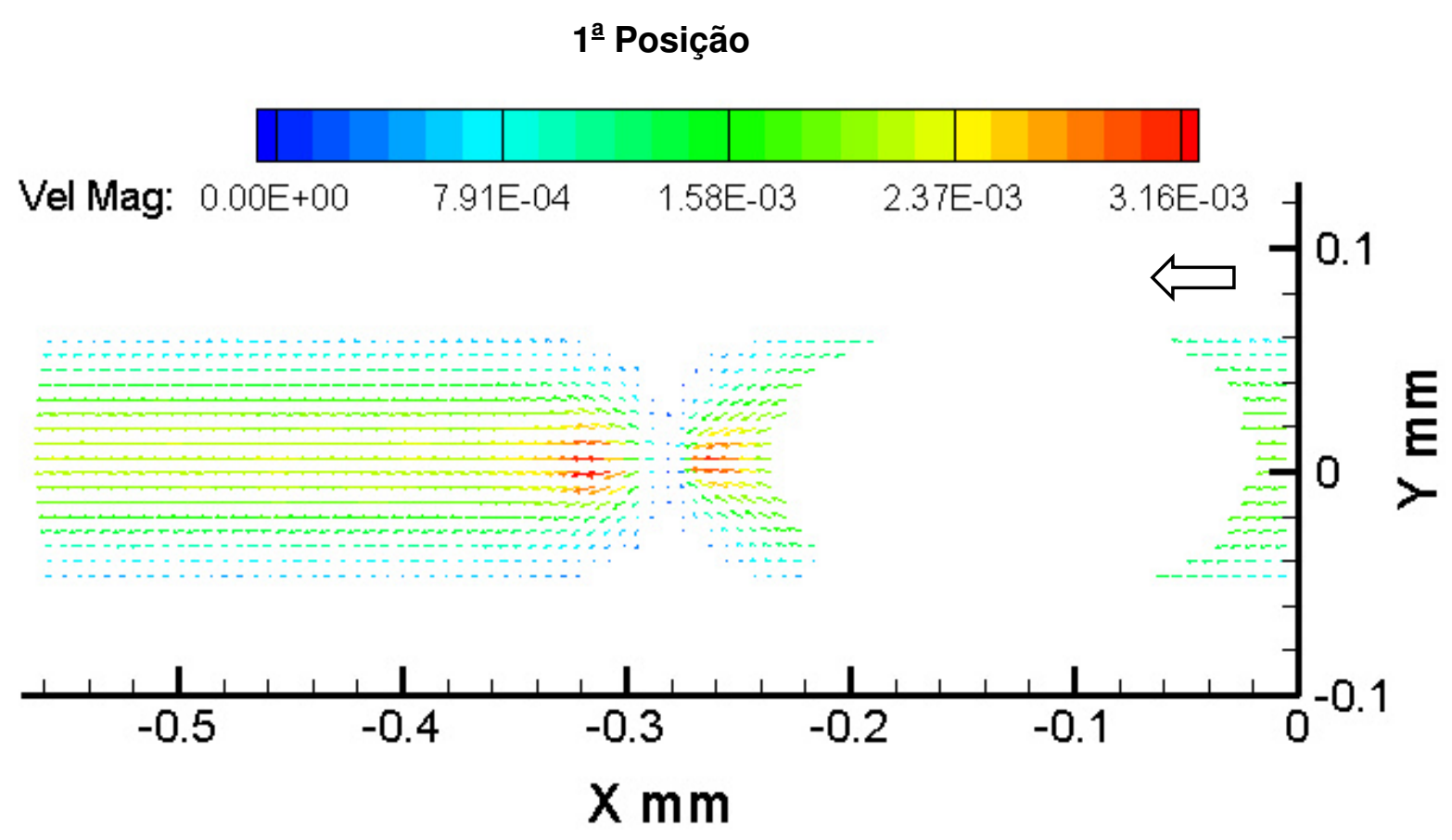

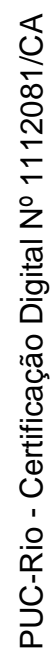

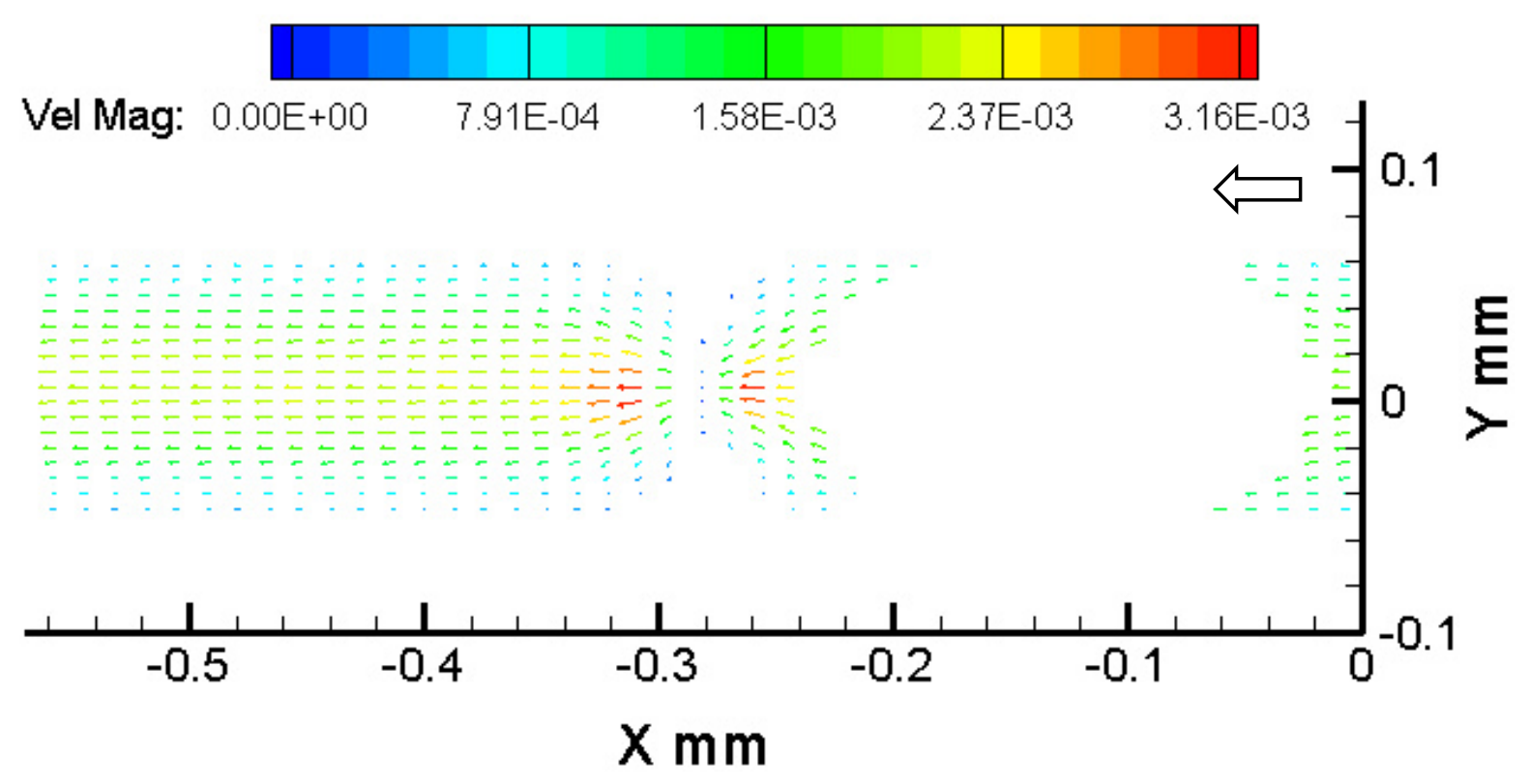

Figura 4.71: Campo de velocidade do escoamento bifásico dos 50 pares de imagens ao redor da primeira posição da gota pequena, através do micro canal com garganta do segundo micro capilar. 


\section{2ª $^{\mathrm{a}}$ Posição}
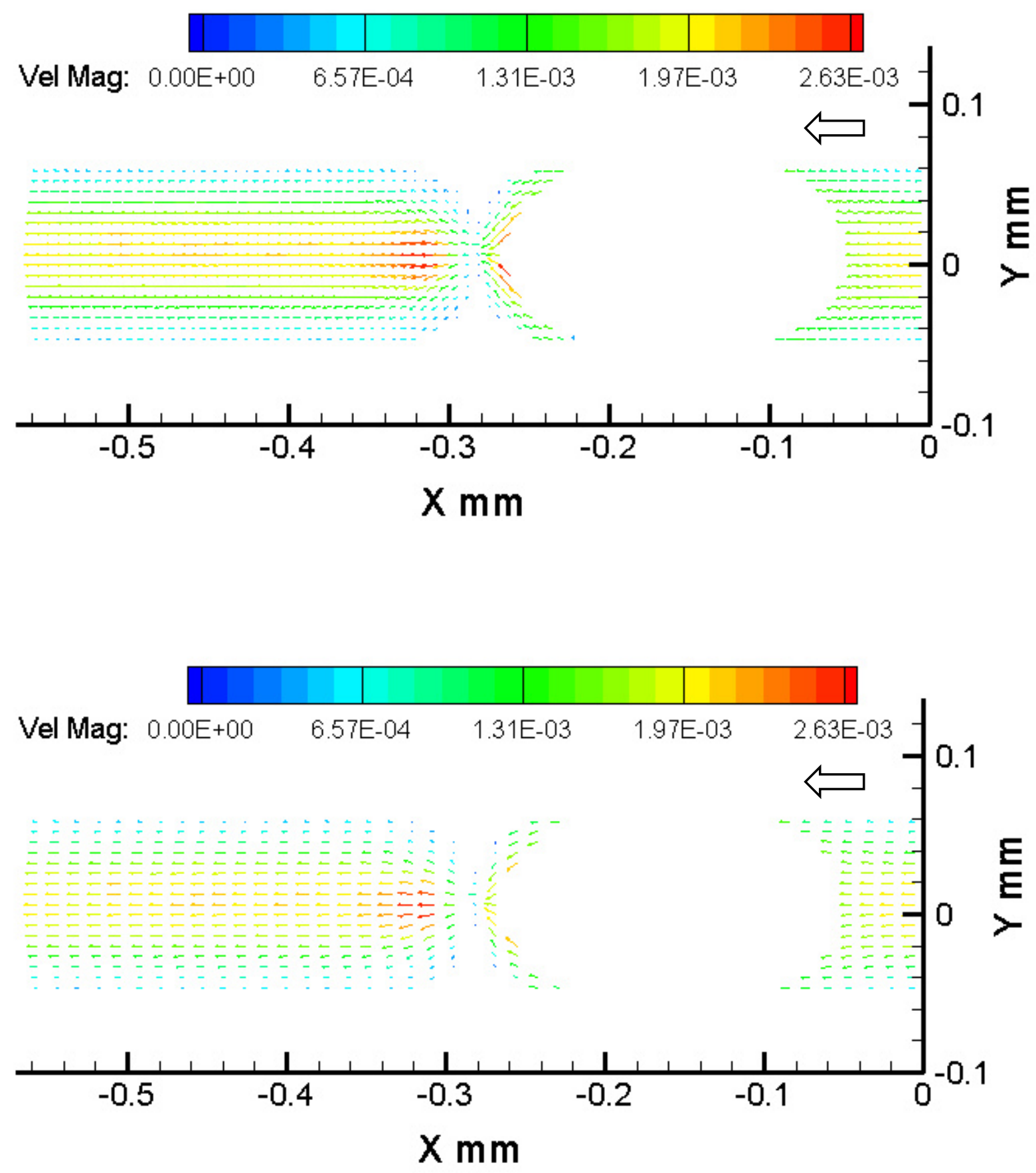

Figura 4.72: Campo de velocidade do escoamento bifásico dos 50 pares de imagens ao redor da segunda posição da gota pequena, através do micro canal com garganta do segundo micro capilar. 


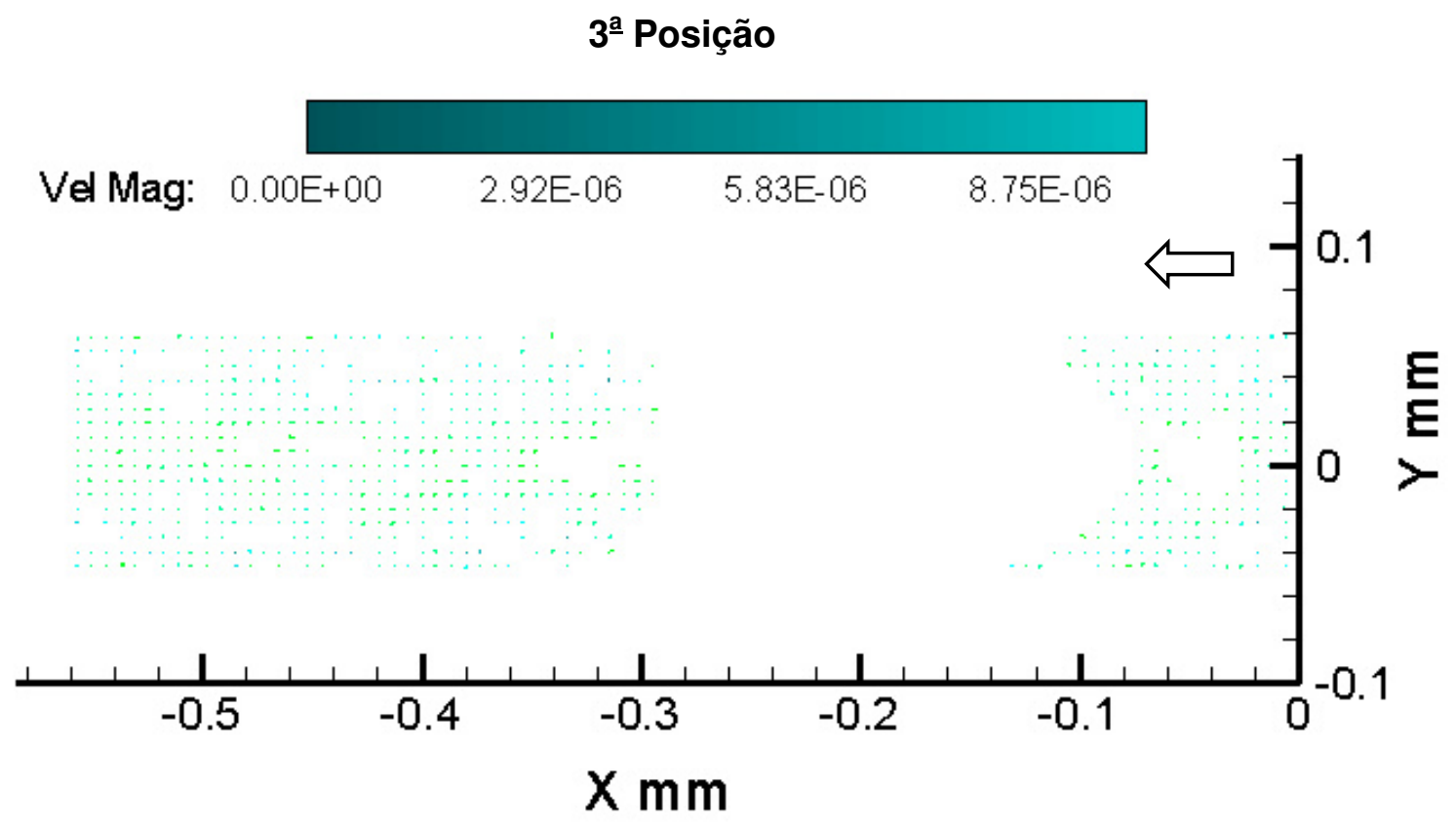

Figura 4.73: Campo de velocidade do escoamento bifásico dos 50 pares de imagens ao redor da terceira posição da gota pequena, através do micro canal com garganta do segundo micro capilar.

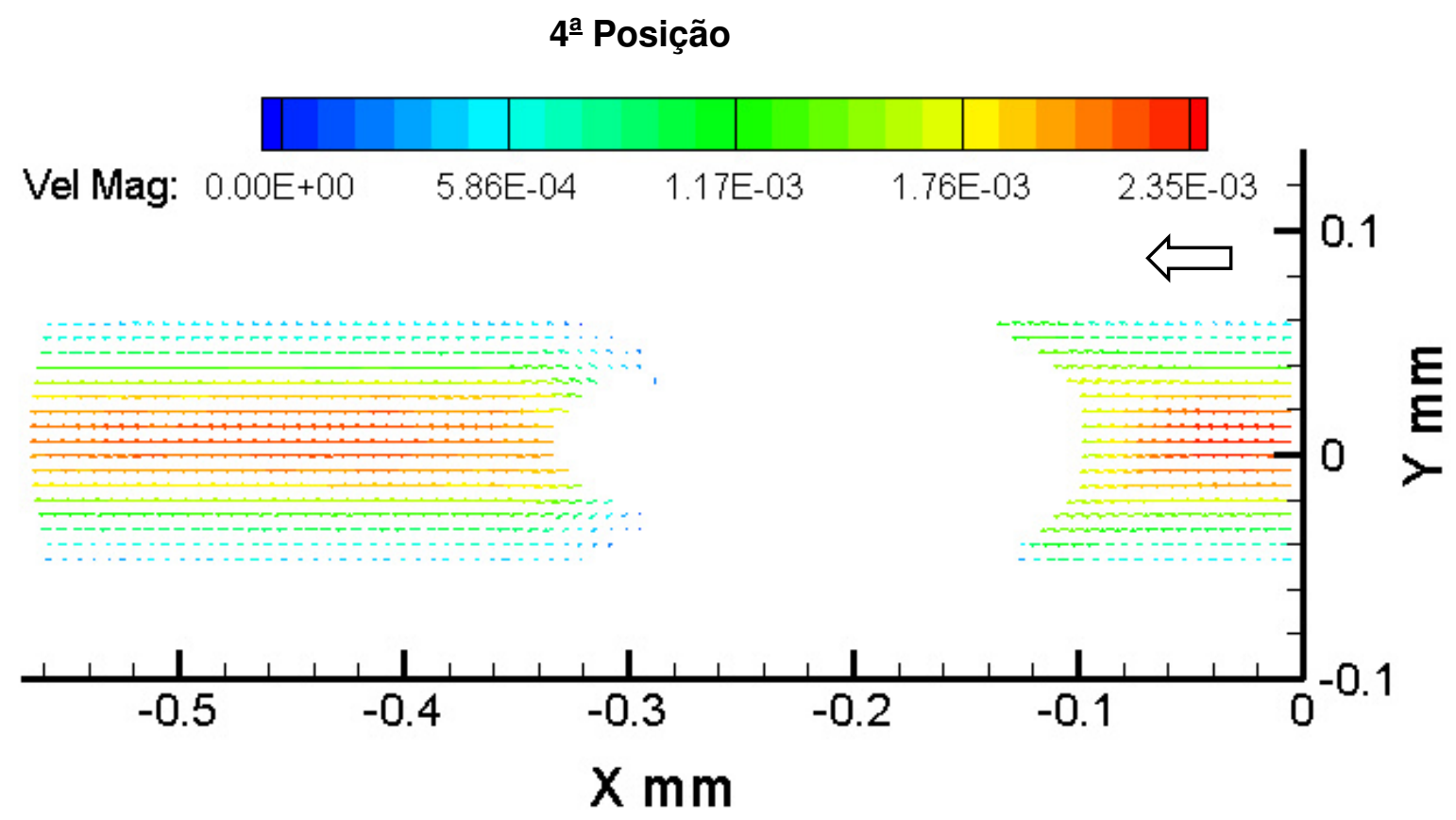




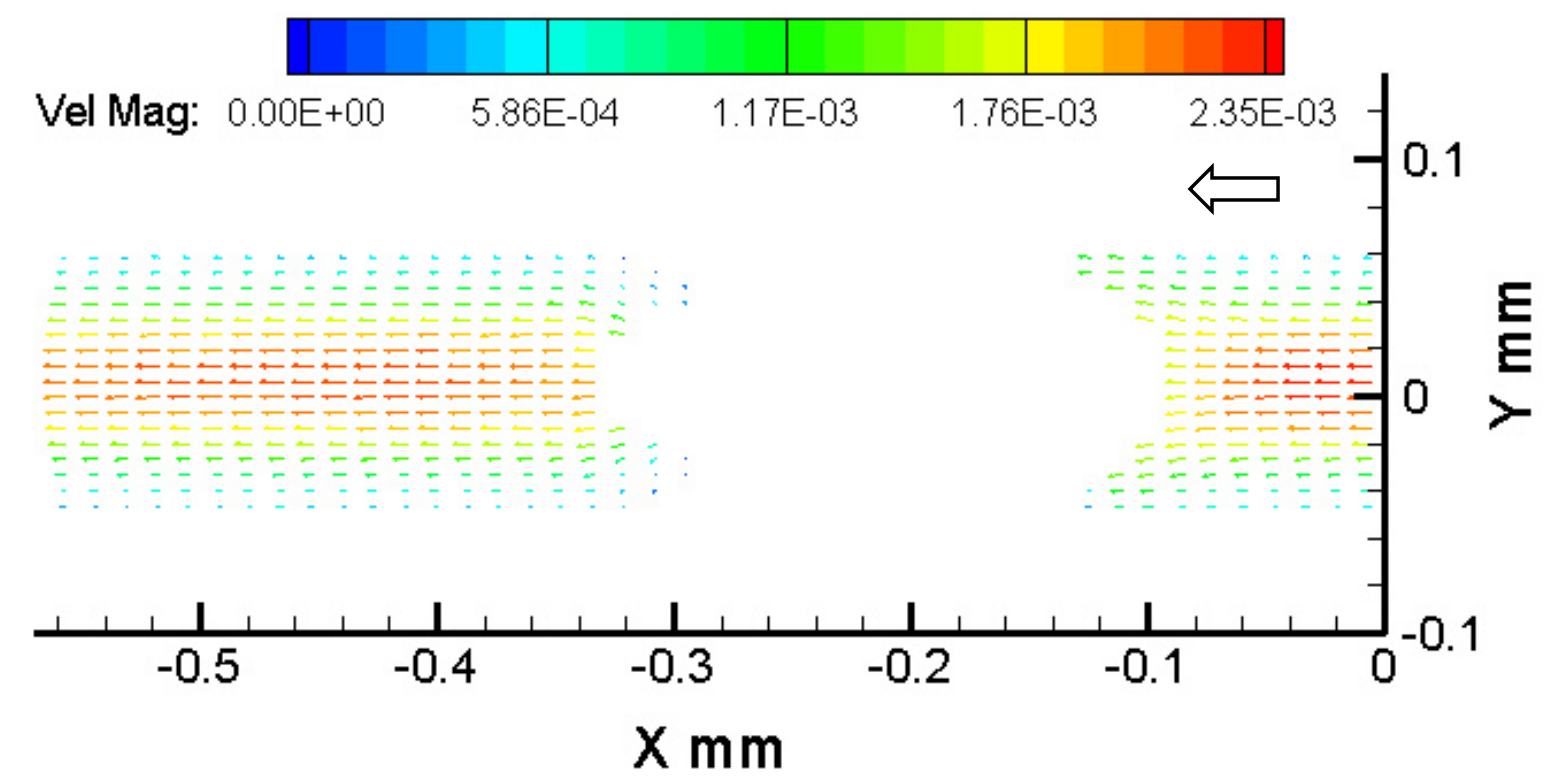

Figura 4.74: Campo de velocidade do escoamento bifásico dos 50 pares de imagens ao redor da quarta posição da gota pequena, através do micro canal com garganta do segundo micro capilar.

Novamente, antes de avaliar o campo de velocidade na região próxima à gota, os perfis de velocidade na entrada e saída do capilar foram determinados e comparados com o perfil parabólico do escoamento desenvolvido.

A tabela (4.9) apresenta a velocidade média do escoamento, calculada a partir da vazão imposta, e as velocidades médias, calculadas a partir dos perfis de velocidades medidos na entrada e saída do capilar, para as quatro posições da gota. Observa-se uma grande variação das velocidades médias com o tempo (posição da gota).

\begin{tabular}{|c|c|c|c|}
\hline $\begin{array}{c}\text { Gota Pequena } \\
\qquad \alpha=1,4\end{array}$ & $\begin{array}{c}\mathrm{V}_{\text {média }} \\
\text { Escoamento } \\
\text { injetado } \\
\left(\times 10^{-4} \mathrm{~m} / \mathrm{s}\right)\end{array}$ & $\begin{array}{c}\mathrm{V}_{\text {média }} \\
\text { Exp. Perfil } \\
\text { Entrada } \\
\left(\times 10^{-4} \mathrm{~m} / \mathrm{s}\right)\end{array}$ & $\begin{array}{c}\mathrm{V}_{\text {média }} \\
\text { Exp. Perfil } \\
\text { Saída } \\
\left(\times 10^{-4} \mathrm{~m} / \mathrm{s}\right)\end{array}$ \\
\hline 1'a - Posição & 9,499 & 9,785 & 11,12 \\
\hline $2^{\mathrm{a}}$ - Posição & 9,499 & 10,04 & 10,035 \\
\hline 3ª - Posição $^{\text {a }}$ & 9,499 & 0 & 0 \\
\hline $4^{\mathrm{a}}$ - Posição & 9,499 & 11,28 & 10,605 \\
\hline
\end{tabular}


Tabela 4.9: Valores de velocidades experimentais dos perfis de entrada e saída do escoamento, ao redor das 4 posições da gota pequena, através do micro canal com garganta no segundo micro capilar.

$\mathrm{Na}$ terceira posição, a gota ficou presa na garganta, fazendo com que a velocidade do escoamento fosse quase nula. Nas demais posições a tendência é sempre a velocidade experimental maior que a velocidade média do escoamento. As figuras (4.75) e (4.76) são apresentados os perfis de velocidades experimentais na entrada e na saída do escoamento, e o perfil de velocidade teórico, para cada posição da gota na garganta.

ENTRADA

$\mathrm{X}=-6.56 \times 10^{-3} \mathrm{~mm}$

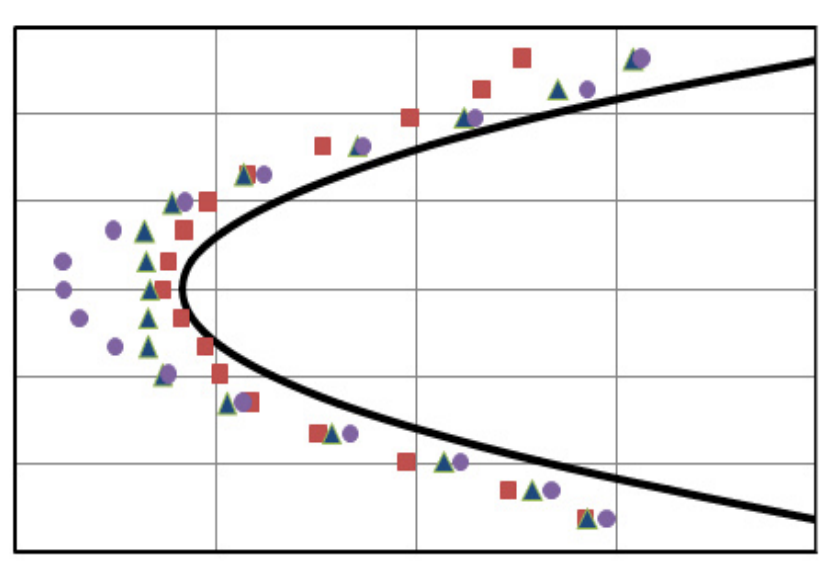

0.06

0.04

0.02

$0>\bar{\xi}$

$-0.02$

$-0.04$

$-0.06$

\subsection{E-03 \\ 1.8E-03 \\ $1.2 \mathrm{E}-03$ \\ $6.0 \mathrm{E}-04$ \\ $0.0 \mathrm{E}+00$}

\section{Velocidade}

$[\mathrm{m} / \mathrm{s}]$

Figura 4.75: Comparação dos perfis parabólicos e experimentais na entrada do micro canal com garganta do segundo micro capilar, em 3 posições da gota pequena. 


\section{SAIDA}

$X=-0.557 \mathrm{~mm}$

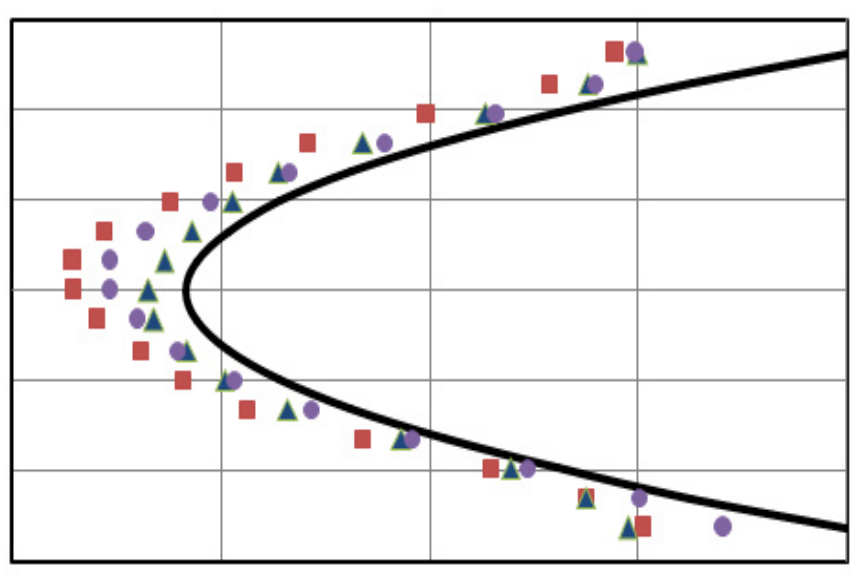

0.06

0.04

0.02

$0>\bar{\Xi}$

$-0.02$

——Perfil parabólico

$-0.04$

- Perfil saida-1a posição

$-0.06$

- Perfil Saida-2a posição

2.4E-03

$1.8 \mathrm{E}-03$

1.2E-03

$6.0 \mathrm{E}-04$

$0.0 \mathrm{E}+00$

- Perfil Saida-4a posição

\section{Velocidade \\ $[\mathrm{m} / \mathrm{s}]$}

Figura 4.76: Comparação dos perfis parabólicos e experimentais na saída do micro canal com garganta do segundo micro capilar, em 3 posições da gota pequena.

Como neste caso a garganta é menor do que no caso anterior, o efeito de bloqueio do capilar pela gota é ainda mais forte. Após a passagem pela garganta, a vazão do escoamento é maior do que a vazão imposta, devido aos efeitos de compressibilidade. A variação da velocidade ao longo da linha de simetria para três posições da gota é apresentada nas figuras (4.77), (4.78) e (4.79). Pode-se observar que na seção reta de menor área $(x \approx 0,28 \mathrm{~mm}$ no gráfico) as velocidades são muito baixas. Observando-se os campos completo de velocidade ao redor da gota, apresentados nas figuras (4.80), (4.81) e (4.82) percebe-se que as velocidades são quase nulas em $x \approx 0,28$; o que certamente viola o principio de conservação de massa. Provavelmente a velocidade nesta seção é tão maior que no resto do escoamento, que o intervalo de tempo utilizado na técnica de $\mu$-PIV não foi pequeno o suficiente para obter uma medida precisa do campo nesta região. 
- Veloc. Exp. 1a posição

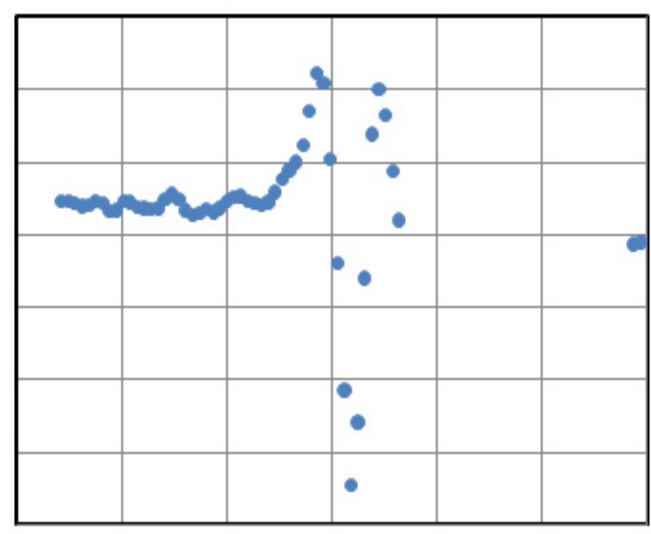

$3.5 \mathrm{E}-03$

3.0E-03

2.5E-03

苞

2.0E-03

$1.5 \mathrm{E}-03$

$1.0 \mathrm{E}-03$

5.0E-04

$0.0 \mathrm{E}+00$

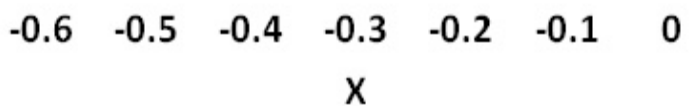

$[\mathrm{mm}]$

Figura 4.77: Variação da velocidade na linha de simetria do micro canal com garganta do segundo micro capilar, ao redor da primeira posição da gota pequena.

- Veloc. Exp. 2a posição

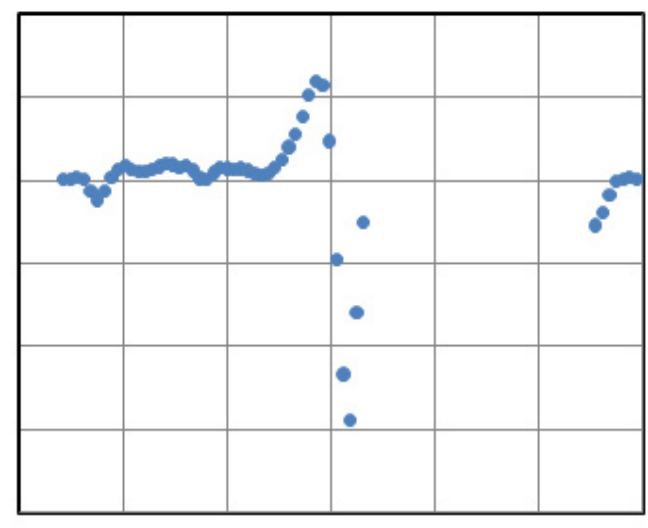

$3.0 \mathrm{E}-03$

2.5E-03

2.0E-03

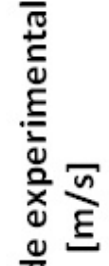

$1.5 \mathrm{E}-03$

จิ

$1.0 \mathrm{E}-03$

$5.0 \mathrm{E}-04$

$0.0 \mathrm{E}+00$

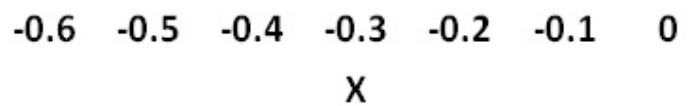

$[\mathrm{mm}]$

Figura 4.78: Variação da velocidade na linha de simetria do micro canal com garganta do segundo micro capilar, ao redor da segunda posição da gota pequena. 
- Veloc. Exp. 4a posição

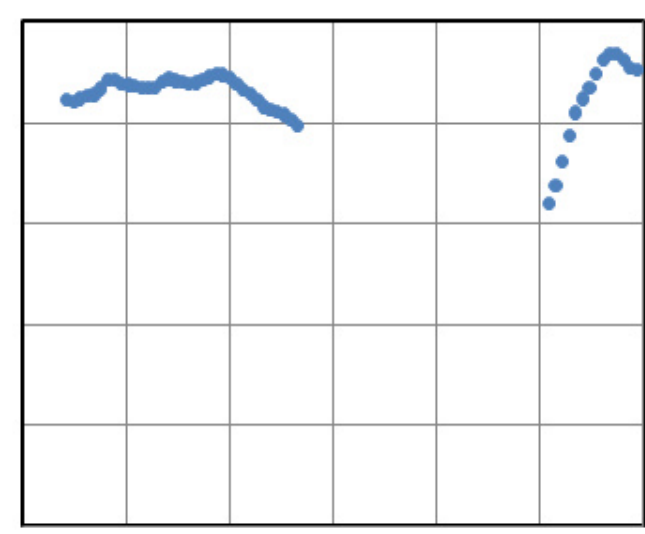

2.5E-03
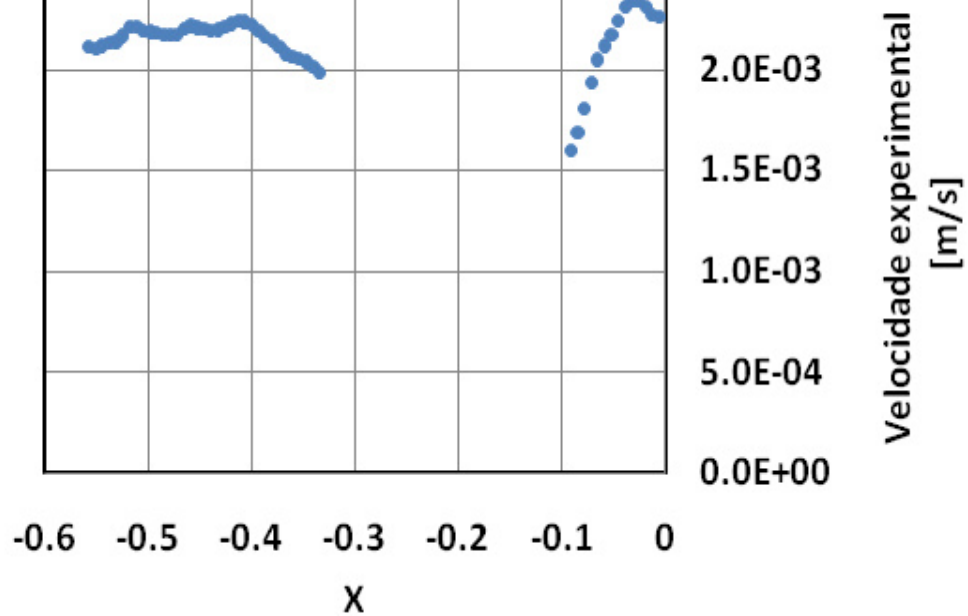

$[\mathrm{mm}]$

Figura 4.79: Variação da velocidade na linha de simetria do micro canal com garganta do segundo micro capilar, ao redor da quarta posição da gota pequena.

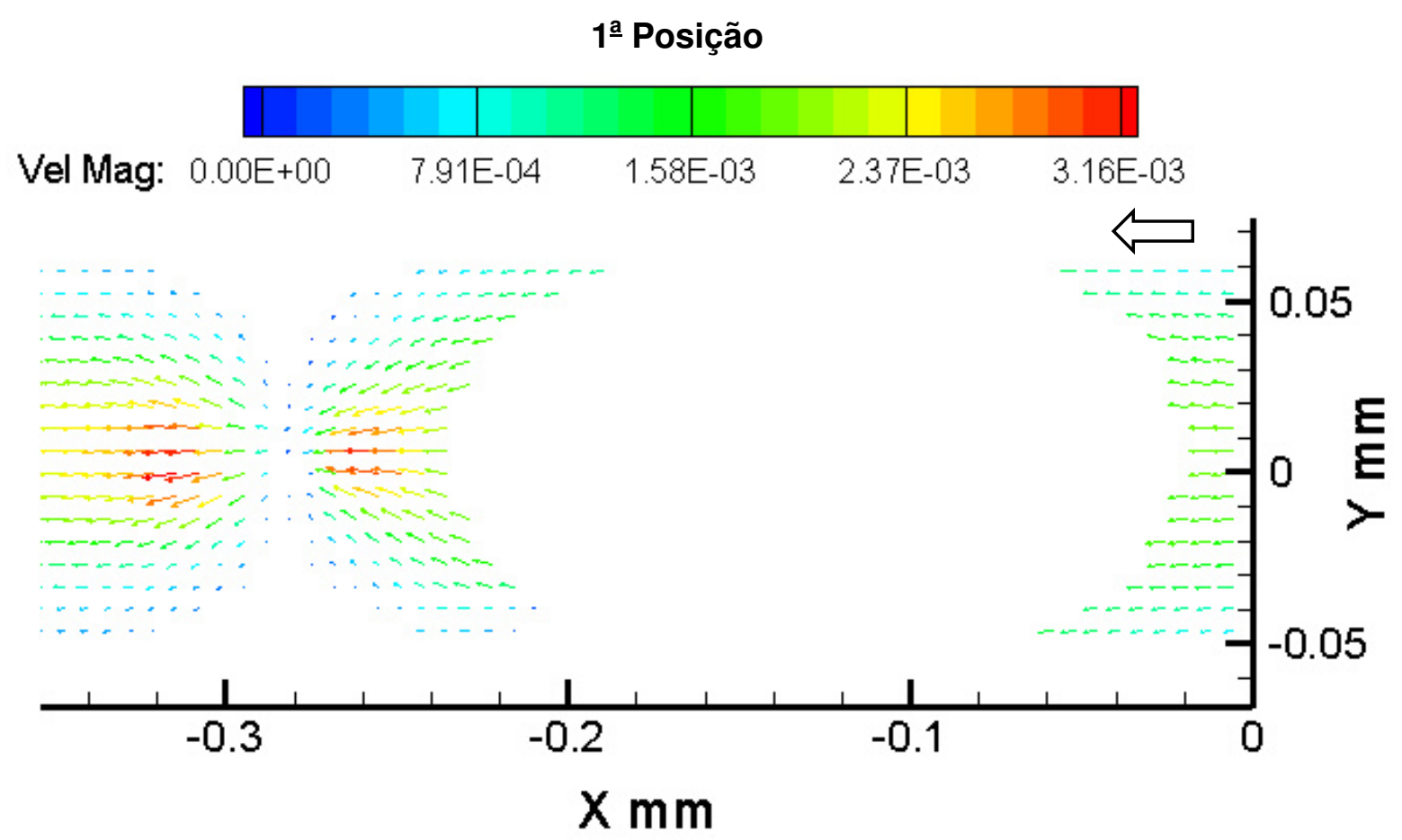

Figura 4.80: Campo de velocidade do escoamento bifásico dos 50 pares de imagens, na interface óleo-água à montante da primeira posição da gota pequena, através do micro canal com garganta do segundo micro capilar. 


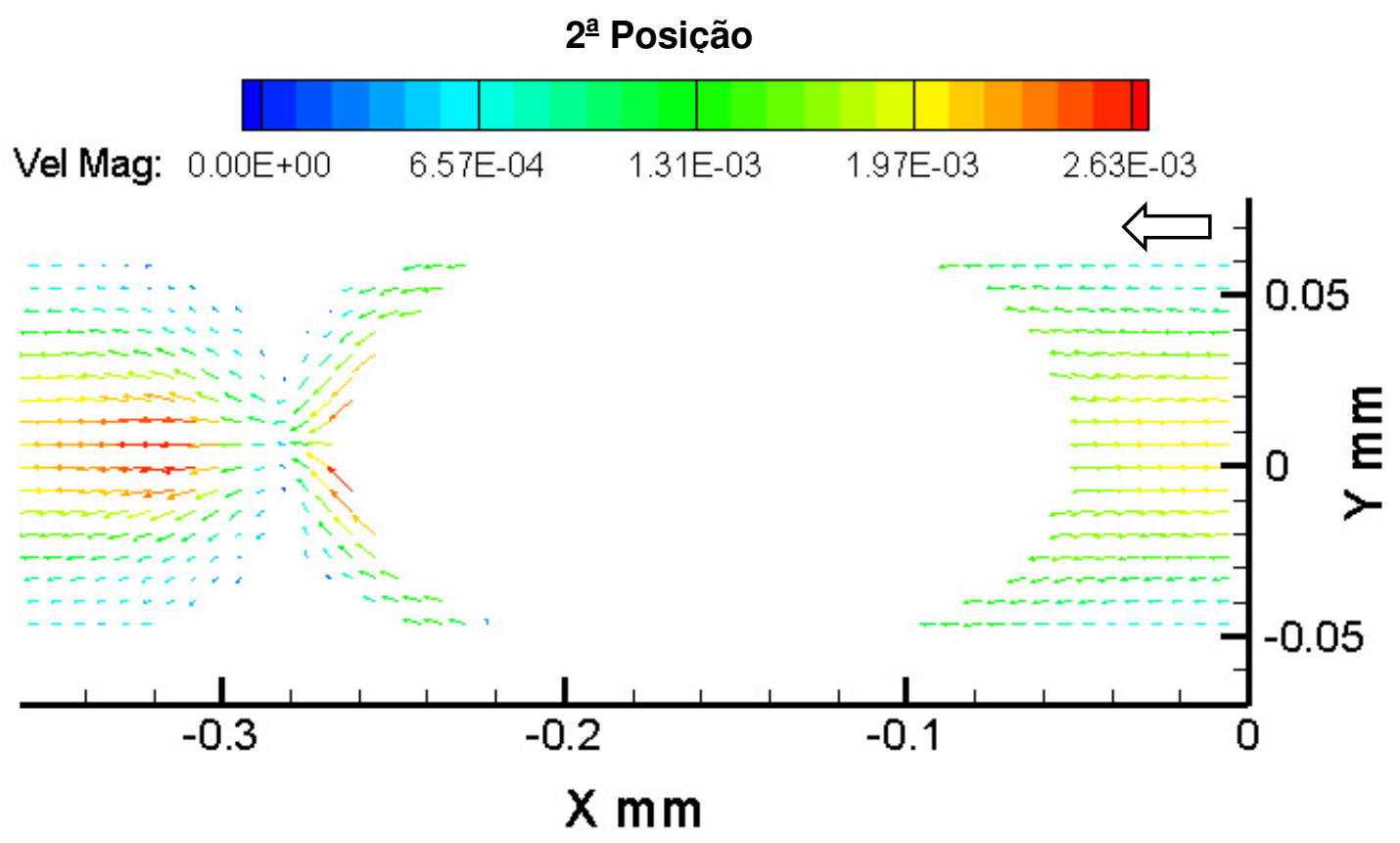

Figura 4.81: Campo de velocidade do escoamento bifásico dos 50 pares de imagens, na interface óleo-água à montante da segunda posição da gota pequena, através do micro canal com garganta do segundo micro capilar.

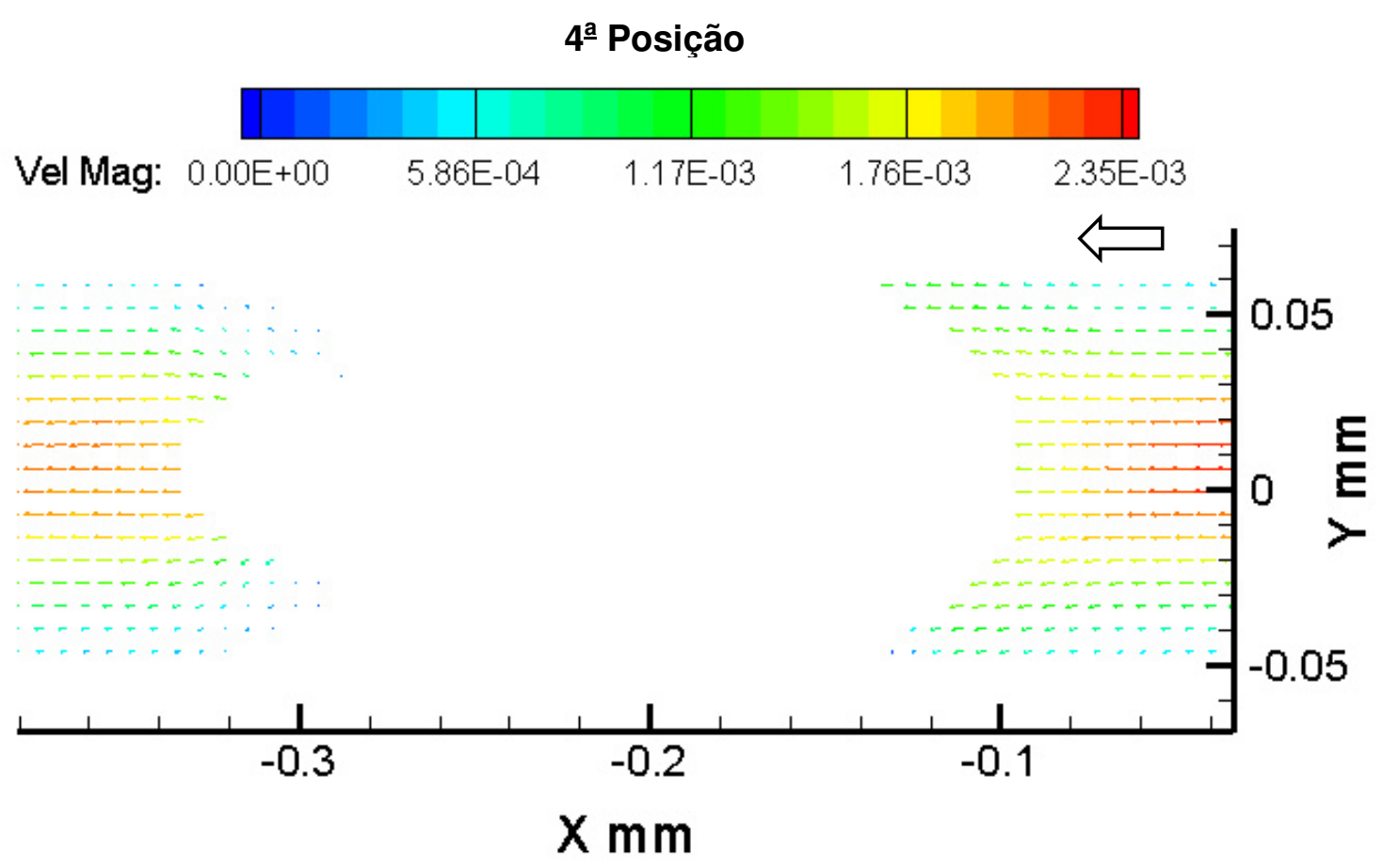

Figura 4.82: Campo de velocidade do escoamento bifásico dos 50 pares de imagens, na interface óleo-água à montante da quarta posição da gota pequena, através do micro canal com garganta do segundo micro capilar. 


\section{5 \\ Conclusões e Sugestões}

\section{1. Conclusões}

A presente dissertação apresentou um estudo do escoamento monofásico (água) e bifásico (gota de óleo suspensa em água) através de micro canais com seção reta constante e com uma garganta. Estas geometrias podem servir como modelos simplificados da função de dois poros adjacentes em um meio poroso. A medição do campo de velocidade da fase contínua e a velocidade da gota foram determinadas através da técnica de velocimetria por imagem de partículas em escala micrométrica ( $\mu$-PIV).

A utilização do sistema $\mu$-PIV permitiu realizar processos de préprocessamento, processamento e pós-processamento nas imagens adquiridas. No pré-processamento foram utillizadas as técnicas de "Imagem de Intensidade mínima" e "Substração de fundo" para remover o ruído do fundo. No processamento foi utilizada a técnica "Média amostral" afim de minimizar os problemas de um número insuficiente de partículas nas imagens e do movimento browniano das mesmas. A resolução espacial utilizada nas medições foi de $13 \mathrm{x}$ $13 \mu \mathrm{m}^{2}$. No pós-processamento foram empregadas as técnicas "Validação do vetor mediana local" e "vetor condição" para remover e substituir os falsos vetores.

$\mathrm{Na}$ análise do escoamento monofásico através do microcanal de seção reta constante, os valores da velocidade dos perfis experimentais obtidos com o sistema $\mu$-PIV foram comparados com os valores da velocidade do perfil parabólico calculado através da solução analítica correspondente ao escoamento laminar completamente desenvolvido. Esta comparação confirmou a forma parabólica do perfil de velocidade medido. O erro percentual entre a velocidade experimental média e a velocidade média injetada foi de apenas $0.44 \%$, demonstrando que as medições com o sistema $\mu$-PIV foram bastante próximas à solução analítica. 
Para avaliar os efeitos da geometria do micro capilar no escoamento monofásico, foram utilizados 2 micro canais com diferentes diâmetros de garganta. O primeiro micro canal possuiu diâmetro mínimo na garganta de 85 $\mu \mathrm{m}$, e o segundo micro canal possuiu um diâmetro mínimo na garganta de $46 \mu \mathrm{m}$ (quase a metade do primeiro micro canal com garganta).

No primeiro micro canal com garganta, o cálculo das velocidades experimentais médias na entrada e na saída do escoamento monofásico foi comparado com a velocidade de injeção imposta. Observou-se que o erro percentual foi de $3,43 \%$ e $1,47 \%$ respectivamente. No segundo micro canal com garganta, o erro percentual das velocidades experimentais médias na seção de entrada e de saída do escoamento monofásico foi de 1,49\% e 0,61\% respectivamente.

Em ambos os casos, a forma parabólica dos perfis de velocidades experimentais foi confirmada. As velocidades experimentais máximas foram obtidas na zona da garganta do micro capilar, como esperado. Porém no segundo micro canal com garganta, percebeu-se que as velocidades experimentais foram quase nulas em $x \approx-0,28$; contradizendo o principio de conservação de massa. $O$ fato foi que a velocidade do escoamento nesta seção foi consideravelmente maior que no resto do escoamento, e que o intervalo de tempo não foi suficientemente pequeno para obter uma medida precisa do campo nesta região. Desta forma, os valores medidos não foram considerados na análise.

Para avaliar os efeitos devido à presença de gotas de óleos no escoamento em estudo foram gerados dois tamanhos diferentes de gotas (gota pequena, $\alpha=1,4$, e gota média, $\alpha=1,5)$. Vale ressaltar que 0 tamanho de ambas as gotas foram maiores que o diâmetro do micro canal, e que as partículas fluorescentes foram suspensas na fase contínua. Como o escoamento com gotas suspensas é inerentemente transiente, as medições utilizando a técnica de $\mu$-PIV ficam muito complexa e imprecisa. Este problema foi contornado utilizando o fato que o escoamento é periódico, e que todas as gotas eram do mesmo tamanho. O conjunto de imagens utilizado na análise foi composto de imagens do escoamento obtidas em diferentes instantes, mas com diferentes gotas na mesma posição em relação à garganta.

$\mathrm{Na}$ análise do escoamento de uma gota de óleo pequena e média através de um micro canal de seção reta constante, os valores de velocidade obtidos na 
interface óleo-água foram quase constantes, ou seja, a gota move-se com a mesma velocidade sem se deformar. Para ambos os casos, a gota pequena e média se deslocam a uma velocidade maior que do escoamento médio, aproximadamente 1,5 vezes maior.

As velocidades experimentais médias na entrada e na saída do escoamento foram comparadas com a vazão de injeção imposta. Vale lembrar que a vazão total dos dois casos não foi a mesma, já que as vazões das duas fases determinaram o tamanho das gotas formadas. O erro percentual no caso da gota pequena foi de $4,41 \%$, e $2,41 \%$, e na gota média foram de $1,39 \%$, e $1,93 \%$ respectivamente.

Longe da gota o escoamento da fase contínua recupera o perfil parabólico e a velocidade experimental na linha de simetria do micro canal foi máxima a uma certa distância da gota.

Para obter o campo de velocidade relativo à gota (pequena e média), a velocidade da gota foi subtraída do campo de velocidade do escoamento bifásico. Observou-se um fluxo na parte central do micro canal escoando a uma maior velocidade que a gota (na mesma direção), e voltando contíguo à parede do micro capilar escoando a uma maior velocidade que a gota (no sentido oposto). A razão disto foi devido a que o escoamento apresentou um trem de gotas ao longo do canal do micro capilar, e a linhas de corrente confirmaram este movimento do escoamento.

$\mathrm{Na}$ análise do escoamento da gota de óleo pequena através do primeiro micro canal com garganta (diâmetro mínimo de $85 \mu \mathrm{m}$ ) o escoamento foi avaliado em três diferentes instantes de tempo, o que corresponde a três posições diferentes da gota ao longo da garganta. Nas três posições relativas à garganta, a velocidade da gota foi sempre maior que a velocidade média do escoamento, da mesma forma que aconteceu no escoamento bifásico através do micro canal de seção reta constante.

Observou-se que a velocidade ao longo da interface não foi constante, porque a gota é deformada durante a passagem pela garganta, causando uma aceleração na gota conforme foi escoando por seções menores.

As velocidades médias calculadas através do perfil de velocidade experimental nas 3 posições da gota, não foram iguais à velocidade média imposta. Além disso, a velocidade média variou com o tempo (posição da gota). Uma hipótese para tal fenômeno é que os efeitos de compressibilidade do líquido podem ser importantes nas vazões muito baixas utilizadas neste trabalho. 
$\mathrm{Na}$ análise do escoamento da gota de óleo pequena através do segundo micro canal com garganta (diâmetro mínimo de $46 \mu \mathrm{m}$ ) o escoamento foi avaliado em quatro posições diferentes da gota ao longo da garganta.

Novamente, as velocidades médias calculadas através do perfil de velocidade experimental nas 4 posições da gota, não foram iguais à velocidade média imposta. Além disso, a velocidade média teve uma grande variação com o tempo (posição da gota), devido ao efeito de compressibilidade do liquido e o efeito de bloqueio do capilar pela gota já ainda mais forte.

Observaram-se nos campos completo de velocidade ao redor da gota, que as velocidades foram quase nulas também em $x \approx 0,28$, da mesma forma que aconteceu no escoamento monofásico através do micro canal com garganta. Conforme explicado anteriormente o intervalo de tempo utilizado na técnica de $\mu$ PIV não foi suficientemente pequeno para obter uma medida precisa do campo nesta região (garganta).

Os resultados obtidos mostraram a variação do padrão do escoamento devido à presença de gotas de óleos, e forneceram informações importantes de como a gotas de óleo mudam a mobilidade do fluido injetado quando o mesmo escoa através de poros com gargantas menores do que tamanho das gotas.

\section{2 . \\ Sugestões}

Devido à limitação do campo de visualização no microscópio não se conseguiu determinar com precisão o campo de velocidade na garganta do segundo micro canal, tanto para o escoamento monofásico e bifásico. Então, se deveria aumentar a capacidade de aumento das lentes do microscópio utilizado, para poder conseguir medir velocidades altas em regiões pequenas do escoamento.

Outra melhora no sistema $\mu$-PIV deveria incluir uma câmera de alta velocidade (frame/s) e um laser de maior potência e frequência, para medir fenômenos fluídicos transientes em dispositivos microfluídicos.

Seria interessante ter medidas da pressão na seção de entrada em conjunto com a medida do campo de velocidade. Estudos futuros deveriam 
incluir o efeito da variação da relação de viscosidade (gota mais ou menos viscosa) e diferentes vazões (número de capilaridade) no escoamento. 
6

Referências bibliográficas

[1] IEA. International Energy Agency. Key World Energy Statistics. Disponível em: <http://www.iea.org/publications/freepublications/ publication/kwes.pdf>. Acesso em: Julho de 2012.

[2] ROSA, A. J; CARVALHO, R. S.; XAVIER, J. A. D.. Engenharia de Reservátorios de Petróleo. Rio de Janeiro: Interciência Petrobras, 2006.

[3] QUINTELLA, A. C. E. F.. Deslocamento de líquidos viscoelásticos em tubos capilares. Tese de doutorado, DEM, PUC - Rio, 2006.

[4] HOMSY, G. M.. Viscous fingering in porous media. Journal of Fluid Mechanics, vol. 19, pp. 271-311, 1987.

[5] SANTANA, A.. P.S.C. de Recuperação suplementar. Apostila do curso de tecnologia e gás, 2008.

[6] GUILLEN, V. R.; ROMERO, M. I.; CARVALHO, M. S.; ALVARADO, V.. Capillary-driven mobility control in macro emulsion flow in porous media. Journal of Multiphase Flow. Vol. 43, pp. 62-65, March 2012.

[7] McAUliffE, C. D.. Oil-in-Water Emulsions and Their Flow Properties in Porous Media. Journal of Petroleum Technology (JPT) - SPE 4369, pp. 727-733, June 1973.

[8] RIDEAL, K. E.. An introduction to surface chemistry. Cambridge U. Press, Cambridge London, 1926.

[9] SANTIAGO, J. G.; WERELEY, S. T.; MEINHART, C. D.; BEEBE, D. J.; ADRIAN, R. J.. A particle image velocimetry system for 
microfluidics. Experiments in fluids 25, pp. 316-319. Springer-Verlag, 1998.

[10] CALHOUN, J. C.. Fundamentals of reservoir engineering. University of Oklahoma Press, 1953.

[11] RALPH, L.; MASSIMILIAN, R.; SEBASTIAN, G.; JERRY, W.. MicroParticle Image Velocimetry ( $\mu$-PIV). Recent developments, applications, and guidelines. Journal of The Royal Society of chemistry. Vol. 9, 2551-2567, June 2009.

[12] THERMO SCIENTIFIC PARTICLE TECNOLOGY.. Product catalog and technical reference guide: Fluoro-Max. Fluorescent Particles Dyed Red Aqueous, 2011.

[13] MEINHART, C. D.; WERELEY, S. T.; GRAY, M. H. B.. Volume illumination for two-dimensional particle image velocimetry. Meas. Sci. Technol. Vol. 11, pp. 809-814, 2000.

[14] LEE, S. J.; KIM, S.. Advanced particle-based velocimetry techniques for microscale flows, Microfluidics and Nanofluidics, Vol. 6, pp. 577-588, 2009.

[15] MEINHART, C. D.; WERELEY, S. T.; SANTIAGO, J. G.; ADRIAN, R. J.. Micron-resolution velocimetry technique in Laser Techniques Applied to fluid Mechanichs. New York: Springer-Verlag, pp. 57-70, 2000.

[16] SUSHANTA, K. M.; SUMAN, C.. Microfluidics and Nanofluidics Handbook. Fabrication, implementation and applications. New York, Taylor \& Francis Groups, 2012.

[17] SVEN, M. H.. Development of micro-PIV techniques for applications in microfluidics systems. Tese de doutorado. Technical University of Denmark, 2008. 
[18]TSI, Webinar Training Series. Disponível em: <http://www.tdylec.net/technical_info/webinar/pdf/20100729_piv.pdf>. Acesso em: Julho de 2012.

[19] ADRIAN, R. J.. Twenty years of particle image velocimetry. Experiments in fluids, vol. 39, pp. 159-169, 2005.

[20] PRASAD, A.. Particle image velocimetry. Current Science, vol. 79, pp. 51-60, 2000.

[21] MeinhaRT, C.; WeReley, S. T.; SANTIAGO, J. G.. A PIV Algorithm for Estimating Time-Averaged Velocity Fields, Journal of Fluids Engineering, vol. 122, pp. 285-289, 2000.

[22] SAMARAGE, R. C.; JOSIE, C.. Optimisation of temporal averaging processes in PIV. Experiments in fluids. Vol. 52, pp. 617-631. Springer-Averlag, 2011.

[23] RAFFEL, M; WILLERT, C.; KOMPEHANS, J.. PIV. Particle Image Velocimetry. A Practical Guide, $1^{\text {st }}$ edition, 2002.

[24] WESTERWEEL, J.. Digital Particle Image Velocimetry-Theory and Application. Thesis/dissertation, Delft University, 1993.

[25] HO, B. P.; LEAL, L. G.. The creeping motion of liquid drops through a circular tube of comparable diameter, Journal of fluids Mechanics. Vol 71, pp. 361-383, Grã Bretanha, 1975.

[26] OLBRICHT, W. L.; LEAL, L. G.. The creeping motion of immiscible drops through a converging/diverging tube. Journal of Fluid Mechanics, vol. 134, pp. 329-355. 1983.

[27] WESTBORG, H.; HASSAGER, O.. Creeping Motion of Long Bubbles and Drops in Capillary Tubes, Journal of colloid and interface Science, vol. 133, pp. 135-147. Denmark, 1989. 
[28] MARTINEZ, M. J.; UDELL, K. S.. Axisymmetric creeping motion of drops through circular tubes. Journal of Fluid Mechanics, vol. 210, pp. 565-591, 1990.

[29] TSAI, T. M.; MIKSIS, M. J.. Dynamics of a drop in a constricted capillary tube. Journal of Fluid Mechanics, vol. 274, pp. 197-217, 1994.

[30] MeINHART, C. D.; WeRELEY, S. T.; SANTIAGO, J. G.. PIV measurements of a microchannel flow. Experiments in fluids, vol. 27, pp. 414-419. Springer-Verlag, 1999.

[31] MEINHART, C. D.; ZHANG, H.. The Flow Structure Inside a Microfabricated Inkjet Printhead; Journal of microelectromechanical systems, vol. 9, pp. 67-75. IEEE, 2000.

[32] OKUDA, R.; SUGIL, Y.; OKAMOTO, K.. Velocity Measurement of blood flow in a microtube using micro PIV system. Journal BioFluid Flow. University of Tokyo, June 2003.

[33] SHINOHARA, K.; SUGIL, Y.; AOTA, A.; HIBARA, A.; TOKESHI, M., KITAMORI; T., OKAMOTO, K.. High-speed micro-PIV measurement of transient flow in microfluidic devices, Meas. Sci. Technol., vol. 15, pp.1965-1970, 2004.

[34] STEIJN, V. V.; KREUTZER, M. T.; KLEIJN, C. R.. $\mu$-PIV study of the formation of segmented flow in microfluidic T-junctions. Chemical Engineering Science. 2007, vol. 62, pp. 7505-7514. 2007.

[35] LAC, E.; SHERWOOD, J. D.. Motion of a drop along the centreline of a capillary in a pressure-driven flow. Journal of Fluid Mechanics, vol. 640, pp. 27-54, 2009.

[36] ROBLES, C. O. A. F.. Análise Experimental do escoamento de emulsões óleo em água através de micro-capilares com garganta. Dissertação de Mestrado, DEM, PUC - Rio. 2011. 
[37] THE DOLOMITE CENTRE LTD. Disponível em: <http://www.dolomite-microfluidics.com/images/stories/PDFs/ datasheets/linear_connectors_product_datasheet.pdf>. Acesso em: Maio de 2012.

[38] SYRINGE PUMPS-COLE-PARMER. Disponível em: <http://www.coleparmer.com/catalog/product_view.asp?sku=7490300 >. Acesso em: Abril de 2012.

[39] TSI INC. Micro particle image velocimetry operation manual. Fluids Mechanics. Agosto. 2006.

[40] POWERVIEW ${ }^{\mathrm{TM}}$ 1.4MP CAMERA-TSI Disponível em: <http://www.tsi.com/uploadedFiles/_Site_Root/Products/Literature/Sp ec_sheets/2980276-1-4MP.pdf>. Acesso em: Março de 2012.

[41] NEW WAVE RESEARCH.-LASER GEMINI PIV. Disponível em: <http://www.samwoosc.co.kr/pdf/new-wave/PV-GEM-DSa40312.pdf>. Acesso em: Março de 2012.

[42] GARCIA, C. D. E.. Formação de emulsões em uma junção de micro canais em T. Dissertação de Mestrado, DEM, PUC - Rio, 2011.

[43] KOUTSIARIS, A. G.; MATHIOULAKIS, D. S.; TSANGARIS, S.. Microscope PIV for velocity-field measurement of particle suspensions flowing inside glass capillaries. Measurement Science and Technology 10, pp. 1037-1046, 1999.

[44] WHITE, F. M.. Mecânica dos Fluidos. 7. Ed. McGraw Hill, 2003.

[45] BOLINDER, J.. On the accuracy of digital particle image velocimetry system Technical Report Lund Institute of Technology ISSN 0282-1990, 1999.

[46] CAMERA-PIXELINK Disponível em: <http://www.camcor.com/ 
cat/pixelink-PL-A662-color-Firewire-microscope-camera.html>. Acesso em: Maio de 2012.

[47] BORHAN, A.; M, C.. Effect of surfactants on the motion of drops through circular tubes, Journal of fluids mechanichs, vol. 4, pp. 2628-2640. University Park, 1992.

[48] MIELNIK, M.; SAETRAN. L.. Micro particle image velocimetry-an overview. Turbulence 10, pp. 83-90. Kielce, Polônia, setembro 2004.

[49] AKBARI, M.; SINTON, D.; BAHRAMI, M.. Laminar Fully Developed flow in periodically converging-diverging microtubes. Heat transfer engineering, 31:8, pp. 628-634, 2010.

[50] WERELEY, S. T.; GUI, L.; MEINHART, C. D.. Advanced algorithms for microscale particle image velocimetry. AIAA Journal, vol. 40, pp. 1047-1055, June 2002. 